\title{
QUALITY SYSTEM IN HIGHER EDUCATION: FUTURE PERSPECTIVES
}

\author{
Professor Abdulsattar Mohammed Al-Ali, Ph.D Eng. \\ Industrial Engineering and Operation Management, \\ Senior Member IIE, MCSCMP, ASQ, EFQM. \\ Former Professor \\ Department of Production and Minerals, \\ The University of Technology, \\ Baghdad - Iraq \\ asmalali.alali@gmail.com
}




$$
\text { بسم الله الرهمن العهيم }
$$

وها أوتنيته هن العلى إلا تهليلا .

صكة الله العظيه 
الالهصاء

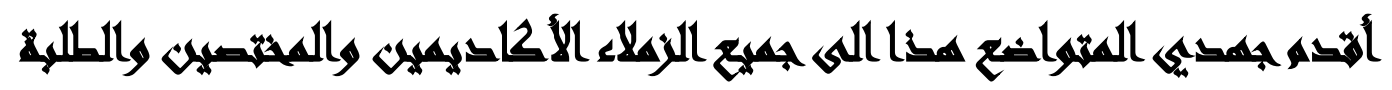

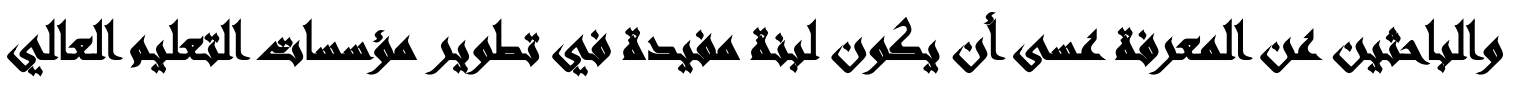

هيه العراة والمطن العبريه.

.

الموالهن

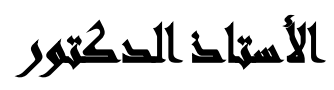

المرب المتخار مهمد العليه

2021

$\mu$ 


\section{THE PRPOSED QUALITY SYSTEM OF HIGHER EDUCATION INSTITUTIONS: Future Perspective}

The Contents:

Preface

Part One: Introduction to Total Quality Management and Business Process Reengineering Chapter One: Quality Management in Higher Education

1.1-Higher Education Environment

1.2- Higher Education Quality Orientation

Chapter Two: Quality of Higher Education Processes

2.1- Introduction

2.2- Quality Audit Agency (QAA)

2.3- A basic Model of the Education Processes

2.4- Total Quality Management (TQM) in Higher Education

2.4-1- The Model

2.4.2- TQM Principles, Processes, and Tools

2.4.3- The Importance of Continuous Improvement

2.5-TQM Implementation Efforts in Higher Education Institutions

Chapter Three: The Framework of Business Process Reengineering.

3.1-Introduction

3.1.1- BPR Concept

3.1.2- BPR in Higher Education

3.2- Reengineering of Higher Education: Reinventing teaching and Learning

3.2.1- BPR Dimensions

3.2.2- BPR Benefits

3.3- Business Process Reengineering Mechanism

3.3.1- The Concept of BPR Mechanism

3.3.2- The Important Issues

3.3.3- Key Elements of BPR

3.4-Performance Indicators

3.4.1- Performance Indicators classification

3.4.2- Key Performance Indicators

3.4.3- Key Performance Indicators Components

3.5- The Framework of BPR

3.5.1- BPR Areas

3.5.2- Process Redesign

3.5.3- Business Process Reengineering Mapping

Part Two: Mutually Implementation of Business Process Reengineering (BPR) Total Quality Management Processes (TQM)

Chapter Four: Implementation BPR Project for TQM

4.1- Business Process Reengineering (BPR) Models

4.4.1- BPR Solving Network

4.4.2- Build an Organizational Robustness 
4.4.3- Speed-to-Customer (Stakeholders)

4.2- Total Quality Management Processes

-Overview

4.2.1- TQM Principles

4.2.2- Important TQM Issues

4.2.3- Benchmarking

4.3- Business Process Reengineering (BPR) for Total Quality Management (TQM)

4.3.1- Important Issues

4.3.2- Pitfalls of Business Process Reengineering

4.4- How to Implement Successful BPR

4.4.1- Implementation phases of BPR

4.4.2- Information Technologies and BPR

4.5- The Linkages between BPR and TQM

Chapter Five: Implementation Total Quality Management in Higher Education Institutions

- Overview

5.1- Introduction

5.2- Implementation Program Quality Assurance Plan in Higher Education Institutions

5.2.1- development of Quality Assurance Framework

5.2.2-Program Quality Audit Agency (QAA)

5.3-The Higher Education Quality Perspectives

5.3.1- Student-Customer TQM Perspectives

5.3.2-TQM Perspectives of HEIs

5.3.3- Role of Higher Education in $21^{\text {st }}$. Century

5.4- TQM Contributions to Academic Processes in Higher Education

5.4.1- Quality of Academic Processes

5.4.2- PDCA in the Classroom

5.5-TQM Implementation Efforts in Higher Education Institutions

Chapter Six: Accreditation and Criteria-Based Evaluation Systems in HEIs

6.1- Introduction to Criteria-Based Evaluation System

6.1.1-Relationship Criteria to Academics' Programs

6.1.2-Continuous Assessment-Features and Purpose

6.1.3- Learning, Teaching, \& Research Model

6.2- The Concept of Education Assessment Criteria

6.3- Programs Evaluation System 6.3.1-Curriculum Evaluation

6.3.2- Course Evaluation

6.4- Learning Outcomes

6.4.1- Method Course Design

6.4.2- Course Learning Outcomes

6.4.3-Instructors' Learning Outcomes

6.4.4- Learning Outcomes Guide

6.5- Evaluation Education Effectiveness

6.5.1- Student Evaluation of Instructor Performance

6.5.2- Peer-to-Peer Assessment

6.6- Infrastructure Evaluation 
6.6.1- Information Communication Technology

6.6.2- Labs Evaluation

6.6.3- Library Evaluation

Chapter Seven: Research Management in Higher Education Institutions

Overview

7.1- Introduction

7.1.1- Students' Learning Education Research

7.1.2- Academic Research Works

7.1.2.1- Academic Research

7.1.2.2- Professional Research

7.2- Establishment the Scientific Research Center

7.3- Evaluation Research Works

7.3.1- Reasons for Declining the Higher Education

7.3.2-Evaluation Methods of Research Works

7.3.3- Establishing the National Education Qualification Center

\section{Chapter Eight: Conclusion and Recommendations}

8.1-Conclusion

8.2-Recommondations and Suggestions

- References

- Author's Short Biography 


\section{PREFACE:}

The Success of higher education institutions depends on their management strategy on how to identify, classify, analyze and react to the effective approach of problem solving. Higher education provides deep knowledge and understanding about the nation, society and the global scenario in order to develop new learners with information on different ways of life. It mainly develops the ability of the students to question and seek truth and make him/her competent to critique on contemporary issues. So, in this regards the instructors (teachers) also play a vital role not only for the students but also for society as a whole. In this 21 st century, the growth and demand for technology is increasing faster and changes in educational strategies, policies, practices, and programs curriculums, therefore, the instructors (teachers) have to well equipped with the new techniques, methods, and pedagogical skills, so that the standard of education can be maintained.

The present study depicts the role of higher education context and the implementation of Total Quality Management (TQM) beside the Business Process Reengineering (BPR) in higher education. This study oriented on TQM that will have an excellent impact on the higher education institution's goals, mission and vision, and creates value in enhancing quality and assuring growth of national economy. Even though the implementation of TQM brings a wide range of changes in HEI's, many institutions are not prioritizing its implementation. To conclude, total quality management is a concept rather than a process by itself. The TQM cannot be implemented overnight, and the HEIs must analyze various obstacles carefully for the effective implementation of TQM for achieving continuous improvement and sustainability.

However, the learning is an active process of constructing rather than acquiring knowledge and construction is a process of supporting that construction rather than communicating knowledge. In other words, learning should be an activity in depth context. Concern about quality of teaching and quality of learning in higher education is widespread. In the United States for example, criticism of the current level of accountability of public higher education institutions has led to the introduction of mandatory evaluation instruments in many states. Internationally, similar concerns are echoed, and a report of World Bank policy (1994), which is examining the state of higher education in developing countries also calls for "introducing policies designed to give priority to quality" as a critical direction for national reform.

Furthermore, this study also illustrates the efforts to implement Business Process Reengineering (BPR) within the Total Quality Management principles and processes in higher education institutions. These applications are of general interest since these institutions are complex organizations with many stakeholders ranging from society at large to local governments, parents, students, faculties, and staff. In other words, a multidisciplinary institution is responsible for addressing simultaneously a myriad of needs, wants, and claims of nation.

Successful business process reengineering implementation in higher education institutions must begin with teaching and learning, rather than administrative processes. Addressing educational processes first will naturally force a reconsideration of such 
features as the students' program curriculum, faculty load, academic and non-academic areas utilization, the academic calendar, course scheduling, instructional resources like information communication technology (ICT), and the design of student-faculty interaction.

The alleged success of Total Quality Management (TQM) principles and processes in the revitalization of higher education and service delivery institutions worldwide has led to a growing interest in the potential applications of TQM principles and processes to education at the education levels.

Early efforts to bring TQM to higher education settings have focused on administrative processes, which are largely similar to those of any large service organization. Under increasing cost containment pressures, higher education administrative units have to do more with less, and process improvement becomes an overriding priority. Total Quality Management is a commitment to excellence by everyone in higher education institutions excellence achieved by teamwork and a process of continuous improvement. TQM means dedication to being the best, to delivering high quality education and services, which meet or exceed the expectations of stakeholders and society as well.

As with any significant cultural change, TQM requires strong leadership at all levels. Inspiring academic and administrative staff to do things differently takes leaders who can communicate what needs to be done and why. It takes leaders who have a clear goal or vision, can impart that vision to others, and then demonstrate through action how to make the vision a reality. Most of all, TQM requires leadership that empowers people to work toward achieving their shared vision. No single higher education institution has successfully implemented and maintained progress in the concepts of Total Quality Management without leadership by top management.

Finally, as higher education institutions are leaders in the use and innovation of the technologies that makes perfect sense that they also embark on reengineering their institutions. In addition to (ICT), the impact of the top management to the success of reengineering is insurmountable. We believe that BPR and TQM are the only things that stand between higher education institutions and disaster in this fast-changing world. It is time for higher education institutions to reinvent themselves.

\section{PART ONE: INTRODUCTION TO TOTAL QUALITY MANAGEMENT AND BUSINESS PROCESS REENGINEERING}




\section{CHAPTER ONE: QUALITY MANAGEMENT IN HIGHER EDUCATION}

\section{OVERVIEW:}

In the last decade, many higher education institutions in developing countries have increased their interest in studying and applying principles of quality management to higher education. There is general agreement on the tools of quality management; however, there is limited discussion and no universally agreed upon model of quality management. So, this meeting should achieve an agreement with a time table to build a model of quality management in higher education institutions that has three components: quality of design, quality of conformance and quality of performance.

The discussions so far on quality in higher education and its measurement are premised on two important considerations: that the central activity of higher education is that of maximizing the student's educational development; and that it is the continuing improves- improvement to maximize student learning and development. These remain the primary goal of higher education institutions and should be the focus of any concern over quality in higher education and its measurement. In relation to change as a result of quality initiatives reveals two broad ways of thinking about quality; one relating to context and the other relating to stakeholders (Watty, 2002). The first gives quality a context-specific meaning where quality is attached to a context and as a consequence quality becomes meaningful. For example, references to the quality of assessment, student intake, academic programs, teaching and learning, research work, the student experience, and program designs are not uncommon. Any attempt to define or attach meaning to the term is largely ignored and one is left to assume that it is 'high' quality that is being referred to as opposed to 'good' or 'poor' quality.

A second way of thinking about quality relates to a stakeholder-specific meaning, where quality is considered having regard to a variety of stakeholders. They have an interest in higher education and each having the potential to think about quality in different ways. In particular the early works of several authors highlight the importance and value of considering quality from a variety of stakeholder perspectives (Watty, 2002).

With the implementation of TQM in higher education, a radical change can be brought for bringing about satisfaction among the stakeholders for maintaining quality in an effective manner. Moreover, the TQM is basically concerned with the system approach (input, process, output, and outcomes), which can be implemented after identifying the constraints of higher education. The system, should apply to the higher education institutions to provide a framework to identify research, teaching and operational improvement opportunities.

\section{1-HIGHER EDUCATION EVIRONMENT:}

At the beginning, it's more useful to make some definition and discuss the characteristics of the Learning Environment (LE). According to The Glossary of Education Reform (29 August, 2014), Learning environment refers to "the diverse physical locations, contexts, and cultures in which students learn". Since students may learn in a wide variety of settings, such as outside-of-school locations and outdoor environments, the term is often used as a more accurate or preferred alternative to classroom, which has more limited and 
traditional connotations. Developing a total learning environment for students in a particular course or program is probably the most creative part of teaching. While there is a tendency to focus on either physical institutional learning environments (such as classrooms, lecture theatres, library, and labs), or on the technologies used to to create online Personal Learning Environments (PLEs), learning environments are broader than just these physical components as shown in Figure (1.1). They will also include. (Anthony, 2020)

- The characteristics of the learners;

- The goals for teaching and learning;

- The activities that will best support learning;

- The assessment strategies that will best measure and drive learning

- The culture that infuses the learning environment.

By keeping many of the systematic components of assessment removed from the programme level, faculty can focus on what matters most to them, maintaining ownership and improvement of their own department's curriculum. In other words, centralizing the assessment infrastructure to (1) handle data storage, (2) provide planning resources for instructional faculty, (3) organize quality peer review processes, (4) report quality enhancement information, and (5) develop communication formats for external viewer's encourages localization of a department's programmatic curriculum development.

Figure (1.1) a learning environment from a teacher's perspective (Anthony, 2020)

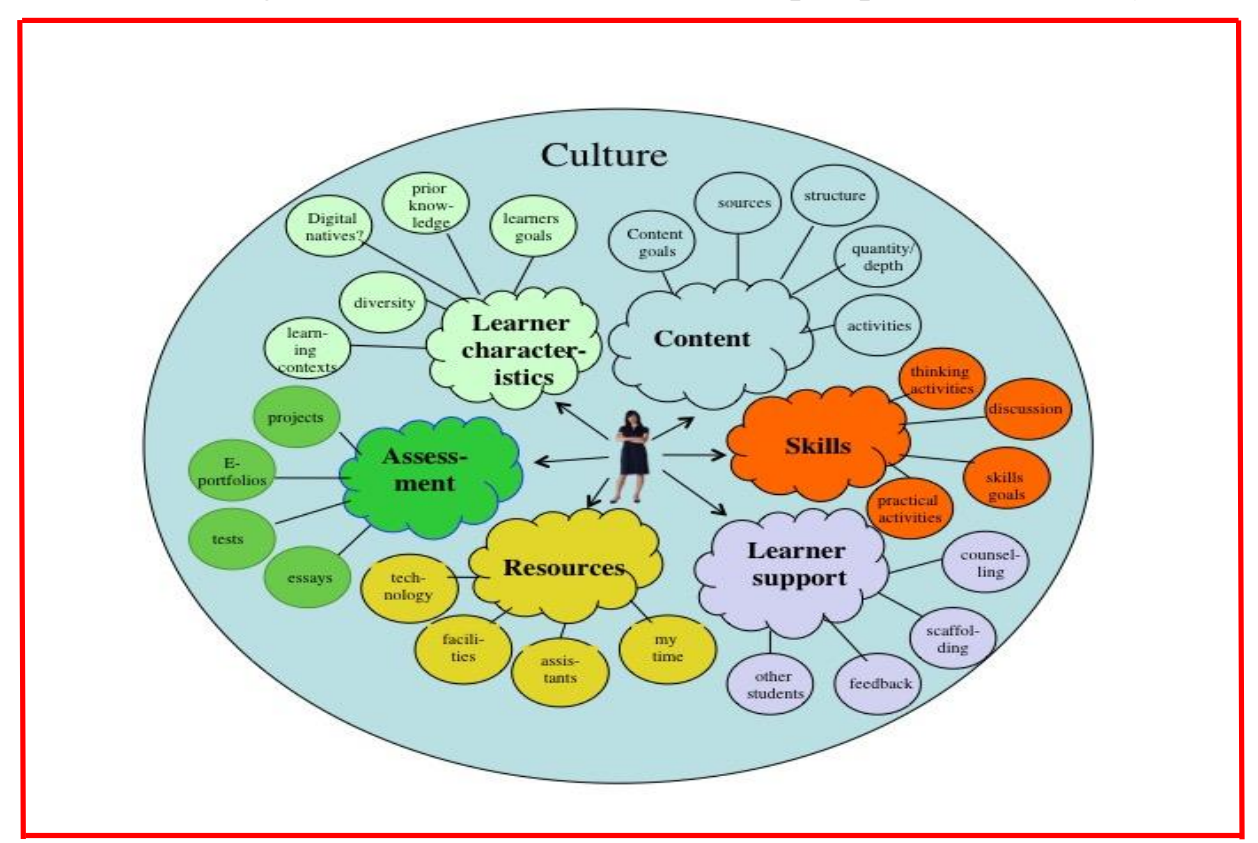

Figure (1.1) illustrates one possible learning environment from the perspective of a teacher or instructor. A teacher may have little or no control over some components, such as learner characteristics or resources, but may have full control over other components such as choice of content and how learners will be supported. Within each of the main 
components there are a set of sub-components that will need to be considered. In fact, it is in the sub-components (content structure, practical activities, feedback, and use of technology, assessment methods, and so on) where the real decisions need to be made.

According to Ronald Barnett (1992) there are four predominant concepts of higher education. These are: (Sudha, 2013)

1- Higher education as the production of qualified human resources: In this view, higher education is seen as a process in which students are counted as "products" absorbed in labor market. Thus, higher education becomes input to the growth and development of business and industry.

2- Higher education as training for a research career: In this view, higher education is preparation for qualified scientists and researchers who would continuously develop the frontiers of knowledge. Quality within this view point is more about research publications and transmission of academic discipline to do quality research.

3- Higher education as the efficient management of teaching profession: Many strongly believe that teaching is the core of educational institutions. Thus, higher education institutions focus on efficient management of teaching-learning provisions by improving the quality of teaching, enabling a higher completion rate among the students.

4- Higher education as a matter of extending life chances: In this view, higher education is seen as an opportunity to participate in the development process of individual through a flexible, continuing education mode. Interestingly, all these four concepts of higher education are not exclusive; rather they are integrated and give an overall picture of higher education. If we look at the activities of higher education institutions (colleges, universities, and academic research centers), will realize that teaching, research and extension form the three main functions of higher education.

However, higher education is generally understood to cover teaching, research and extension. Scientific and technological advancement and economic growth of a country are as dependent on higher education as they are on the working class. Development of indigenous technologies and capabilities in agriculture, food security and other industrial areas are possible because of our world-class higher education infrastructure. Higher education also provides opportunities for lifelong learning (continuing education centers), allowing people to upgrade their knowledge and skills from time to time based on societal needs.

The core elements in which different organizational and individual activities take place may cause a variety of influences on sustainable development (SD) impact areas: economy, societal challenges, natural environment, policies, culture, and demographics. The Figure (1.2) shows the (SD) impact framework of higher education institutions .Within these impact areas, this review has resulted in a set of specific themes that further specify direct and indirect impacts on (SD), which may be plausibly attributed to higher education institutions. Systematic and reliable assessment of the impacts of HEIs is a crucial premise for managing and improving the contribution of higher education institutions to (SD). (Findler, and Schönherr, 2019).

The Figure (1.2) highlights not only the assessment and reporting as a cross-cutting requirement but also identifies it as one of the fundamental challenges to more systematic consideration of impacts. This is because many assessment approaches focus on (SD) performance within higher education institutions but appear not to have been designed to 
assess impacts from the perspective of a whole institution approach, particularly regarding indirect impacts (Findler, and Schönherr, 2019).

Figure (1.2) The (SD) impact framework of higher education institutions.

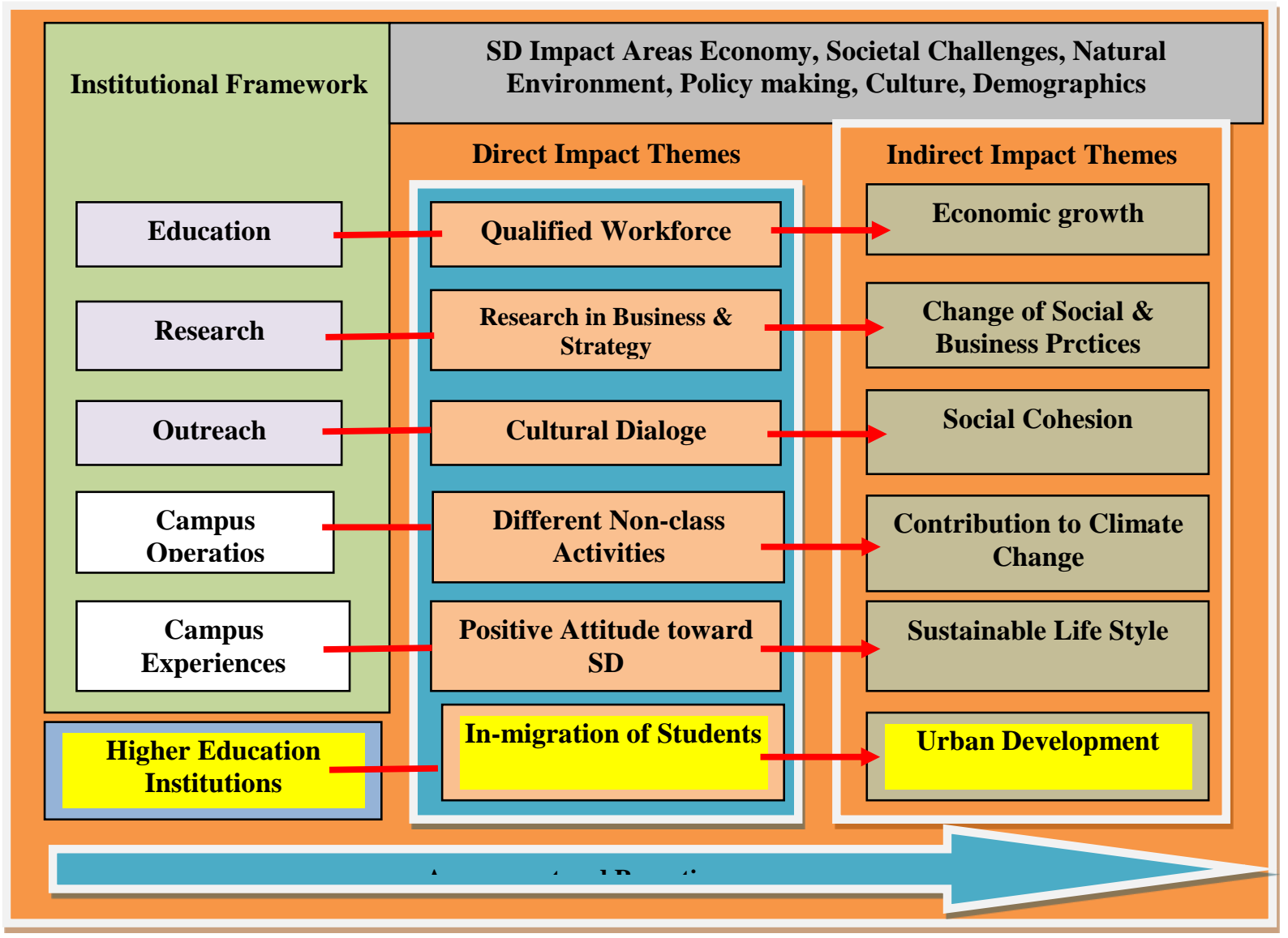

\section{2- HIGHER EDUCATION QUALITY ORIENTATION:}

If we look at quality, it's often misunderstood or used as a synonym for quality assurance or standards (Niedermeier, 2017).

Quality assurance does not define quality; it checks the quality of processes or outcomes, and can have proposed of compliance, control, accountability or improvement/enhancement. The important difference is that quality is a concept and quality assurance is a collection of methods on how to check, maintain and enhance quality with different processes, tools and instruments on different levels starting from the policy all the way down to the programme and course level.

Standards are often widely misunderstood and sometimes used as a synonym for quality. There is indeed a close relation between the two terms. A standard can be a pre-set criterion (e.g. lectures should be rated "good" in evaluations of the faculty) or a level of attainment (e.g. the lectures of the faculty have been rated "average" by the students). Usually standards are measurable indicators and used with the means to compare and assess things. Quality on the other hand refers to the process (e.g. how the lecture has been done). A 
much discussed topic when talking about standards and quality is whether the quality of the educational process can be measured by the standard of the outcomes.

There are four boards types of standards in higher education institutions, these are: (Harvey 2012)

1- Academic standards which relate to the intellectual abilities of students;

2- Standards of competence which relate to the technical abilities of students;

3- Service standards which refer to the service provided by the institution to the student;

4. Organisational standards which are principles and procedures by which the institution assures that it provide an appropriate learning and research environment.

Moreover, if the stakeholders were asking to define the quality of higher education, they will be most probably all define it with very diverse focus as shown in Table (1.1).

From the above deferent understanding the concept of quality, there are a universities that are suffering from several problems, some of them are critical. These problems are declining student enrollment, low research productivity and decreasing student retention. The higher education institutions need an approach to deal with these problems. The most solution that applied to such problems all over the world is the application of quality management (QM) principles (ISO Quality, 2020). There are a large number of higher education institutions (HEIs) all over the world has been successfully applying these principles. However, the difficulty of applying quality management principles to the HEIs' activities (curriculum design, research works, daily operations and teaching, community services) leads to believe that the HEIs needed a framework to apply the principles more effectively.

Table (1.1) Stakeholders quality definition (Based on Harvey 2012)

\begin{tabular}{|l|l|}
\hline Quality focus on .. & Stakeholder \\
\hline Students & $\begin{array}{l}\text { Practical use and usefulness for future employment vs. use for personal } \\
\text { fulfillment }\end{array}$ \\
\hline Faculty's Members & $\begin{array}{l}\text { Processes of learning management achievements of the institution (tangible } \\
\text { and intangible) }\end{array}$ \\
\hline $\begin{array}{l}\text { University } \\
\text { Management }\end{array}$ & Achievements of the institution (tangible and intangible) \\
\hline Alumni & Job opportunities \\
\hline Employers & Competences of the graduates \\
\hline Government & Percentage/ Number of alumni \\
\hline Community/Society & $\begin{array}{l}\text { Ethical and socially responsible productive persons; } \\
\text { Proud of national citizenship; } \\
\text { Production of new knowledge to cope with present and future challenges } \\
\text { (know-how breakthrough) }\end{array}$ \\
\hline
\end{tabular}

Higher education system has different interests, goals, priorities, values, needs, and motivational instincts as compare to other business organizations. Highly qualified and well motivated faculty members are like brain and blood for any academic institute. They can develop the students both personally and professionally. If talented and competent staff members are not motivated enough by their leadership, and if they are not happy with their job, department and HEIs' management, then they may leave the institution.

Faculties and instructors (teachers) are the makers of students through the learning processes, so, they are those influencing personalities and role models. Also, they refine their students' skills and polish their personalities and make them responsible citizens, productive persons, and leaders for tomorrow. So, HEIs' leaders can use various internal 
and external motivating factors to motivate faculty members. And they can put their extra efforts to produce bright and successful students, good learning environment, strong culture, and good image of institute. Thus the conceptual framework will be beneficial for all stakeholders of the HEI and for the society as a whole. (Siddique, et al., 2011)

Furthermore, the higher education institutions should deploy the following highly important factors for increasing the motivation upon faculties (faculty members), employees, and students.

(a) Organizational Effectiveness: The effectiveness indicators that are present in more or less in each study are; students' development, effective management and leadership of academic institute, faculty satisfaction, quality of teaching, HEI's culture, environmental impact, parental involvement, acquisition of recourses and their efficient usage.

(b) Motivations of Faculty Members: The term "Motivation" describes reason for action to be taken and stimulates an organism to perform certain action to achieve the desired goals. According to (Tella et al. 2007) motivation is like other psychological processes as perception, attitude, learning etc. He further described that motivation speaks for relationship among "need", "drive" and "incentive". That is if there will be a felt need or deficiency of anything, then it will stimulate the organism to perform a specific action i.e. drive. And when the organism will perform certain action then he may get desired reward i.e. incentive.

(c) Leadership in Higher Education: The definition of leadership is the "ability to influence others and to direct their efforts to achieve success". Leaders have different leadership styles through which they can lead their subordinates, some are authoritarian, some might be democratic, some are achievement oriented, and many other. (House, 2004) Additional motivating factors for the proposed framework are:

(1) The lack of discussion in the quality management literature about well-structured frameworks of quality that are used in education.

(2) The involvement of various disciplines within the HEIs in different aspects of quality. This is an attempt to find ways of operationalzing the concept of quality management in higher education.

(3) The successful application of the framework in the HEIs and the need to share this information.

(4) The need for a framework to structure the debate and process on how the HEIs may increase quality-related research. A HEI that prides itself on quality management education ought to be more visible in the quality research community.

Figure (1.3) shows the template of the motivation framework in higher education institutions (Siddique, et al., 2011).

Figure (1.3) the template of the motivation framework in higher education institutions

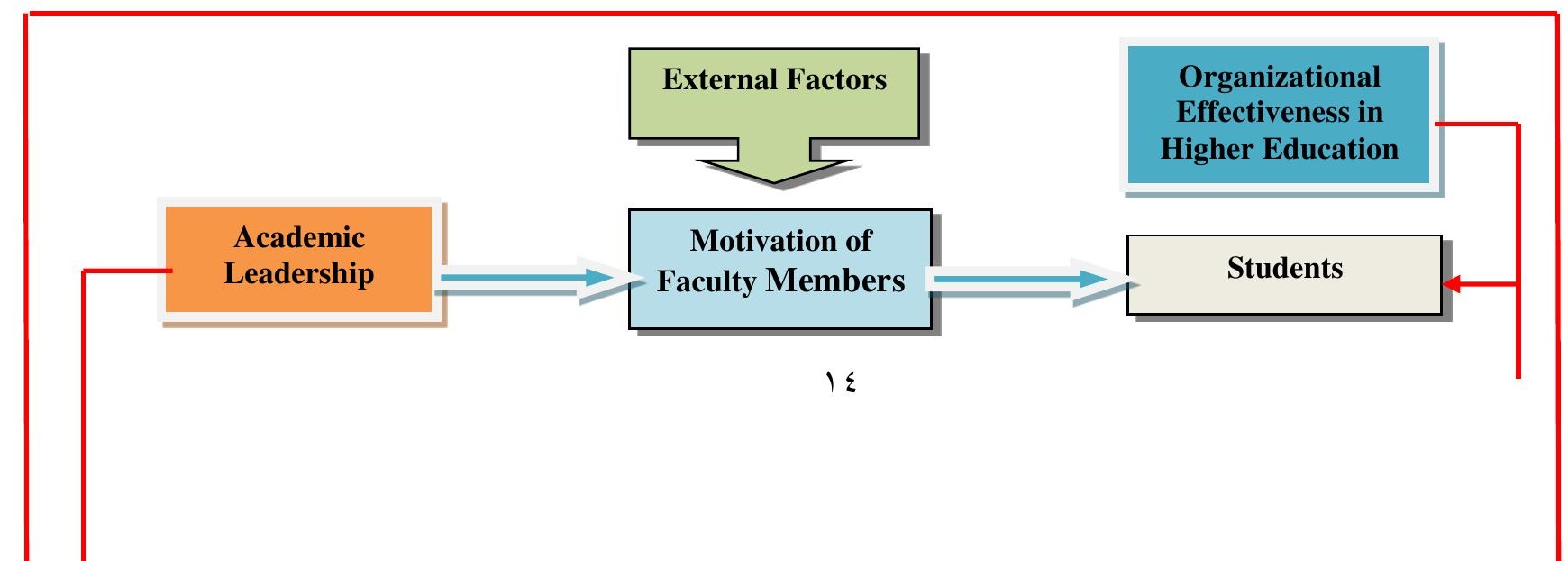



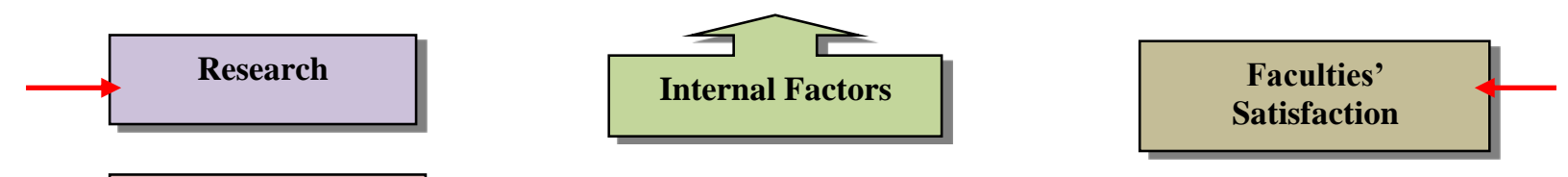

Educational

Administration

Meanwhile, there are some of the commonalities of all three levels of quality monitoring include:

1- Use of systematic processes of continuous improvement;

2- Demonstration of feedback loops whereby instructors improve the curriculum based on deficiencies revealed by their research on student learning quality;

3- Use of direct assessments, such as programme instructors' evaluation of senior design projects, rather than indirect student surveys, to demonstrate student learning performance;

4- Faculty members' engagement in the assessment process.

\section{3- ACCREDITATION and QUALITY ISSUES:}

Accreditation is the process by which a government or private body evaluates the quality of a higher education institution as a whole or a specific educational program in order to formally recognize it as having met certain pre-determined minimum criteria or standards. The result of this process usually awards a status (a yes/no decision) of recognition, sometimes of a license, to operate within a limited time of validity. The process can imply initial and periodic self-study and evaluation by external peers. The accreditation process generally involves three steps with specific activities, namely: (Vlăsceanu, et.al, 2007)

1) A self-evaluation process conducted by the faculty, the administrators and the staff of the institution or academic programmers, resulting in a report that takes as its reference the set of standards and criteria of the accrediting organization;

2) A study visit conducted by a team of peers selected by the accrediting organization which reviews the evidence, visits the premises, and interviews the academic and administrative staff, followed by an assessment report including a recommendation to the commission of the accrediting body; and

3) Examination by the commission of the evidence and recommendation on the basis of the given set of criteria concerning quality and resulting in a final judgment and a formal decision for the institution and other constituencies, if appropriate.

The higher education institutions now should have and complete their accreditation systems regarding the collection of curriculum programs' outcomes, student learning assessment and graduated evidence. Also, the institutions should have using that evidence 
to improve and understand how colleges and universities use assessment data is a goal for further development. In general, the assessment practices and processes which done in some U.S.A. universities across alignment with the assessment principles included the following: (Baker, et.al, 2012)

(a) Embedding assessment into institutional processes such as program review or governance structures;

(b) Securing support from administrative leadership by:

- Making resources available for and supporting the professional development of faculty and staff

- Providing a vision for assessment

- Providing and encouraging space for discussion and collaboration

(c) Engaging faculty in and fostering ownership of assessment

(d) Sharing information widely regarding assessment and results of assessment to both internal and external audiences.

(e) Engaging more stakeholders in high education processes especially in the preliminary stages of fully engaging a variety of stakeholders in their assessment practices.

(f) Establishing more robust assessment of assessment processes or utilizing the already collected assessment data more effectively.

(g) Becoming more transparent with assessment processes and results and with sharing promising practices externally.

Operating from an internally develop evaluation instructions and regulations defining a set of quality standards. A centralized HEI peer review committee external to the colleges and departments makes sure that they sustain well-developed planning standards that apply to the most demanding evaluative criteria expected by the multiple review entities. For example, while evaluation program requires some direct learning assessment, the committee asks that nearly all learning outcomes use direct assessment. In addition, the program process requires student learning at the graduate level. Furthermore, HEI's evaluation standards require programmes develop diagnostic plans that identify strengths and weaknesses in programme performance, an outcome of all program evaluation teams.

Peer Review: Peer review is a well-established academic process in higher education institutions. In their traditional format, peer review generally involves "a visit by a group of well-regarded academics in a particular field to undertake an assessment".

Systematic peer review sustains programme compliance to standards. For example, program now requires engineering educators to provide summaries of their assessment results, not data dumps - long presentations of research results that lack explanatory discussions. The peer review committee annually reminds out of compliance programmes to provide these summaries and informs them on ways to improve their data presentations. When engineering instructors need assistance in developing learning research or researching into the impact of their 
outreach services, they can call upon resources or expert staff centrally, without maintaining this expertise within their own department.

The assessment process should follow the following steps: (Based on Baker, et.al, 2012)

(a) Uses of faculties' and student learning evidences and evaluation results for institutionlevel (university and departments) improvement should include:

1-Setting institutional priorities and strategic planning

2-Informing institutional decision making

3-Incorporating results into accreditation efforts

4-Framing assessment at the institution level

5-Revising institutional outcomes

6-Improving student engagement and success

7-Creating a culture of teaching and learning

8-Enhancing faculty collaboration across campus

9-Reflecting on assessment processes and institutional practices

(B) Uses of student learning evidence for program- and classroom-level improvement include:

10-Setting faculty priorities

11-Securing resources for professional development

12-Improving student support services

13-Revising curriculum, courses, and assignments

14-Informing program reviews/departmental self-studies

15-Aligning curriculum, and

16-Improving program outcomes

Incorporating all these pieces into the assessment process can prove the recognition by each that using evidence of student learning is a time-intensive process involving opportunities for reflection and requiring a space for discussion and shared understanding of what results mean for the institution and student learning. 


\section{CHAPTER TWO: QUALITY OF HIGHER EDUCATION PROCESSES \\ 2.1- INTRODUCTION:}

Over the last decades, total quality management (TQM) has moved from manufacturing and service sector applications into the public sector, especially into education. Many institutions all over the world have implemented total quality management programs with the intention of translating Total Quality Management principles, such as advocacy for shared decision making or customer focus, into practical applications. The results of such efforts have been mixed and well documented.

In the nineties from last century, with increasing pressure on higher education institutions to decrease costs and increase efficiency, the interest in potential applications of programs such as TQM or reengineering has grown. The quality movement has addressed quality in education since its early developments, and some of the finding fathers of the quality movement, like Ishikawa, went so far as to say that quality begins and ends with education. Deming also had a particular interest in learning, which for him defined to a large extent what the human experience is about. Further, Deming's Plan - Do Check/Study - Act model for quality improvement and his fourteen points have been influential in the systematic introduction of quality processes in schools and universities. (Meher and Baral, 2019)

Building upon its strengths and experiences, the quality movement has interpreted the concept of quality in education as learning from experience (the fundamental notion underlying the $\mathrm{P}-\mathrm{D}-\mathrm{C} / \mathrm{S}-\mathrm{A}$ model) and process improvement. In other words, quality improvement in education can be achieved by improving critical processes of the educational system such as training of teachers, student learning, and planning. It is difficult to argue against these basic ideas. However, they may be more difficult to operationalize than what is commonly thought, and they may just represent "one" perspective on quality in education, one among various others discussed below.

Any application of TQM to higher education implies a basic consensus among experts regarding what TQM is. Garvin (1987) shown how quality concepts moved from inspection to quality control, to quality assurance, and finally to a strategic view of quality.

Furthermore, other researchers argued with the development of the service sector, the notion of service quality has become increasingly important. Some researchers conducted an exploratory investigation, which revealed " 10 potentially overlapping dimensions" that stakeholders use in forming expectations about and perceptions of service quality. They analyzed executive responses and obtained the following insight (Qa, et.al, 2005):

"A set of key discrepancies or gaps exists regarding executive perceptions of service quality and the tasks associated with service delivery to consumers. These gaps can be major hurdles in attempting to deliver a service which consumers would perceive as being of high quality".

A simplistic approach to quality assessment would be to briefly describe what quality is, set certain standards that can be assessed compare these with the work done in each institution and draw a conclusion on the quality of the institution in question. Unfortunately, quality in higher education as well as defining a way to measure is not a simple issue. Furthermore, the complexity of the process increases since the set of quality 
attributes to be measured and their relative weight is not constant but varies according to the different stakeholder point of view (Tsinidou, et.al, 2010).

A popular approach for evaluating quality in Higher Education Institutes is the quality function deployment (QFD). QFD is one of the total quality management (TQM) techniques, which can be applied for process and design improvement. The purpose of QFD is to visualize cause-and-effect relationships starting from the customer needs all the way down to the production process. Numerous reports also documented the benefits and results of adopting TQM principles in the various colleges and universities (Hwarng and Teo, 2001). There is a measure service quality by replicating or adapting five-dimension (tangibles, reliability, responsiveness, assurance and empathy) SERVQUAL model SERVQUAL defines five dimensions for quality (Parasuraman et al. 1988):

1-Tangibles: The appearance of physical facilities, equipment, support services and service personnel.

2- Reliability: The degree to which the knowledge, skills learned and services are offered accurately, dependably and on time without errors.

3- Responsiveness: This refers to the willingness to help customers and meet their needs and wants. In difficult situations, it is also the ability to respond effectively.

4- Assurance: The confidence and trust that the customers hold towards the institute and the feeling of safety in case of danger.

5- Empathy: The attention and care that the institution may offer to customers. This part also refers to convenient operating hours.

Cronin and Taylor (1992), in a study with sample across four industries, developed and tested a performance-based measure (SERVPERF). They argued that SERVQUAL was too simplistic for complex cognitive evaluation processes. They contended that the perception of service quality already entails an expected service. Rather than using "gap scores," They also said that a direct measure of perceptions was preferable. (Based on Qa, et.al, 2005). However, Pitt, et.al (1995) argued that although SERVPERF had superior predictive power, it had inferior diagnostic power, because it provided less information. In an effort to reconcile the debate, Zeithaml, et.al (1993) later introduced the notion of a "zone of tolerance" into their model. They suggested that service expectations exist at two levels which customers use as standards in assessing service quality:

(a) Desired: The level representing a blend of what customers believe "should be" provided, and

(b) Adequate: The minimum level that customers were "willing to accept."

Between these two levels is a "zone of tolerance" that represents the range service performance that a customer considers satisfactory.

Furthermore, Education services are often intangible and difficult to measure, since the outcome is reflected in the transformation of individuals in their knowledge, their characteristics, and their behavior. Moreover, when we assess quality of higher education institutions (HEIs), issues such as autonomy and independence complicate the whole process. In this context, accreditation agencies that operate globally have been trying to assess the quality offered by the institutions by evaluating and accrediting their degrees and the educational work offered. However, the operation of these agencies has not greatly 
influenced the perception of quality in the sector or clarified issues on institutional quality assessment.

Moving towards the same direction, the European Commission has put member of states to harmonize their way of operating so as to increase transparency, accountability, and comparability of EU Higher Education Institutions. This contributes to the creation of a competitive market where quality is the distinguishing factor between higher education institutions. (Commission of the European Communities, 2003).

\section{2- QUALITY AUDIT AGENCY (QAA):}

To improve the education system, the higher education institutions need to establish internal quality mechanisms (QAA) that work well to maintain the quality of teaching and learning. Usually, the quality audit focuses on measurement and external accountability, which takes away academic ownership of the audit process. Peer observation is an example of a tool how interviewers used to resist audit-related work, which resulted among them towards audit-related mechanisms. 'Game playing' refers to practices adopted by academics that represent mock or inauthentic compliance. (Cheng, 2005)

Academic review and audits have some advantages. The process is to have the ability to identify unnecessary duplication of programs. Quality Audit Agency (QAA) has proposed a concentration of resources on higher education institutions subjected to a definitive quality assurance framework plan as shown in the following Figure (2.1). The essence of the framework plan will cover the following aspects: (Based on Cheng, 2005)

1- Equality of standards of qualifications with the same name.

2- Spelling out universities' expectations of what they expect students to achieve on their courses.

3- Subject benchmark information and threshold standards.

4- Development of codes of practice to show best practice in other provision student support, governance, etc.

5- Introduction of academic reviewers.

One of the main issues that needs deliberative is the Quality Audit Agency (QAA) in quality assessment. It believes that it could achieve this by finding the right balance between emphases on internal assessment and peer review. So, all institutions may be a subjected to a definitive quality assurance framework plan shown in Figure (2.1).

The essence of the framework plan will cover the following aspects:

1- Equality of standards of qualifications with the same name.

2- Spelling out universities' expectations of what they students to achieve on their courses.

3- Subject benchmark information and threshold standards.

4- Development of codes of practice to show best practice in overseas provision, students support, governance, etc.

5- Information of academic reviewers.

6- Quality assurance of HEIs' academic programs has been adopted around the world and is widely recognized as a vital component of every reputable educational system.

Figure (2.1): Quality audit agency's new quality assurance framework plan 


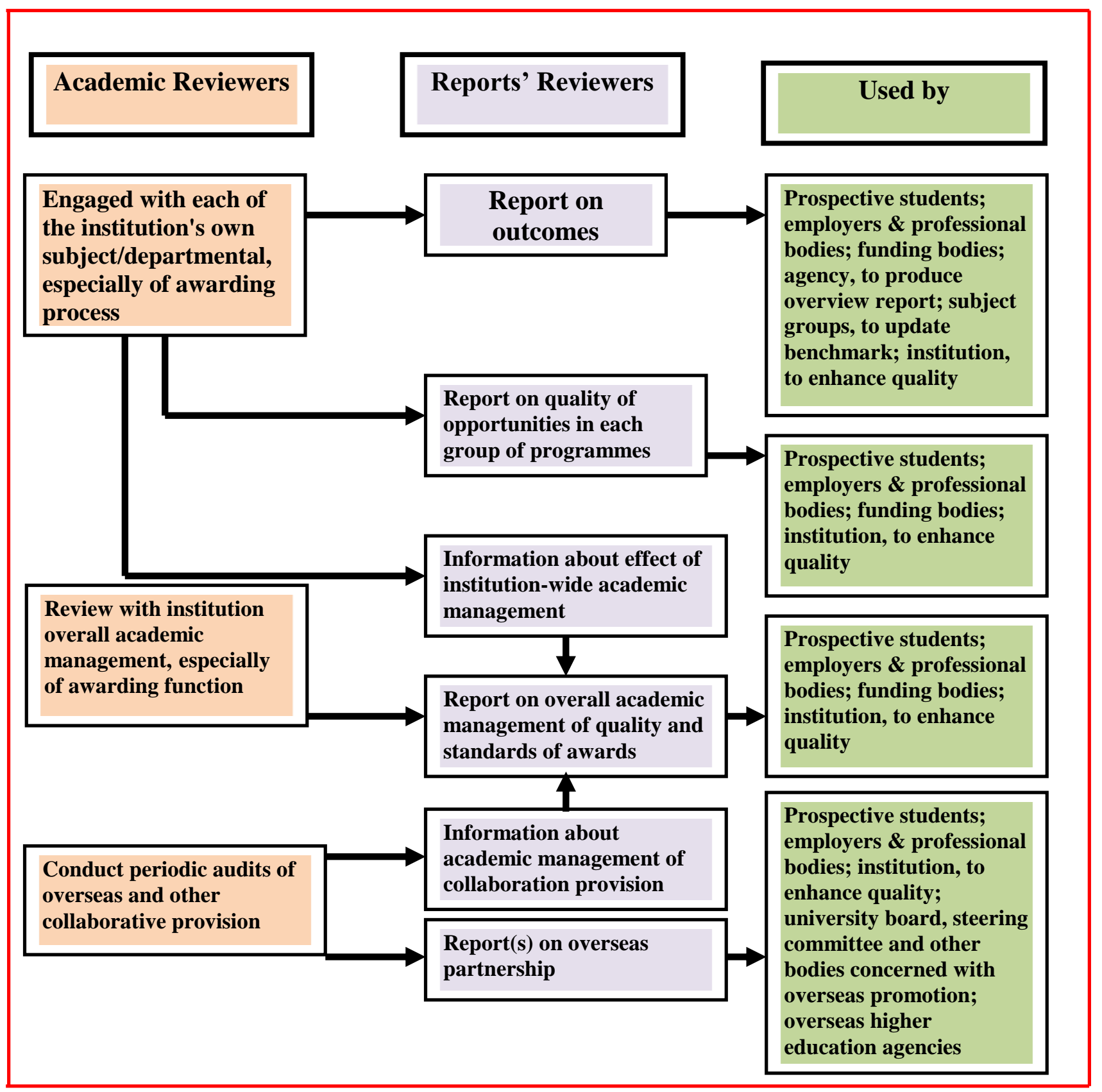

As part of their ongoing commitment to a robust system of quality assurance that reflects international standards societies' publicly assisted higher education institutions renew their commitment to quality assurance with the Quality Assurance Framework (see Figure 2.1).

Considerable international experimentation in the development of quality assurance processes, along with increasing pressure for greater public accountability, has raised the bar for articulating degree level expectations and learning outcomes in higher education. The new approach for assessing the quality of higher education is based on the quality assurance method, hence its name - the quality assurance framework plan. TQM, however, 
emphasizes prevention and continuous improvement. Therefore, costs will be minimized and the institutions will improve their effectiveness over time (Cheng, 2005).

On the other side, The American Society for Quality (ASQ) Organization stated that the Quality standards are defined as "documents that provide requirements, specifications, guidelines, or characteristics that can be used consistently to ensure that materials, products, processes, and services are fit for their purpose. Accordingly, the Standards provide higher education institutions with the shared vision, understanding, procedures, and vocabulary needed to meet the expectations of their stakeholders. Because standards present precise descriptions and terminology, they offer an objective and authoritative basis for universities and stakeholders to communicate and conduct business. Figure (2.2) shows the major core quality assurance standards.

Higher education institutions should turn to standards for guidelines, definitions, and procedures that help them achieve objectives such as: (ASQ, 2021)

- Satisfying their stakeholders' quality requirements

- Ensuring their students and services are safe

- Complying with regulations

- Meeting environmental objectives

- Ensuring that internal processes are defined and controlled

Figure (2.2) Quality assurance standards (ASQ, 2021)

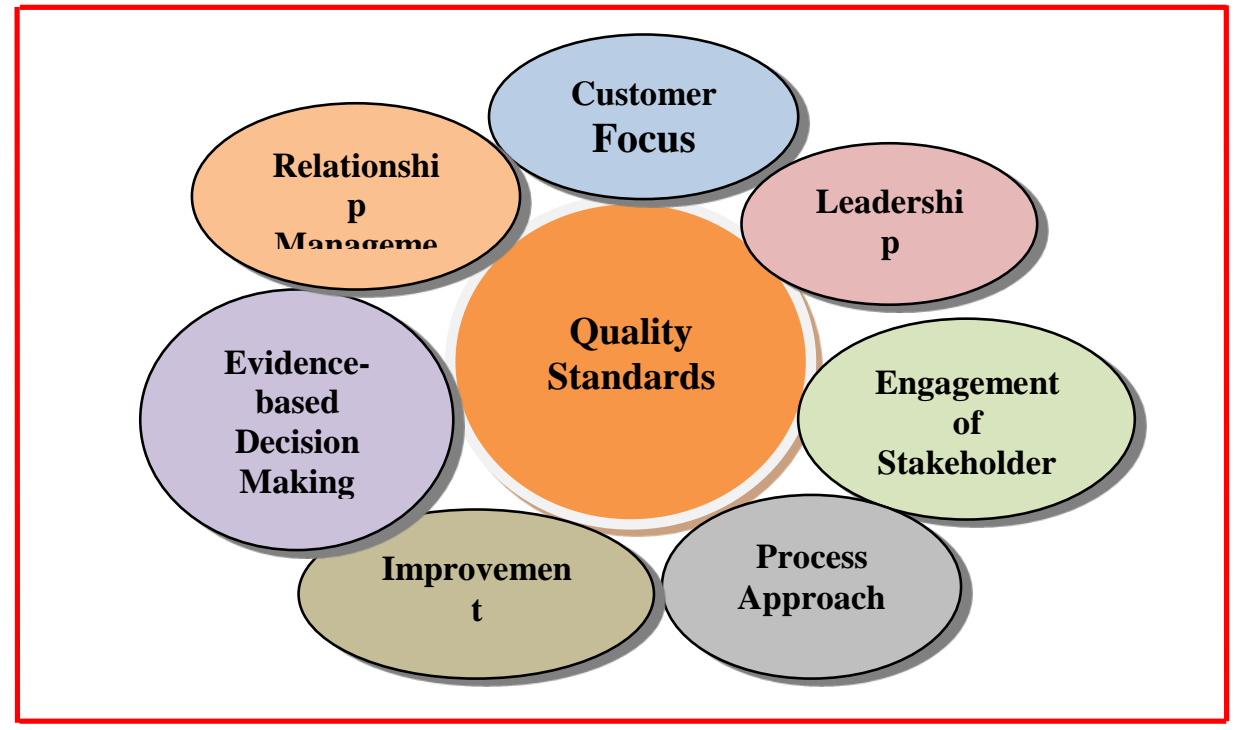

In particular for example, all Ontario's universities (Canada) and their Quality Council commit to the principles articulated below: (Anthony, 2020).

Principle 1: The best interest of students is at the core of quality assurance activities.

Principle 2: While primary responsibility for quality assurance in all undergraduate and graduate programs offered by university, it has vested in the University Quality Council (UQC) final authority for decisions concerning all aspects of quality assurance. 
Principle 3: The Quality Council operates at arm's length from both the institutions and the government to ensure its independence of action and decision.

Principle 4: With this responsibility to grant and withhold approval comes the Quality Council's recourse to substantial sanctions and remediation for use when necessary and as a last resort.

Principle 5: The Quality Council will have due and iterative processes in consultations with institutions, and have robust appeal processes.

Principle 6: The Quality Council itself will undergo a regular periodic quality assessment review by a review committee that includes, equally, reviewers who are external to the system and to the province, and reviewers who are internal to the system and to the province. This review will take place at least every eight years.

Principle 7: The Quality Council acknowledges and respects the autonomy of the institutions and the role of universities' council and other internal bodies in ensuring the quality of academic programs as well as determining priorities for funding, space, and faculty allocation.

Principle 8: The higher education institutions have vested in the Quality Council the final authority for decisions concerning ratification of Institutional Quality Assurance Processes (IQAPs), approval of new programs and compliance with the Audit Protocols. As the primary agents for quality assurance, all higher education institutions have designed and implemented their own (IQAPs) that is consistent not just with their own mission statements and their university Degree Level Expectations, but also demonstrably embodies the principles and procedures articulated in this Quality Assurance Framework.

\section{3- A BASIC MODEL of the EDUCATION PROCESSES:}

There are a wide variety of ways to think about important classroom processes. Building on the Rhetorical Process, the Educational Process Model consists of inputs, an integrative process, outputs, outcomes and feedback. The objective process includes resources, method and experiences; the subjective process involves philosophy, purpose and outcomes. The integration elements of purpose and method further divide: objectives and audiences; and instructional technology and methodology. These four integration elements form interactive rather than linear processes, with pedagogy as the integrative center (Beck, 2009). A highly simplified, linear model of the educational process is shown in Figure (2.3).

In this model education is defined as the system in which inputs (students, teachers, classrooms, educational materials, etc.), through the mediation of critical processes (learning and teaching), become outcomes (students with specific skills, measurable knowledge, etc.) and more broadly defined outcomes from the outputs (not only an educated, but the most important as a productive individuals - workers).

This model encompasses only a limited aspect of the educational process. Nevertheless, it is useful to illustrate the difficulties inherent to the general discourse on quality improvement in education. From Niedermeier, (2017) model we can develop four different sets of definitions of quality in education.

Figure (2.3), Education (Learning) process. 


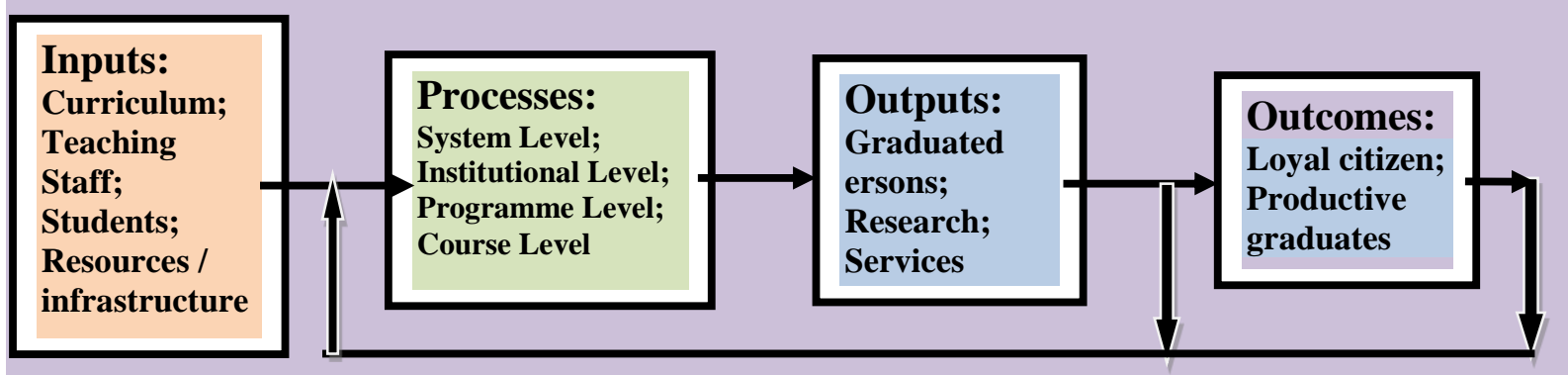

Source: Niedermeier, 2017, with author's modifications.

\section{INPUTS:}

Educational inputs are seen as fundamental to quality in education. In other words, trained instructors (teachers), appropriately equipped classrooms, good educational materials, and motivated students all contribute greatly to learning. This definition of quality is often implicitly used in the public discourse spent on education (measured at the national level as a percentage of Gross National Product - GNP) and the perceived quality of education. It can be said that quality of education understood as quality of inputs dominates the educational policy discourse.

So, the inputs of quality in education mean:

- Quality of education is equivalent to quality of inputs such as trained teachers, safe and well - equipped institutions, and students who have prerequisite skills and knowledge and are eager to learn.

- Good educational systems mean good education.

\section{PROCESSES:}

The greatest strength of the quality movement lies in applied notions of process improvement. In other words, from this perspective quality improvement is equivalent to process improvement. In theoretical terms it is difficult to argue against this definition. In practice, many contributions of quality practitioners to the improvement of quality in education have been full of lofty intentions but based on naive conceptions of educational processes. It can be said that processes are industry specific, and critical educational processes such as learning and teaching are particularly complex, since an important part of these processes is invisible and immeasurable.

The most important contributions of quality practitioners to quality of education have been in the areas of planning and resource allocation. Therefore, it is no wonder that most success stories focus on improvements in administrative and service areas.

So, the process of quality in education means:

- The quality of education depends fundamentally on how we do things, and improvement comes about by changing the way we do things based upon our experience. We can do more with the same resources.

- Quality of teaching and learning about the best quality of education.

\section{OUTPUTS:}


Quality in education from the perspective of outputs refers to familiar notions such as educational standards, skills, and cognitive development. One of the reasons defining quality of education in terms of outputs seems appealing is that outputs can often be measured. However, what is frequently forgotten is that the achievement of certain educational standards (commonly measured through use of standardized tests, which for the sake of this discussion we will assume to be able to measure what they intend to measure) is not equivalent to learning.

There are a wide variety of ways to think about important classroom processes. Many of these are expressed in models that derive from research based on John Carroll's (1963) model of school learning. His major premise was that school learning is a function of time. To be more specific, Carroll proposed that (Huitt, 2006)

\section{School Learning $=\mathbf{f}($ time spent/time needed $)$.}

Carroll defined time spent as a function of (i.e., resulting from or composed of) opportunity and perseverance (Huitt, 2006). The measure he proposed for opportunity was allocated time or the amount of time the classroom teacher made available for school learning. The measure Carroll proposed for perseverance was engagement rate or the percentage of the allocated time that students were actually on task. Allocated time was multiplied by engagement rate to produce engaged time or time on task which is defined as the number of minutes per school day that students were actually engaged in school work.

\section{Opportunity, perseverance}

\section{Aptitude, ability to understand instruction, quality instruction}

Carroll defined time needed as a function of aptitude, ability to instruction, and quality of instruction. (Huitt, 2006)

Strictly speaking, from the Carroll's formula, the learning (understood here as an output, not as a process) refers to a ratio between an initial state and a later state. Simplifying the process, we can conceive a student who knows $(\mathrm{X})$ in the beginning of course and should have (Y) at the end. Learning would be defined as the ratio between (Y) and $(\mathrm{X})$ :

\section{Y / X = L or Learning when $L$ should be greater than $X$}

It may also be useful to define ( $\mathrm{R})$ as the level of resources or inputs needed to bring about (L), which is a number of lessons, time spent studying, cost of the lessons. Under this conception of quality we will attempt to maximize (L) as a function of (R); i.e., bring about maximum learning for a given level of resources.

\section{$L=f(R)$ and maximum efficiency is achieved at max. $f(R)$}


Using this framework, quality in education is equivalent to the achievement of educational goals with maximum efficiency, i.e., with minimal investment of resources. When it comes to education the main difficulty in using this definition of quality exclusively is that some of the inputs (resources) are difficult to measure in order to define efficiency levels. The main reason is that not all inputs are standardized (students may have different natural abilities and additional resources such a supporting home environment).

The policy implications of this apparently simple notion of quality of education as learning are significant: (Based on Huitt, 2006)

1 - The very good education institution may not be so good when measured in terms of learning as defined above. With optimal resources or inputs such as smart students who come from a highly supporting family environment, trained instructors (teachers), good learning materials, and a high entry level into the system ( $\mathrm{X}$ in our equation; i.e., the knowledge students have when they begin the formal learning process), it may be easy to achieve high standards. However, they achieve on a case-by-case basis environment of high educational standards is not equivalent to high efficiency, or maximum learning as a function of resources. Higher learning may take place in poor institution where students come from challenging environment.

2- The argument above (to be tested on a case-by-case basis) may provide support to one of the key policy goals of large education systems, equity. Commonly, it is believed that equity cans only be achieved at the expense of quality. However, it may be useful to test the hypothesis that these two concepts are largely what the statistician would call orthogonal, or unrelated. In other words, higher equity does not necessarily imply lower quality. There may even be cases when higher equity (decreasing the variance of level of resources available throughout the system) leads to higher efficiency of resources utilization, one of the key ways to define quality in education.

3- Although it may be tempting to define quality as the attainment of specific educational outputs (standards), it may be the most efficient alternative, and if the achievement of certain standards is the key goal (e.g., a certain level of math competence for high graders) then an unequal resource allocation (even under the assumption of constant efficiency throughout the system) will be necessary to compensate for unequal levels of inputs.

It can be argued that in our function for learning (L) maximum efficiency can be achieved as a function of inputs or resources (R) available and the entry level of the students $(\mathrm{X})$. This may not represent the greatest practical challenge to quality in education defined as learning, as long as expectations for (Y) which is what students should know at the end of a course.

So, the outputs of quality in education mean:

- Quality means achieving specific standards of excellence.

- Learning is the true measure of the quality and efficiency of education.

\section{OUTCOMES:}

Outcomes refer to a societal perspective of the value of education. There is a difference between a student who has developed specific skills or mastered a given body of knowledge (educational outputs) and the notion of a responsible citizen or a productive workforce. Most of society cares about the latter, but the educational system should concentrate on the former. 
What is often forgotten is that different societies may have different values and, therefore, place different emphasis upon specific outcomes. For example, in traditional societies the integration of the students into the existing social setting was and still is considered to be more important outcomes than practical, economic goals.

The outcomes of quality in education means:

- A quality education should develop a sense of responsible citizenship in individuals (loyal citizens).

- A productive graduated workforce.

\section{4- TOTAL QUALITY MANAGEMENT (TQM) in HIGHER EDUCATION:}

Education is an important and effective tool of social change and a means of improving welfare of an individual. Higher education contributes to national development through dissemination of specialized knowledge and skills. Higher education institutions are a major source for providing the human capital required for knowledge production. TQM in higher education is a process that involves the institutions adopting a total quality approach to the entire academic process and environment (i.e. attempting to improve the quality of instruction and in the process, the students' meaningful learning in every possible way) so that the needs of the students and society are best served.

There are three generic approaches to TQM in higher education (Based on Meher, and Baral, 2019).

Firstly, there is a customer focus where the idea of service to the students is fostered through staff training and development, which mainly promotes the choice and autonomy of the students.

Secondly, there is a staff focus and is concerned to value and enhance the contribution of all members of staff to the effectiveness of an institution's operation to the set of policies and priorities.

Thirdly, there is a focus on service agreements stance and seek to ensure conformity to specification at certain key measurable points of the educational process. The example is the evaluation of assignments by faculty within a specified time frame. Generally, regards the quality of higher education completely depends on the satisfaction of the students who are the end customers and the other stakeholders which benefit from the education system. However, there are two types of customer; (a) external (students - customer and product), employer, community\& educators from different institutions) and (b) internal - other instructors, service department staff.

Total Quality Management can be of benefit at many levels of the educational process; however, it is certainly unrealistic to see such efforts as the solution to the serve education crises that are experiencing. If TQM is about learning and building upon specific experiences, then its need to focus on documenting and evaluating the many different pilot experiences that are now occurring. Consistent with TQM principles, even a failure represents a step in the right direction as long as learn from it.

Therefore, in order to maintain quality in higher education TQM can be implemented which gives focus on customers' satisfaction, maintaining standards, accountability, credibility, prestige, and status of an educational institution. 


\section{4-1- The Model:}

The concepts formulated by TQM founder, W. Edwards Deming, provides a framework that can integrate many positive developments in education, such as teaching, academic management, cooperative learning, and outcomes-based education. Meanwhile, words like learning and curriculum are not found in Deming's 14 principles. Some of Deming's terminology needs to be translated to schools as well. For example, superintendents and principals can be considered management. Teachers are employers or managers of students. Students are employees, and the knowledge they acquire is the product. Parents and society are the stakeholders. With these translations made, it's seen many applications to schools. Adapting to TQM will make important changes in classroom. By the help of this method, the communication between student and teacher will disappear. Therefore, students and their selfconfidences will increase within guidance. (Meher, and Baral, 2019).

The philosophy behind the proposed model (Figure 2.4) somewhat resembles the model promoted by Juran, which has components of planning, control and improvement. Juran used this model (Juran's Trilogy) for managing quality. In order to manage quality effectively one has to plan (quality planning), control (quality control), and improve (quality improvement) quality. The proposed model builds on Juran's model is: (DeFeo, 2019)

- Quality Planning (Quality by Design)

- Quality Control ( Process Control and Regulatory)

- Quality Improvement (Lean Six Sigma)

From the mentioned above models, the basic parameters of quality can be grouped into three areas as shown in Figure (2.4):

- Quality by design

- Quality of conformance; and

- Quality of performance

This framework for quality can provide a model which the higher education institutions can work with to clarify their emphasis on quality and quality - related research. A brief description of these three parameters and the proposed model that uses to visualize their relationships are provided in the sections that follow.

1- Quality by Design: The Quality by Design process for higher education development is intended to build quality into educational based on characteristics that define knowledge and qualification. The quality by design defines as "the practice of using multidisciplinary team to conduct conceptual thinking, program design, and learning process planning all at one time". The quality-by-design program process builds quality in from the beginning of development the higher education strategies and makes certain that this quality is maintained through statistical. Analytical and risk-management approaches, rather than tested for it after the fact. Quality by design requires that the education developer begins to think about society and nation growth rights at the beginning of development process. Figure (2.4) shows the components of quality by design. (PMS, 2020)

Figure (2.4) the components of quality by design 


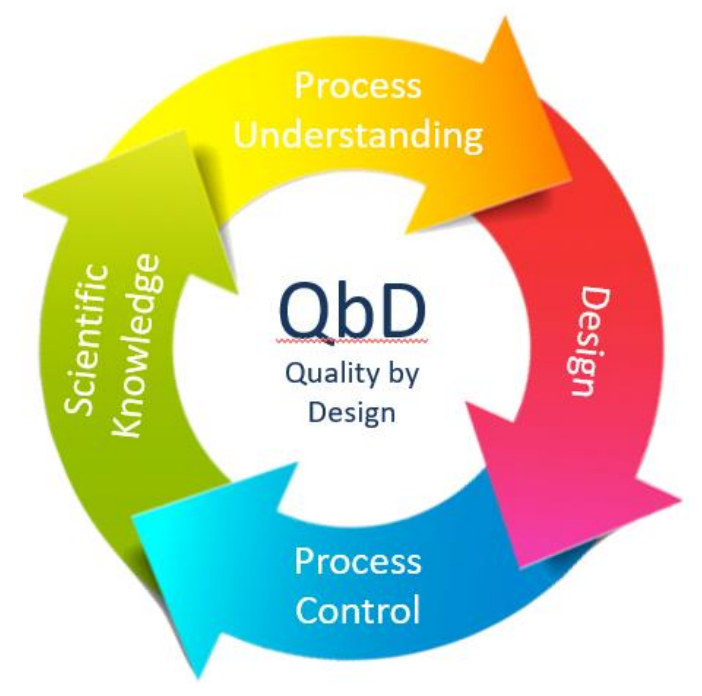

2- Quality of Conformance: Two elements of quality structure - design by quality and conformance quality are recognized and described in the literature (Meirovich, 2006). For the purpose of this study, the Quality of conformance is defined as a "fit between the attributes of an actual education process output and its qualification and specification". In order to satisfy stakeholders, quality should be high on both dimensions. So, the quality of conformance deals with how well HEIs and their stakeholders confirm to the design requirements, including the education processes' cost requirement, for example, statistical quality control techniques are heavily used here.

Quality of conformance as compliance with specifications reflects an educational operation, or internally oriented aspect of quality. Adherence to specifications stems from a high level of consistency and low variation in educational processes. Better conformance quality is achieved when things are done right, i.e., when the efficiency is high. Quality of conformance can be rather easily measured through statistical means such as process capability (the ratio between programs' specification and control limits). Tools for improvement of conformance quality are tools of statistical quality control such as control charts, scatter diagram etc. A general definition of design quality as a match between educational programs' characteristics and stakeholders' needs can be specified by invoking the concept of a zone of tolerance in stakeholders' expectations (Zeithaml, and Bitner, 2003).

A tolerance zone is the distance between desired and adequate levels of expectations. A desired level of expectations stands for the maximum level of stakeholders' expectations while the adequate level reflects the minimum level of quality. This is an acceptable to stakeholders' expectations while the adequate level reflects the minimum level of quality that is acceptable to stakeholders. Design quality is the highest when there is no discrepancy between values in programs' specifications and corresponding values in a program's tolerance zone. Programs' specification also represents a "zone", or a range between upper and lower education's specification limits; a target, or nominal value usually lies in the middle. See the Figure (2.5) shows the quality conformance in higher education institutions .

Figure (2.5) Quality conformance in higher education institutions 


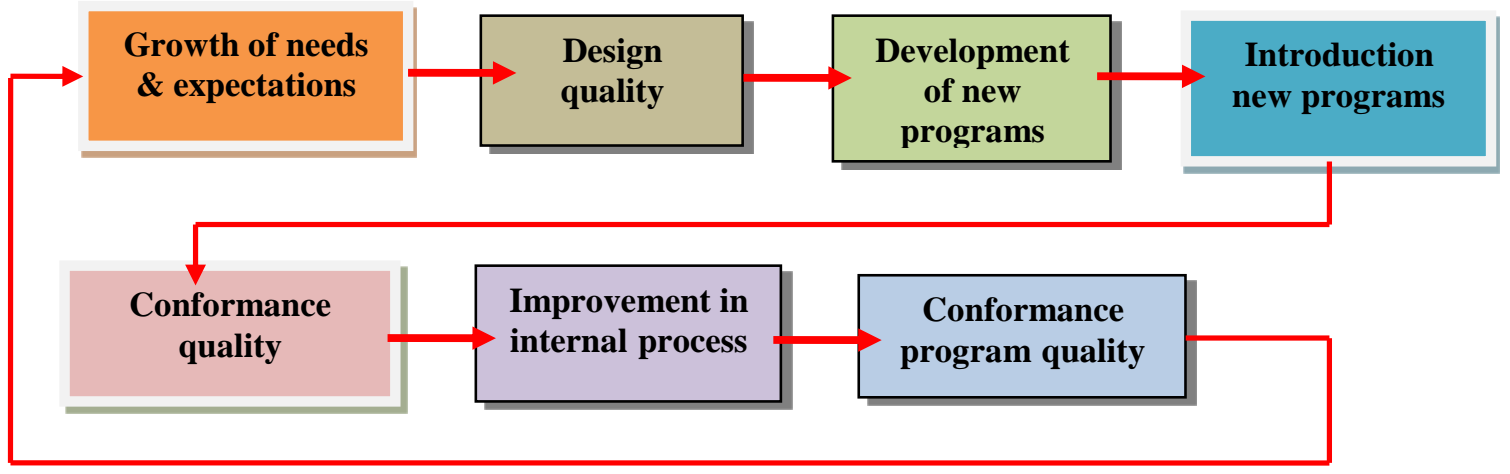

Source: Meirovich, (2006), with author's modifications.

3- Quality of Performance: Quality of performance in HEIs deals with how well the graduated persons of educational processes match the expectations of stakeholders, and how well it's perceived and accepted by the stakeholders. Stakeholder satisfaction, outcomes analysis, knowledge level comparison, (quality of education programs), costs of programs, etc. would be some of the approaches used here. Quality assessment here is a means of assessing the quality of what is actually provided by higher education institutions. The quality assessment involves the judgment of performance against criteria, either internally or externally. This gives rise to a potential source of conflict, precisely because quality criteria for education are so difficult to agree. Another potential problem with quality assessment is that it is usually intended to be mission sensitive. It examines the quality of education provision against the expressed aspirations of the individual institution. If the institution has high aspirations, quality is to be measured against this yardstick. That might make it more difficult for a HEI to succeed than another which set itself lower aspirations. (Tam, 2010)

However, the higher education institutions should established special system criteria (indicators) for evaluation the performance of their educational systems. Indicator systems approach to evaluating HEIs compares performance across a range of indicators. There are several characteristics associated with performance indicators. These are: (Tam, 2010)

First, a performance indicator should have a monitoring function. It can be defined as "an item of information collected at regular intervals to track the performance of a system".

Second, an indicator is usually quantitative.

Third, performance indicators are objective-related; they are 'statements, usually quantified, on resources employed and achievements secured in areas relevant to the particular objectives of the higher education institution.

The model for quality management in higher education institutions discussed here, will integrate these parameters, operationalizes them and then applies them to the university research, teaching and other operations. These parameters are interrelated through a feedback mechanism, e.g. low quality of performance may lead to a change either in quality of design and/or quality of conformance. Similarly, low quality of conformance may necessitate better control techniques or change(s) in design, etc. The feedback mechanism and resulting changes imply the continuous improvement aspect of the relation. This relation can be represented as shown in Figure (2.6). This model it could be a good 
one for the university to adapt to integrating quality into operational, curricular (both design and classroom teaching), research, and community services - related issues.

Figure (2.6) Relationship between the components of the model

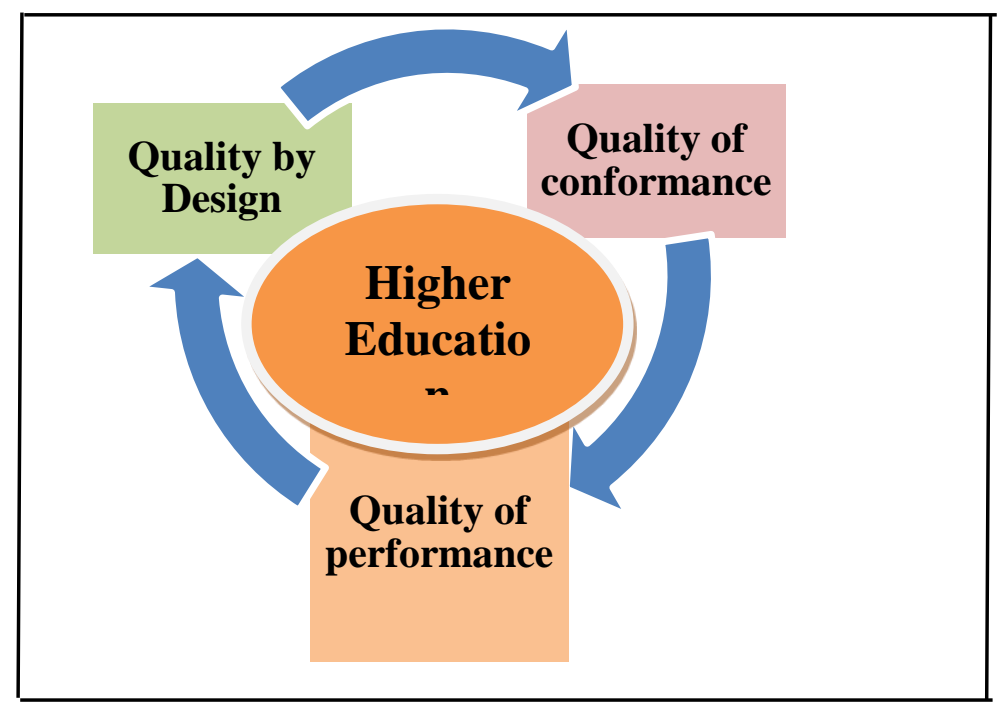

Meanwhile, if higher education institutions are to be evaluated, it is therefore necessary to acquire information about:

1. The outputs (outcomes) which higher education institutions aim to produce;

2. The inputs which higher education institutions need to produce these outputs;

3. Quantitative measurements of each higher education institution's inputs and outputs;

4. The technical relationship between inputs and outputs.

\subsection{2- TQM Principles, Processes, and Tools:}

Quality in higher education institutions should be assessed according to the perceptions of students, academic and administrative staff, and other stakeholders (HEI management, society, employers). This means that development of intellectual skills and knowledge that will equip graduates to contribute to society through productive and satisfying different careers. The graduates should be as innovators, decision makers and leaders in the local and global economy. The ability of graduated individuals to satisfy the requirements of the stakeholders and quality in higher education are an open system at various levels i.e. students (as a product and customers, or as a part of stakeholders), instructors (teachers), curriculum, institutional and nationwide level. (Samad, and Thiyagarajan, 2015) (Najafabadi, et.al, 2008)

The higher education institution should emphasizes that the concept of TQM, as a whole thought, is a combination of values, methodologies and tools, where they have jointed to accomplish higher stakeholders satisfaction with less resources consumption, as shown in Figure (2.7). This whole concept can be taken to mean as a management system. Their interpretation from this system view is that techniques and tools support the values and together they form a whole. The higher education institutions should strongly believe that this definition provides a comprehensive understanding of what TQM really is and assists institutions to implement it successfully. 
However, it's useful to distinguish between the following concepts of TQM in trying to address the question, "What is TQM?"

Principles: these are core values such as "the customer is first" or the need for "shared decision making". They can be found in the writings of the leading writers of the field and in the most important TQM models.

Tools: The tools are used by teams in the context of the processes mentioned above. They integrate creative (e.g., brainstorming) and analytical (e.g., Cause - and - effect Diagram) approaches to problem solving. The best - known TQM tools are the seven quality control tools and the seven management and planning tools. Some tools are known under different names (e.g., Ishikawa or fishbone diagram) and have been adapted from more complex applications (e.g.,) PERT analysis used in engineering applications such as project management.

Methodologies' Processes: These are some specific implementation approaches for diverse needs different levels of the organization:

- Quality improvement teams

- Self - directed teams

- Daily management

- Flowcharting techniques

- Quality function deployment

- Hoshin planning (strategic planning)

- Statistical process control

- Experimental design

- Other related processes useful for quality improvement efforts are benchmarking and reengineering.

- The 14 Deming's TQM tools mentioned before are complemented by other tools, such as the force field diagram and brainstorming.

\subsection{3- The importance of Continuous Improvement:}

Total quality management (TQM) requires a never-ending process of continuous improvement that covers people, equipment, suppliers, materials, and procedures. The basis of the philosophy is that every aspect of an operation can be improved. The end goal is perfection, which is never achieved but always sought. Figure (2.8) illustrates the flow of activities that are necessary to achieve TQM

The Japanese use the word Kaizen to describe this ongoing process of unending improvement the setting and achieving ever higher goals. Whatever word or phrase is used, defects, and six-sigma are used to describe such efforts. (For detailed information see the related references, please).

Figure (2.7) Components view of TQM

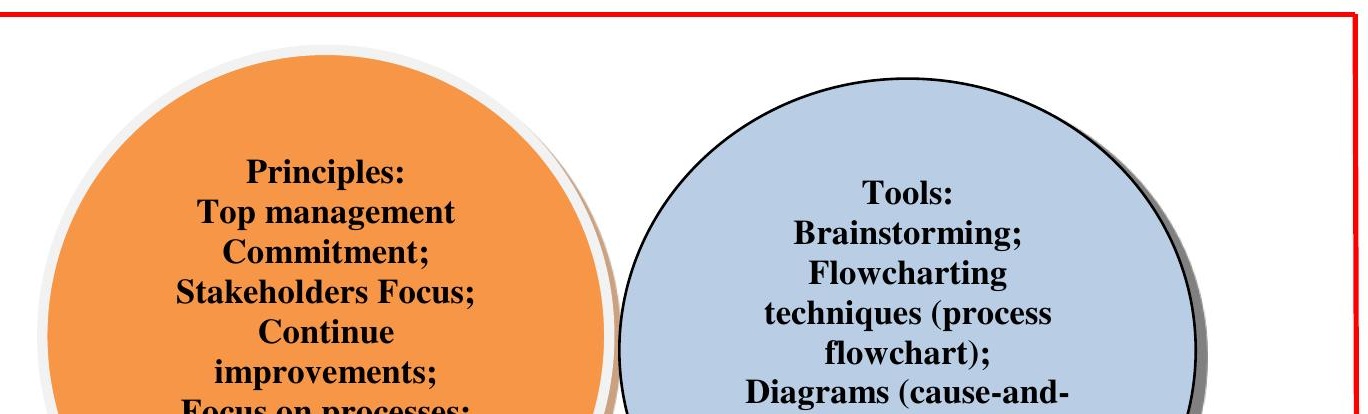




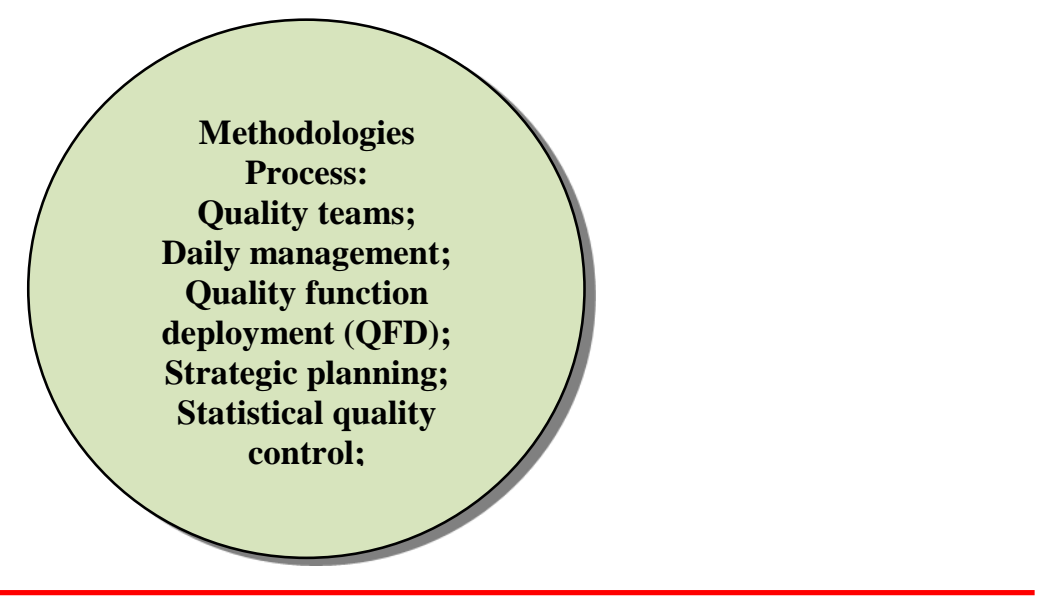

Employee Empowerment: Employee empowerment means involving employees in every step of the production or service processes. The definition of employee empowerment in HEIs is "allowing the academic and administrative staff to retain sufficient autonomy over programs and work performance and/or involvement in broader workplace/decision making cooperation and draw upon their latent skills, but not so much as to forfeit managerial control" (Marchington, et.al, 1993).

Techniques for building employee empowerment include: (Craig, 2019)

1- Building communication networks that include all staff.

1- Developing open, supportive supervisors and academic leaderships.

2- Moving responsibility from both managers and academic leaderships' management to operation educational units and programs supervisors.

3- Building high-morale organizational HEI.

4- Creating such formal organization structures as administrative and academic teams and quality circles.

Figure (2/8) the flow of activities that are necessary to achieve TQM

\section{Organizational Practices:}

Leadership

Mission Statement

Effective Educational Systems

Stakeholders Support

Training and Development

Yields: What is important and what is to be accomplished 


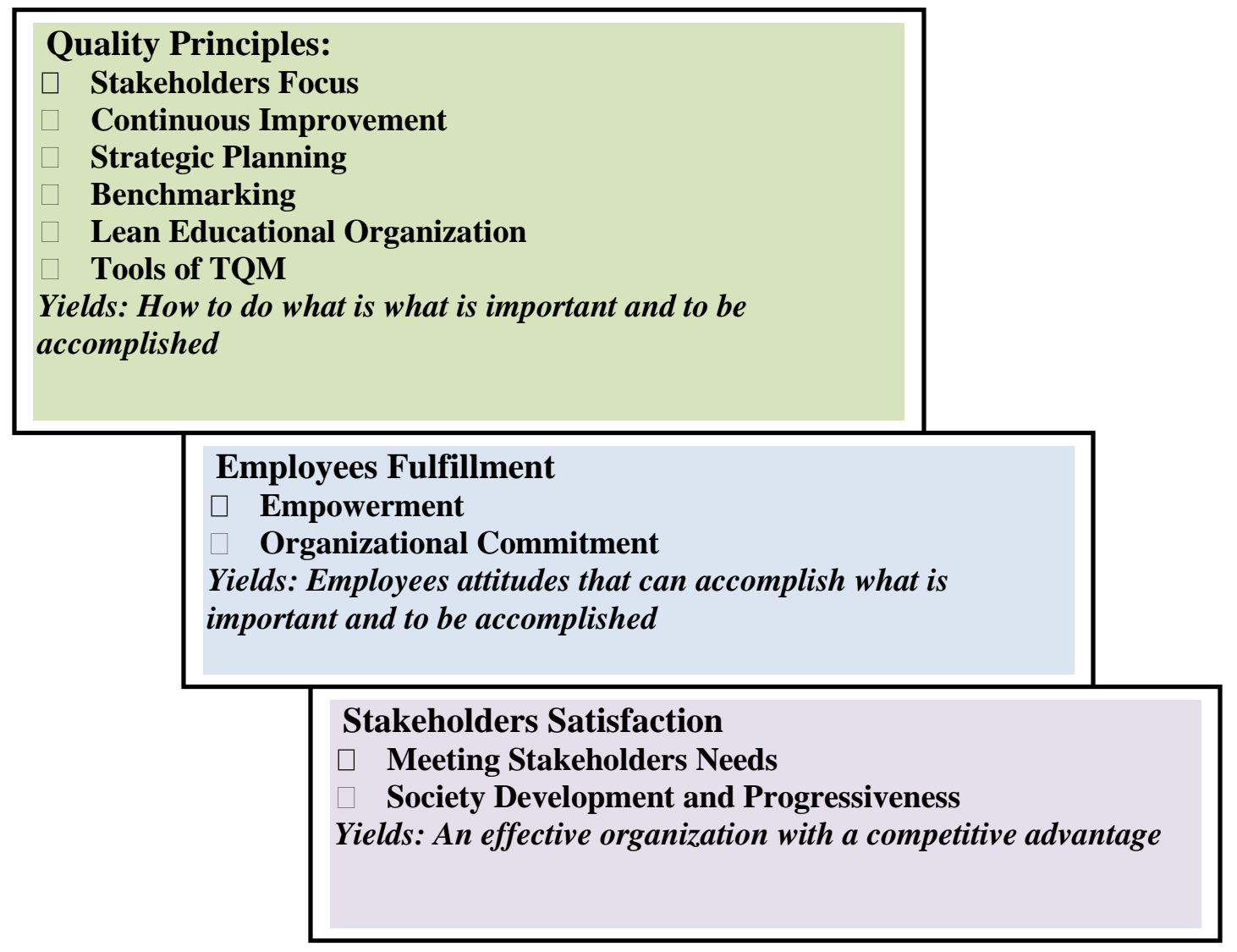

\section{5-TQM IMPLEMENTATION EFFORTS in HIGHER EDUCATION INSTITUTIONS:}

Any educational institution which wants to implement TQM should develop its own model. The proposed model for implementing TQM in Higher Education Institutions should have the following principles. (Based on Pushpa, 2015)

1- Understanding/Identifying: The top management of the educational institution should first understand what TQM is and educate its culture to all employees.

2- Decision for Change: The top leadership management must make decisions for bringing in change for achieving quality management system and motivate other employees and faculties to adapt to changes.

3-Preparation for implementing changes: The higher education institution must determine the requirements of all stakeholders, identify the goals and vision to be achieved and prepare strategies to facilitate the flow of communication between and within the different levels of the administrative and academic units. 
4- Training and education to academic and administrative staffs: The higher education institution must devise training and development programmes to educate and equip academic and administrative staffs, guiding them to carry on their work such that they will support the institution in meeting its goals thereby achieving quality.

5-Initiative: The higher education institution must take an initiative and give a start with new assignments and projects. There is no achievement without a beginning. Hence, a good leader may be selected by the Higher Education Institutions to begin and motivate all staff members for quality performance. Benchmarking may also be regarded as one of the effective tools for the successful implementation of TQM.

6-Evaluation: The higher education institutions must evaluate their performance annually for quality sustenance and improvement so that they will be able to achieve high level of performance and success in this competitive scenario. In this stage, the institution will be able to identify any problem and obstacle that is responsible for not achieving TQM and may take measures for overcoming such obstacles.

7-Recognition: This is necessary to motivate an academic and administrative staffs, which will boost their morale and self-interest. Monetary or Non-monetary rewards may be awarded to staffs to make them feel committed to their job as well as institution which will in the long run ensure quality.

8- Continuous Improvement: TQM is a continuous process, so it is an unending process of improvement. The TQM process should be reviewed and communicated to all levels of academic and administrative staffs on a regular basis.

The important conclusions are intended to be descriptive rather than normative and reflect the experiences of many higher education institutions. Some of the most important applications of TQM principles, processes, and tools in higher education institutions are: (Based on Pushpa, 2015)

1- To use process improvement teams and models in administrative units: Administrative processes in higher education institutions are similar to those of other service organizations; therefore, it is not surprising that early TQM implementation efforts in higher education institutions have started in administrative units, such as admissions, the registration office, or finance and accounting department, human resource and other administrative units where the implementation experience of other service organizations could be applied.

2- To use TQM processes such as Hoshin (strategic) planning: One key TQM principles is the need to content the mission and vision of an institution with short-, medium-, and long-term objectives and implementation plans. This may seem to be an obvious requirement in any planning effort, and not a particular contribution of TQM. However, the congruence of objectives and means is difficult to achieve in practice when the PDCA model (the key model of process improvement) has not been institutionalized. Vision and mission statements tend to be somewhat abstract, and, therefore, difficult to translate into achievable objectives. Within the context provided by the institutional mission and vision, TQM processes (such as Hoshin planning) provide a framework that develops coherence between clearly stated objectives and specific implementation plans to achieve such objectives in a stated amount of time. 
3- To use TQM processes in academic units: With little exception, attempts to introduce TQM processes into academic units should not be stalled. Also, should give the existing processes such as tenure, teaching and learning, values and principles such as academic freedom, otherwise the TQM project implementation may failures. To introduce TQM in academic units with any hope for success, the first step is to examine which values would relate to TQM, and, secondly, which objectives would appropriate for academic functions. Are the standards by which faculty performance is evaluated something that is functional within a "TQM" framework?

Tenure is a process based on values such as "academic freedom," rooted in widely held societal beliefs such as the need to encourage independent intellectual inquiry and reflection. Academics are supposed to be to freely voice their opinions without fear of retaliation by the administration. Higher education institutions are held to be areas in which diverse opinions can be freely expressed, rather than so called "one-party" organizations with singular ideological and political agendas.

It is inappropriate to engage in a discussion regarding values such as academic freedom with concepts such as efficiency. Values provide a fundamental framework upon which HEIs are built, and cannot be directly measured for "efficiency." Efficiency can only be measured against clearly defined strategic objectives, and values precede strategy. Therefore, if academic freedom is an essential value, it cannot be judged by concerns with efficiency. Thus, a more direct "framing" question is whether tenure is the best process to ensure academic freedom. So, from a pragmatic perspective, it is unlikely that tenure will be abolished in tradition and experience. Still, the difficulty of implementing TQM in academic units remains. An organizational analysis of academic institutions might provide some answers. Higher education institutions are essentially "loosely coupled systems" in which committees and subsystems (each class or course) have a high degree of autonomy. This is the fundamental operational basis of a "college" or "department" in which each member is seen as a specialist in his/her field.

It is likely that TQM experiences related to the development of teams formed by professionals (as in Quality Function Deployment applications) may be relevant for academic environments. Also, consistency between mutually agreed-upon objectives and specific implementation efforts can be sought. However, any efforts to bring about a major power shift under the guise of efficiency concerns are likely to fail. Centralization of power proposed by the administrators of academic units will be stand against by the academic staff with a clear collegiate tradition.

4- To use TOM processes for the development of new academic programs: Processes such as quality function deployment allow the planners, to take into account the interests and needs of diverse constituencies in the development of new programs and services. This approach may be particularly well suited to the development of new academic programs in HEIs. Those programs in which the skills and depth knowledge require by stakeholders should plan an important role in programs' design.

5- To foster the development of partnerships among communities, business, and educational institutions: This means the initiatives of HEIs to build partnerships with a 
community to more effectively plan and carry out projects to improve the communities they share. It draws primarily on the experience of the HEIs and community initiatives for much important collaboration that should focuses on higher education partnerships to design the strengthen the human, organizational, economic, and physical capacity of the society. It highlights partnerships that strengthen the capacity of individuals to achieve economic self-sufficiency by securing better employment; of different eco-national organizations to grow and provide better services and more opportunities for community sustainable development.

6- To introduce TQM principles and values into mainstream educational thought: Some of the founders of the quality movement, such as Deming, Juran, and Feigenbaum, have written about fundamental changes they consider necessary in educational practices. Deming went as far as advocating the abolition of the grading system, which, in his view, fosters senseless competition and stifles the basic human instinct to learn for the sake of learning. So, they indicated that TQM is both a philosophy and a set of controlling principles that represent the equilibrium of a continuously improving organization. TQM is not only a programme, it is a process which is continuous, involves everyone in an organization, and links business process reengineering. Further, to meet their customers' needs and expectations.

Accordingly, the quality in higher education (as mentioned before) with reference to various characteristics as stakeholders' satisfaction, leadership, managing teaching and learning performances, developing efficient programs, research works, and community services quality and improving in teaching,

7- To introduce TQM curricula into professional programs, such as engineering and business: TQM models describing particular TQM processes, such as team-based problem solving or statistical process control (SPC), increasingly are part of business and engineering core courses such as organizational behavior or operational management. Engineering curricula had integrated SPC long before the quality movement acquired high visibility.

\section{CHAPTER THREE: The FRAMEWORK of BUSINESS PROCESS REENGINEERING (BPR):}




\section{1-INTRODUCTION:}

\subsection{1- BPR Concept:}

Reengineering became a suitable solution to success and development of organizations in general and specifically in educational one. Process reengineering will undoubtedly eliminate stereotypes in operations and thus help to change old structures and reach innovative ways and thus help to bring significant benefits to the Organization. According to (Farmer, 1993) re-engineering operations help customer satisfaction, increased flexibility, improved competitiveness and increased productivity. The re-engineering can be used to solve past management failures, there are many factors like competition, change, financial risks, Customers, economic trends, operational challenges, and global business trends. Business Process reengineering is "the fundamental rethinking and radical design of business processes to bring about dramatic improvements in performance".

BPR is defined by Hammer and Champy (1995) as "the fundamental rethinking and radical redesign of business processes to achieve dramatic improvements in the critical, contemporary measures of performance, such as cost, quality, service, and speed". Given the above background and to serve as an operational definition for purposes of this study, BPR can be defined as the "strategic redesign of core higher education processes that are critical to the enhancement of an institution's strategic planning process and should be aimed at achieving improvements in institutional performance. This BPR definition covers the application of BPR within the higher education institutions of both the private sector and the public sector.

However, to compete efficiently it necessitates that all kinds of education should be relevant to the national economy and national sustainability development's requirements. These institutes have to review processes to work effectively and efficiently by reducing costs and identifying core competencies. With a high level of competition, and competencies being imitated by other organizations, HEIs can no longer rely on what they consider their strengths.

The major economic forces affecting countries and organizations over the last decade have been liberalization, privatization, and globalization. In turn, these have lead to number of influences and pressures on national economies and high education as well. Chief among these is the powers of: (Based on Harb and Abazid, 2018)

Stakeholders; the power of stakeholders has been perhaps the most important factor shaping HEIs. As a result, HEIs have to continually learn, and adapt to changing stakeholders' choice, and requirements. This power compels an HEI to move from a bureaucratic mode to a responsive mode of educational operation: to be flexible and lean, able to meet stakeholders' demands cost effectively.

Information; the power of information (largely arising from advances in information communication technologies - ICTs) can help HEIs in this continual learning and adaptation processes. With ability to transfer volumes of data globally from one institution to another, knowledge networking and knowledge management becomes possible.

Global Investors; the power of global investors in higher education is a range of dominated opportunities, no longer bounded by regional or national boundaries.

Market Place; the power of marketplace generates fierce time-based competition. This either motivates an HEI to learn faster, to become better at providing quality and value 
of academia (teaching and learning programs, curriculums, research activities, and community services or it causes the complacent to fail.

Simplicity; the power of simplicity is the move to streamlines education systems, strategies, and procedures within the HEIs and the move away from a ritualistic culture to an empowering and autonomous structure. This involves reengineering design of education processes and the forging of community partnerships to eliminate delays and bottleneck.

Organization; the power of organization is the ability to use self-knowledge, information communication technologies (ICTs), and modern education practices to change the shape of the institution. It is now possible to create much leaner, more agile HEIs based on high performance skilled knowledgeable teams.

A further definition of the concept of BPR as "the rethinking and radical design of the major processes of organizations to achieve results of tremendous improvement in modern performance measures: service, quality, cost and speed of work (Hammer and Schambee, 1995). This definition includes four basic features of BPR that could successfully applied in the HEIs: Fundamental Rethinking, Radical Redesign, Dramatic Results, and Processes. Their interpretation as follows:

* Fundamental Rethinking: It means that the time has come for each HEI and each its staff members to look at the way they work and review what they are doing and ask themselves: Why do they do it? Is this work valuable? Can it be done better? All these questions are posed by the principle of BPR in a scientific way that helps HEIs to reach answers to these important questions.

* Radical Redesign: BPR it includes radical solutions to the current problems of education processes, which is characterized by a method of BPR from other administrative concepts that were mostly seeking urgent solutions and improvements to the problems of education processes, teaching methods, and obstacles.

* Dramatic Results: BPR is not about formative and relative improvements, but achieved huge and high-performance. HEIs that have successfully implemented the concept of BPR

have achieved tremendous results in increasing the value of education processes, staff productivity, increasing research outputs, and providing better community services.

* Processes: The principle of BPR is characterized by focusing on the work systems (education processes) or known as the main processes and not departments.

\subsection{2- BPR in Higher Education:}

All higher education institutions, from small colleges to large campus institutions, are involved in some complex processes to deliver effective teaching and learning, research works, and community services. It is usually plain to see that there is room for improvement for the methods used. The issue now becomes, how do they tackle the problems and what do they tackle first? The implementation of new systems then becomes imperative since it's usually a drive for considering how to carry out the business process.

Successful reengineering in higher education must begin with both academics activities (teaching and learning, research, and services), and administrative processes (human resource management, finance, and other administrative units). Addressing educational processes first will naturally force a reconsideration of such features as the programs' curriculums, instructors' (teachers) load, classrooms' utilization, the academic 
calendar, course scheduling, instructional resources like technology, and the design of student-faculty interaction, and other students' services.

A significant part of the difficulty of thinking about reengineering in higher education arises from the absence of clear analogs between stakeholders and higher education institutions. As many academics would contend that academic process is of a fundamentally different order from business process: it resists business models of productivity. It also resists the sort of quantification economy requires. For this reason, some people argues that reengineering should be applied only to administrative processes, namely the support processes that are the business-like side of higher education. Porter acknowledges that the core processes-teaching, learning, and research --remain resistant to standard business process reengineering. He ascribes this resistance in part to the fact that attempting to reengineer these core processes requires a degree of agreement among administrators, faculty, and trustees that is unlikely to be achieved (Stahlke and Nyce, 1993).

If the academic activities (including teaching and learning) in higher education institutions are to be reengineered, then a different set of assumptions must be embraced and implemented. A strong program of reengineering must proceed from the following assumptions:

- The fundamental teaching-learning unit is the teaching- learning task;

- The relationship of instructor (teacher), learner, and content varies from one teaching-learning task to another;

- Traditional methods and modern technological tools together form a unified set of tools and methods, each of which is appropriate to some teaching-learning tasks and not to others; and

- Methods and tools must be scaled to fit the learning environment.

These assumptions will require a rethinking of academics' activities, teaching and learning that can profoundly affect the roles and responsibilities of the student and the instructor, administrative support processes and calendars, and, in short, the entire structure and delivery of higher education. The resulting reengineering promises to increase the effectiveness of the academic's activities, teaching and learning process, to lead to more efficient use of resources, and ultimately to increase both the effectiveness of and accessibility to higher education (Stahlke and Nyce, 1993).

\section{2- REENGINEERING OF HIGHER EDUCATION: REINVENTING TEACHING AND LEARNING 3.2.1- BPR Dimensions:}

Since several decades, Business Process Re-Engineering (BPR) is has been used as a change management strategy in higher education institutions all over the World. A number of interrelated pressures have created the need for change in the higher education institutions such as: expansion of higher education; changing student profile; pressures from industry; increased competition; information technology (IT) capability. However, 
higher education institutions (HEIs) are seeking to maintain the three 'Es' of efficiency, effectiveness and economy, by adopting the new managerial techniques (Based on Allen and Fifield, 1999).

The power of BPR is that it can provide the means by which the HEI is able to achieve a radical change in performance. This is achieved by simplifying and streamlining the major education processes, by eliminating all redundant and non-value adding steps, by reducing the number of stages-transfer points of work and by speeding up the work - often through the use of information technologies and systems. Thus, fundamental attributes of BPR are that it:

Results in radical change in teaching and learning methods;

Assumes clean slate change;

Focuses on end-to-end processes of the education system;

Is top-down directed structure;

Information technology enables the teaching and learning, and research activities and so on.

However, a little has changed in the basic assumptions as to how higher education is to be carried on: the lecture hall, the library, the tutorial, and the laboratory remain the structural constants of college and university education. These constants assume that higher education is best carried on by bringing the students to the repositories and masters of learning. A strong program of reengineering in HEIs must proceed from the following assumptions :( Once more based on Stahlke and Nyce, 1996)

The fundamental teaching-learning unit is the teaching-learning tasks;

the relationship of teacher, learner, and content various from one teaching-learning task to another;

Traditional methods and modern technological tools together from a unified set of tools and;

$\square$ Methods, each of which is appropriate to some teaching-learning tasks and not to others; and methods and tools must be scaled to fit the learning environment.

Business process re-engineering (BPR) has been identified in some quarters as a means by which higher education institutions can meet these pressures for change, utilizing IT to increase efficiency and effectiveness. These assumptions will require a rethinking of teaching and learning that can critically affect the roles and responsibilities of the student and the instructor, administrative support processes and calendars, and in short, the entire structure and delivery of higher education.

The resulting of reengineering promises increase the effectiveness of the teachinglearning process, to lead to more efficient use of resources, and ultimately to increase both the effectiveness of and accessibility to higher education.

An Asynchronous Model of Teaching and Learning require relationships among instructors (teachers), students, and programs' content, where content is understood as including learning materials. These relationships may combine any two or all three components. BPR could enable HEIs to develop organisational structures that enable innovative teaching and learning methods, whilst maintaining some element of the important student-teacher relationship. The term "asynchronous" to refer to activities and relationships that do not require complete simultaneous involvement of all participants and 
elements; rather participants and elements are present as needed for appropriate, stable design of teaching and learning (Stahlke and Nyce, 1996).

In the typical lecture hall, for example, instructor and learner are together, but the role of learning materials are present, but the teacher plays a more limited role. By providing parameters for the design of teaching-learning tasks, an asynchronous model lends itself to considering questions as to what is taught, what is learned, who is involved, and what unrealized, role in teaching and learning. This role is defined variously by what the instructor has available, has had time to learn, or can find an appropriate use for, and by what students have access to, are familiar with, and are willing to use. In all of these ways, technology usually plays an adjunct role to other, more traditional modalities for teaching and learning, including lecture, laboratory, library, textbook, tutorial, and practices.

The classroom lectures remain the basic unit to begin reengineering and fiscal planning. In order to begin reengineering teaching and learning, Educators must first challenge the notion "default mode". Instead of designing for economical scheduling and movement of people, academics must attend to the teaching-learning task and its properties. With the teaching-learning task as the unit of organization for course content, its can borrow the concept of "object" from contemporary software technology. This means an object is a self-contained block of information with certain intrinsic relationships to other objects. These objects can be designed in such a way that the necessary combinations of student, content, tool or methods, and instructor are most effectively associated. The nature and design of these objects will have to emerge from experiments, innovation, and reflection; if reengineering is to succeed, the artifacts of a new model cannot simply be built out of traditional elements of higher education. Teacher-learner communication can be mediated electronically by means of fax, electronic mail, electronic bulletin boards, or online conferencing system as appropriate.

A crucial component required for the establishment of institution wide processes and dependencies in a HEI, is the introduction of an integrated IT infrastructure. This enables information to be transferred and accessed throughout the institution and information becomes an institution-wide resource. That is exactly this enabling infrastructure that facilitates and helps drive the process of redesigning processes and procedures of the institution. An institution-wide IT strategy leads to effective networking of voice, data and video; these are accessed regionally, nationally and even internationally. Information to be a resource, that generates the knowledge required to achieve the goals and objectives of the modern institutions. For this reason, information can be regarded as a key source of competitive advantage (Allen and Fifield, 1999).

Appropriate library or text assignments, laboratory experiences, database searches, or small group efforts can associate learner and materials. Evaluation can be carried on individually, peer-to-peer, in groups, or by various electronic means. Such an approach to reengineering offers opportunities to test and extend notions of learning and teaching in higher education by appropriate matching of tool/mode. Learning tasks, and participants, and by scaling the design of the object to the environment of the task. Among the consequences are more precise definitions of instructors and students responsibilities. For example, instructor responsibilities include selecting and sequencing learning materials and activities, monitoring and evaluating student progress and performance. The tutorial 
interaction with the top (15\%) and bottom (15\%) of students, lecture/discussion as needed and appropriate and online discussion as needed. Student responsibilities include performance of teaching-learning tasks as prescribed or recommended, completion of evaluation exercises, and interaction, live or electronic, with the instructor or other students.

\subsection{2- BPR Benefits:}

The pressures for change within the higher education sector are evident worldwide and the pace of change is ever increasing. McRoy and Gibbs (2009) contend that doing more with less; improving the quality of learning and learning experience. And improving efficiency and effectiveness are some of the pressures public higher education institutions constantly grapple with across the globe. The public higher education institutions are of late under pressure and face many of the challenges that are also faced within the private sector. In response to these pressures for change and in the efforts to become more efficient and effective, public higher education institutions should adopt management techniques that were originally practiced within the higher education institutions.

The means of achieving improvements in institutional performance in higher education differ regarding the approaches followed and frameworks utilized by different institutions across education sectors, they share a commonality. Improvement in institutional performance is mainly achieved through the adoption of a comprehensive approach that focuses on a framework for successful BPR principles $\left(\mathrm{O}^{\text {ee }}\right.$ Neill, 2003 and Mushaathoni 2015).

Some benefits of an Asynchronous Model Reengineering teaching and learning along lines required by an asynchronous model will stimulate the evaluation and reevaluation of the role of teaching and learning in higher education. The parameters of appropriateness and scalability will allow asking questions about matters that even reform efforts in higher education have frequently taken for granted: the basic objects and structures of the HEIs. It is these objects and structures that successful program of reengineering must both work through and challenge. For students, an asynchronous model will provide greater responsibility for learning, control over pacing of learning activities, and multiple modes of interaction with instructors and peers. For instructors, the model presents research opportunities in teaching and learning and in higher education itself.

Business Process Re-engineering (BPR) as a quality improvement initiative is commonly applied in the business sector for attaining efficiency, effectiveness and for making the activities customer-focused. It is somehow a new phenomenon in the Higher Education context, which provides an opportunity for monitoring and evaluating the progress of the reengineering effort. Moreover, BPR is used in quality improvement initiatives in higher education institutions for a number of reasons (Lemmalodesso, 2012):

Firstly, BPR methodology provides the means of codifying experience, knowledge and ideas that can be evaluated and tested.

Secondly, BPR methodology allows for planning and monitoring activities in the higher education institutions. It enables them to develop a clearer picture of its core processes and associated problems (teaching - learning, research, and community services).

Thirdly, those involved or affected by the re-engineering activity have a clear understanding of their roles and tasks. In addition to that, it facilitates communication 
between those individuals who are leading BPR and different parties with the result that progress is seen as a result of monitoring activity of the overall process re-engineering.

Fourth: Simplified and streamlined operations - At the end of this entire BPR project, the higher education institution is left with a streamlined operations that has cut out superfluous processes (or unnecessary steps in a process) that used to slow things down. By doing this, efforts become more directed towards organizational objectives, employees have a clear path to take, and stakeholders will be much happier with the service they receive.

Fifth: Increased Efficiency - By eliminating redundancy in higher education institutions and tweaking processes, things will move through the process more easily and faster, greatly increasing overall efficiency.

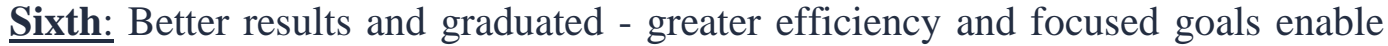
institutions' employees to put more energy towards building relationships with stakeholders through streamlined, digitized processes.

Finally, BPR allows for the identification and development of standards for required qualifications and skills of academics staff, administrative people, students. The key skills required for BPR include process modeling, organisational development techniques and the skills to deal with resistance to change.

The most natural arena in which to apply an asynchronous model is distance education, where the asynchronous relationship among teacher, learning, and content is unavoidable. However, much of the design of distance education courses has attempted to replicate the on-campus lecture hall and discussion format. The use of one- or two- way television and two - way audio is clearly a compensatory measure that has led to significant investment in infrastructure and facilities simply to preserve a default mode of teaching and learning. Instead, the fact that instructor and learner cannot be in the same place at the same time should form the basis for redesigning distance education courses around modular learning objects that use appropriate and properly scaled tools and methods. The asynchronous model can also extend other modes. The class notion of tutorial can be mediated by electronic bulletin board for asynchronous discussion, real-time conferencing systems can support synchronous meetings and electronic mail and file transfer can support the submission of assignments.

A wide variety of graduate courses emphasizing research can be redesigned to emulate the use of the Internet for collaborative research among scientists, reserving faceto-face lecture and discussion only for those modules requiring that sort of synchrony. Much supervision of thesis and dissertation works is already carried on over a distance. While face-to-face conferences are often of great value for debating research issues, much comment and criticism requires thoughtful contemplation and writing tasks that do not require synchrony. The range of types of institutions of higher education, for example, is varied enough to require radically different approaches to reengineering.

Identifying educational analogs to the primes of business process reengineering forces us to examine the role of the institution in the society it serves. The HEI, if any, for instance, receives tax money and students' fees to prepare young people for successful, overwhelmingly the primary sets of processes supporting this goal. However, the HEI must 
also recruit and must place these students with employers four or five years later if it is to fulfill its mission. It follows that recruitment of students and placement of graduates is also core processes in higher education.

Finally, for reengineering to succeed, it has to put academic priorities first. What the parameters and principles described here is the possibility of tying teaching, learning, research - traditional academic priorities - to recruitment and placement.

\section{3- BUSINESS PROCESS REENGINEERING MECHANIZM 3.3.1- The Concept of BPR Mechanism:}

During the last decades, Business process reengineering became a business management strategy that focuses on the analysis and design of workflows and business processes within an organization. This strategy directs to a chief the fulfillment of needs and requirements of the stakeholders. This ultimate reason for apply the business process reengineering techniques in higher education institutions. With it, the higher education institutions should provide stakeholders and the national economy a better highly qualified productive graduated people with highly citizenship loyalty.

According to the significant success of BPR, modern higher education institutions must abandon the old control mechanisms that characterize the hierarchical and bureaucratic organization. These control mechanisms are obsolete. Three reasons are advanced on behalf of this claim (Hammer and Champy, 1993) . $\quad$ First,modern information systems, such as expert systems, decision-support systems, and modern digitalization, can provide academic and administrative staffs with information that enables them to make decisions themselves.

Second, the modern higher education institutions' staff (academic and administrative) should be well educated and capable of assuming responsibility. Modern staff expects more autonomy and self-control, and, moreover, expect to have a say in how a teaching learning processes are run.

Third, the higher education institutions' environment has changed. It is much more dynamic and competitive than before. The old bureaucratic system which was geared toward efficiency and control is out of place in an age where flexibility, variety and stakeholders' satisfaction are the keys to success. It is necessary to design higher education institutions that mirror the increased differentiation of stakeholders' demand, and the flexibility and power of the highly developed applications of digital technologies.

The concept of business process reengineering in higher education institutions is to rethink and breakdown the existing teaching - learning, research and community service processes. This allows the institutions to improve these processes, increase the knowledge, and reduce the costs through the updated educational and administrative processes. These means that the BPR enables the analysis and redesign of teaching - learning and administrative processes within and between the higher education institutions in order to optimize end-to-end processes and eliminate the non-value tasks and activities. The sense and the fragments suggest strongly that the institutional control system must be revised. Since an adequate definition of self-control is absent, it is necessary to define more precisely the meaning of self-control as used in this essay.

Combining the general discussion about institutional control with the BPR thinking, self control can be defined as follows. A staff can be said to have self-control if he (or she): (Iden, 1995) 
(a) Is able to design his own role freely or in negotiation with his peers in a department,

(b) Plans his own work, including setting his own goals and standards,

(c) Monitors his own performance,

(d) Has the authority to make decisions in questions that are related to his own work and work environment, and

(e) Is without supervision from formal supervisors.

Therefore, this definition does not suggest that every control mechanism of bureaucratic institutions must be removed. As previously mentioned, this is because institutional control is a complex phenomenon that includes the whole institutions. Some formal control mechanisms that will continue to exist with the idea of self-control are (a) overall policy and strategy formulation, (b) overall education goals and objectives, (c) budgets, and (d) rewarding. These mechanisms are not managed by a self-controlled employee.

It is common to view education-based systems development as a technical problem with a technical solution. However, successful education-based systems development requires attention to four pillars as illustrated in Figure (3.1):

- Strategic alignment with mission and higher education goals.

- Instantiation of principles of education system governance.

- Evaluation of relevant technologies for education development implementation.

- Recognition that education development requires a different mindset than traditional development.

Strategic Alignment: Strategic Alignment, focuses education - oriented system' decisionmaking on mission and education teaching - learning, research and services. Make the goals priorities rather than the preferences of individuals down the chain of command. If the wrong strategy is selected, it can result in an expensive collection of random education system teaching and services that are never used. A successful education - oriented system' strategy includes the following: (Lewis and Smith, 2007)

- Evidence of fulfillment of critical higher education goals.

- Alignment with higher educational institutions architecture and current and future information communication technologies (ICTs) and knowledge sharing infrastructure.

- Realistic choices of educational technologies and infrastructures.

- Realistic and gradual adoption strategy.

- Adequate education - oriented system governance structure.

- Priorities for implementation of BPR.

- Reuse strategy across internal and external educational institutions.

These issues can be addressed through activities that provide a focus to the education oriented system implementation, the overall higher education plan, identification of high priority education processes, and disciplined education - oriented system adoption.

Figure (3.1), Four pillars of BPR in higher education. (Based on Lewis, and Smith 2007 with author's modification).

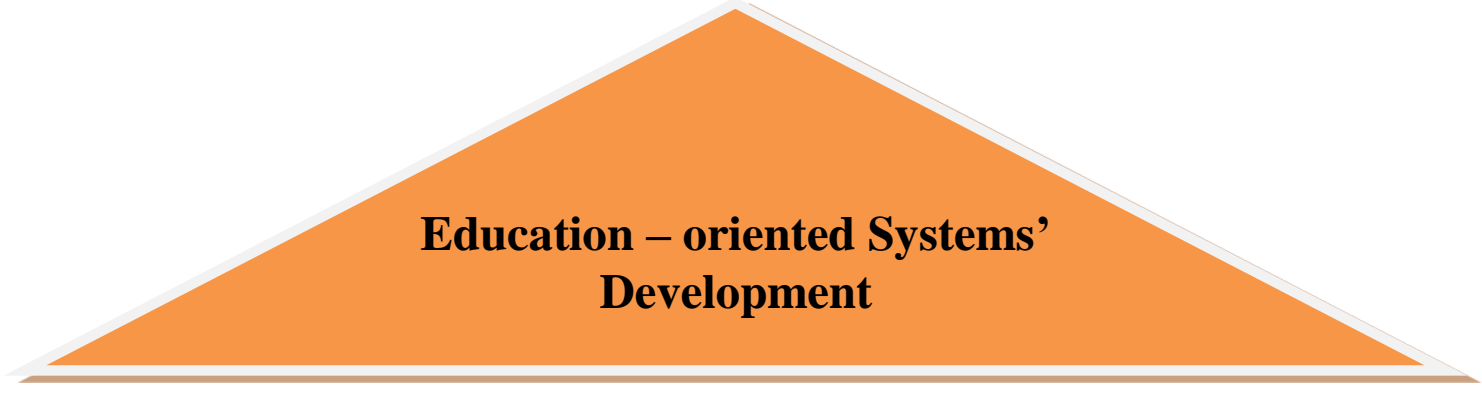




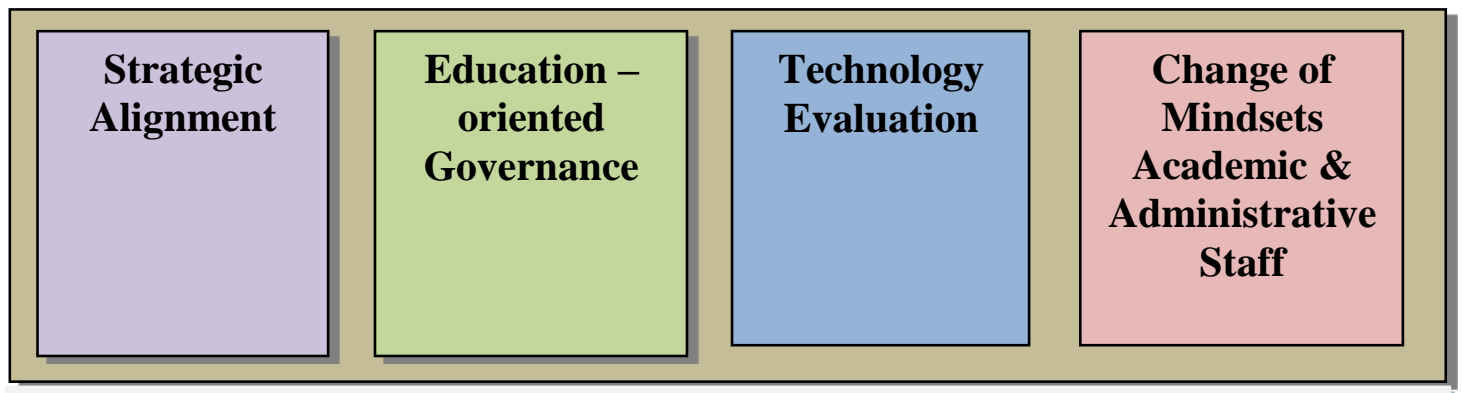

Education - oriented System Design

Focus to education-oriented systems Implementation: The high-level mission and higher education goals need to dictate the focus of an education - oriented system implementation. As an example, four different high-level education goals can lead to four different strategies:

- An education-oriented system to support higher education institutions will have critical needs to ensure performance, availability, and security.

- Increasing information available to stakeholders will focus on intuitive portals and creation of services related to information that is important to stakeholders.

- Integrating new partners will focus on a flexible education system infrastructure.

\subsection{2- The Important Issues:}

Before starting of implementing the BPR, higher education institutions should find the answers for some very important questions, such as:

Why are we doing it?

For whom are we doing it?

Where should we do it?

How do we organize and operate in order to do it?

The other important step is to define the characteristics of BPR before starting the developing the plan of works that should been subject to BPR. These characteristics include the followings:

Be performed where it makes sense;

Be subject to minimal checking and control;

Involve single activities which were previously distinct and separate;

Focus on the process and not the functional activity;

Involve multi-dimensional jobs;

Be performed by empowered individuals and teams;

Be measured by outcomes and not activity level;

Be lead by coaches, not traditional supervisors;

Take place within a flat structure; 
Be managed by leaders, not scorekeepers.

The 3C's (customer, competitors, and continuous improvement) model is basically what allows a company to have a look at the factors that can contribute towards its growth and get rid of disruptions on the path of success. The primary objective behind the $3 \mathrm{C}$ 's model is to point out the ways through which a business strategist can ensure that their business is running successfully, for a longer term (Ohmae, 1982). The driving forces of any systems are three Cs Group: customers, competition and continuous improvement and change as shown in Figure (3.2).

Figure (3.2) the 3Cs Model for higher education institutions

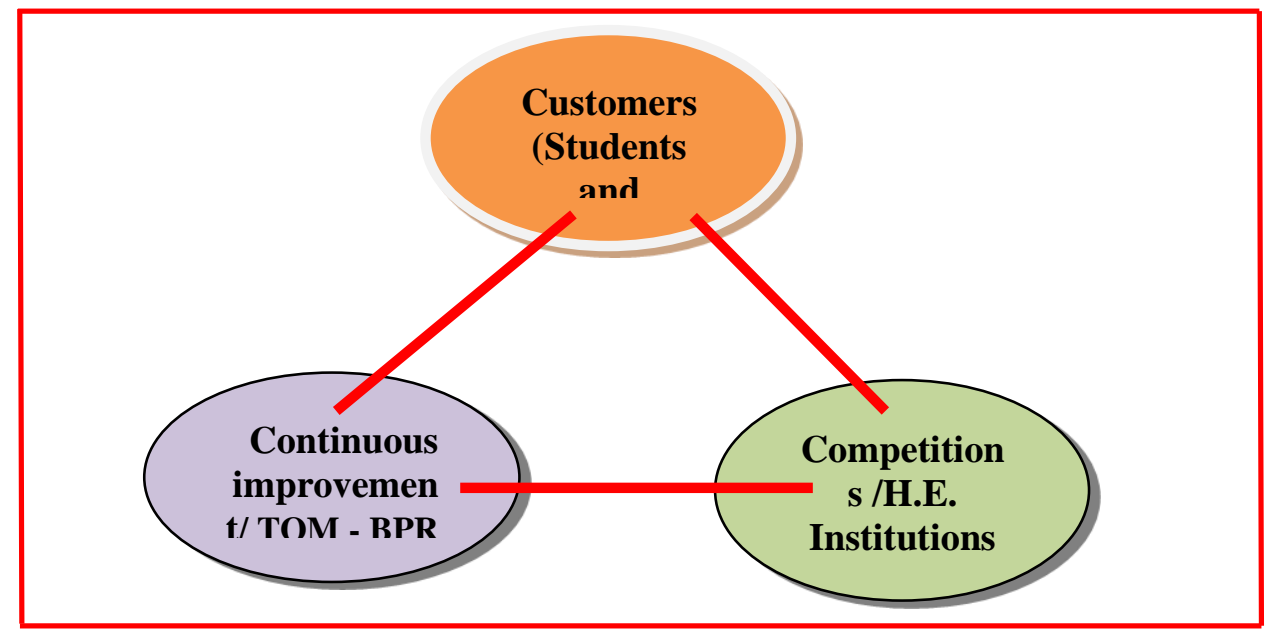

1- The customer is a king. Being the basis for a HEI, the HEI are taking care of the interests of its customers (stockholders) as well as of its national sustainable development can bring a great deal of positivity to the HEI. When a customer's needs, wants, demands, education incentives, decision-making abilities are considered as factors to form a strategy, then it becomes remarkably easy for a HEI to gain a positive outcomes.

Therefore, after a higher education institution is done analyzing its stakeholder's base, the following questions should be asked, in order to set a proper start for the HEI to run:

(a)Where is the support needed? (Where?)

(b)Which type of support is needed? (What?)

(c)Who should each area is given separate support? (Why?) And;

(d)-How to put together effective design support? (How?)

2-Competitions the competition, according to Ohmae (1982) are the strategies that can be formed by studying several functions such as teaching - learning, research, designing of the programs and curriculums, infrastructure, services' activities.

3- Continuous improvement and change is endemic, with new education activities and services have to move fast to adjust to changing environment conditions. Higher Education institutions able to maintain and improve education system quality by:

1-Deploy the new programs and systems of education.

2- New digital technologies to get learners up to speed. 
3-Updating and transforming the programs 'curriculums.

4-Interactive learning and teaching.

5-Digital classroom ensure students access the tests \& assignments.

6-Going electronic devices (laptops, tablets, mobile, etc.), mean access to a lot of data from anywhere, anytime.

All these are taking place in (and as a result of) a transition from a "providers' education" to a "customers' education and loyalty is fought on the basis of:

Programs' curriculums;

Reaction time;

Quality education;

High performance.

Since BPR contributes to reduce the cost of activities via the analysis and redesign of the educational programs and processes of the higher education institutions, it is considered as an effective managerial tool to cope with technological and economical environmental changes. In many instances, the complicated changes brought by BPR projects in all aspects of people, processes, and technologies, have resulted in many issues throughout the BPR implementation process, which has ultimately led to project failures (Hammer and Champy 1995; Fasna \& Gunatilake). Consequently, there is a vital need to pay sufficient attention towards issues in implementation to ensure the success of BPR projects.

Finally, the high failure rate of BPR projects has highlighted the importance of identifying and addressing issues in BPR implementation (Hammer and Champy 1995; Fasna \& Gunatilake). Among which Grover et al. (1995) has summarized a list of (64) BPR implementation issues classified under six categories. Table (3.1) illustrates the potential issues in BPR implementation as put forward by Grover et al. (1995).

Table (3.1) Issues in BPR implementation (Grover et.al, 1995)

\begin{tabular}{|l|l|l|l|}
\hline Category & $\begin{array}{l}\text { Description } \\
\text { Management } \\
\text { support problem } \\
\text { associated with the } \\
\text { management's } \\
\text { active } \\
\text { understanding and } \\
\text { support fort } \\
\text { reengineering }\end{array}$ & $\begin{array}{l}\text { Potential Issues } \\
\text { feengineering; efforts managers' failure to support the } \\
\text { new values and beliefs demanded by the redesigned } \\
\text { processes; } \\
\text { Lack of senior management leadership for } \\
\text { reengineering efforts; } \\
\text { Lack of BPR project champion; Top management's } \\
\text { insufficient understanding about BPR; Insufficient } \\
\text { understanding about the goals of top management in } \\
\text { relation to BPR }\end{array}$ \\
\hline $\begin{array}{l}\text { Technological } \\
\text { competency } \\
\text { problems }\end{array}$ & $\begin{array}{l}\text { Problems relating } \\
\text { to thechnical } \\
\text { infrastructure and } \\
\text { expertise within } \\
\text { the organization }\end{array}$ & $\begin{array}{l}\text { Lack of expertise in IT in the organization; } \\
\text { Limited telecommunication infrastructure; } \\
\text { Limited database infrastructure; } \\
\text { Limited IS application infrastructure; } \\
\text { Insufficient understanding about existing data, } \\
\text { applications, and IT across the organization; } \\
\text { Failure to continually assess emerging IT capabilities; } \\
\text { Lack of IS participation and assistance in the BPR } \\
\text { project; } \\
\text { Failure to aggressively use IT enablers }\end{array}$ \\
\hline $\begin{array}{l}\text { Process } \\
\text { delineation } \\
\text { problems }\end{array}$ & $\begin{array}{l}\text { Potential problems } \\
\text { related to the } \\
\text { identification of } \\
\text { suitable }\end{array}$ & $\begin{array}{l}\text { Scope of reengineered process was defined } \\
\text { inappropriately; } \\
\text { Failure to identify process owners who are responsible } \\
\text { for entire business process; Difficulty in establishing }\end{array}$ \\
\hline
\end{tabular}




\begin{tabular}{|c|c|c|}
\hline & $\begin{array}{l}\text { parameters for the } \\
\text { process involved }\end{array}$ & $\begin{array}{l}\text { performance improvements goals for the redesigned } \\
\text { process; } \\
\text { Failure to include process owners throughout the BPR } \\
\text { effort; } \\
\text { Difficult to forecast HR, financial and other resource } \\
\text { requirements; } \\
\text { Focusing only on evaluation criteria that are easily } \\
\text { measured and quantifiable; } \\
\text { Approach to reengineering was too radical; } \\
\text { Proposed changes to the process were too incremental, } \\
\text { not radical enough }\end{array}$ \\
\hline $\begin{array}{l}\text { Project planning } \\
\text { problems }\end{array}$ & $\begin{array}{l}\text { Potential problems } \\
\text { associated with } \\
\text { planning, setting } \\
\text { up the team and } \\
\text { other preparation } \\
\text { for BPR projects }\end{array}$ & $\begin{array}{l}\text { Lack of strategic vision; } \\
\text { Lack of appropriate planning; } \\
\text { Lack of alignment between corporate planning and IT } \\
\text { planning; } \\
\text { Top management's short-term view and quick fix } \\
\text { mentality; } \\
\text { Identification of candidate process for reengineering } \\
\text { not based on strategic planning; } \\
\text { Failure to understand the customers' viewpoints in BPR } \\
\text { efforts ; } \\
\text { Absence of appropriate training for BPR team } \\
\text { members; } \\
\text { Failure to commit the required resources to BPR } \\
\text { efforts; } \\
\text { Difficulty in finding BPR team members who have } \\
\text { required skills and knowledge; } \\
\text { Lack of authority given to BPR team; } \\
\text { Lack of experience in business reengineering; } \\
\text { Lack of external consultant support for BPR efforts } \\
\text { Difficulty in financially justifying benefits of BPR; Lack } \\
\text { of strategic vision Lack of appropriate planning; } \\
\text { Lack of alignment between corporate planning and IT } \\
\text { planning; } \\
\text { Top management's short-term view and quick fix } \\
\text { mentality; } \\
\text { Identification of candidate process for reengineering not } \\
\text { based on strategic planning; } \\
\text { Failure to understand the customers' viewpoints in BPR } \\
\text { efforts; } \\
\text { Absence of appropriate training for BPR team } \\
\text { members; } \\
\text { Failure to commit the required resources to BPR } \\
\text { efforts; } \\
\text { Difficulty in finding BPR team members who have } \\
\text { required skills and knowledge; } \\
\text { Lack of authority given to BPR team Lack of experience } \\
\text { in business reengineering; } \\
\text { Lack of external consultant support for BPR efforts; } \\
\text { Difficulty in financially justifying benefits of BPR. } \\
\text { aly }\end{array}$ \\
\hline $\begin{array}{l}\text { Change } \\
\text { management } \\
\text { problems }\end{array}$ & $\begin{array}{l}\text { Potential problems } \\
\text { due to the failure to } \\
\text { manage change } \\
\text { from the old } \\
\text { process to the new } \\
\text { process }\end{array}$ & $\begin{array}{l}\text { Failure to anticipate and plan for the organisational } \\
\text { resistance to change; } \\
\text { Failure to consider politics of BPR efforts; } \\
\text { Senior management's failure to commit to new values; } \\
\text { Absence of management systems (e.g. incentive, training } \\
\text { system) to cultivate required values; }\end{array}$ \\
\hline
\end{tabular}




\begin{tabular}{|c|c|c|}
\hline & & $\begin{array}{l}\text { Failure to consider existing organisational culture; } \\
\text { Difficulty in gaining cross functional cooperation; Need } \\
\text { for managing change is not recognized; Necessary } \\
\text { changes in human resource policies for BPR } \\
\text { implementation were not made; } \\
\text { Rigid hierarchical structures; } \\
\text { Line managers in the organization unreceptive to } \\
\text { innovation; } \\
\text { Unreasonable expectations attributed to BPR as a } \\
\text { solution for all organisational problems; } \\
\text { Failure to communicate reasons for change to members } \\
\text { of the organization; } \\
\text { Lack of appropriate employee compensation incentives } \\
\text { in the new process; } \\
\text { Inadequate training for personnel affected by the } \\
\text { redesigned process; } \\
\text { Not enough time to develop new skills for the redesigned } \\
\text { process; } \\
\text { Failure to build support from line managers. }\end{array}$ \\
\hline $\begin{array}{l}\text { Project } \\
\text { management } \\
\text { problems }\end{array}$ & $\begin{array}{l}\text { Problems which } \\
\text { deal with the actual } \\
\text { conduct of the } \\
\text { project }\end{array}$ & $\begin{array}{l}\text { Failure to assess project performance in the early stages } \\
\text { of BPR efforts to provide feedback; Reengineering team } \\
\text { member's conflict between team responsibilities and } \\
\text { functional responsibilities; } \\
\text { Too much emphasis on analyzing the existing process; } \\
\text { Poor communication among BPR team members; } \\
\text { Difficulty in measuring reengineering project } \\
\text { performance; } \\
\text { Ambiguity in job expectations for BPR team members; } \\
\text { Lack of appropriate BPR methodology; } \\
\text { Difficulty in gaining control of reengineering efforts; } \\
\text { Failure to effectively monitor progress of project } \\
\text { according to the schedule; } \\
\text { The BPR effort takes too much time; } \\
\text { Uncertainty about the BPR project's time-frame; Poor } \\
\text { communication between BPR team members and other } \\
\text { organisational members; } \\
\text { Difficulty in modeling and simulating proposed change } \\
\text { to the business process. }\end{array}$ \\
\hline
\end{tabular}

\subsection{3- Key Elements of BPR:}

For the best results, the institutions structure, people, technology, strategy, and other resources have to work together to meet higher education goals. To achieve the goals of implementing the business process reengineering, it's proper to understand and tackle the basic elements of the BPR. These elements are: (Based on Naz, 2013)

1-People: Any higher education institution that seek to create and pursue new paradigms, and attempt to remove functional barriers by redesigning process-driven education workflow cannot hope to do so without the active co-operation of the all academic and administrative staff. The aim is to move beyond "empowerment" to the development of truly "renaissance" employees who can move from one business process development team to another, using their skills and knowledge to enhance the performance of any project. Proper implementation of the BPR is quite difficult just because of lack of concern towards "human issues". The main purpose is to examination how to manage human issues in the higher institution when applied BPR as a project. In the comprehensive change, these 
institutions are required to adapt their superiority as of a conventional focus on forecast and organize to significance speed, innovation, flexibility, quality, service and cost. Required a HR team that is stakeholders- attention and high education- determined and its external associations with stakeholders and panel-oriented within its internal process.

2-Organizational Culture: It is defined as the degree at which organizational standard and principles develop into satisfactory to the employees. Effective culture show signs of professionalism towards its employees that work as team and achieve desired goals to work as a team for achievement of desired objectives (Naz, 2013). The kind of higher institution that is more likely to succeed with a BPR initiative is one that already has a high degree of:

Inspirational leadership - that can articulate a vision, drive the values and create a harmonious climate in which education unit executives, academic and administrative managers, and programs supervisors can all share commitment and flourish equality; Shared values;

Teamwork at all levels;

Connectivity between the various stakeholders-employees, governmental agencies, students and academic staff;

Desire to dominate at the national society.

3- Management and Leadership: Effective utilization of leadership styles enables HEIs to achieve their expected results of BPR. So those in management positions must develop a leadership style. The selection of the style is contingent on the leader's personal traits, and the nature of the activity. Ultimately, the leader has to select a style that will be most effective for the situation at hand. Suitable Leadership style has been recognized as a critical success factor for BPR implementation in the literature (Dabnoon, 2017). The role of leadership in driving, monitoring and controlling the activities related to the change is very important. Hammer, et al (1993) mentioned obstacles in leadership as reason for most of the failures in business process changes. High power of senior management can make an effective start and lead implementation of BPR successfully.

4- Organizational Structure: The concept of a reengineered organization requires the structure to be closely related to, and underpinning, the cultural change required. The kind of shift obviously has tremendous implications for human resource management and development. They need to exhibit:

$\square$ Systems thinking - they must be able to take a holistic view, to integrate hard and soft information, to combine analysis and intuition and balance the varied and multiple interest of the various stakeholders.

Inter-cultural Competence - both within and without the local HEIs. As organizations become increasingly global and increase their dependence on other economies, an understanding of, and sensitivity to different cultures becomes an important requirement.

5-Tools and Techniques of BPR: The essential tools of BPR are the same ones that are needed and exploited in a range of productivity and quality improvement methodologies as described early chapters.

6-Implementation of BPR: Low value-added processes should obviously be removed or redesign, especially if they are high cost. Within process reviews, the aims are to achieve dramatic cost reduction, to become "best in class" and to find "breakpoints"- where the rules of the game are actually changed and "the class" itself is changed. Others then have 
to emulate this new standard- clear evidence of superior performance in one more value metrics clearly recognized within the stakeholders, associated with any or all of:

Robustness - the physical attributes of the education output, in terms of its reliability, and fitness for national economy development.

Cost - costs certainly can have a big influence on education outputs' position.

Education programs' time - the minimum pogroms' times affect operations economics but more importantly allows greater responsiveness to changing stakeholders demands. Flexibility - flexible education processes allow the synchronizing of capacity with student's classrooms' usage and provide the flexibility to respond to mix programs.

Reliability - The reliable processes are in which all activities are performed consistently within the designed schedule.

$\square$ Programs' Design - The program's design processes must relate to stakeholders desirable attributes and to be high "education ability".

$\square$ Good Community Services - involves an empathy with stakeholders and is delivered by well-trained, competent, quality staff with appropriate knowledge, skills, confidence and the right attitude.

Searching for these breakpoints through BPR may be considered in three phases.

Phase 1: Discover;

Phase 2: Redesign; and

Phase 3: Realize

The discussion of these items will discuss in details through the following materials.

\section{4-PERFORMANCE INDICATORS}

\subsection{1- Performance Indicators Classification:}

According to Oxford Dictionary definition of key performance indicator (KPI) is a "quantifiable measure used to evaluate the success of an organization, employee, etc." So, the key performance indicator is a measurable value that demonstrates how effectively a higher education institution is achieving key education goals and objectives. It's useful to introduce and break down the most-used types of key performance indicators (KPIs): (Based on McCluney, 2020)

1. Quantitative Indicators: Quantitative indicators are the most straight-forward of KPIs. In short, they are measured solely by a number. There are two types of quantitative indicators - continuous and discrete. Continuous quantitative indicators can take any value (including decimals) over a range. Discrete quantitative measures include things like complaints, accidents, and rating scales.

2. Qualitative Indicators: Typically, a qualitative KPI is a characteristic of an education process or education programs' decision. Examples of qualitative KPIs include opinions, properties, and traits. A common qualitative indicator that HEIs regularly use would be a students' (stakeholders) satisfaction survey. While some of the survey data would be considered quantitative, the measures themselves are based on the opinion of a person. Qualitative focuses more on the "why" as opposed to the "how."

3. Leading Indicators: Leading indicators are used to predict the education outcome of a change in a process and confirm long-term trends in data. An example of such indicators is:

* Number of graduated students; 
* Number of research publicity;

* Student service perception.

While in and of themselves they are not standalone indicators of success, they are indicative of success in other metrics and serve as an excellent indicator of success in their initiatives. 4. Lagging Indicators: Lagging indicators are used to measure results at the end of a time period to reflect upon the success or failure of an initiative. Often, they are used to gauge historical performance. Some examples of lagging indicators include total students graduated or total incidents. Lagging indicators give institutions the ability to evaluate the effectiveness of their strategic decisions and determine whether their decisions facilitated the desired outcomes.

5. Input Indicators: Input indicators are used to measure resources used during a education processes. Some examples of input indicators include curriculum or program time, students in class room, or education technology. Input indicators are necessary for tracking academic departments' efficiency in higher education institutions with a lot of different programs.

6. Process Indicators: Process indicators are used specifically to gauge the efficiency of a process and facilitate helpful changes. A very common process indicator for support programs are KPIs focused around students support courses. In this example, that data can be used to influence changes in the support process to improve performance.

7. Output Indicators: Output indicators measure the success or failure of an education process or research activity. Output indicators are one of the most used KPI-types. Examples of output KPIs include revenues, profits, or new students acquired.

8. Practical Indicators: Practical indicators take into account existing higher education institution's processes and explore the effects of those processes on the institutions. For this reason, many practical indicators may be unique to certain institution or education processes.

9. Directional Indicators: Directional indicators evaluate specific trends within a HEIs. Where are the metrics moving? Are they improving, declining, or maintaining? An example of a directional metric used by many service organizations would be time on site. An example, this metric is used to measure the time that instructor spend in-class fixing issues and troubleshooting problems. Broad directional indicators can be used to evaluate higher education institution's position within higher education competitors.

10. Actionable Indicators: Actionable indicators measure and reflect an institution's commitment and effectiveness in implementing education program changes. Those changes could be within education processes. These metrics are used to determine how well an institution is able to enact their desired changes within specified time-frames.

11. Financial Indicators: Financial indicators are the measurement of economic stability, growth, and business viability. Some of the most common financial KPIs include gross profit margin, net profit, aging accounts receivable and asset ratios. Financial indicators provide straight-forward insight into the financial health of an institution but must be paired with the other KPI-types mentioned in this article to provide a complete picture.

Understanding the different types of KPIs can help teams to design a well-rounded evaluation system that boosts profits and improves education processes.

\subsection{2- Key Performance Indicators:}


Concentration on outcomes and on core processes actually simplifies performance measurement system. Key Performance Indicators (KPIs) as mentioned earlier are the critical (key) indicators of progress toward an intended result. KPIs provides a focus for strategic and operational improvement, create an analytical basis for decision making and help focus attention on what matters most.

Managing with the use of KPIs includes setting targets (the desired level of performance) and tracking progress against that target. Managing with KPIs often means working to improve leading indicators that will later drive existing (old) benefits. Leading indicators are precursors of future success; old indicators show how successful the organization was at achieving results in the past.

KPIs can be categorized into several different types: (Based on Karlson, 2021)

- Inputs measure attributes (amount, type, quality) of resources consumed in education processes that produce outputs. The education system is design to teach students the knowledge and skills for modern life. Instructors, curriculums, lessons and examinations, and classroom environment are all components of the teaching processes' input to turn the uneducated persons into educated ones.

- Process or activity measures focus on how the efficiency, quality, or consistency of specific processes used to produce a specific output; they can also measure controls on that processes, such as the classroom observations and reflections meetings.

- Outputs are result measures that indicate how much work is done and define what produced educated persons are.

- Outcomes focus on accomplishments or impacts, and are classified as intermediate outcomes, such as productive persons and loyal citizens.

- Project measures answer questions about the status of deliverables and milestone progress related to important projects or initiatives.

Every higher education institutions need both strategic and operational measures, and some typically already exist. Figure (3.3) depicts strategic, operational and other measures as described below:

- Strategic Measures track progress toward strategic goals, focusing on intended/desired results of the end outcome. When using a balanced scorecard, these strategic measures are used to evaluate the HEI's progress in achieving its strategic objectives depicted in each of the following four balanced scorecard perspectives:

- Students/Stakeholder

- Financial

- Education Processes

- Institution's Capacity

- Community services

- Operational Measures, which are focused on operations and tactics, and designed to inform better decisions around day-to-day teaching - learning, research and service delivery or other operational functions.

- Project Measures, which are focused on project progress and effectiveness.

- Risk Measures, which are focused on the risk factors that can threaten institution's success. 
- Staff Measures, which are focused on the human behavior, skills, or performance needed to execute education strategy.

An entire family of measures, including those from each of these categories, can be used to help understand how effectively strategy is being executed.

Concentration on outcomes and on core processes actually simplifies performance measurement. Resulting measures should be clear and simple using the Key Performance Indicators (KPIs) groups as shown in Figure (3.4). The (KPIs) should classify in five major groups. These groups are:

Group One: Performance indicators of higher education institutions (universities, colleges and research centers);

Group Two: Performance indicators of Academia which involved the teaching staff performance, programs and courses and others;

Group Three: Performance indicators of research and scientific relationships;

Group Four: Performance indicators of community services.

Group Five: Performance indicators of infrastructure.

Figure (3.3) depicts strategic, operational and other measures

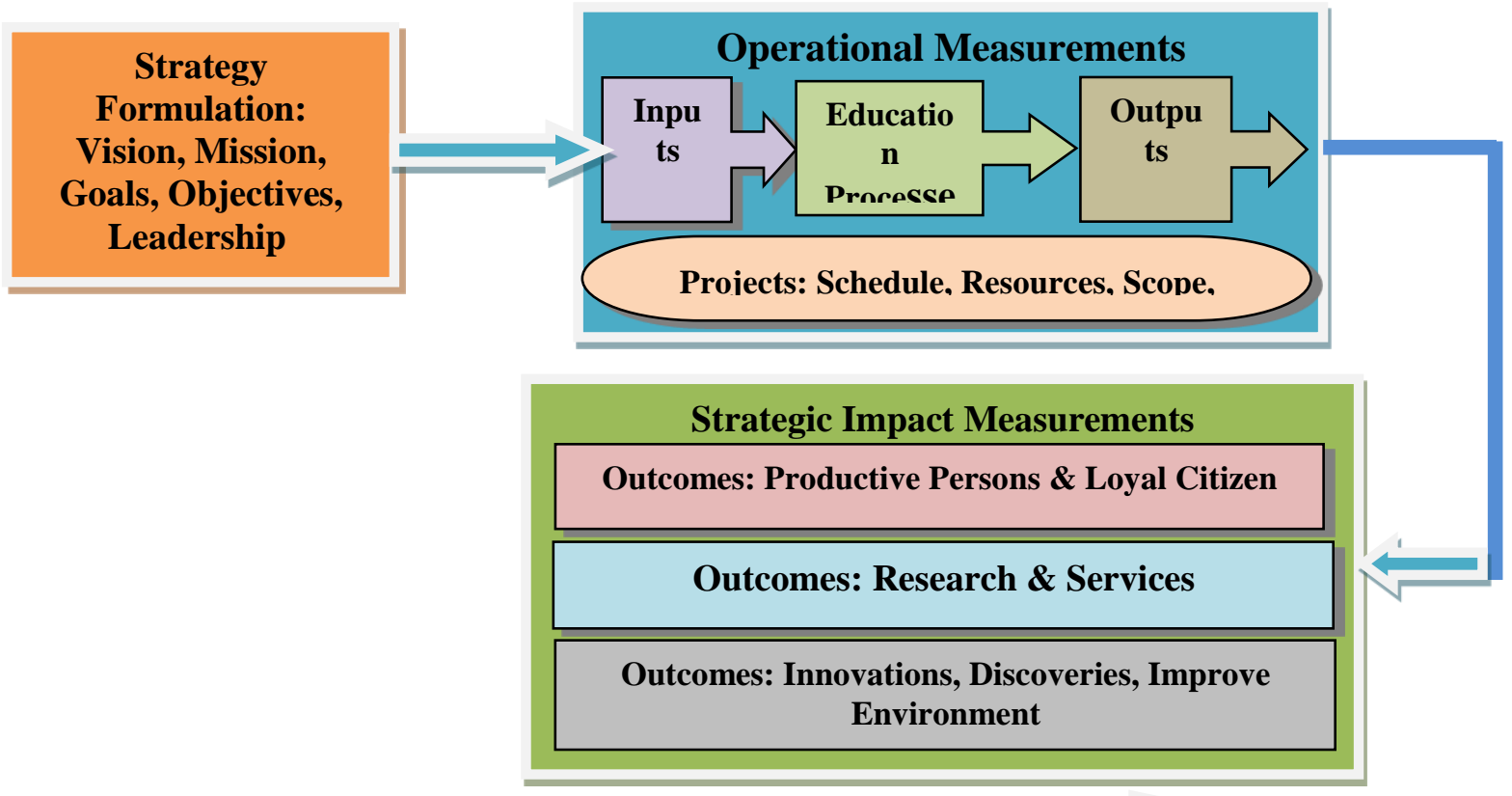

Strategic Education Intelligence (Accumulated Knowledge) Increases 
Figure (3.4) Key performance indicators group

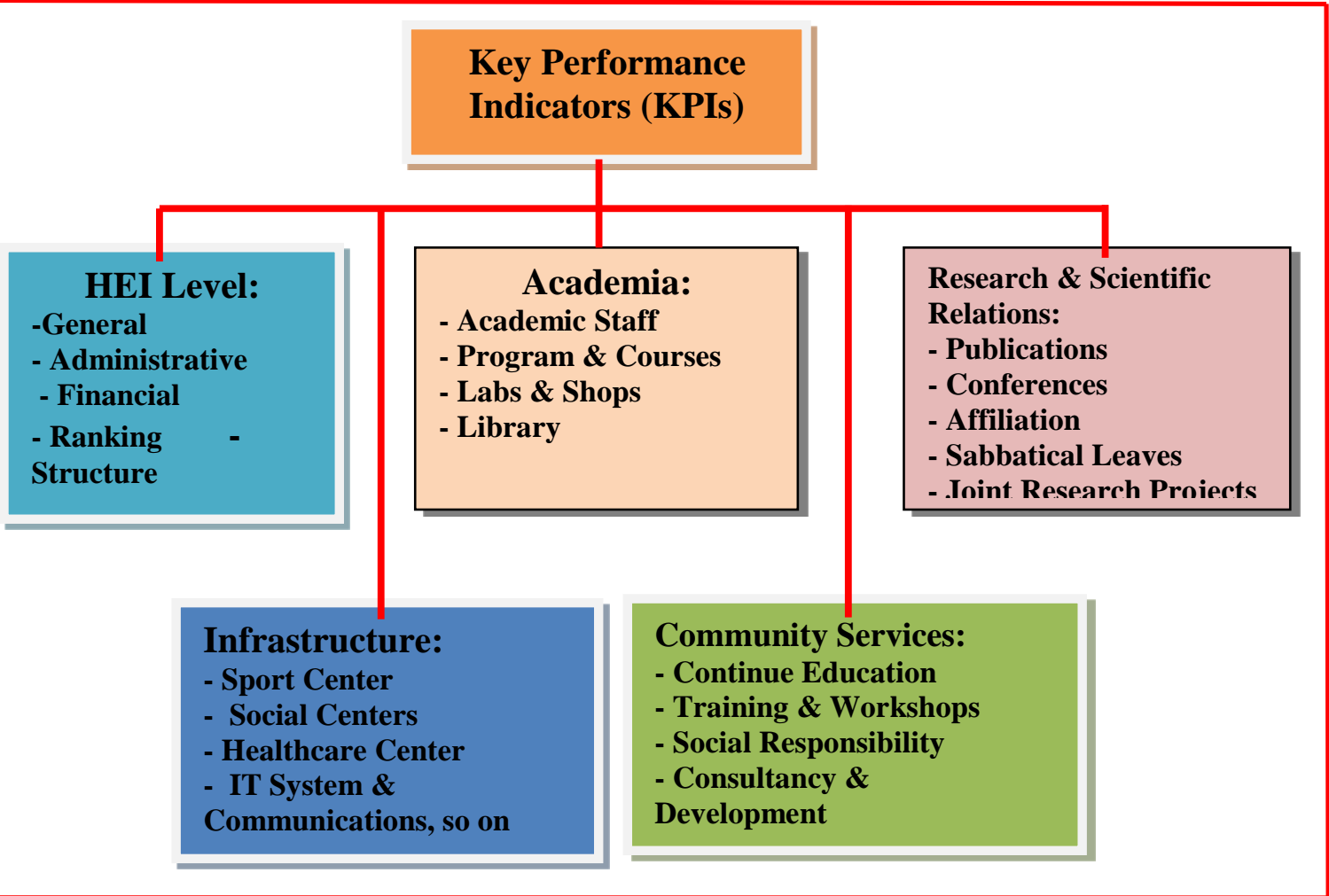

\subsection{3- Key Performance Indicators Components:}

Performance indicators are a means to focus on specific expectations of a program. They facilitate the curriculum delivery strategies, and assessment procedures. There is an important first step that must come before the development of performance indicators, and that is deciding on student outcomes.

The proposed framework of performance indicators in the higher education institutions (HEIs) presented in (Figure 3.4), are developed by author throughout this study. The framework indicators are assessing by applying them to the departments of higher education institutions throughout the country. The departments are ranked on inputs, processes, outputs and outcomes, and following the implications of various weighting schemes are expression briefly.

However, the rationale behind performance models and indicators in higher education institutions is to ensure the education provided to students equips them for employment and provides the nation with a highly skilled workforce that supports economic growth. However, it is not focused solely on economic value; educational, social and political values also influence the development and use of performance models and indicators. Higher education institutions and national level governments use performance indicators for different purposes. 
Higher education institutions use performance indicators for four primary reasons (Chalmers, 2008):

- To monitor their own performance for comparative purposes

- To facilitate the assessment and evaluation of institutional operations

- To provide information for external quality assurance audits, and

- To provide information to the government for accountability and reporting purposes (Rowe, 2004).

Performance indicators used at the national level are designed to:

- Ensure accountability for public funds

- Improve the quality of higher education provision

- Stimulate competition within and between institutions

- Verify the quality of new institutions

- Assign institutional status

- Underwrite transfer of authority between the government agencies and institutions, and

- Facilitate international comparisons (Fisher et al, 2000).

The five groups categories of higher education indicators identified in proposed Figure (3.4) are:

1. Mission, Vision and Objectives.

2. Teaching and Learning Plans and processes.

3. Teaching and Learning Indicators.

4. Internal and External Performance Funds for teaching and learning (including various grants).

5. Organisational Unit Review includes Disciplines, Divisions, Faculties, Schools, and Centres.

6. Curriculum Review includes courses, courses' sets, and programs.

7. Assessment and Feedback Policies.

Furthermore, it's important to take the student's performance indicators as an example. These are usually communicated to students in the program description, and are stated in terms that inform the students about the general purpose of the program and expectations of the faculty. The primary difference between student outcomes and performance indicators is that student outcomes are intended to provide general information about the focus of student learning and are broadly stated of the outcome not measurable. While performance indicators are concrete measurable performances students must meet as indicators of achievement. Performance indicators are developed from program outcomes. Sample student outcomes:

- Students will work effectively as a member of a team.

- Students can apply the principles of math and science to a technical problem.

- Students will have an appreciation for the need to be lifelong learners.

- Students will have effective communication skills.

Once program outcomes have been identified, the knowledge and skills necessary for the mastery of these outcomes should be listed. This will allow the desired behavior of the 
students to be described, and will eliminate ambiguity concerning demonstration of expected competencies. Performance indicators are made up of at least two main elements; action verb and content (referent). The expected behavior must be specified by name, using an observable action verb such as demonstrate, interpret, discriminate, or define. Sample performance indicators:

- Students will know a professional code of ethics. (Knowledge).

- Students will be able to describe the problem solving process. (Comprehension).

- Students will solve research problems through the application of scientific methods. (Application).

The Figures (3.5-3.8) show some suggested key performance indicators developed by author from Figure (3.4) respectively.

Figure (3.5) HEIs key performance indicators

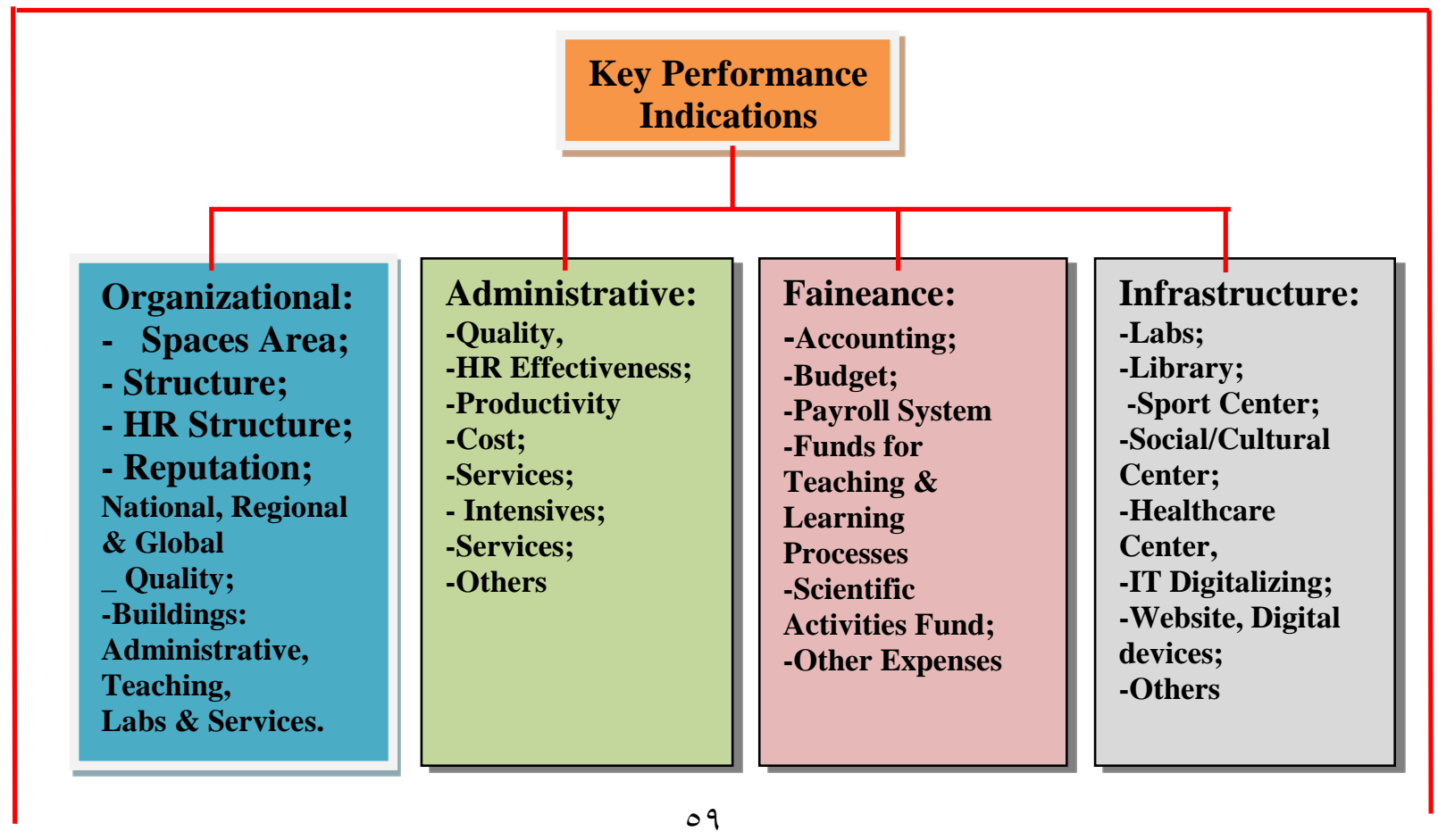


Figure (3.6) Academia key performance indicators

\begin{tabular}{|c|c|c|c|}
\hline & \multicolumn{2}{|c|}{$\begin{array}{l}\text { Key Performance } \\
\text { Indications }\end{array}$} & \\
\hline $\begin{array}{l}\text { Academic Staff: } \\
\text {-Rank Structure; } \\
\text {-Instructor } \\
\text { Effectiveness \& } \\
\text { Outcomes; } \\
\text {-Scientific } \\
\text { Promotion; } \\
\text {-Instructors' } \\
\text { Assessment; } \\
\text {-Instructor's } \\
\text { Contribution; } \\
\text {-Others }\end{array}$ & $\begin{array}{l}\text { Programs \& } \\
\text { Courses: } \\
\text { Program } \\
\text { Outcomes; } \\
\text {-Course Outcomes; } \\
\text {-Subjects } \\
\text { Outcomes; } \\
\text {-Program } \\
\text { Effectiveness; } \\
\text {-Program Ratio; } \\
\text {-Course } \\
\text { Effectiveness } \\
\text {-Others }\end{array}$ & $\begin{array}{l}\text { Labs \& Shops: } \\
\text {-Education } \\
\text { Technology; } \\
\text {-Equipment Ratio; } \\
\text {-Teaching Hours; } \\
\text {-Workshops; } \\
\text {-Peer-to-Peer } \\
\text { Review; } \\
\text {-E-Learning; } \\
\text {-Others }\end{array}$ & $\begin{array}{l}\text { Library: } \\
\text {-Number of } \\
\text { Books; } \\
\text {-Number of Titles; } \\
\text {-E-Library; } \\
\text {-Web-connections; } \\
\text {-Borrowing Ratio; } \\
\text {-Library } \\
\text { Technology; } \\
\text {-Updating Ratio; } \\
\text {-Others }\end{array}$ \\
\hline
\end{tabular}

Figure (3.7) Research and Scientific key performance indicators

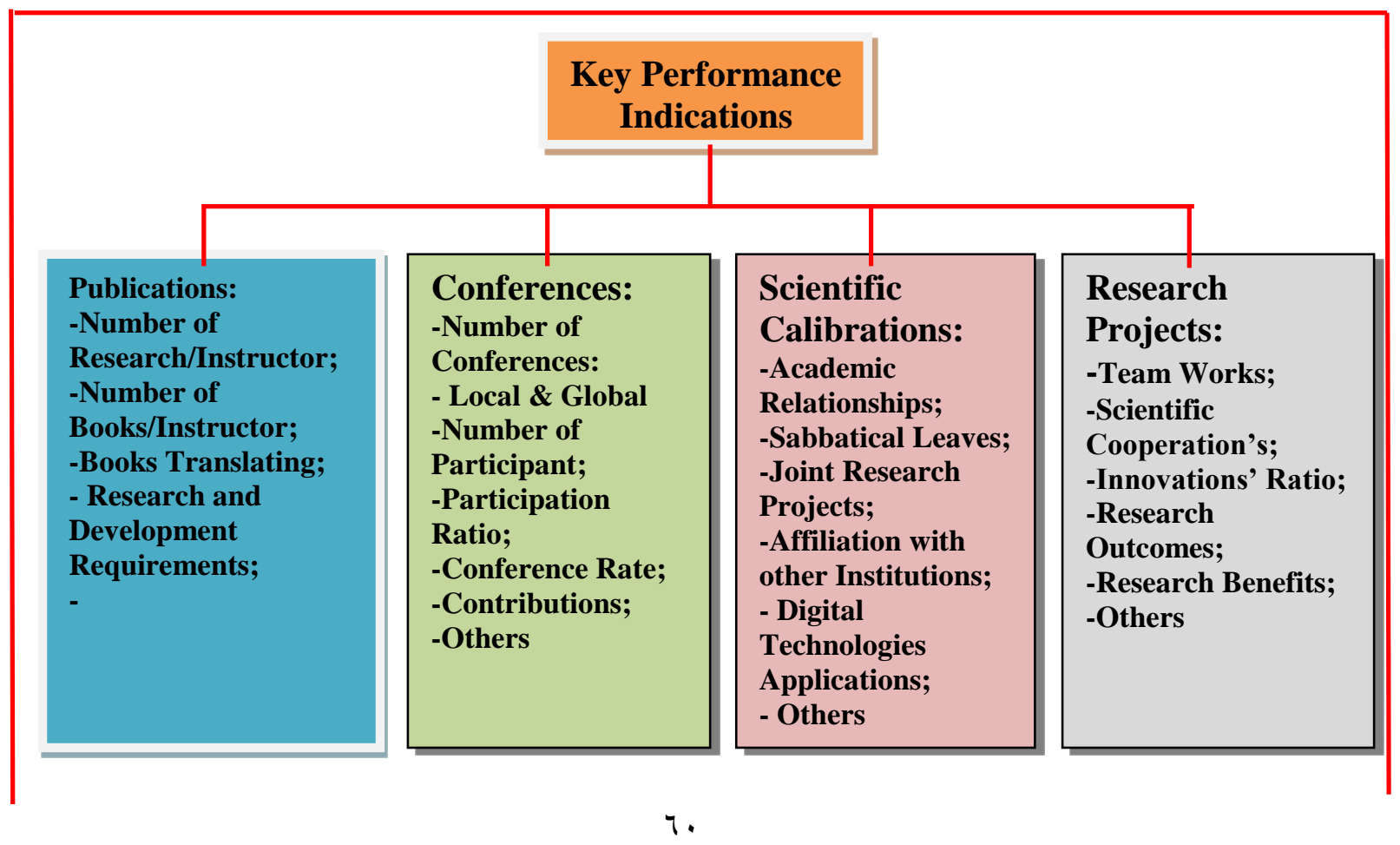


Figure (3.8) Community Services Key Performance Indicators

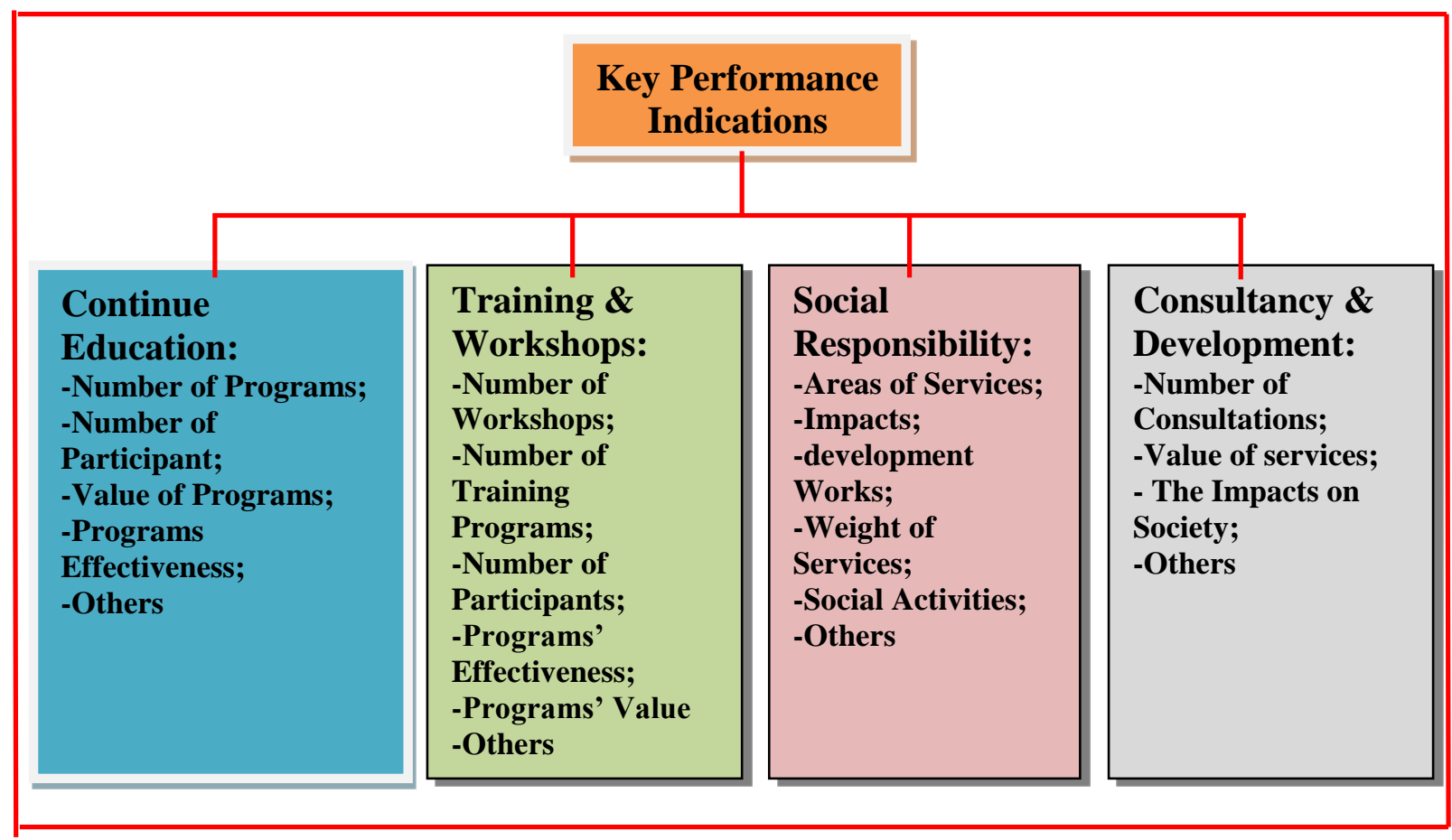

Successful indicator systems, whether at national, institutional or campus levels, incorporate all types of indicators to inform their decision-making and quality assessments. What is often less well understood is the importance of having a balance of all four types of indicators. Emphasis on output or outcome indicators over input and process indicators is likely to result in an unbalanced system with unintended and negative consequences. The importance of the need for a balance of the all types of indicators is particularly important at the national level, where the emphasis can be on output or outcome indicators. It is also important to understand that indicators must be understood as interrelated and linked; for example, input indicators such as level of funding, or student and staff numbers, can have a confounding effect on output, outcomes and process indicators.

Although indicators can depict trends and uncover interesting questions about the state of higher education, they do not objectively provide explanations which reflect the complexity of higher education or permit conclusions to be drawn. Multiple sources of information and indicators are required to diagnose differences and suggest solutions (Chalmers, 2008). Without multiple sources of both quantitative and qualitative information, interpretation may be erroneous. It is therefore imperative that indicators should only be interpreted in light of contextual information concerning institutional operation and with the assumptions and purpose for which the information is being used made explicit. 
In summary, the measurement of quality teaching and learning within the higher education sector should involve indicators which are significant in informing individual and institutional performance; and where feasible, also significant on a common national or sector wide scale. A useful performance indicator is one that informs the development of strategic decision-making, resulting in measurable improvements to desired educational outcomes following implementation.

\section{5- THE FRAMEWORK OF BPR}

\subsection{1- BPR Areas:}

If higher education institutions aspire to be more efficient and competitive it needs to apply the re-engineering principles to redesign their own education processes. It is time for higher education institutions in any country to learn from their institutions counterparts. This is the only approach higher education can take to be more effective as well as efficient. Higher education institutions need to be equipped to respond to this challenge as effectively and efficiently as possible. In order to accomplish this task, higher education institutions need to become "learning organizations".

The purpose of a framework for Business Process Management is to assist higher education institutions to understand and assess the extent of, plan for and execute process based transformations such as BPR. Abdous and He (2008) designed a framework based on their experience in the higher education environment. This framework consists of five non-sequential phases which are supported by three essential elements. The phases are Initiation, Analysis, Re-engineering, Implementation and Evaluation. While the supportive elements are: a thorough understanding of the organisational culture, politics and dynamics; vision, commitment and sustained support from top management; and the availability and appropriate application of technology.

A comprehensive framework using a project-oriented approach for BPM implementation is proposed by Jeston and Nelis (Nel, 2008). Three essential components must support a business process management project for successful implementation:

*Leadership support, which is key to successful implementation of a business process change initiative.

*People change management, as the success or failure of the design and implementation of processes are dependent on people.

* Project management, providing experience and structure to the project.

However, the first step in a BPR project is to understand the organisational strategy. If business process architecture exists, the process change project must take into consideration this architecture, linking current and new business processes to both the organisational strategy and the architecture. Technology, which includes all tools and systems that support processes, must be utilized to facilitate process design and implementation. A BPR project typically follows the phases of launching, understanding the situation and problem. These are innovation of a new design, training and development of people, development of the technology, which may or may not include software, implementation, and the realization of value and the ultimate sustenance of performance (Nel, 2008). 
Accordingly, education processes redesign is the first element of a reengineering framework in higher education institutions. The objective of education processes redesign is to reinvent, reposition, restructure, and de-departmentalize critical education processes. Those will go through a manner that creates a renewed focus on stakeholders' needs, not education as usual with a few added enhancements. Ultimately, our goal is to reengineer higher education institution into several stand-alone focused value centers. This is typically accomplished by a complete overhaul of the institution's infrastructure, including such processes as:

Education (teaching, learning, research, and community services)

Physical labs' equipment and experiments

Teaching technologies and digital applications

Academic and administrative staff

HEIs' management

Some of the activities characteristic of process redesign in higher education institutions include:

1-Linking education processes together to decrease duplications and informational movement, defective education processes' queues, research works, community services, courses' schedule, complexity, and associated costs.

2- Several jobs are combined into one: The formerly distinct tasks/ jobs are combined and compressed into one. The jobs are combined mostly based on the needs and preference of the education processes.

3-Create the healthy conditions for immediate exposure and opportunities achieved by the entire staff.

4-Providing a real-time feedback mechanism to education processes and sub processes. This supports the creation of self-management, self-measurement, and self-adjustment.

5-Process redesign has focused traditionally on making the "as-is" incrementally better.

Finally, the reengineering cause individuals to work from a much broader definition of process redesign than occurs with traditional continuous improvement methods. Process redesign in a reengineering sense depends largely upon an organization's distance from its desired, or "ultimate", state.

Therefore, it is logical that the next generation of education processes redesign includes concurrent activities focused on the following analysis: [Based on Jeston and Nelis (Nel, 2008)]

1- Some education processes currently could be beyond meeting or faraway from not only student-customer but also the stakeholder's needs, and the proper activity to support process redesign is reinforcement of current practices. This usually includes the soft aspects of traditional continuous improvement, such as program building and improving facilitation, staff and leadership skills.

2- Other education processes fall short of meeting student-customer and stakeholders' needs and require small, or/and incremental improvements. This usually includes the traditional TQM problem solving tools (the seven tools, SPC, charting techniques, etc.).

3- Every higher education institution has education processes that, no matter how much reinforcement or incremental improvement are pursued, will never meet the studentcustomer's and stakeholders' needs within the education time window. These are the 
candidates to be reinvented or rediscovered. One of the largest causes of reengineering failures has been the lack of tools to deal with reinvention needs.

\subsection{2- - Process Redesign:}

The roadmap of process redesign should include the following issues.

1-Ten P Business Reengineering Checklist: The ten P's Business Reengineering Checklist (Figure 3.9) is used in conjunction with business process mapping. The 10 P's checklist adds dimensional value for each activity that is a education, technology, or administrative processes. (Design based on Gallia, 2019, and Ring, 2014)

Figure (3.9) Ten P's Business Reengineering Checklist

\begin{tabular}{|c|c|c|c|c|c|c|c|c|c|}
\hline \multicolumn{5}{|c|}{ Process Description: } & \multirow{2}{*}{\multicolumn{5}{|c|}{$\begin{array}{c}\text { Date: } \\
\text { Data Collection }\end{array}$}} \\
\hline \multirow{2}{*}{$\begin{array}{l}\text { Category } \\
\text { (10Ps) }\end{array}$} & \multirow[t]{2}{*}{ Answer } & \multicolumn{3}{|c|}{ Answer Rating } & & & & & \\
\hline & & Complete & Partial & Missing & Source & Data & Required & Who & When \\
\hline \multicolumn{10}{|l|}{ Purpose } \\
\hline \multicolumn{10}{|l|}{ Procedure } \\
\hline \multicolumn{10}{|l|}{ Practice } \\
\hline \multicolumn{10}{|l|}{ Participant } \\
\hline \multicolumn{10}{|l|}{ Pace } \\
\hline \multicolumn{10}{|l|}{ Place } \\
\hline \multicolumn{10}{|l|}{$\begin{array}{l}\text { Period } \\
\text { Frequency }\end{array}$} \\
\hline \multicolumn{10}{|l|}{ Product } \\
\hline \multicolumn{10}{|l|}{ Department } \\
\hline \multicolumn{10}{|l|}{ Performance } \\
\hline & $\begin{array}{l}\text { Total } \\
\text { Check } \\
\text { Marks } \\
\end{array}$ & & & & & & & & \\
\hline
\end{tabular}

\section{Important Notes:}

1- Decide and describe the business segment or process to be analyzed.

2- For each of the checklist categories, fill in the answer to the category in as much detail as possible.

3- For each answer provided, check off whether it is a complete, partial, or missing answer.

4- Total the number of check marks in each of the rating columns.

5- If you have $(80 \%)$ or more of the check marks in the "complete" rating column, you understand your business segment or process very well.

6- Identify the data required to complete the answers to the categories, determine the data sources, and decide who will obtain the data and when.

7- Collect the data.

2- Business Process Reengineering Methodology: The most frequent question asked among business process re-engineering (BPR) practitioners is: "what methodology do you follow?", or, "what model do you use?" BPR consultants are characterized and differentiate themselves by the methodology they apply. According to Vakola and Rezgui (2000), a methodology is simply theory put into practice aiming at dealing with real world situations. There are, however, a number of problems related to the use of a methodology. One important reason which explains the reluctance of developing and using 
methodologies or models in the BPR context is that the widely accepted methodologies are based on how the business processes should change. Also based on how the organization should adapt itself in this change, rather than on the evaluation of current practices and on the codification of successful practical experiences.

Moreover, the BPR literature search reveals that there are an increasing number of successful re-engineering implementations and case studies using BPR methodologies. Although each business situation has some unique characteristics, an appropriate methodology will need to allow for assessment and re-use of existing successful approaches and practical experiences.

The use of a methodology is essential for a number of reasons (Based on Vakola, and Rezgui, 2000). First, a methodology provides a means of codifying experience, knowledge and ideas, in a form that not only can be easily applied, but also can be evaluated and tested. Second, a methodology offers a certain level of organization, and facilitates planning and monitoring. In BPR initiatives, a methodology enables the organization, on the one hand, to have a clear picture of its current processes along with their associated problems. and, on the other, to design the new state of these processes. In addition, by following a certain methodology, BPR "re-engineers" have the opportunity to monitor and evaluate the progress of the re-engineering effort. Third, a methodology enables those who are involved or affected by the BPR to understand their tasks and clarify their roles. A BPR methodology which is clearly defined and explained to those who are leading the BPR work can facilitate the communication between them, and serve as a kind of "contract" in which all the parties understand their responsibilities and are, therefore, able to monitor the overall process re-engineering progress. Finally, adoption of a methodology allows a standard set of required skills to be identified and developed.

Key skills required for BPR include process modeling, organisational development techniques, and skills to deal with resistance to change. There are, however, a number of problems related to the use of a methodology. One important reason which explains the reluctance of developing and using methodologies or models in the BPR context is that the widely accepted methodologies are based on how the business processes should change and how the organization should adapt itself in this change, rather than on the evaluation of current practices and on the codification of successful practical experiences.

\section{3- Business Process Reengineering Results:}

Clear understanding of an education segment or reason for a process's existence.

Compelling reason to eliminate the education segment or process where no clear answer can be found.

\subsection{3- Business Process Reengineering Mapping:}

Examines the problems and the implementations of business process reengineering' techniques in the higher education experiences help the team work to use system analysis. Structural analysis of business process reengineering work flow (such as education program cycle), by distinguishing how work is actually done from how should be done what function a system should be perform from how the system is built to perform 
these functions. So, the process map is a diagram that shows the followings:

*What an HEI does and how it delivers education processes and service

* Major processes in place, the key activities that make up each administrative and academics' process;

* Sequencing of those activities, the inputs and resources required and outputs produced by each activity;

* Process maps are a way of ensuring that the activities making up a particular process to deliver the best services to customer.

1- BPR Roadmap: Many different and inconsistent definitions of business process reengineering map (BPRM) have been proposed so far. Most of the current definitions have in common that they support the whole life cycle of a business process and enable continuous improvement. The management of the whole education processes life cycle in conformity with development and dependability objectives: confidentiality, institutional integrity, programs' availability, teaching-learning reliability, safety and systems' maintainability. The business process life cycle comprises analyzing, optimizing and designing the education processes in accordance with the HEI's strategies, allocating programs applications and high skilled staffing, implementing and executing the education processes to support knowledge and information exchange. Furthermore, monitoring and aggregating the education operational data for the purpose of decision making and continuous improvement. (Neubauer, et.al, 2006).

There are four major steps of BPR mapping; these are (Based on Neubauer, 2006, and Bansat, 2014):

(a) Process identification which means knowing the process of each program of the HEI is crucial in understanding how work should be done and how it could serve the needs of stakeholders.

(b) Information gathering means regarding the key personnel involved in the work process. These individuals can make changes to the process so they should be involved in crafting the process map. Other pertinent information that should be gathered includes programs objectives, risks, control mechanisms, and measure of milestones. (c) Interviewing and mapping means this step will validate if the identified processes are clear and if work set are being effectively carried out.

(d) Analysis means any inefficiency in the process should be purged immediately and best practices should serve as a model for the whole education process.

Accordingly, business process mapping (see Figure 3.10) is a scooping tool used to document and diagnose the standard internal business processes that deliver outputs and/or services to the stakeholders. This tool helps the HEI's management understand the sequence of activities, relationships, processes and studies; plans cycle times, resources consumed administrative and academic processes' costs, information and physical activity flows, and processes' participants.

Figure (3.10) Business Process Mapping (Based on Bansat, 2014)

\section{"Education Process"- Sequence of Events}

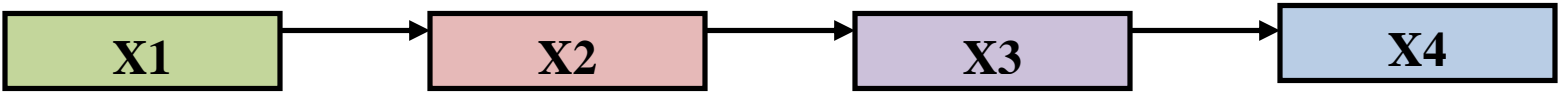




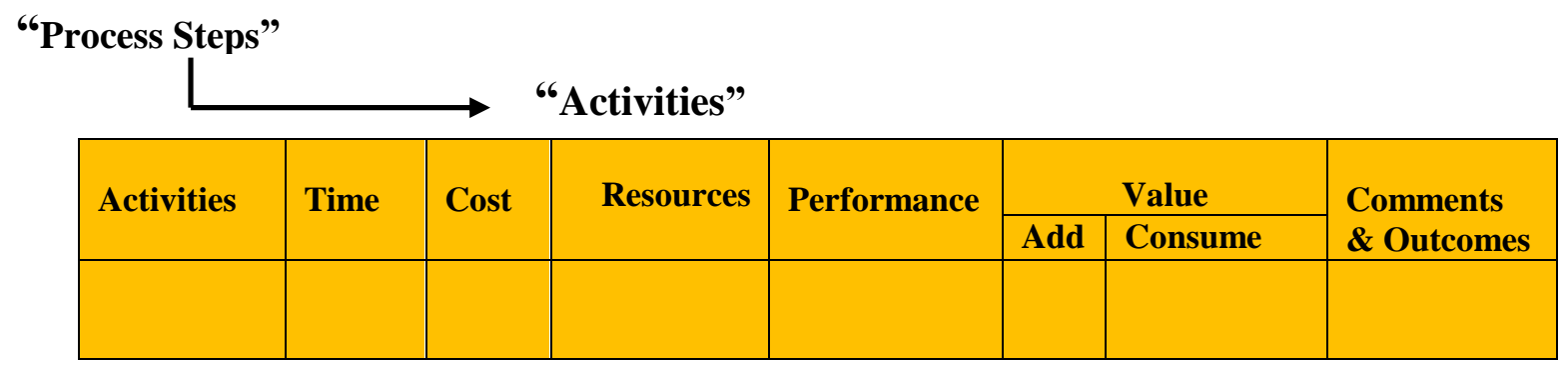

2-BPR Methodology: includes the following steps:

1- Chart the major cross-functional process steps and the sequence of events in a administrative and academic processes.

2- Document the specific activities and elements of each process step.

3- Determine critical descriptive data to analyze and assess the activities that are required to complete each process step.

4- Apply the (10 P in Figure 3.9) Business Reengineering Checklists to each activity in the process.

5- Segment value-adding and value-consuming efforts in the process and begin identifying opportunities to eliminate, combine, or streamline process activities.

\section{3- BPR Results:}

Cross-functional administrative and academic processes maps.

Process dynamics, redundancies, disconnects non-valuable steps.

A solid foundation

\section{PART TWO: MUTUALLY IMPLEMENTATIONS of BUSINESS PROCESS REENGINEERING (BPR) and TOTAL QUALITY MANAGEMENT (TQM)}

\section{CHAPTER FOUR: IMPLEMENTATION BUSINESS PROCESS REENGINEERING}

This chapter will deal with the concepts and methodologies of adoption the BPR and TQM for developing the redesigning the higher education institution to achieve a new more progressive ways of doing the business.

\section{1- BUSINESS PROCESS REENGINEERING (BPR) MODELS 4.1.1- BPR Solving Network:}

Quality improvement concepts initially utilized in industry have been applied to different types of organizations which are to reduce error and variation in outcomes. The Plan-Do-Study-Act (Deming's' PDCA) methodology is one of the most commonly used tools in quality improvement. The PDCA cycle is an iterative, four step model for 
improving a process (Deming, 1986). The first step is the development of a plan in which predictions of outcomes are clearly stated and tasks are assigned. It is in this phase that the "who, what, when, and where" of the plan is decided. In the "do" phase, the plan is implemented. Data and results obtained are then analyzed in the "study" phase. Last, the plan is adopted, adapted, or abandoned in the "act" phase based on the evaluation of the data in the prior step. The learning from one cycle should guide the cycles that follow.

On the other side, the concepts behind business process reengineering, are rooted in the other business improvement methods, such as sociotechnical approach, quality oriented methods, industrial engineering and competitive IT. Among these approaches, one of the most popular in the last decades was quality movement. Like reengineering, it is a process centered approach, which recognizes the value of stakeholders' needs, employee empowerment, and cultural change. Unlike reengineering, the focus of Quality efforts has always been on continuous and gradual enhancement of the existing processes (Davenport, 1996).

The business process reengineering methodology that proposed here by this study is vary in its components, the importance attached to the components of education processes (teaching and learning, research works, and community services). The relation and order among them. Figure (4.1) illustrates the framework of common components of a BPR methodology and their relationship through an abstract influence diagram. The diagram also shows the relationship among BPR heuristics with TQM components. These heuristics are rules of thumb that are based on the experiences of consultants and practitioners of BPR project. These heuristics provide guidelines for designing and implementing higher education institutions (Atefi, 1997).

BPR Methodology: internal and external education environments are complex. Almost everywhere HEIs are undergoing rapid and significant changes driven by such pressures as stakeholders' expectations, new digital technologies, and growing local and global competition. As a result, many education processes within HEIs are dynamic and constantly changing. In order to survive in such environments, HEIs are forced to continually revise their education processes to respond quickly to changes. There are some methodologies and tools available to help institutions improve their administrative and academic processes. However, these methodologies adequately support the practitioner through all stages in the business process improvement (BPI) activity. Therefore, there are three objectives that have been chosen to address this, namely to:

1. Develop a structured and procedural method of business process improvement.

2. Seek expert opinions to identify and contrast this method against leading HEI practices. 3. Evaluate and refine the method through practical application.

Each objective has been addressed in turn by a specific phase of research and these are described as follows. (Based on Vakola, and Rezgui, 2000)

Phase 1: Forming the initial structure and content of the BPI methodology: The purpose of this initial stage was to develop a prototype methodology based around current frameworks where possible.

Phase 2: Initial confirmation of the BPI methodology: To develop the methodology further, an initial validation process was conducted to seek expert opinions to contrast the 
methodology against leading HEIs practices. "Experts" should be chosen from people who were academics, consultants or practitioners in the field of business BPI.

Phase 3: Testing the BPI methodology through industrial application The BPI methodology was then evaluated to determine whether it was valuable in practice. The approach here was first to guide the application of the methodology in practice, and to assess whether the methodology could provide practical aid in the activity of BPI. Therefore, the set out to determine the following questions:

1. Could the methodology be used in practice?

2. Are there any problems and difficulties with the methodology?

3. Are the results worth the effort and are they useful to the host institution?

The methodology presented in this section is the final outcome of an iterative process from theory, practice, and author's experience. The BPR implementing methodology has been given the acronym model-based and integrated process improvement methodology. It is a generic ten-step procedural approach that guides the actions and decisions of a process design team (see Figure 4.1).( Based on Atefi, 1997)

1- Construct a detailed institution chart of the institution or division under study.

2- Define the services provided to the institution and the level of resources consumed to provide these services.

3- Identify an individual chart of account costs directly related to the business process and accumulate costs into a business process project cost bucket.

4- Develop a listing of the core education or/and administrative processes that deliver valued services to the all stakeholders. Most higher education institutions have three major processes (teaching-learning, research, and community services).

5- Plot on the organizational chart how each of the education or/and administrative processes is accomplished. Connect the plotted points with a freehand amoebae figure that embodies all functions that make this process a reality.

6- Develop an execution plot that shows the level of involvement of each person (faculty member, university management and administrative) who is identified in a function that contributes to this process.

Figure (4.1) the framework of BPR components (Based on source Atefi, 1997 with author's modification)

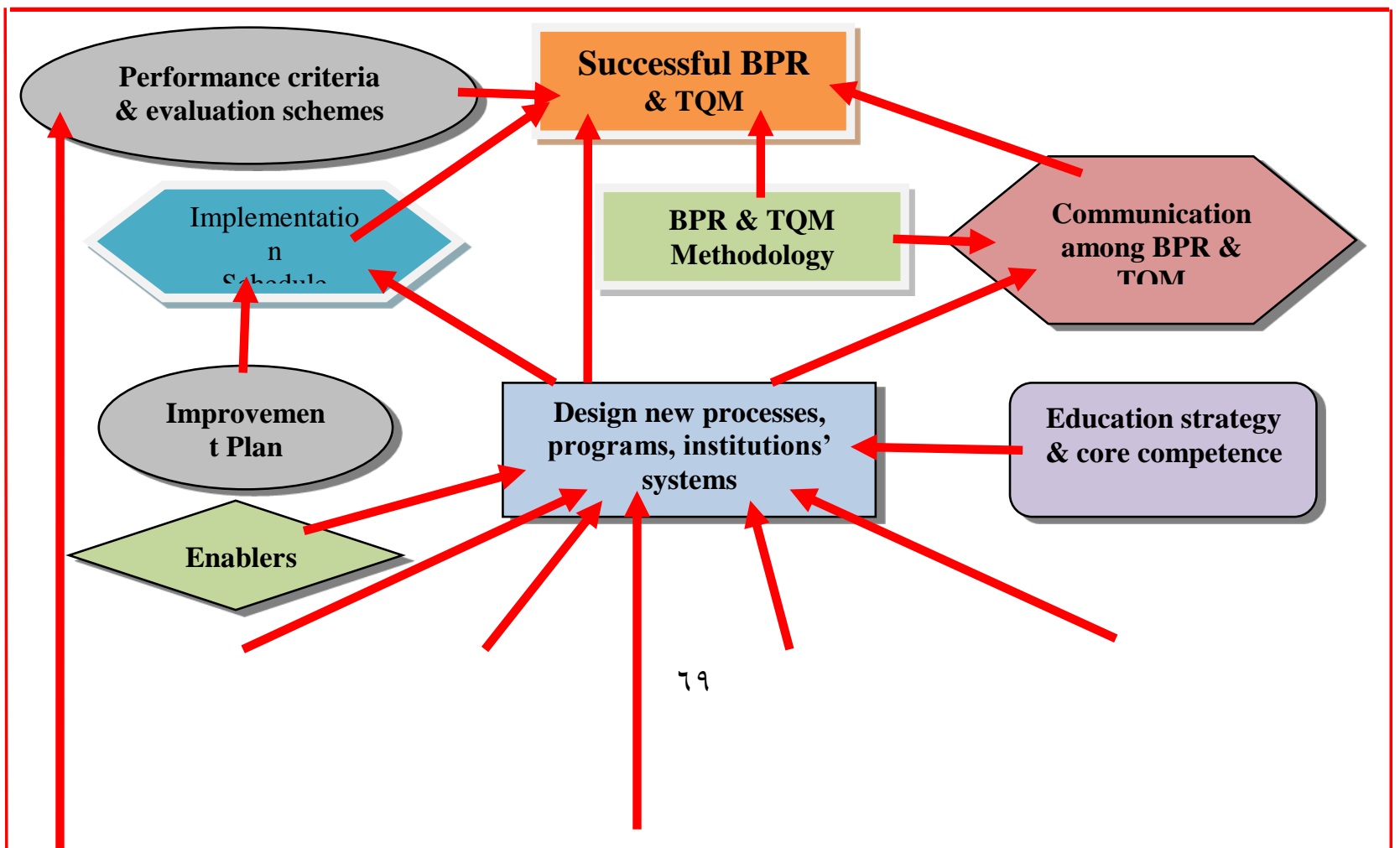



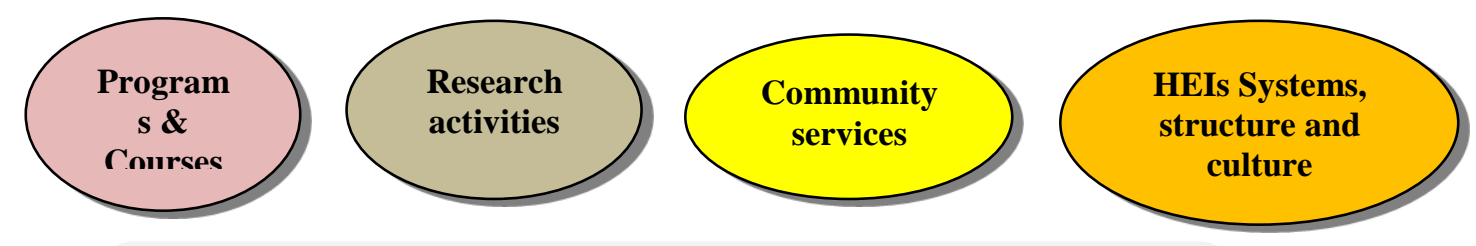

Understanding \& analysis current processes, resource availability, managerial commitment and support, and understanding stakeholders perspectives

Continue HEIs' System Improvement

Important notes for Figure (4.1): Follow the (ADAPT shown in Figure 4.2) steps:

1- Align resources toward a common set of reengineering goals and objectives that will generate new organizational orders, such as agility, seamlessness, self-management, and the best possible performance.

2- Deploy resources to work toward the achievement of education processes reengineering goals and objectives.

3- Act or try something new. Keep in mind that with education processes reengineering it is difficult to plan until you take action first (that is, unplug the existing system and start from scratch).

4- Plan the next set of actions and the definitions of success.

5 - Tinker or check and adjust your progress based on the latest information.

7- Determines if any of the work being performed in the rings can be eliminated or transferred to the doer ring. Most of the outer rings cause the majority of delays that the doer ring experiences.

8- Calculate ratios of total resource consumption based on services provided by the education and administrative processes (this is used as the statistical base for allocating costs).

9- Allocate total costs to education and administrative processes provided based on the level of resource consumption.

10-Compare the value added with the value consumed and determines activities any future reengineering or continuous improvement efforts will focus on.

\section{Business Process Reengineering Results:}

$\square$ An analysis of value of education and administrative services versus cost of major elements of an education processes.

$\square$ Definition of education costs drivers (Activity Cost System).

Finally, the ADAPT (Figure 4.2) model is an analytical network to support education reengineering that is similar to the Deming's PDCA cycle for TQM. PDCA is a repetitive sequential process, and ADAPT is a network of conceptual activities connected by tightropes. Figure (4.3) illustrates the education activity network. 
Education Cost Value Matrix (ECVM): The education Cost Value Matrix (shown in Figure 4.4) is a final part of the BPR's network, which is base on activity-based costing system (ABCS) and management approaches. Its objective is to analyze an education processes in terms of values added versus values consumed. The definition of activitybased costing system is a "is a method of assigning overhead and indirect costs - such as salaries and utilities - to outputs and services. The ABC system of cost accounting is based on activities, which are considered any event, unit of work, or task with a specific goal.

\subsection{2- Build an Organizational Robustness:}

The definition of organizational robustness is to have the resilience and flexibility to be able to turn things around, to make changes, and to swiftly take up education opportunities and address challenges. Robustness may be defined as the ability of a multiagent system to recover from failures and exceptions. An exception may be defined as a departure from an "ideal" system behavior. Recovery would then involve the execution of some corrective measures to reinstate the ideal system behavior (Kamboj and Decker 2008).

Achieving robustness is particularly challenging in dynamic and semi-dynamic education environments, since the problem characteristics, available resources or agent capabilities may change over time. Multiagent organizations for such environments must include two components: the first component is responsible for monitoring the performance of the HEI and for discerning whether or not the measured performance falls within the design parameters of the institution. The second component is responsible for explicitly changing the HEI if it fails to meet its design goals (Kamboj and Decker 2008). This process for the HEI robustness goes through the following steps:

A- Organizational Involvement Mapping: The Organizational Involvement Mapping Tool is a process to understand better the core higher education or educational processes that deliver a valued outputs (graduated productive persons with citizenship's loyalty) or/and community services to stakeholders and sustainable national development. Most HEIs have three core education and educational processes (teaching-learning, research works, and community services) that should not be confused with education functions. HEIs are arranged in a vertical hierarchy, but education processes flow in horizontal and diagonal directions and do not necessarily follow the formal structure. Organizational Involvement Mapping depicts visually the education and educational processes' flows, and is involved in their execution. (Refer to 3.5.3 for more details).

Figure (4.2) ADAPT (out-of-box PDCA)

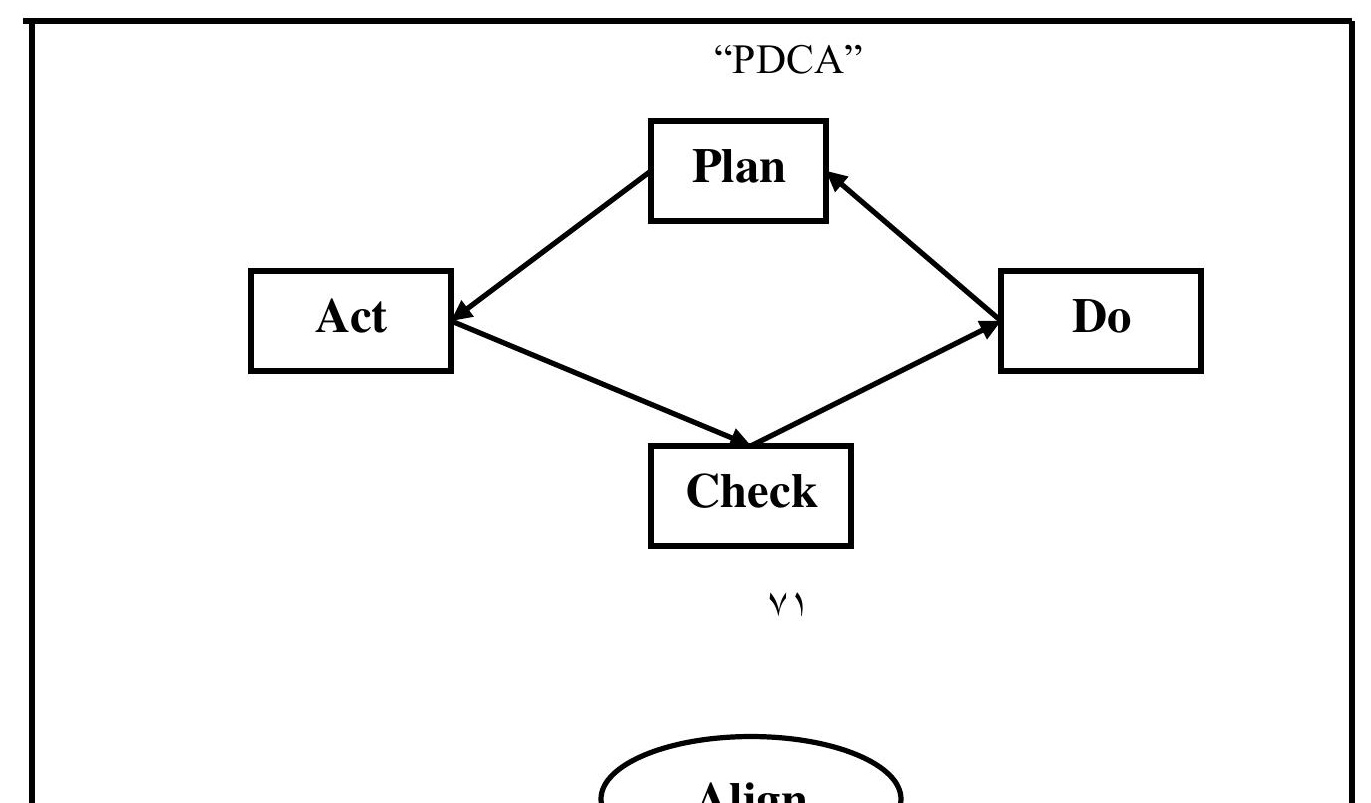


"ADAPT"

\section{B- Business Process Reengineering Methodology: (Refer to 4.4.1)}

Business Process Reengineering Results:

Identify core education and administrative processes.

$\square$ Visualization of how these education and administrative processes interact and are accomplished.

$\square$ Classification of those involved in these processes.

$\square$ Identification of work that can be moved to doers or eliminated.

Figure (4.3) Education Activity Network

$\underset{\text { Efficient Stakeholders Response (ESR) }}{\longrightarrow}$

Higher Education Institution Management

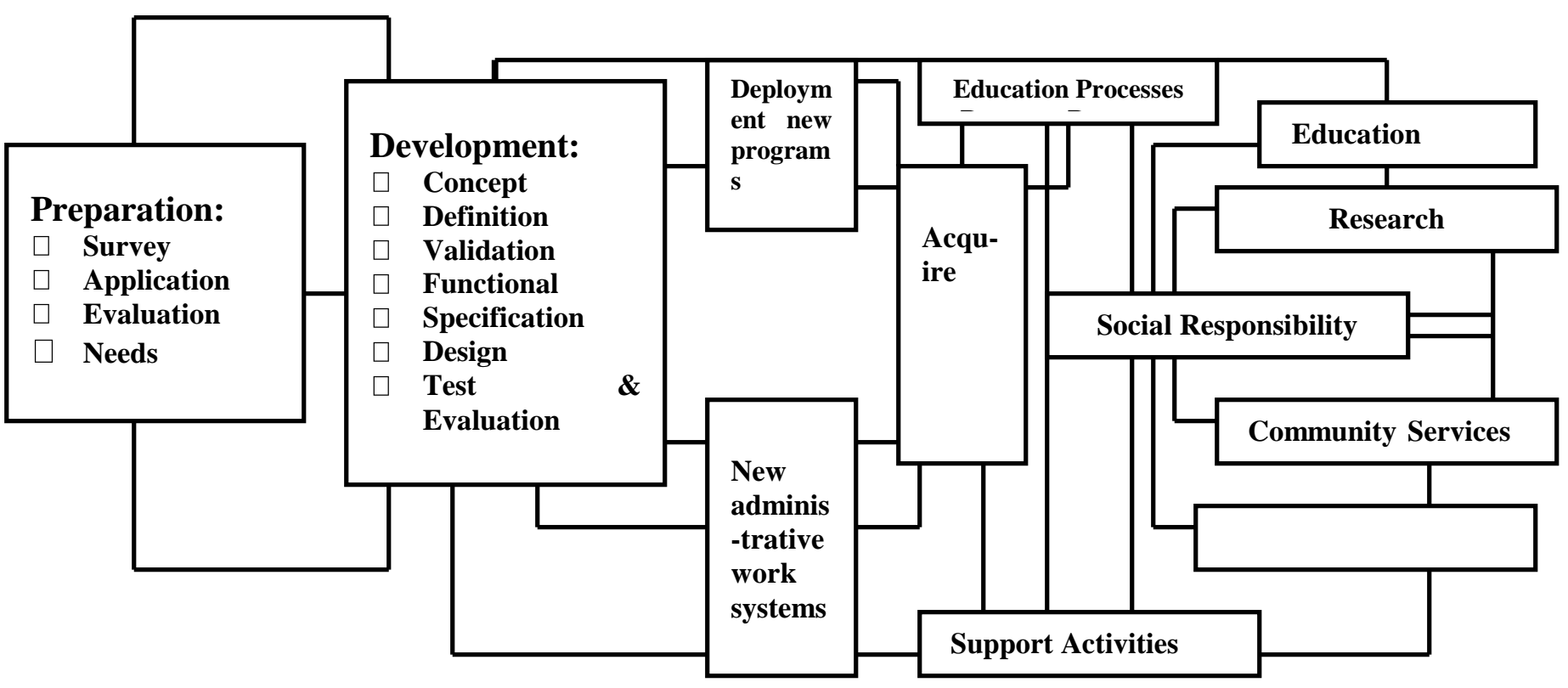


Figure (4.4) Service Cost Value Matrix

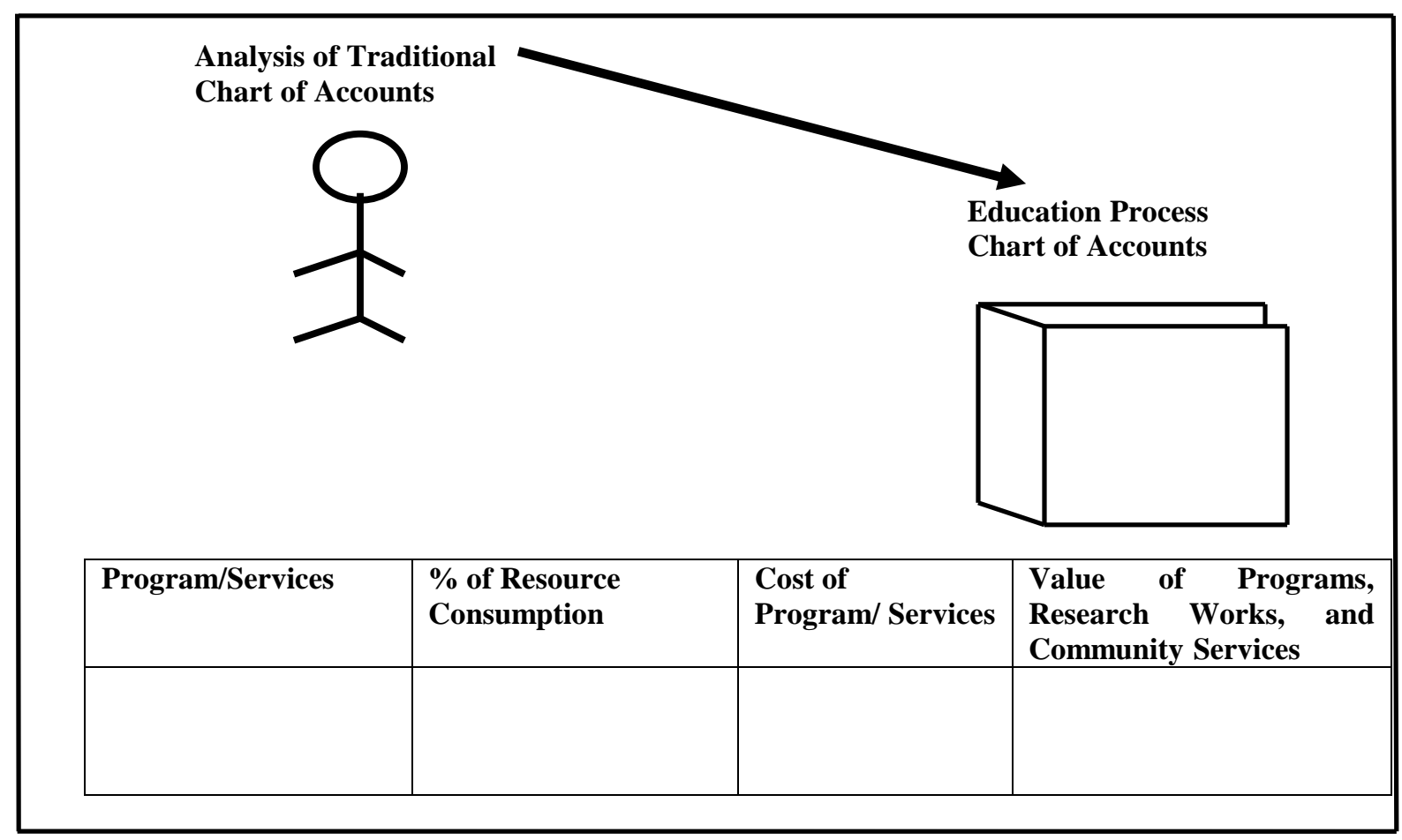

\subsection{3- Speed-to-Customer (Stakeholders):}

Providing solutions to stakeholder's problems and answering their questions are a priority in ensuring their satisfaction. However, the speed at which you offer those services matters most because stakeholders hate waiting. By the time a stakeholder approaches higher education institution for assistance, they need it quickly. There are several techniques and applications that can be used by HEI to reinvent their education processes. These techniques are Six Sigma, Lean, Total Quality Management (TQM) and Business Process Re-engineering (BPR), and more (Slack, et al., 2007). Among these techniques, BPR is considered as the most appropriate in today's education environment because it improves HEIs' performance (Hammer \& Campy, 1993).

According to Magutu, et al.(2010) the speed is an element of timeliness. Speed is a competitive dimension that enables one to make the desired output or provide a service very quickly. HEIs' performance is improved when the duration taken for a stakeholders to receive a graduated productive persons and community services since the requisition has been minimized/shortened (Sungau, et al., 2013; Slack, et al., 2007). Customers (all members of stakeholders) can judge the institutional education services as good or bad depending on the time spent during consuming an education at higher education institution. 
In this regard, HEIs have to make sure that their education and services processes are effective enough in order to provide valuable teaching and learning outcomes that delight their customers.

However, the speed in stakeholders' support establishes trust among higher education institution that is reliable. Here's why: they are guaranteed to accessing help on time. Stakeholders need assistance on time 24hours/7 days a week and when HEIs provide it to them; they will always trust the institutions. Wondering how to achieve this? With live messaging software, government and private agencies are available to serve HEIs stakeholders on time. There are several ways that could higher education institution achieves the speed to stakeholders services through the reengineering. These ways are discussed below (Based on Magutu, et al., 2010; Sungau, et al., 2013; Slack, et al., 2007).

A-Development Process Mapping: Business process mapping and re-engineering (or BPR) is essentially laying out some, or all, of the processes of a business, connecting how they fit together, and identifying what you can do to improve them. The goal is to approach an administrative and/or academic process as a single, holistic process designed to provide an outputs or services. Each process within it works towards that objective, and our job as business process mapping and re-engineering experts is to see where you can save time and money within that process. A process map is a planning and management tool that visually describes the flow of work. Today, business process mapping is closely tied to software applications, and in many ways, business process mapping mirrors the requirements gathering stage for a major software implementation project.

Using process mapping software, process maps show a series of events that produce an end result. A process map is also called a flowchart, process flowchart, process chart, functional process chart, functional flowchart, process model, workflow diagram, business flow diagram or process flow diagram. It shows who and what is involved in a process and can be used in HEIs and can reveal areas where a process(s) should be improved. Development Education Process Mapping (Figure 4.5) is a reengineering tool used to define the structured, logical steps and the elapsed cycle times a higher education institution deploys to develop new administrative and academic processes. The purpose of process mapping is for a higher education institution is to improve efficiency. Process maps provide insight into a process, help teams brainstorm ideas for process improvement, increase communication and provide process documentation. Process mapping will identify bottlenecks, repetition and delays. They help to define process boundaries, process ownership, process responsibilities and effectiveness measures or process metrics.

The tool can be used in conjunction with other reengineering tools (that is, touch development time versus elapsed development time, Development Process Capability, 10 P's Checklist, Organizational Involvement Mapping, and so on).These tools pinpoint areas and practices of the existing product development process that can be examined to reduce activities' cycle times and improve development processes and work quality. It can be also used as a basis for developing "fast lane" development rules that bypass normal development practices for certain exceptional situations. 
The methodology: The methodology should be developing through the following steps. 1- Learn as much as possible about the process you're reengineering. Whether you're brought in from the outside or you're re-mapping your own internal institution processes, this is a critical stage to help you understand the processes you're changing and what you want to change them to.

2- Define the current process development phases; guidelines check sheet items, and formal approval requirements.

3- Determine organizations, functions, departments, and specific activity skills involved in the current development process.

4- Develop "as-is" Development Process Maps for those new processes development efforts that known (for processes currently being developed, or for processes already released for education programs).

5- Supplement Development Process Maps with descriptive or performance information, such as cycle times, development costs, time-to-graduation performance, educational involvement, budgets, and so on.

6- Develop "to-be" development process maps based on questions, such as, "How would you develop this new process all over again knowing what we know today? What would you have done differently? How could we have saved (50\%) of the administrative time? How could we have reduced education program (or service) cost by (20\%)? What changes will produce breakthroughs in education development?" Note: These maps can be developed in focus groups or brainstorming sessions.

7-Reengineer the education development processes, including phase definitions, roles and responsibilities, phase review and gate keeping, design review procedures, project/resources management methodologies, and success measurement.

6- Directions and requirements for developing a flexible, agile, rapid-response education development process.

In conclusion, successful BPR can potentially create substantial improvements in the way HEIs do education and can actually produce fundamental improvements for administrative and education operations.

Figure (4.5) Development process mapping

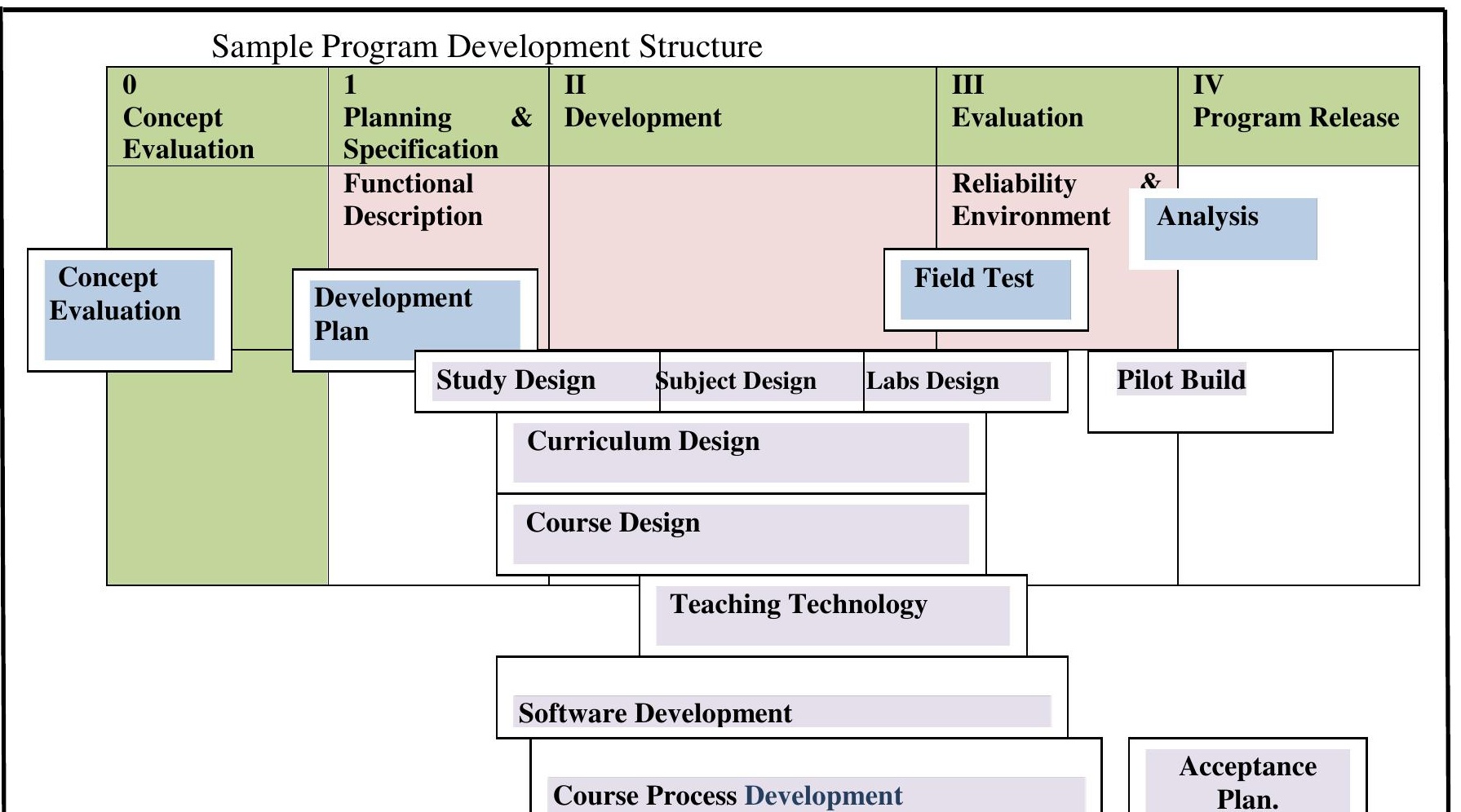




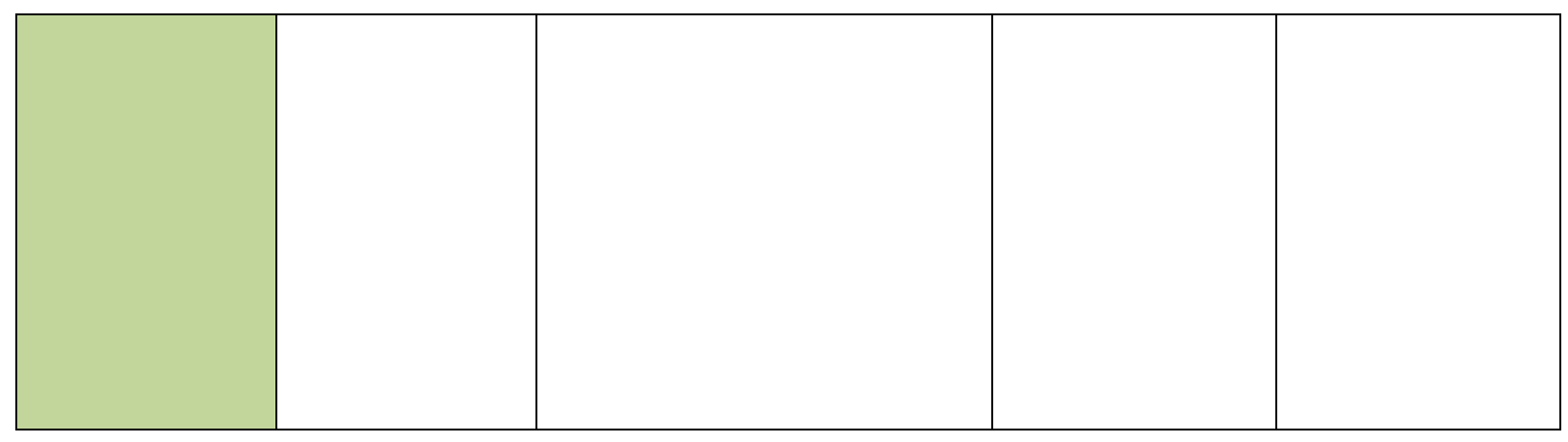

Business Process Reengineering:

B-Development Project Mapping: Development Project Mapping is a reengineering tool used to take an inventory of development projects-in-process. According to Enginess (2017) business process mapping and re-engineering (or BPR) is essentially laying out some, or all, of the processes of a administrative and academia, connecting how they fit together, and identifying what you can do to improve them. The goal is to approach a education as a single, holistic process designed to provide a graduated productive people or/and services.

Today, business process mapping is closely tied to software applications, and in many ways, business process mapping mirrors the requirements gathering stage for a major software implementation project. In general, a business process mapping and reengineering project may take the following steps:

(a) Go in and gather information: Learn as much as possible about the process you're reengineering. Whether you're brought in from the outside or you're remapping your own internal company processes, this is a critical stage to help you understand the processes you're changing and what you want to change them to.

(b) Map the processes you find: Next, you need to map the processes that need reengineering.

(c) Analysis: This is the guts of the exercise. With a good idea of the process and the ecosystem that it lives in, it's time to start identifying weak points, strong points, and areas of concern. The aim is to uncover structural system problems like:

- Inefficient systems - are people doubling up on work?

- Needless complexity - can steps be removed?

- Error-prone processes - are there any areas that make mistakes more common?

- Non-automated processes - can we automate any of this work? 
(d) Process re-engineering and implementation: Solve the problems you identified, and put those solutions into place. Implementation usually involves a software solution, but it doesn't have to.

(e) Gap analysis: No process is perfect. What problems does the new system create, and how can we solve them? (It's a very iterative approach).

The key with BPR and mapping is that it doesn't focus on the task, the person, or even the job. It focuses on a bird's eye view of the process - start to finish - and identifies areas where there is room for improvement. BPR is best focused on how to fundamentally change the way an institution does education and services processes, rather than grafting solutions onto existing (but faulty) processes.

\section{The methodology:}

1- Create an inventory of educational programs' development efforts based on the following classifications:

$\square$ Derivatives: Projects that are cost-reduced versions or enhancements of existing educational programs.

$\square$ Platform: Fundamental improvements in cost, quality, functionality, or performance over previous generations.

$\square$ Breakthroughs: Significant developments to existing educational programs and processes.

$\square$ Research and Development: Creation of new knowledge processes that eventually translate into society development.

Strategic Alliances: Activities outside the boundaries of the map that fit one of the categories previously mentioned.

2- Develop a descriptive profile for each project (for example, resources, costs, priorities, market potential, risk, and so on).

3- Determine Phase-To-Date and Phase-To-Finish facts, such as cost, program cycle time, financial impact, resource constraints, trade-offs, and so on.

4- Purge the development workload based on short-term criteria and particular time-tomarket needs.

5- Repeat the process monthly to manage development resources, program workflow, resource gaps, budget overruns, and development velocity.

\section{2- TOTAL QUALITY MANAGEMENT PROCESSES Overview:}

According to the definitive text, chapters one and two, Total Quality Management (TQM) is a management technique based on the idea that all "employees continuously improve their ability to provide education and service processes that stakeholders will find of particular value." The concept of Total Quality Management can be found right in its name: The word "total" implies that all employees in the higher education institutions, from top management to lowest process unit to fulfillment, are obligated to improve performance and effectiveness. And "management" indicates that this methodology should be a focused effort. Leadership should provide funding, training, staffing, and clearly defined goals to actively manage education and service quality on an ongoing basis.

4.2.1- TQM Principles: (summary based on several TQM list references) 
As with most management methods and techniques, implementation and success, the most common TQM definition includes the following eight principles.

1. Stakeholders Orientation: The first of the Total Quality Management principles puts the focus back on the stakeholders who beneficial the higher education institutions outputs (outcomes) or community services. The stakeholders determine the quality of HEIs' outputs. If these outputs fulfill a need and last as long as or longer than expected, stakeholders know that the HEIs have spent their money on a quality outputs. When HEIs understand what their stakeholders want or need, they have a better chance of figuring out how to get the leading role of society. This will achieve only by getting a right students, high skilled people (academic and administrative staff), education programs, materials, infrastructure (particularly digital information technologies), and processes in place to meet and exceed their expectations.

To implement this TQM principle needs the followings:

- Research and understand the stakeholder's needs and expectations.

- Align HEIs' objectives with stakeholders' needs and national sustainable development.

- Communicate with stakeholders, measure satisfaction, and use the results to find ways to improve education and services processes.

- Manage stakeholders' relationships.

- Find a balance for satisfying stakeholders and interested national economical parties.

The benefits of being stakeholder-focused include:

- More society and government support, increased revenue, market share, and mindshare.

- Strong stakeholders' loyalty leading to further development of education processes.

- Increased possibility that satisfied stakeholders will be highly competitor.

2. Total Employee Commitment: To improve performance, administrative and education processes, or education development need the total commitment of all employees at the higher education institutions. They need to understand the vision and goals that have been communicated. They must be qualified and sufficiently trained and given the proper resources to complete tasks in order to be committed to reaching goals on time.

To implement this TQM principle:

- Clearly communicate and acknowledge the importance of each individual (administrative and academic staff) contribution to the completed educational programs, scientific research, and community services.

- Stress that each team or individual accepts ownership and give them the responsibility and opportunity to solve problems when they arise.

- Encourage employees to self-evaluate performance against personal goals and objectives, and make modifications as necessary to improve education processes' workflow.

- Acknowledge successes and optimized performance to build confidence in higher education institution' staff and its stakeholders. 
- Make responsibilities clear, provide adequate training, and make sure the resources are used as efficiently as possible.

- Encourage employees to continually seek opportunities to learn and move into other roles to increase their knowledge, competence, and experience.

- Create a healthy transparency environment where employees can openly discuss problems and suggest ways to solve them.

- Provide a strong and beneficial intensive and award program for both administrative and academic staff.

The key benefits of total employee commitment include:

- Increased employee retention because employees are motivated, committed, and actively involved in working toward stakeholder's satisfaction.

- Individual and team innovation and creativity in problem-solving and process improvement.

- Employees who take pride and accountability for their own work.

- Enthusiasm for active participation and contribution to continual improvement.

3. Process Approach: Adhering to processes is critical in quality management. Processes ensure that the proper steps are taken at the right time to ensure consistency and speed up all processes.

To implement this TQM principle:

- Use Total Quality Management tools such as process flowcharts to define and delineate clear roles and responsibilities so everybody knows who does what at certain times.

- Create a visual action plan so everybody can easily see the specific activities that need to be completed to achieve the desired result.

- Analyze and measure current activities to see where improvements can be made or where steps in the process are creating bottlenecks.

- Evaluate the impact of processes and activities may have on stakeholders, and nationwide society.

Benefits of a process approach include:

- Faster development education and administrative cycles, high skilled graduated people, valuable research outcomes, significant community services, lower costs, and increased revenue and benefits

- More consistency and predictable outcomes

- Focus on continued improvements and success 
4. Integrated System: Typically a higher education institution has many different colleges, departments, and administrative units each with their own specific functions and purposes. These units and functions should be interconnected with horizontal processes that should be the focus of Total Quality Management. But sometimes these organizational units and functions operate in isolated silos without collaborative with the stakeholders. In an integrated system, everybody in every unit should have a thorough understanding of policies, standards, objectives, and processes. Integrated systems help the HEI to look for continual improvement in order to achieve an edge over the competition.

To implement this TQM principle:

- Promote a work culture focused on quality.

- Use flowcharts and other visual aids to help employees understand how their functions fit in with the rest of the institution.

- Use as-is process analysis to see where improvements can be made.

- Make training available for employees who need to learn new processes and who want to explore opportunities for advancement.

Benefits include:

- Focus on quality that will help educational and administrative staff to achieve excellence and meet or exceed stakeholders' expectations.

5. Strategic and Systematic Approach: The International Organization for Standardization (ISO, 2020) describes this principle as: "Identifying, understanding and managing interrelated processes as a system contributes to the organization's effectiveness and efficiency in achieving its objectives." Multiple processes within a development of education and administrative processes cycle are managed as a system of processes in an effort to increase efficiency, improve quality and performance.

To implement this TQM principle:

- Provide all staff members with the proper training and resources that will help them complete their individual steps in the process.

- Continually improve processes and outputs, and upgrade equipment as necessary to reach goals.

- Make continual improvement a measurable objective for all employees.

- Recognize, acknowledge, and reward innovations and process improvements.

Benefits include:

- An ability to quickly identify, reacts, and fixes process bottlenecks or breakdowns.

- Overall improved organizational capabilities and improved performance. 
6. Continual Improvement: Optimal efficiency and complete stakeholders' satisfaction doesn't happen in a day, so, the HEI should continually find ways to improve processes and adapt its outputs and services as stakeholders' needs. As previously stated, the other Total Quality Management principles should help HEI keep an eye toward continual improvement. To implement this TQM principle needs:

- Implement policies to establish education and administrative outputs, processes, and system improvements as measurable goals for individuals, teams, and departments.

- Recognize, acknowledge, and encourage innovation to improve processes and development.

- Encourage employees to participate in available training sessions to learn and take on new and additional roles.

Benefits include:

- Improved knowledge and capabilities to increase performance

- Improvement goals strategically aligned with HEI's capabilities and goals

- Quick reaction times to recognize and fix bottlenecks and broken processes

7. Fact-based Decision-making: Analysis and data gathering lead to better decisions based on the available information. Making informed decisions leads to a better understanding of stakeholders and nationwide market share. To implement this TQM principle:

- Analyze and check data to ensure that it is reliable and accurate.

- Make relevant data available to stakeholders.

- Use valid methods to gather and analyze data.

- Make decisions based on the facts learned from the data in addition to team experience and intuition.

Benefits include:

- Ability to make informed decisions

- Ability to analyze and defend past decisions by referencing factual records

- Ability to change past decisions based on data review

8. Communications: Everybody in the HEI needs to be aware of plans, strategies, and methods that will be used to achieve goals. There is a greater risk of failure if individual don't have a good communication plan.

To implement this TQM principle:

- Establish an official line of communication so that all employees know about updates, policy changes, and new processes.

- Where possible, involve employees in decision-making.

- Make sure everybody in every college, department, and administrative units understands their roles and how they fit in with the rest of the institution.

Benefits include:

- Boost in morale and motivation when employees understand how their contributions help the institution achieve its goals 
- Interdepartmental coordination and cooperation

- Elimination of silos

- Ability to more accurately measure the effectiveness of current policies and procedures

- Higher motivation from employees to achieve goals because they are part of the decision-making process

At the heart of TQM is the conviction that it is possible to achieve defect-free work most of the time. This assertion is phrased in various ways as right first time, working smarter or zero defects. Right first time or zero defects is the result of an emphasis on prevention, the diligent use of measurement and process controls and the data-driven elimination of waste and error. It serves as a goal for continuous improvement and prevention is the aim of all quality assurance. Through planned and systematic action such as documentation of work processes or cost of quality audits, quality assurance prevents quality problems.

\subsection{2- Important TQM Issues:}

The building robust quality system, the higher education institutions should follow the basic issues.

A-Acceptable Quality Levels: Quality education and administrative acceptance level has a number of factors, including that the goods will be safe to use, and that they will be reasonably durable. Acceptable quality is determined by what a reasonable stakeholders fully familiar with the graduated students' level would regard as acceptable (Banton, 2020). However, the acceptable quality level (AQL) is a measure applied to outputs and defined in (ISO 2859-1) as the "quality level that is the worst tolerable." The AQL shows how many defective components are considered acceptable during random sampling quality inspections. It is usually expressed as a percentage or ratio of the number of defects compared to the total quantity.

Accordingly, the Acceptable Quality Level (AQL) works properly in higher education institutions for the quality level of the graduated students, research, and services. An example, "Goods" in a number of low quality graduated persons is below the predetermined amount, that graduated persons is said to meet the acceptable quality level (AQL) of higher education institution. If the acceptable quality level (AQL) is not reached for a particular graduated student's batch of goods, the institutions should review the various parameters in the education processes to determine the areas causing the defects.

The AQL of a education can vary from one program to another, academic department to another, research and services to an others, and even higher education institution to another. Medical graduated students, for example, have stringent AQLs because defective physicians are a health risk. This situation also plasticized to all academics departments and programs including the curriculum and courses as well. However, an example, if we consider an $\mathrm{AQL}$ of (5\%) on an academic program run, this percentage means that no more than (5\%) of the batch can be defective. If an academic program run is composed of (140) students, only (7) students can be defective. If (10) students are defective, the academic team should consider the causes. This figure of (10) or more defective students is known as the rejectable quality level (RQL). 
AQL Defects (Failure): Instances of failure to meet stakeholders and nationwide sustainable development quality requirements are termed as defects. In practice, there are three categories of defects:

1-Critical defects: Defects, when accepted could harm stakeholders and national economy. So, such defects are unacceptable. Critical defects are defined as 0\% AQL.

2-Major defects: Defects usually not acceptable by the stakeholders, as they are likely to result in failure. The HEIs should establish a ratio of AQL for major defects.

3-Minor defects: Defects not likely to reduce the ability of the graduated persons for its intended purpose but that differ from specified standards; some stakeholders will still hire such graduated ones. Also, the HEIs should establish a ratio of AQL for minor defects.

B-Cost of Quality (COQ): The Cost of Quality concept has been continuously improved into a fully developed financial model that has many strategic benefits.Its defined as a methodology that allows an HEI to determine the extent to which its resources are used for activities that prevent education poor quality. Also, appraise the quality of the HEI's outputs or services, and that result from internal and external failures. Having such information allows a HEI to determine the potential savings to be gained by implementing process improvements.

According to (CQE Academy, 2021), the cost of poor quality (COPQ) is defined as the costs associated with providing poor quality outputs and services. When it comes to Quality \& Cost, there are four different categories that can be utilized to capture HEI's quality related costs, these are:

- Prevention Cost - costs associated with activities specifically designed to prevent poor quality in administrative and academic processes.

- Appraisal Cost - costs associated with activities specifically designed to measure, inspect, evaluate or audit processes to assure conformance to quality requirements.

- Internal Failure Cost - costs incurred when a graduated persons fails to conform to a quality specification before graduation.

- External Failure Cost - costs incurred when a graduated persons fail to conform to a quality specification and skills required by the stakeholders.

The total cost of quality then is simply the sum of all these cost categories; Prevention, Appraisal, \& Failure Costs (Internal \& External) as shown in Figure (4.6). The Total Quality Cost can be summarized as all investments in the prevention of defects, the testing of outputs to assure Quality, or the failure of outputs to meet a stakeholders and nationwide sustainable development.

Figure (4.6), The elements of total cost of quality

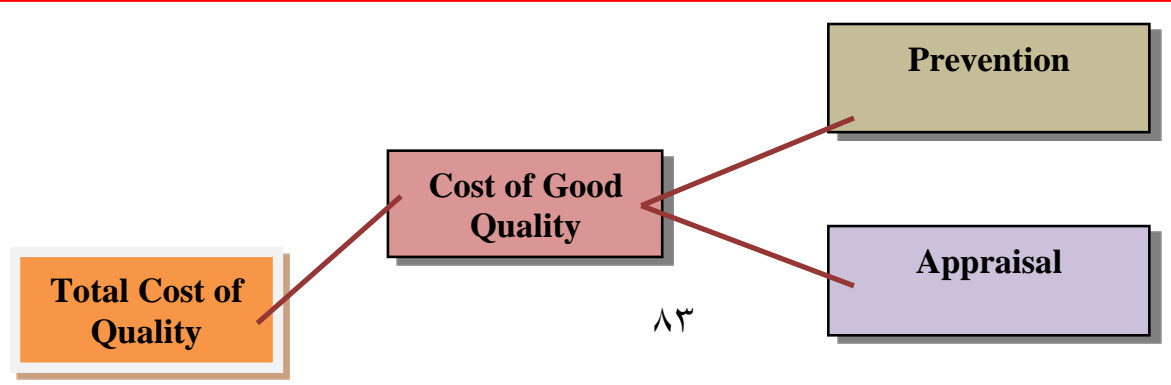




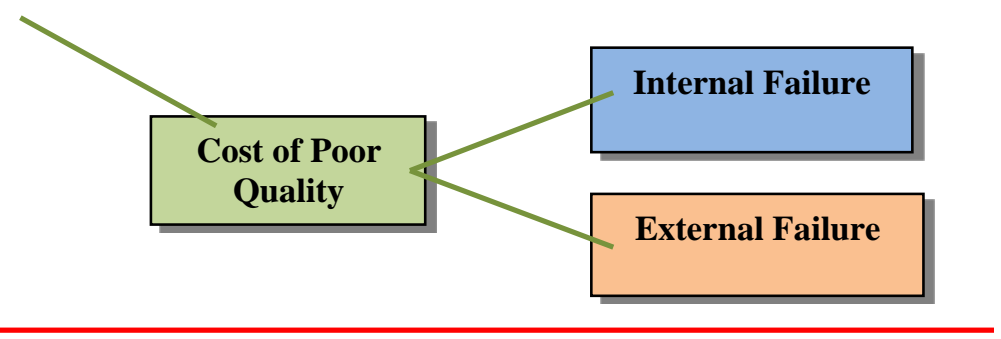

There are really two "good" quality cost categories (Prevention \& Appraisal) and two "bad" categories (Internal Failures \& External Failures). These are known as the Cost of Good Quality \& the Cost of Poor Quality.

Prevention Cost: As mentioned above, prevention costs are those costs or activities that are specifically designed to prevent poor quality in outputs. These costs ensure that administrative processes and academic programs' are design and built right the first time by preventing or reducing errors from occurring. So, investments in this category result in a lower total COQ over time always have the best Return on Investment (ROI) of the HEIs' systems. That why the Prevention costs should be viewed as an investment in cost-avoidance, and by avoiding a non-conformance the HEI will eliminate all the waste associated with that non-conformance.

These include the wasted features and materials of programs' curriculums the manpower required to investigate and disposition the non-conforming features and materials, and the lost opportunity cost/education capacity associated with programs' time \& resources, and many more hidden costs. Also if the prevention administrative and academic activities are powerful enough, the HEI can also eliminate any need to appraise outputs for quality conformance. In essence, the HEIs are ensuring that the outputs or/and service is always made right the first time.

Appraisal Costs: Appraisal costs are associated with measuring and monitoring teachinglearning activities and student's acceptance plan requirements related to quality conformance and auditing. These costs are associated with the graduated students from high HEIs, education processes, programs and curriculum, research activities, and services to ensure that they conform to specifications. Appraisal costs are also considered an investment, not a loss, because you're assuring that quality specifications have been met, and you're preventing unnecessary failure costs, etc.They could include:

- Verification: Checking of incoming graduated students from high schools, teachinglearning processes' setup, and supplementary courses, digitizing information technologies, materials and well-equipped labs against agreed specifications.

- Quality Audits: Confirmation that the total quality education system is functioning correctly.

- Graduated from high schools rating: Assessment and approval of high schools' outputs and environment services. 
Internal Failure Costs: Internal failure costs are incurred to remedy defects discovered before the graduation and outputs or service is delivered to the stakeholders and nationwide economy. These costs occur when the results of work fail to reach design quality standards of HEIs and are detected before they are transferred to the stakeholders. They could include:

- Waste Activities: Performance of unnecessary poor teaching work or holding of programs west time as a result of errors, poor teaching-learning processes, weak academic program, and lack of communications due to missing the digital information technologies.

- High Failure Rate: defective students and rate of leavers (drain) due to study failure or/and poor students' moral for study.

- Supplementary Courses or Teaching Programs: These mean the extra teaching courses for correction of low level of students by different causes or errors.

- Failure analysis: Activity required establishing the causes of internal programs or service failure.

External Failure Costs: External failure costs are incurred to remedy defects discovered by stakeholders (labor markets or government agencies). These costs occur when graduated students or services that fail to reach design quality standards are not detected until after transfer to the stakeholders. They could include all education programs and curriculum alterations, modifications and updating and servicing of both programs and running a training programs and workshops to both staff members and graduated students. External Failure Costs are, by far, the most expensive category of Quality Cost.

These failures occur because the prevention activities \& appraisal process (Inspection \& Testing) did not detect the error before graduation which now has resulted in stakeholders and nationwide economy agencies dissatisfaction \& additional costs. Failure Costs can also be viewed as a penalty for poor quality. And can be avoided through prevention \& appraisal.

[This material based on the ASQ Quality Improvement Pocket Guide: Basic History, Concepts, Tools, and Relationships, ASQ Quality Press, and CQE Academy, 2021].

C-Everyone is Involved: A core definition of total quality management (TQM) describes a management approach to long-term success through stakeholder and society satisfaction. In a TQM effort, all members of HEIs participate in improving education and administrative processes, students' education, community services, and the culture in which they work. At the heart of the TQM is the concept of intrinsic motivationinvolvement in decision making by the employees. Employee involvement is a process for empowering members of HEIs to make decisions and to solve problems appropriate to their levels in the institution.

Involving employees, empowering them, and bringing them into decision making process provide the opportunity for continuous process improvement. The untapped ideas, innovations, and 
creative thoughts of employees can make the difference between success and failure. Employee involvement improves quality, increases productivity and improves performance, because (Ferhan, 2009):

- Employees make better decisions using their expert knowledge of the process.

- Employees are more likely to implement and support decisions they had a part in making.

- Employees are better able to spot and pinpoint areas for improvement.

- Employees are better able to take immediate corrective actions.

- Employee involvement reduces management friction by encouraging more effective communication and cooperation.

- Employee involvement increases morale by creating feeling of belonging to the organization.

- Employees are better able to accept change because they control the work environment.

- Employees have an increased commitment to unit goals because they are involved.

Employee's involvement should not be looked at as a fad that will go away soon. It is a way of life, crucial to TQM, and it can mean difference between being competitive and going out of education industry. Employees, particularly academic staff not senior management, hold future of the HEIs in their hands. The sign over the HEI entrance the sign "No one of us knows as much as all of us."

D-Synergy in Teamwork: The concept of synergy can be summarized by the physics concept of "the whole is greater than the sum of its parts" (Federer, 2013). A collaborating team will likely produce stronger results than any individual and therefore creating synergy within a team is a critical management unit's leadership role. Under strong leadership, a team with synergy can develop into one that can execute flawlessly and drive results. On the other hand, a lack of synergy can show that the most talented individual will not deliver results due to a culture of discord, turnover, poor results and increasing disharmony.

Synergy is the combined action that takes place when different individuals collaborate for one common cause that improves results by the sharing of perceptions, insights and knowledge. A leader who promotes a culture of synergy can drive teamwork and improved results. The key points for success in teamwork are the following (Moran, Abramson \& Moran, 2014):

1- Team members need to be valued as individuals.

2- Individuals need to feel integrated within a team.

3- Team leader must be fair to all team members and treat them equally.

4- The team must be confident.

5- Individuals must enjoy themselves.

The idea of synergy in teamwork, where the whole is greater than the sum of its parts, is a key concept in TQM where it is used to promote collaboration, consensus, 'creative conflict' and team winning. These are detailed as follows:

Collaboration in planning quality improvements, new systems, the documentation of processes, or problem-solving.

Consensus in dealing with conflicting views.

Creative conflict - conflict can have both positive and negative consequences. 
Team 'winning' - rather than an individual accolade, winning becomes a group achievement.

Behavioral analysis (BA) of their performance in-groups is also helpful for quality improvement teams. There are eleven behaviors exhibited in-groups, as shown in Figure (4.7).

F-Management Role Feedback: Performance feedback is vital to enable HEIs' managers and academic rolling staff at all levels to improve their contribution to the institution. Feedback is information about the gap and each discipline can independently between the actual level and the reference fine a concept as long as they adhere to the level of a system parameter which is used respective definitions consistently. For example, information on instructors' outcomes at the end of each semester more importantly to the head of the academic department used in evaluation of knowledge across instructors' future is feedback. Also, feedback provides information on where a rolling head of the academic department is today and gives an indication of the level of improvement compared with previous feedback (Ramaprasad, 1983).

There are six general management areas where feedback is important in the total quality process as follows:

1- Leadership (directive/supportive): task management; delegation; decision-making.

2- Teamwork: interactive behaviors; participation.

3- Communications: active listening; two-way information sharing; personal rapport.

4- Motivating presence (visibility/ accessibility/ encouragement/ interest); recognition; reward.

5- People development; personal performance reviews; career development; succession planning.

6- Commitment to the quality process: use of a quality delivery process, TQM system; quality improvement projects/application of the problem-solving process.

Figure (4.7) Groups of behavior

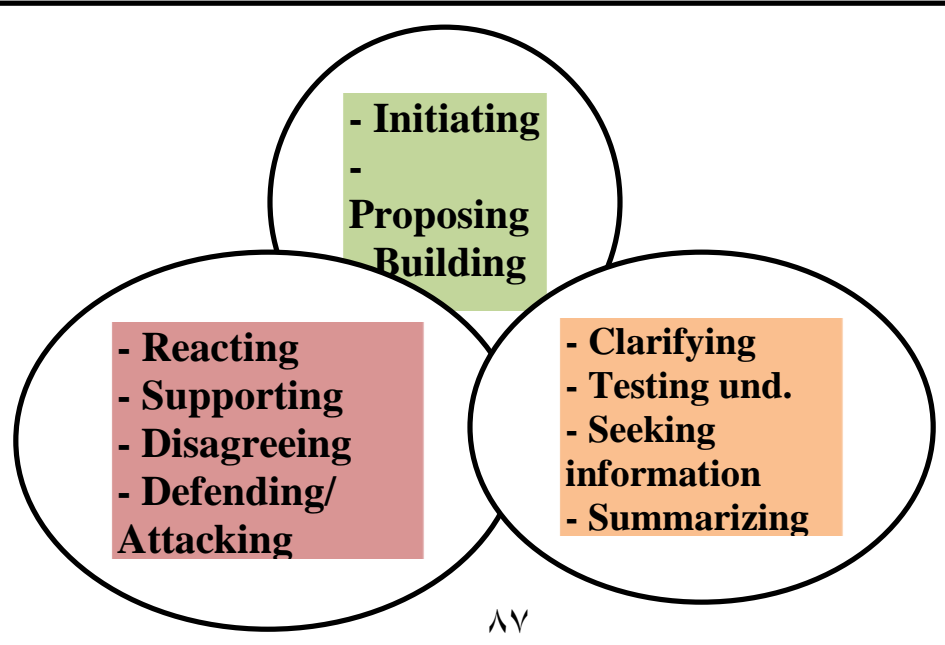




\section{Control / process:}

- Bringing in

- Shutting out

\subsection{3- Benchmarking:}

Benchmarking is a continuous process of evaluation of higher education institutions 'outputs, research activities, community services and practices with respect to those of the strongest HEIs competitors nationwide, or of the HEIs recognized as worldwide leaders. Either the HEI adopts these practices, or it adapts them with the aim of improving its performance. In a direct way, the benchmarking is a process of evaluation and improvement of performance (Camp, 1995). Benchmarking process, as described in Maire, and Büyüközkan and Bemowski $(1997,1991)$ is divided in several steps that we regroup in two phases as follow:

A. Phase One - Self Analysis: Three steps of this first phase measure and analyze the internal performance of the HEI as a baseline to compare to others.

\section{1- General description:}

Step 1: To define activities, stakeholders, and results of the HEI processes. The benchmarking teamwork must first understand in great detail their own institution: how they do, what they do; what their problems and strengths are; their measures and data. To perform an improvement approach consists first in making sure that all academic and administrative staff, students; and stakeholders are satisfied and welling to go the benchmarking deal.

Step 2: To define good system measurements. This step consists of defining a system of measures allowing the benchmarking team evaluation of their higher education institution's activities results (especially through the satisfaction level of stakeholders using these results) and allowing comparing them with other institutions. These quantitative or qualitative measures have to be sufficiently general to share with benchmarking partners and sufficiently specific to produce a significant evaluation. Stakeholders' satisfaction, profit performance, freedom from deficiencies, education systems' features, education and administrative processes; research works outcomes, community services, and teaching and supporting labs and digital information technologies are some of the performance measures.

Step 3: To revise and improve the current institution's performance. On the basis of steps 1 and 2 results and analysis of team current HEI's performance through graphic outputs has to be undertaken. This analysis leads to a diagnosis of principal institution malfunctions and poor quality processes. Also lead to the proposal of a scheme of corrective actions for these malfunctions and processes. In this step, the benchmarking team examines the factors that influence performance to learn which characteristics are most important and which is least important. The collected performance data create the baseline and structure for benchmarking comparisons. 
2- Methods and tools for the first phase: The first phase, based on a diagnosis, contains an analysis of the functioning of the HEI so as to display its strong and weak points.

B. Phase 2 : Pre-Benchmarking: The first two steps of this phase aim to target relevant elements that will be subject and partners of a benchmarking study.

\section{1- General description:}

Step 4: To establish priorities and to select what has to be subject of a benchmarking. All processes, activities, resources, outputs or services can be the subject of a benchmarking study. To decide what it has to benchmark, it is necessary to identify the critical success factors which should be prioritized.

Step 5: To choose benchmarking partners. The purpose for the HEI is to become better (not necessarily the best) in a given area, this leads to the choice of the "good" benchmarking partners in area identified in step (4). The principal goal is to learn the practices used by institutions-competitors and other best practice HEIs to achieve superior results.

2- Methods and tools for the second phase. The second phase of the benchmarking process involves data analysis of one or more higher education institutions. In order to learn the relations and/or the structures of quantitative or qualitative data, data analysis techniques are employed.

\section{3- BUSINESS PROCESS REENGINEERING (BPR) for TOTAL QUALITY MANAGEMET (TQM) \\ 4.3.1- Important Issues:}

Faced with a rapidly changing higher education environment, institutions are under pressure to effect dramatic performance improvements. The best way to achieve such a goal is business process reengineering with total quality management. The aim of reengineering is to facilitate the match between stakeholder's opportunities and corporate capabilities, and in doing so, reengineering represents a radical shift away from traditional task-based thinking to process-based thinking. Business process reengineering involves changes in structures and in processes within the higher education environment. Many approaches, methods, and techniques have since appeared and constitute the foundations of BPR as it is presently known. Davenport notes six areas which influenced the emergence of BPR namely, the total quality approach, industrial engineering, the systems approach, the socio-technical approach, the diffusion of innovations, and the use of information systems for competitive advantage (Based on Renu, 2013).

The success of business reengineering projects is largely dependent on the knowledgeable higher education management of business reengineering project and risk factors. All barriers to business reengineering implementation success are the result of underlying root causes. Sometimes these root causes are not self-evident. Therefore it seems necessary to study the areas for potential root causes of barriers to business reengineering implementation success. An unclear definition of just what is BPR; unrealistic expectations; inadequate resources; taking too long; lack of sponsorship; wrong scope too narrow or too wide; too great or too little reliance on new information technology, and lack of an effective methodology are the common mistakes of BPR. Besides the common barriers to effective implementation of BPR, as time passes, some myths concerning the BPR concept also represent obstacles in front of BPR projects. 
Before starting implementation of business process reengineering in the HEI, the management should understand common myths associated with it and how they related to the education. Some of these myths include :( This material based on Debunking, 2015). 1) BPR doesn't need to happen on Enterprise Resource Planning (ERP) applications: This could be regarded as the most misguided of all the BPR myths. Every enterprise resource planning (ERP) system (software that integrates the core education processes and can be used to collect, store, manage and interpret data) will most likely affect the administrative and education processes. While most of these changes will be positive improvements, some effort will still be required to adapt to the new environment.

2) Simply implementing a new ERP system will drive education processes' improvements: This may as well be regarded as the most myth in the higher education regarding business process reengineering. ERP systems nowadays are extremely robust and flexible.

3) ERP project teams should focus on "to-be" rather than "as-is" processes: For higher education institutions making the changes or the employees doing the work every day, then the current processes absolutely do matter. Therefore, it is important that you examine the current status of education processes.

4) Many higher education executives think that they can implement the BPR improvements without organizational changing management. This is, however, a very misguided view because the most effective business process reengineering efforts succeed largely because of the way the organization changes and not due to the optimized processes.

5) The HEI can't reengineer business processes before knowing which software are going to implement: The how, what and when of what higher education institution does is not tied to your software. Though a new BPR greatly improves the education processes, the general nature of education operations won't change much. Thus, it is better to evaluate and improve education processes before select or implement any new system.

6) All education processes need to be overhauled before selecting and implementing a new BPR system: Some higher education executives believe that they need to totally reengineer their institutions before selecting and implementing a new ERP system. This is not true. Rather, what most successful businesses focus on is improving their major areas of competitive advantage as part of their ERP implementations.

7) Business process reengineering will cause ERP implementation to take more time and money to implement: The undoing of many failed ERP implementations is to assume that "doing things right" will cost more time and money than cutting corners along the way. It may look good on paper to exempt the tedious aspects of business processes, but the reality is that your project will most likely take longer to implement and likely fail if toe that line.

\subsection{2- Pitfalls of Business Process Reengineering:}

Business Process Reengineering brings radical changes in the organisational structure, administrative and academic work methods, procedures, processes, performance, appraisal systems, behaviour and altitude of employees and therefore, successful 
implementation of BPRE in quite difficult. Because HEIs vary widely in their culture and characteristics, their employees vary in their behaviours, it is not easy to identify the pitfalls that management should avoid while implementing BPR. Figure (4.8) illustrates the eight steps of BPR. (Chand, 2020).

Figure (4.8) Steps of BPR

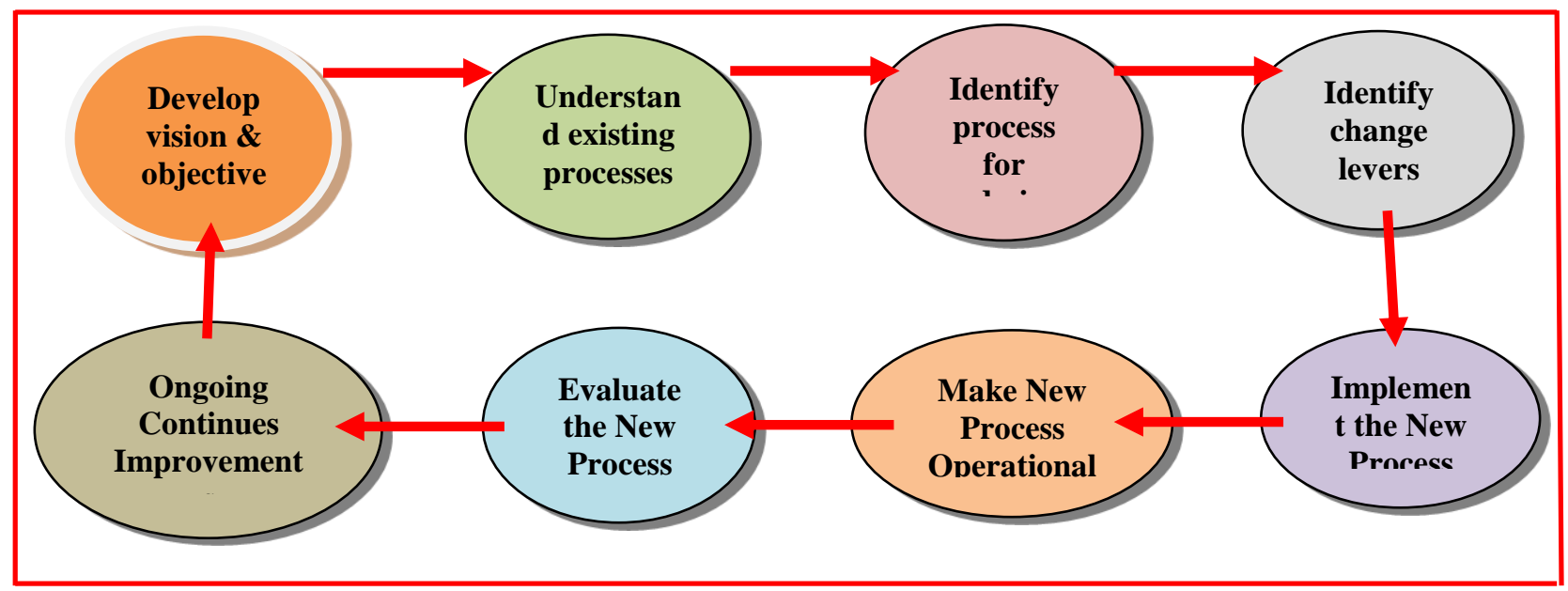

BPR can be easily introduced in higher education institution that have academic and administrative staff who are receptive to new ideas and keen to accept change in their ways of doing things for the benefit of the institution. The staffs in these institutions understand the short-comings of some of the existing education and services' processes. Also have open mind and are prepared to contribute significantly for implementing radical improvements for the survival and growth of their institutions in a competitive local and global markets. Resistance to BPR usually occurs at junior and middle management levels. They suffer from the feeling of insecurity when they are asked to examine their tasks for the purpose of improvement. They have an unfounded fear that process-oriented thinking would result in the loss of power, jobs, control and authority for them. In some institutions, even top managers exhibit resistance to change and are not supportive of BPR.

Many problems that arise in BPR are due to the limitations of BPR and the pitfalls in BPR. The limitations are (Chand, 2020):

(a) BPR is not a panacea to achieve instant competitive advantage.

(b) BPR is not simple or easy to implement.

(c) Many organisations may not be able to invest the time and resources required to implement a radical, clean state approach.

(d) Significant process improvement requires the use of advance information technology (digitalizing IT).

(e) Improvement within each functional area is necessary in addition to improvement in the institution's cross-functional processes.

(f) People who perform the work each day, have the best understanding of the processes they use, and also know to improve them, rather than crossfunctional teams or top management. 
(g) The core-business processes are designed to satisfy particular stakeholders' needs in the "one best way". Most BPR efforts do not seem to consider what will happen if that stakeholders needs changes.

Some of the common pitfalls of BPRE are:

1- Improper knowledge of reengineering.

2-Reengineering too many education and administrative processes at initial stages.

3 - Lack of training for process owners and team members.

4- Improper monitoring of reengineered processes.

5- Wastage of time due to detailed process analysis.

6- Fear of failure.

7- Unfavourable institutional environment.

8- Delay in achieving results.

9- Inability to quantity improvement.

10- Complacency of management.

11- Non-availability of adequate resources.

12- Limited employee awareness, and

13- Discontinuance of BPR after achieving benchmark.

\section{4- HOW to IMPLEMENT SUCCESSFUL BPR:}

The successful implementation of BPR project usually goes through several phases with a number of enablers. However, the factors that are important to BPR success include, which will discuss later on:

- Business process reengineering team composition.

- Educational processes needs analysis.

- Adequate digital information technologies' infrastructure.

- Effective change management.

- Ongoing continuous improvement.

\subsection{1- Implementation phases of BPR:}

One of the most popular trends in BPR is the use of outside consulting firms for reengineering. It's important to state that most of the BPR efforts had external assistance from the consultants throughout the entire reengineering process or at certain part of the process (Fasna, and Gunatilake, 2019). Hence, it is clear that reengineering efforts can either be executed entirely by in-house teams or by in-house teams with the aid and guidance of BPR consultants. Moreover, according to Zigiaris (2000), choosing a specific approach for implementing BPR projects is a crucial decision to be taken by HEIs.

The first complete "pattern" to implement BPR has been proposed by Hammer and Champy (1993) and since then, numerous structured-based methodologies have been proposed for BPR implementation (refer to the previous chapter of this study). Accordingly, the pre-BPR implementation phase can be considered as consisting the steps 
"preparing for reengineering" and "mapping and analyzing the AS IS process". Whereas BPR implementation phase includes "design of the TO BE processes", and "implement the reengineered processes". Similarly, the key step to be performed in post-BPR implementation phase is "improving continuously" (Emerie-Kassahun and Molla, 2013). This proposed conceptual process for BPR implementation is presented in Figure (4.9) which drawn based on Fasna, and Gunatilake, (2019).

Before embarking on BPR, you must implement certain processes to ensure success at the end of it all. Under each phase depicted in Figure (4.9), certain key activities should be performed. These key steps shown in Figure (4.8) are summarized in the five following phases:

Phase One - pre-BPR implementation, which include: Prepare for BPR: Planning and preparation are vital for any activity to be successful. As part of your preparations, you need to understand stakeholders expectations and where existing education or/and administrative processes fall short of meeting their needs. After identifying these customerdriven objectives, you can formulate the following steps:

- Discover reengineering opportunities

- Develop and define vision and objectives

- Determine project scope

- Determine internal and external actors

- Establish steering teams

- Establish reengineering

Phase Two: Preparing for BPR: Map and analyze the "as-is process": Before the reengineering team can proceed to redesign the process, they should understand the existing process. One of the most important aspects of BPR is that improvements should lead to dramatic results. This as-is phase must be thoroughly understood and analyzed. Without it, you will find it difficult to add any value to the process. These steps are:

- Identify the processes

- Understand the existing processes

- Map the current process

- Analyze the mapped

Phase Three: Design "to-be process": The objective of this phase is to produce one or more alternatives to the current, existing business process. The first step is benchmarking. The term refers to "the comparing of both the performance of the HEI's processes and the way those processes is conducted with those of relevant peer organizations to obtain ideas for improvement." The several "to-be models" finally developed are validated.

- Identify change levers

- Define methodology

- Develop a detailed plan for implementation

- Prepare a prototype

Figure (4.9), The implementation phases of BPR project

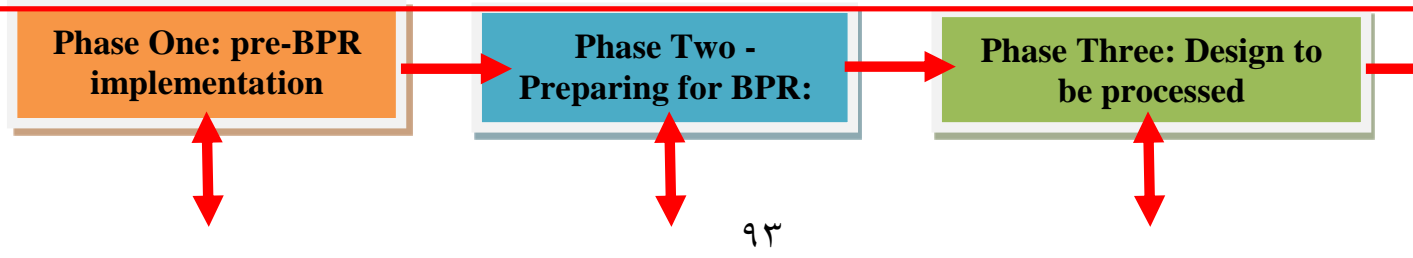




\section{Discover reengineering opportunities; Develop vision \& objectives; Determine project scope; Determine BPR actors \& team; Establish reengineering
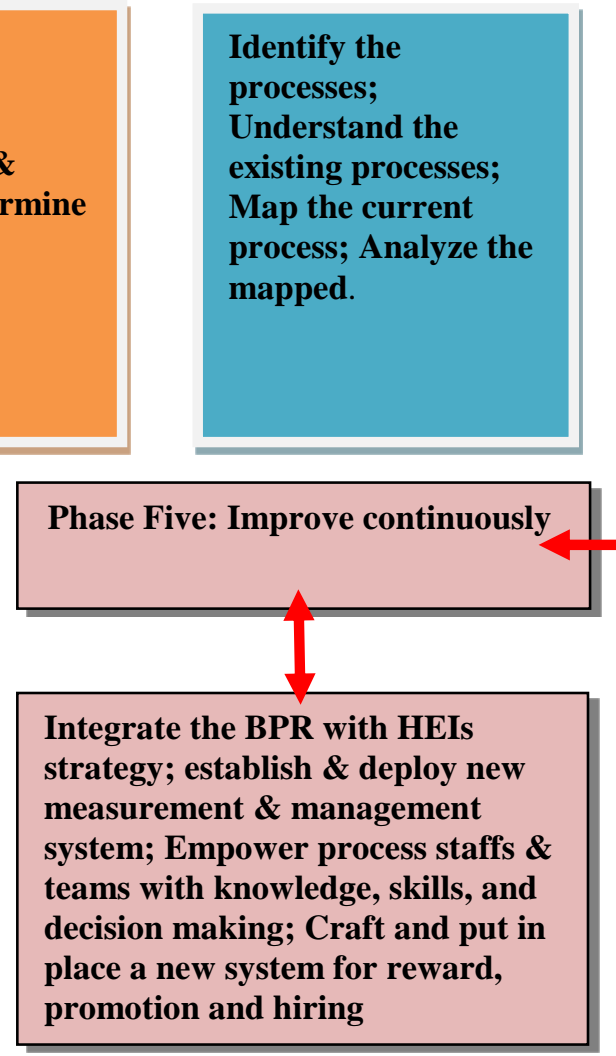

Understand the

Map the current process; Analyze the mapped.
Phase Three- Design to be processed:

Identify change levers; Define methodology; Develop a detailed plan for implementation; Prepare a prototype

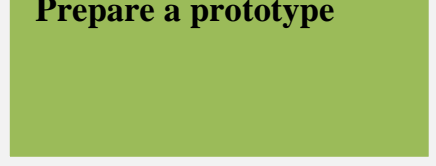

Phase Four-Implement reengineered processes

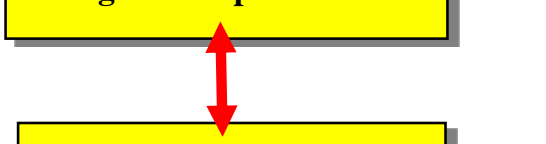

Communicate changes with stakeholders; Make new process operational; Determine the impact of changes to way of work; Managing change

Phase Four-Implement reengineered processes: This is the most difficult stage, as there is a lot of resistance to BPR here. In this phase, the transition plan is validated and its pilot versions are designed and demonstrated. Likewise, training programs for both academic and administrative staffs are initiated, and the plan is executed on a full-scale level. These are:

- Communicate changes with stakeholders

- Make new process operational

- Determine the impact of changes to the way of work

- Managing change

Phase Five: Improve continuously: A process cannot be reengineered overnight, so the need to improve the reengineered process continuously. Here, the BPR team must monitor two aspects: the progress of action and the results. The former is measured by gauging how much more informed the people feel, how much more commitment management shows, and how well the change teams are accepted by those in the institution. As for monitoring the results, this includes such measures as the attitude of staffs, stakeholders perceptions, government agencies' responsiveness, and so on. These are:

- Integrate the BPR with higher education institution strategy

- Establish and deploy new process performance measurement and management system 
- Empower process staffs and process teams with knowledge, skill and decision making power

- Craft and put in place a new system for reward, promotion and hiring

For each of the phases highlighted above, there are techniques and tools vital to their execution. To ease this process, it's important to create a checklist that details these processes, tools, and techniques. And for each phase, there's a timeline for completion.

\subsection{2- Information Communication Technologies (ICTs) and BPR:}

Information Communication Technologies (ICTs) work as a soul of BPR, and helps the process of reengineering in different ways like digitalizing computerization of manual systems, expending specific location educational processes to a virtual processes and effective and efficient alteration in the processes of the education. Business process Reengineering needs some tools to take place these tools are called enablers. As it is the processes of having something new at work, it may be about that how to do the work or how to acquire the work, whatever the main concern of BPR; (ICTs) are the main enabler (Morton, 2015). IT has an important role in the reengineering to be set in, many studies have proved it that (ICT) is the basic capacitor to change in the process or redesigning of the system.

Some of the examples of using (ICT) in the education processes are: the use of applications the digital technologies upon the relational databases, technology of imaging, data exchange on electronic mode and education and administrative management. The degree of collaboration will be higher the effectiveness of the system will be more. The processes can be defined in to three different types like inter-organization processes, interfunction teaching \& learning processes and research, and interpersonal processes. These classifications have been made on the bases of entities and activates involves in it (Morton, 2015). The example of the use of information communication technologies in interorganization processes are like using relational data bases, networking like local and wider areas network (LAN \&WAN), e-conferencing, and exchange of data within the organization. On the other hand inter-functional education processes includes the teleconferences and other networks through telecom.

The structure and organization of higher education institutions will be increasingly complemented by project-and knowledge-driven relationships and engagements. However, social media platforms and an increasingly project-based approach to work will break up hierarchies and silos as a matter of survival. Project BPR will be an additional organizational element which will lead to a cultural revolution. Cooperation and fast formation and disbandment of teams for projects will be a cultural trait that HEIs will leverage and embed in their teaching-learning processes, research activities, and community services.

Technological Innovation: ICTs' capabilities involve improving information access and coordination across organizational units. It is so powerful that it can actually create new process design options, rather than simply support it. . According to Bill Gates, to be successful in the digital age, higher education institutions need to develop a new digital 
infrastructure similar to the human nervous system. This new digital system enables institutions to run smoothly and efficiently, makes them respond quickly to emergencies and opportunities, provides a mean for quickly getting valuable information to all their staff members who need it. This in turn empowers employees to make decisions and interact with customers (Gates, 2006).

Technological Innovation has been the underlying purpose for construction design and use of Management Information System (MIS). MIS is a set of trained human elements and the digital elements needed to obtain and convert data into decision-making information. Information communication technologies (ICTs) have been ascribed as one of the achievements of the technological scientific revolution that has a direct and significant impact on the formation of work within institutions (Husameddin and Mohammad, 2018).The use and application of ICTs have many benefits for whole higher education institutions including academics' staff; faculties and departments, and administrative management systems. These includes but not limited to raising the level of performance, creating value for the organization, inter-firm competition, effective decision-making and re-engineering of operations (Morocco, 2006). Similarly, technological innovation may come in handy when lecture rooms are to be redesigned to make learning easier and comfortable to the students, constructing of solar panels to provide alternative source of power to the institution etc.

All these facilities are made possible with the help of technological innovation. Cloud Apps: Cloud-based higher education institution

networks and projectization lead to an increasing number of external education partners. These partners are often engaged on experience, research cooperation, data sharing, and affiliated cooperation and calibrations. However, today teleconferencing operations' have run without owning the fixed and wireless lines, or their own call centers, among other elements. Modern corporations will depend more on the integration of external knowledge work sharing in their research teams. Again, digital platforms accelerate this development tremendously (Kumar, et.al. 2017).

Digitization of the HEI: These two aspects lead to another trend: the digitalization of the higher education institution itself. Digital agents will take over operations for dispatchers, call center agents, and controllers. They will further expand the share of fully digitized endto-end processes. An increasing number of corporations will no longer own major assets such as large office buildings or workshops.

Data-driven: Data is the currency of digitization. Data skills will be needed to drive all aspects of daily teaching - learning processes, research activities, and community services' operations, decisions, and capabilities. Whether ownership of data platforms will lead to new power structures and monopolies in the education sphere is an unanswered question. Political powers and society will have a say on this, but without a doubt, HEIs must learn to capitalize and secure their data assets.

Human- or machine-centered: The concept of the human-or-machine centered or learning here is about embedding human talent into new agile structures. This is not 
meaning that the human talent should be replaced by artificial intelligence and machinelearning technologies.

Performance Indicators: To assess Information-communication technologies (ICT) infrastructure in higher education institutions, the research needs to develop or adapt a set of performance indicators. According to Nuttall (1994), there is no agreement on the definition of performance indicators. However, there is a large measure of agreement that performance indicators provide information about the state of a social system. To arrive at a performance indicator, institutions need to collect relevant statistics or to conduct surveys of a particular process. Idrus et al. (1998) suggest a number of ways of measuring performance indicators, including quantitative and qualitative measures. Nuttall (1994) adds there are views that the inclusion of both types of measures allows the performance indicators to portray the full richness and diversity of the process, and focus beyond the trivial and unimportant.

Computers: One way of assessing Information and Communications Technologies' (ICT) infrastructure with regards to academic computing is through the number of computers available to students and academic staff. The availability of computers connected to the Internet shows the capacity of higher education institutions to provide access to the Internet and extent of user coverage. The more computers are connected to the Internet, the more the campus community is able to access the Internet as a rich source of information. It also indicates the level of capacity and sophistication a higher education institution has in promoting more accessibility to technologies. The performance indicators are (Mokhtar, 2006) :

a. Ratio of all computers to students

b. Ratio of internet-enabled computers to students

c. Ratio of all computers to academic staff

d. Ratio of internet-enabled computers to academic staff

Network and Internet: The type of network and Internet connection used is a measure of quality of connectivity and signifies the efficiency (speed, quality) of accessing information which may include multimedia resources that take time to download. A fast network and higher Internet bandwidth allow teaching and learning Web-based resources easier to manage. They also enable large volume of research data to be transferred and shared between collaborating higher education institutions throughout the world. The performance indicators are:

a. Network specification

b. Internet bandwidth 


\section{c. Wireless coverage \\ d. Network/Internet performance}

Display Screen Technologies and Peripherals: Display screen technologies have made significant inroads into teaching practice. According to Becta (2004), ninetyeight percent of colleges in the United Kingdom use data projectors and ninety-one percent use electronic whiteboards. They are commonly used in a role similar to traditional classroom tool. Such use includes using presentation software with display screen technology to replace the use of overhead projector and transparencies. ICT peripherals include devices used with computers for various teaching, learning and research purposes. The performance indicators are:

\section{a. Classrooms equipped with display screen technologies \\ b. Peripherals}

Software and Information Systems: The availability of software, learning platforms and academic information systems has become a very important factor in the success of academic computing implementation in higher education institutions. Learning management systems allow online learning environment by enabling the management, delivery and tracking of blended learning (i.e., online and traditional classroom) for academic staff and students. Academic information systems allow institutions to manage academic administration efficiently. They may also integrate with other departments, such as human resources, accounting and e-commerce, so that administrative and supervisory tasks are streamlined and automated. The performance indicators are:

\section{a. Application software \\ b. Learning platforms \\ c. Academic/student information systems}

Finally, the applications of information technology can play important roles in all five phases of BPR efforts as follows: (based on Attaran, 2004)

1- The opportunity IT provides is to utilize newer and better technology to develop a strategic vision and to help improve the business process reengineering before it is designed.

2- The capabilities of IT to track information and break down geographic and organizational barriers are useful in understanding the higher education institution's strengths and weaknesses, and market structure and opportunities.

3 - The focus is on finding different approaches to manage education processes, which can be found and be adapted from practices of HEIs inside and outside of the country. 4- IT can facilitate the reengineering design process through the use of project management tools. Project management tools along with electronic communication; enable ongoing communication of the reengineering process between users and facilitators. 
5- Gathering and analyzing information about the performance and structure of an all processes is an important step in identifying and selecting process for redesign. IT can facilitate this step with the use of tools that provide modeling and flow simulation, document business processes, analyze survey data, and perform structuring evaluation. Technologies such as computer-aided systems engineering (CASE) are designed primarily to draw process models.

6- Computing technologies have facilitated a process-oriented approach to education system development where a database is shared in different functional units participating in the same business process.

7-Telecommunication technologies such as LANs, groupware, etc. have improved collaboration among personnel of different functional units in their efforts to accomplish a common business process.

8-Making data digital from the start can provide a whole range of positive results. When figures are in electronic form, employees can look at them in any detail or in any view they desire, can study them and pass them around for collaboration.

9-Input from employees and information on stakeholder's requirements is essential in reengineering. IT applications allow HEIs to build a data base to track stakeholder's satisfaction, analyze complaints, and obtain employee's feedback for ways to improve stakeholders' satisfaction.

10- IT capabilities are used for information exchange and to improve inner and outer HEIs collaboration.

11-Electronic communications enable ongoing and real time communication of the process between users and facilitators. IT helps to overcome geographic barriers.

\section{5- THE LINKAGE BETWEEN BPR and TQM:}

Higher education institutions are experiencing a modification from highly education oriented beliefs to the stakeholders' needs oriented philosophy. Higher education institutions use different strategies to increase the worth (value) of their products/ services and to gain the competitive edge in the global edge. Progressively more HEIs are becoming familiar with the strategic significance of excellence and quality management. Many of them have arrived at the result that efficient total quality management and/or business process reengineering can augment their competitive talent and offer tactical benefits in the market. This principle is pursued by many HEIs, both big and small, research oriented and teaching-learning oriented, profit and non profit to figure out and develop their approaches towards total quality management. The importance of total quality management and business process reengineering are mounted because of two main factors: Tough competition education institutions; and quality means right education's specifications, valuable research, value community services, in the right time and right cost.

The HEIs' product / service are valued when it is achieved as International Education Standards' requirements and be a part of the International HEI Ranking. As quality and perfect performance are complementary for each other so performance of education institutions increases when there is good totally education quality. Education quality means creativity and in order to be considered creative, the product, service or idea should be different from that which was before and it must also be suitable to the goal at hand, correct and valuable (Azhar, 2003). 
When all the game is about improving the education quality, HEIs are using different tools for quality improvement TQM (total quality management) and BPR (Business process reengineering) are two such tools. TQM is defined - as shown in the part one-as an incorporated approach which is proposed in order to develop the quality at all the levels of higher education institution. And quality should be developed according to the standards of International Standards of Education.TQM is a belief for supervising the institutions in such a method, which assist it to fulfill the demands of the stakeholders and prospect effectively and efficiently without negotiating the moral standards (ISO 8402, 1994). TQM is considered to be one of a very successful management approaches which deals with the education quality of outputs and services; and gaining long term objectives by this.

$\mathrm{BPR}$, on the other hand, is the rapid and radical redesign of the higher education institution to optimize the education workflow and increase quality performance in an institution and achieve the dramatic highly quality education outputs' performance (Kettinger, et.al., 2007). The changes that take place during BPR are fast and drastic as discussed earlier. The increased pressure from the competitive environment has directed the HEIs in changing the focus of top management from the understanding of responsibilities towards the determining of quality education processes and rationalizing towards market and stakeholders direction. HEIs have been constantly conducting experiments with either single or both of these models (TQM \& BPR). For struggling with the matter of executing education quality, managing processes' change, and improvement in education, research, and community services, accomplishing success and for gaining the competitive edge.

Moreover, the higher education institutions have demonstrated clear linkages between TQM and BPR. These linkages are: (Based on Azhar, 2013)

1- Both originated from discipline outside conventional management theory.

2- Just as Statistical Process Control enabled the organizational changes central to TQM, the effects of Information Technology enabled BPR have been largely organizational.

3- TQM and BPR have resulted in flat organizational structures.

4- Both TQM and BPR have focused on process thinking, on continuous improvement in the quality of processes, and on the redesign of processes.

5-TQM and BPR have both been long-term strategies.

6-Both have emphasized the importance of a team culture.

7-Both have required a fundamental change in organizational culture.

8-Both have challenged conventional measurement systems.

9-Lack of senior management commitment has frequently been cited as a major reason for TQM and BPR failure.

10-TQM's quality-driven focus has been based on satisfying stakeholder's requirements.

11- Benchmarking has been a key feature of both TQM and BPR.

12- TQM has sought to reduce the number of suppliers and has developed practices such as just-in-time and Kankan, radically improving the supply process.

13- Implementation of both TQM and BPR has shared similar characteristics. Figure (4.10) describes how a hierarchy of teams has linked senior management to deployment.

14- Both approaches have required substantial vision and leadership. 
Lack of senior management commitment and the need for short-term results have frequently been cited as reasons for the failure of TQM and BPR initiatives. The commonality of implementation methods (see Figure 4.10) would suggest that BPR could be used as part of a TQM implementation program, with quality improvement teams being a logical extension of process redesign teams.

Figure (4.10) Implementation through teams (TQM, and BPR)

\begin{tabular}{|l|l|l|l|}
\hline TQM & $\begin{array}{l}\text { Business Process } \\
\text { Improvement }\end{array}$ & BPR & Management Level \\
\hline Quality Control & $\begin{array}{l}\text { Executive } \\
\text { Improvement Team }\end{array}$ & Steering Committee & Senior \\
\hline $\begin{array}{l}\text { Process Quality } \\
\text { Teams }\end{array}$ & $\begin{array}{l}\text { Process Improvement } \\
\text { Team }\end{array}$ & Reengineering Teams & $\begin{array}{l}\text { Senior, } \\
\text { Multidiscipline }\end{array}$ \\
\hline $\begin{array}{l}\text { Quality Improvement } \\
\text { Teams }\end{array}$ & $\begin{array}{l}\text { Department } \\
\text { Improvement Team }\end{array}$ & $\begin{array}{l}\text { Continuous } \\
\text { Improvement }\end{array}$ & Process Level \\
\hline Individuals & Task Teams & & Employee \\
\hline
\end{tabular}

\section{CHAPTER FIVE: IMPLEMENTATION TQM IN HIGHER EDUCATION INSTITUTIONS OVERVIEW:}

In the last decade, many higher education institutions all over the world have increased their interest in studying and applying principles of total quality management to improve the teaching-learning, research and community services' processes. There is general agreement on the tools of total quality management; however, there is limited discussion and no universally agreed upon model of total quality management. According to Frazer (1994) quality in higher education is important because HEIs must be accountable to all stakeholders (academic and administrative employees, society, employers, and students), and each other.TQM has become the most significant quality philosophies for measuring the overall HEI quality. Also, one of the main contributions of TQM application in the HEIs is this philosophy will contribute positively in increasing the stakeholders' satisfactions. Recent researchers on TQM have brought a widely updated plan for educational reforms and modernization of higher education institutions. 
Accordingly, it can be concluded that TQM can be implemented in HEIs but still there is a gap of knowledge of how to achieve successful implementation of TQM in HEIs. The information about critical success factors of TQM may help to remove the implementation barriers (Nadim and Hinai, 2016).

\section{1-INTRODUCTION:}

Different institutions have found themselves in difficult situations at different times which are often self-inflicted. Most of the time, these problems arise due to bad decisions taken by top management, breakdown of relationships and trust issues, equipment malfunction or even low employee morale which often leads to lowproductivity. During the last decades, the efficiency of administrative processes has become a major concern for many organizations. This situation can be comfortably handled or tackled by utilizing different strategies and methods (Rashidat, and Anthony, 2019). The concepts of Business Process Re-engineering and total quality management became the suitable panacea to the problems militating against the success and competitive advantage of most institutions. The positions BPR and TQM are in the category of necessary tools for survival and growth of any institution.

However, there are many of higher education institutions in the Arab world are suffering from several problems, some of them are critical. Some of these problems are declining student enrollment, low scientific research productivity and decreasing student retention. The higher education in Arab world needs an approach to deal with these problems. The most solution that applied to such problems is the application of total quality management (TQM) principles. There are a large number of higher education institutions all over the world has been successfully applying these principles. However, the difficulty of applying quality management principles to the higher education institutions"' activities (programs and curriculum design, research, daily operations and teaching) led to believe that the HEIs need a framework to apply the principles more effectively.

Additional motivating factors for the proposed framework are: (Rashidat, and Anthony, 2019).

1- The lack of discussion in the quality management literature about well-structured frameworks of quality that are used in education.

2- The involvement of various disciplines within the HEIs in different aspects of quality. This is an attempt to find ways of operationalzing the concept of quality management in higher education.

3- The successful application of the framework in the HEIs and the need to share this information.

4- The need for a framework to structure the debate and process on how the HEIs may increase quality-related research. A HEI that prides itself on quality management education ought to be more visible in the quality research community.

By keeping many of the systematic components of assessment removed from the programme level, faculty can focus on what matters most to them, maintaining ownership and improvement of their own department's curriculum. In other words, centralizing the assessment infrastructure to: (1) handle data storage, (2) 
provide planning resources for instructional faculty, (3) organize quality peer review processes, (4) report quality enhancement information, and (5) develop communication formats for external viewer's encourages localization of a department's programmatic curriculum development (Based on Mokhtar, et.al., 2006).

Some of the commonalities of all levels of quality monitoring include: (1) use of systematic processes of continuous improvement; (2) demonstration of feedback loops whereby instructors improve the curriculum based on deficiencies revealed by their research on student learning quality; (3) use of direct assessments, such as programme instructors' evaluation of senior design projects, rather than indirect student surveys, to demonstrate student learning performance; (4) faculty instructors' engagement in the assessment process.

Compliance with standards is a characteristic of quality. Operating from an internally developed evaluation rubric defining a set of quality standards centralized HEI peer review committee external to the colleges. So, makes sure that college sustains well-developed planning standards that apply to the most demanding evaluative criteria expected by the multiple review entities. For example, while evaluation program requires some direct learning assessment, the committee asks that nearly all learning outcomes use direct assessment. In addition, the program process requires student learning at the graduate level. Furthermore, higher education institutions' evaluation standards require programmes develop diagnostic plans. These plans should identify strengths and weaknesses in programme performance, an outcome of all program evaluation teams.

With a high level of competition and competencies being imitated by other institutions can no longer depend on the old ways of education processes; as a result, there is a need to re-organize processes. Total quality management (TQM) combined with business process re-engineering (BPR) will undoubtedly eliminate stereotypes in processes and eventually assist to replace old structures and reach innovative ways which will ultimately bring about a significant benefit to the institution.

\section{2-IMPLEMENTATION PROGRAM QUALITY ASSURANCE PLAN IN HIGHER EDUCATION INSTITUTIONS}

Over the last decades, Total Quality Management has moved from manufacturing and service sector applications into the public sector, especially into education. Many institutions outside the have implemented pilot Total Quality Management programs with the intention of translating TQM principles, such as advocacy for shared decision making or customer focus, into practical applications. The results of such efforts have been mixed and, as yet, well documented.

In the nineties from last century, with increasing pressure on higher education institutions to decrease costs and increase efficiency, the interest in potential applications

$$
1 \cdot r
$$


of programs such as TQM or/and BPR has grown. The quality movement has addressed quality in education since its early developments, and some of the finding pioneers of the quality movement, like Ishikawa, went so far as to say that quality begins and ends with education. Deming also had a particular interest in learning, which for him defined to a large extent what the human experience is about. Further, Deming's Plan - Do Check/Study - Act model for quality improvement and his fourteen points have been influential in the systematic introduction of quality processes in schools and universities. (Bank, 2000).

Building upon its strengths and experiences, the quality movement has interpreted the concept of quality in education as learning from experience (the fundamental notion underlying the $\mathrm{P}-\mathrm{D}-\mathrm{C} / \mathrm{S}-\mathrm{A}$ model) and process improvement. In other words, quality improvement in education can be achieved by improving critical processes of the educational system such as training of instructors (teachers), student learning, and planning. It is difficult to argue against these basic ideas. However, they may be more difficult to operationalize than what is commonly thought, and they may just represent "one" perspective on quality in education.

Any application of TQM to higher education implies a basic consensus among experts regarding what TQM is. Garvin (1987) shows how quality concepts moved from inspection to quality control, to quality assurance, and finally to a strategic view of quality.

\subsection{1- Development of Quality Assurance Framework:}

At an organisational level, the Quality Assurance Framework (QAF) reflects a strong commitment to evidence- based decision-making and continuous improvement. This is consistent with THINK's aim to achieve excellence in all aspects of its work through accountability, collaboration and teamwork, academic and administrative staffs, and a student-centred approach to learning and teaching. The Quality Assurance Framework is designed to maintain the highest standards in meeting regulatory and legislative requirements. THINK values feedback and participation from staff and students in enhancing its effectiveness and acknowledges the importance of external reference points in monitoring and measuring performance. The Quality Assurance Framework is set out as below: (Jukes, 2019).

1-Integrated planning, which sets the focus for "what we do" as an educational provider of excellence.

2-Integrated Review, which sets the balances and measures to verify "how we know" Think is an educational provider of excellence.

3-Risk Management, ensuring THINK remains flexible to risks and their potential impact.

At an organisational level, the Quality Assurance Framework reflects a strong commitment to evidence-based decision-making and continuous improvement. This is consistent with THINK's aim to achieve excellence in all aspects of its work through accountability, collaboration and teamwork, and a student- centred approach to learning and teaching. (Based on THINK Education, 2020)

The Quality Assurance Framework is designed to maintain the highest standards in meeting regulatory and legislative requirements. THINK values feedback and participation from staff and students in enhancing its effectiveness and acknowledges the importance of 
external reference points in monitoring and measuring performance. The Quality Assurance Framework is set out in Figure (5.1).

Figure (5.1), Quality assurance framework

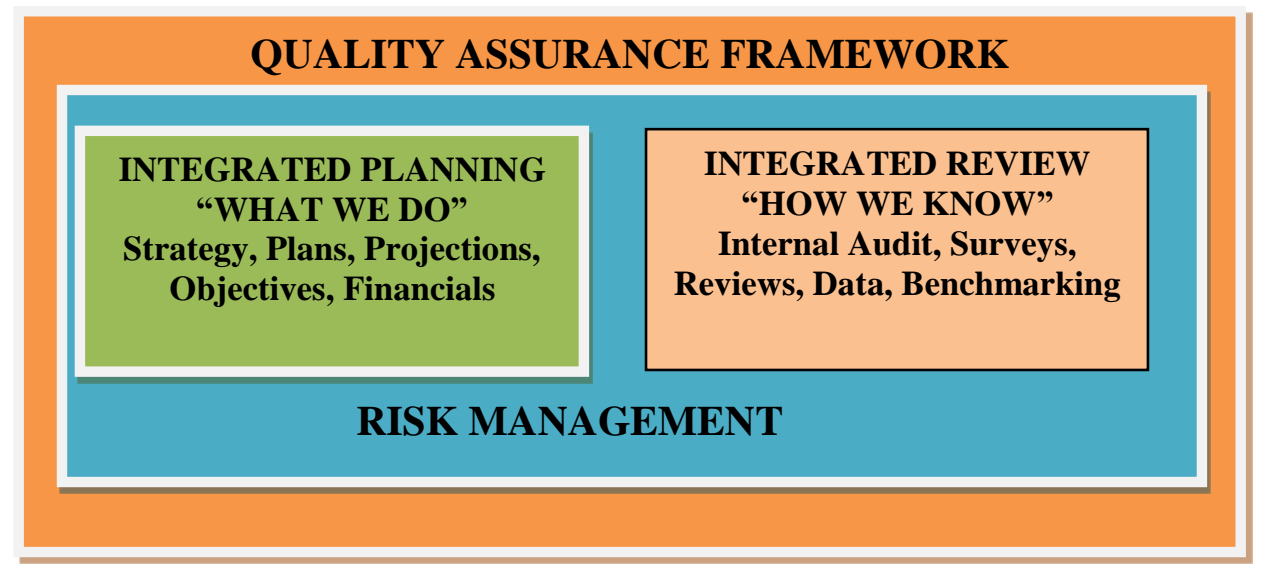

The quality assurance framework has three components:

- Integrated Planning, which sets the focus for "what we do" as an educational provider of excellence

- Integrated Review, which sets the balances and measures to verify "how we know" Think is an educational provider of excellence

- Risk Management, ensuring THINK remains flexible to risks and their potential impact.

The Academic Board is responsible for quality assurance of all academic activities, including active oversight of policies and procedures relating to quality assurance, academic quality benchmarking projects and actions arising, effectiveness of academic integrity processes, and academic standards in teaching and scholarship in accordance with the THINK Learning and Teaching Plan.

The Quality Assurance Framework has embedded the Plan, Implement, Monitor or/and Review, and Improve (PIMI) quality assurance and continuous improvement model as shown in Figure (5.2).

Figure (5.2) Quality assurance framework

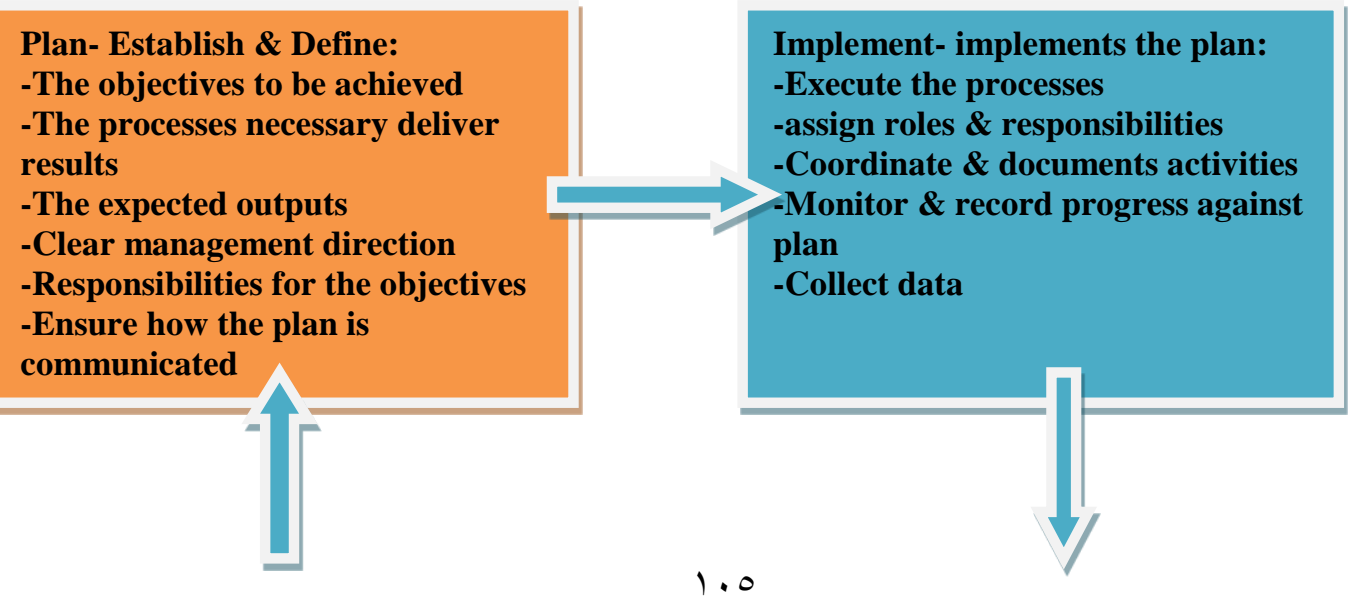




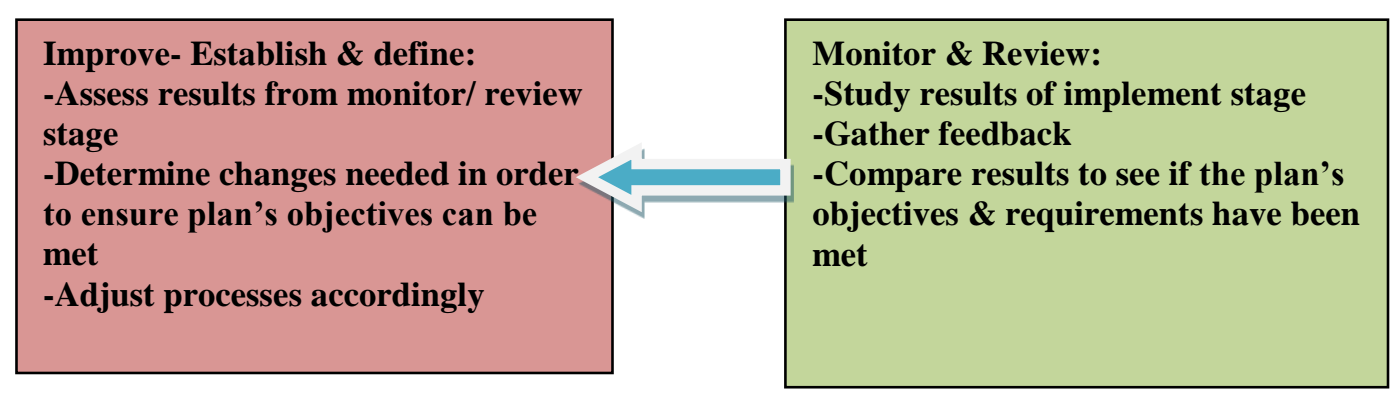

\section{Risk Management}

This framework enables THINK to achieve its strategic promises, ensure quality outcomes and meet its statutory and regulatory obligations. THINK is committed to the following quality management principles:

1- Continuous improvement approach embedded at all levels of the business

2-Evidence-based and inclusive decision-making processes

3-Monitoring outcomes against its stated goals, performance indicators and targets

4-Using internal and external review mechanisms to identify improvement opportunities and implement action plans and mitigation strategies

5- Developing a culture of ownership, participation and responsiveness where all academic and administrative staff understands their individual and collective responsibility for quality processes and outcomes.

The Governing Board actively oversees quality assurance through responsiveness to periodic reports on the quality of academic programs, including reviews and reports on delivery of programs with other parties inside and outside the HEI that lead to a THINK award, as well as regular review of academic quality risks.

The Executive Learning and Teaching Committee (ELTC) oversees learning and teaching and provides the Academic Board with strategic analysis and advice on a regular basis on learning and teaching, and course performance to enable measurement of outcomes and trends. At a Vertical level, the Vertical Learning and Teaching Committees provide advice to the Executive Learning and Teaching Committee, the Academic Board and THINK's Executive in undertaking the following tasks: (Jukes, 2019).

- Monitor the implementation of the vertical learning and teaching plans.

- Provide leadership in reviewing, revising and developing courses, including:

- Providing the Academic Board with advice and recommendations on the accreditation of new teaching courses and major revisions to existing courses.

- Review and approve minor changes to subjects and courses on scope on behalf of the Academic Board.

- Endorsement of programs' courses for submission to authorized Government Commissioner Agency for accreditation. (This agency should establish at the higher education national leadership)

- Endorsement of programs' courses for submission to Faculty Scientific Committee for addition to scope and acceptance. 
- Review annual courses' review cycles to ensure equivalency of learning outcomes, assessments and student workloads across all modes of delivery.

- Review the curriculum mapping (study plan) process documentation to ensure appropriateness of alignment and coherence of course design throughout the proposed course.

- Provide leadership in assessing, monitoring and improving the quality of learning and teaching.

- Monitor retention rates and oversee retention improvement initiatives.

- Provide a framework for the professional development of teach facilitators (lecturers) and academic managers.

- Encourage teaching excellence through collaboration and sharing of innovation and good practice.

- Review and monitor Examination Committee and Academic Progression reports.

- Support and guide the development of library and learning services and resources.

- Ensure academic policies, procedures and guidelines support learning and teaching.

- Provide an environment for discussion on current teaching and learning issues and support Campus and College based improvements.

\subsection{2-Program Quality Audit Agency (QAA):}

The HEI Program Quality Assurance model promotes institutional learning and renewal, guides decision-making and promotes accountability. At an institutional level, the Program Quality Assurance Framework reflects a strong commitment to evidencebased decision-making and continuous improvement. The Quality Assurance Framework is designed to maintain the highest standards in meeting regulatory and legislative requirements. Quality Audit Agency (QAA) has proposed a concentration of resources on higher education institutions subjected to a definitive program quality assurance framework plan as shown in the Figure (5.3-A-B-C) as an example. One of the main issues that needs deliberative is the Quality Audit Agency (QAA) in quality assessment. It believes that it could achieve this by finding the right balance between emphases on internal assessment and peer review. (Findlay, 2020).

However, all institutions should be a subjected to a definitive program quality assurance framework plan shown in Figure (5.3-A-B-C). The essence of the framework plan will cover the following aspects :( see Chapter Two)

1- Equality of standards of qualifications with the same name.

2- Spelling out universities' expectations of what they expect students to achieve on their courses.

3- Subject benchmark information and threshold standards.

4- Development of codes of practice to show best practice in overseas provision student support, governance, etc.

5- Introduction of academic reviewers.

Program Quality Assurance Chairman at HEIs' Board (PQAC) provides a process for the ongoing formative and summative evaluation of education programs and the services that support learning and impact academic delivery. The Institution Program Quality Assurance model promotes institutional learning and renewal, guides decisionmaking and promotes accountability. The new approach for assessing the quality of higher education is based on the program quality assurance framework shown in Figure (5.3-A- 
B-C). This framework has three elements: Annual Curriculum Review (ACR), Annual Program Mix Review (APMR) and Program Quality Review (PQR). PQA also includes the cyclical review of online elective General Education courses (Adapted from Findlay, 2020).

A- The Annual Curriculum Review (ACR): is the process used to review and revise curriculum based on higher education institution's strategic directions. This is an applicable Program Quality Review (PQR) recommendations; new Program Standard releases; feedback from students, professors, alumni, advisory committee members, program councils; and analyses of various surveys, and other data. The process results in the development of a new version of the curriculum to be offered in the next academic year and assists in maintaining program currency and relevancy. Outcomes that emerge from (ACR) include course loading, timetabling, Course Outline Mapping and Management System (COMMS) content, and program publications.

B- Annual Program Mix Review (APMR): The Annual Program Mix Review is a review of the Quality Index and Financial Contribution of all full-time higher education institution's programs against established benchmarks.

C- The Program Quality Review (PQR): is a comprehensive cyclical program quality review process, normally conducted every five years for all programs. Building on Annual Curriculum Review (ACR) activities, each program is assessed against established quality criteria which include College strategic directions. Findings, recommendations for improvement, and an implementation plan are documented in a (PQR) report. Accountability for implementation of the recommendations rests with the Dean. The Program Quality Assurance (PQR) process also includes a comprehensive review of each online course in the General Education course in the program's courses pool. Courses in the General Education pool are program independent and are not reviewed during (PQR). Each pool course must be reviewed at least every five years.

Figure (5.3 - A) Annual Curriculum Review (ACR)

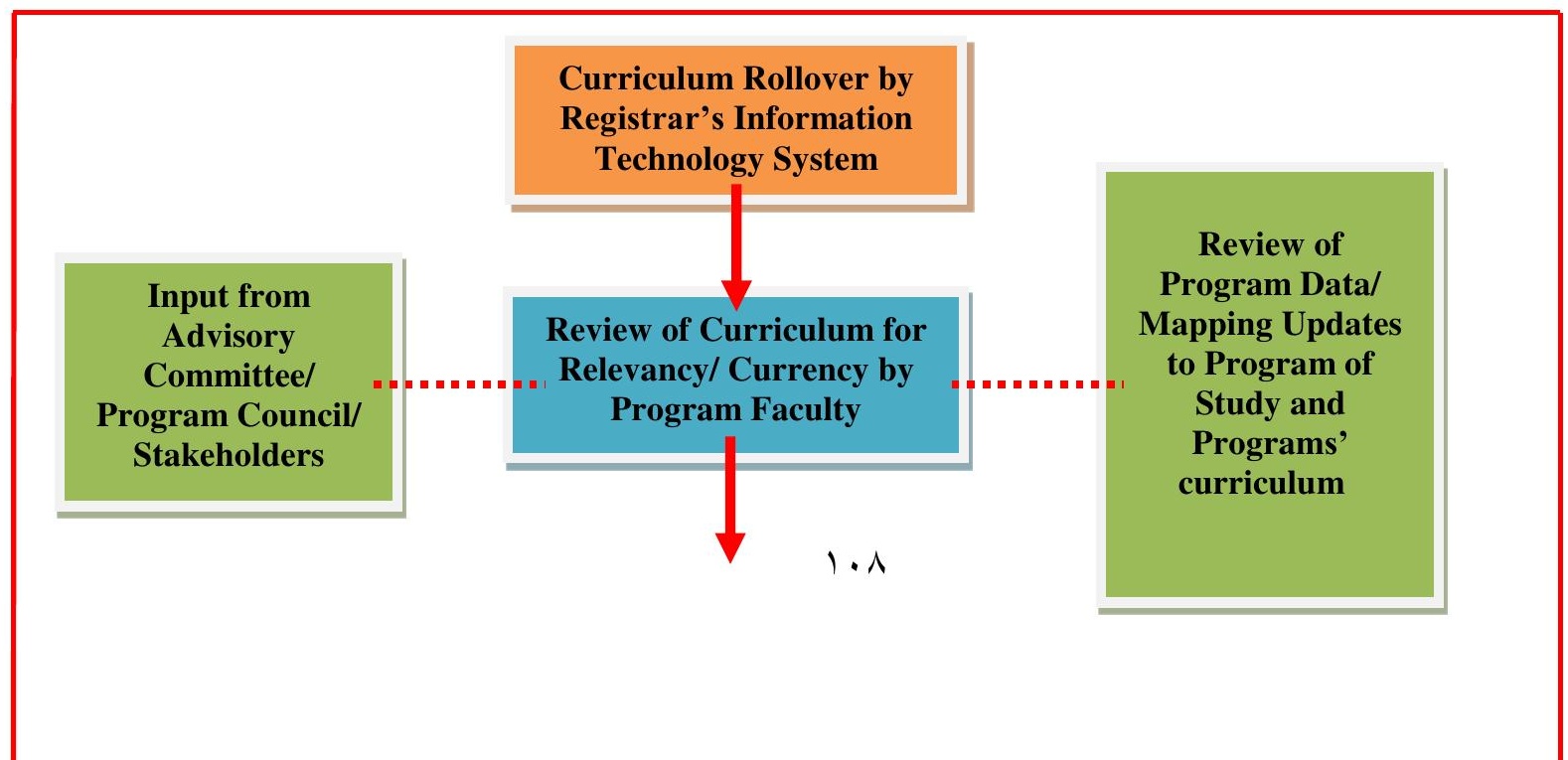




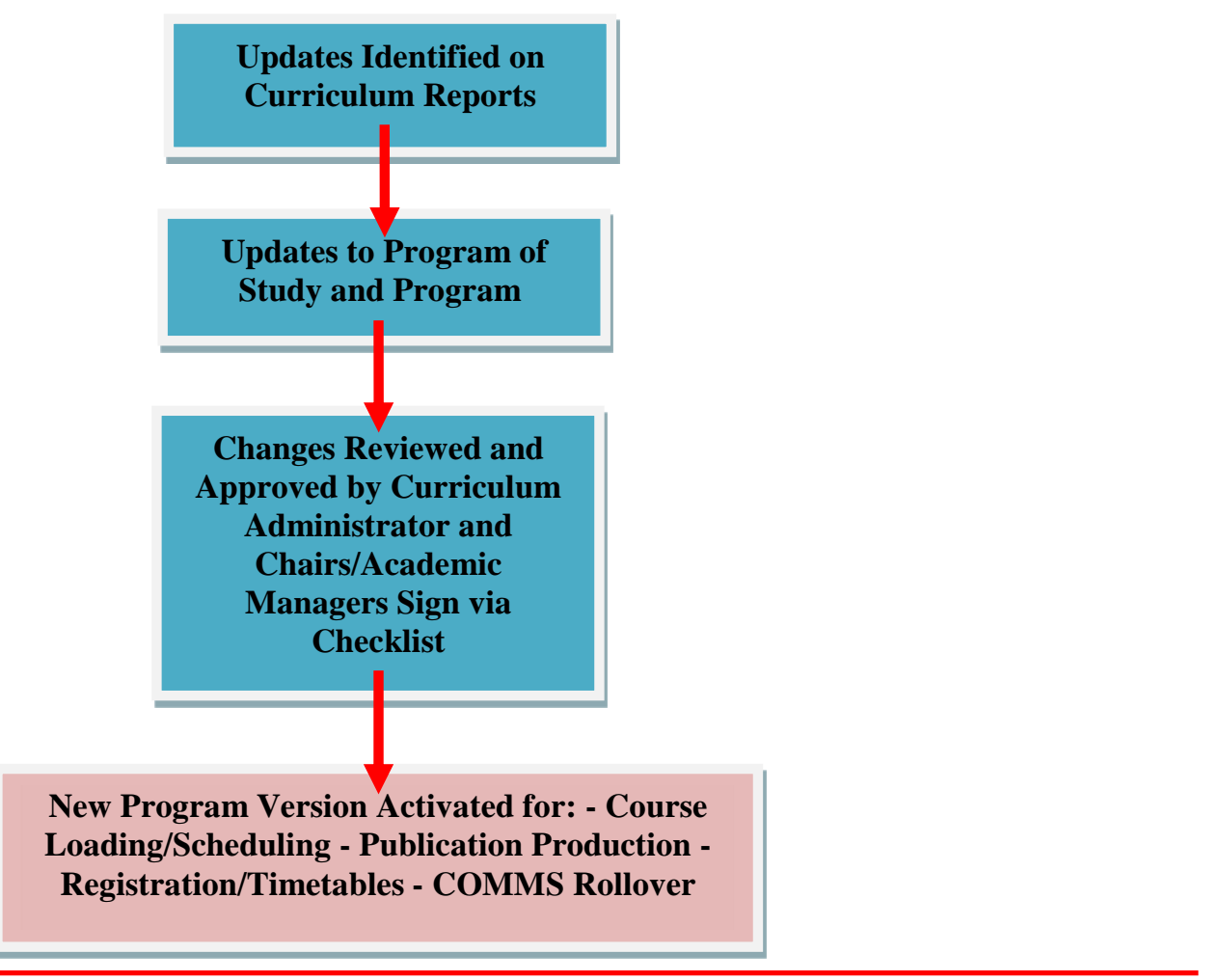

Figure (5.3- B) Annual Program Mix Review (APMR)

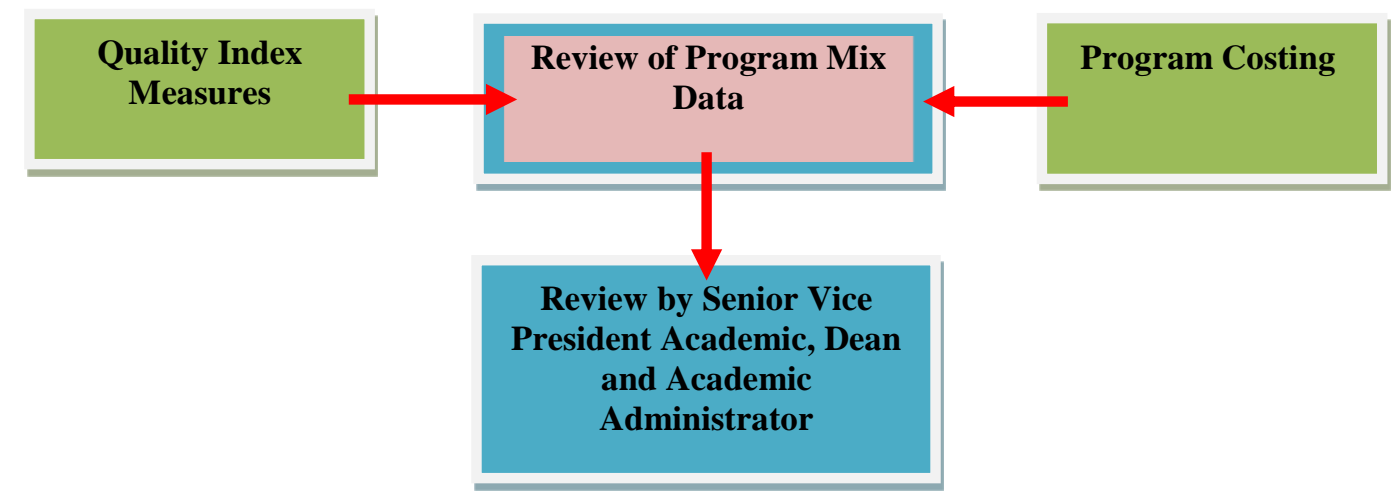




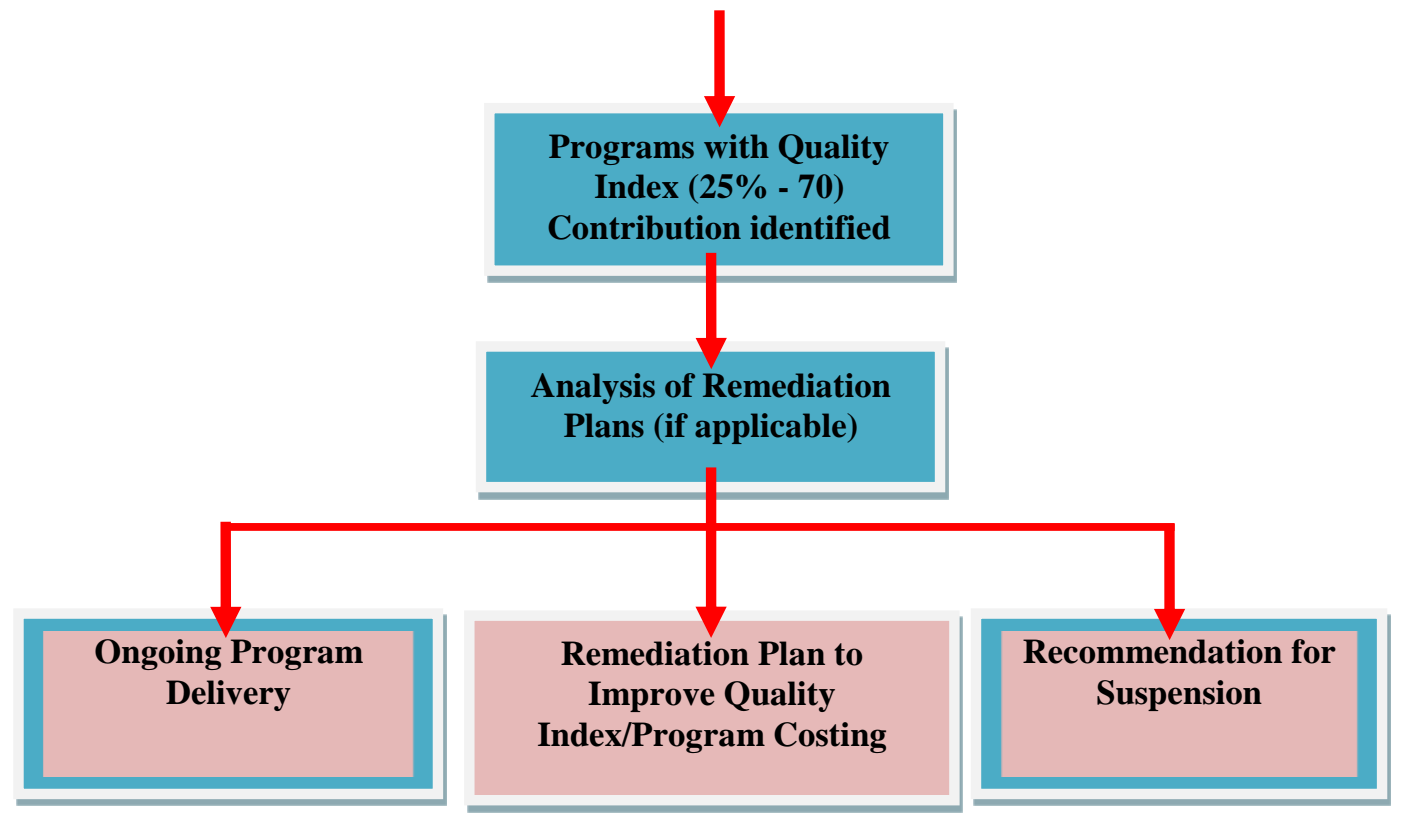

Figure (5.3-C), The Program Quality Review (PQR)

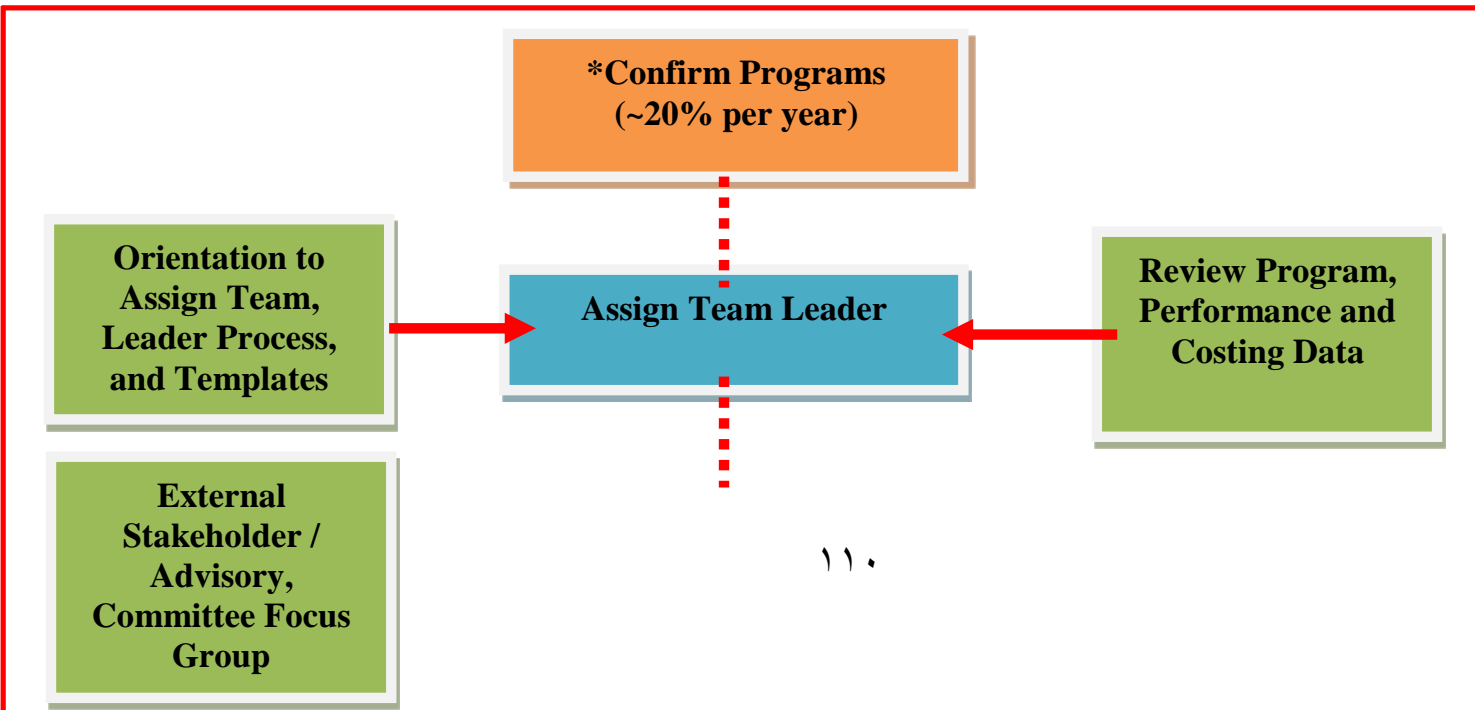




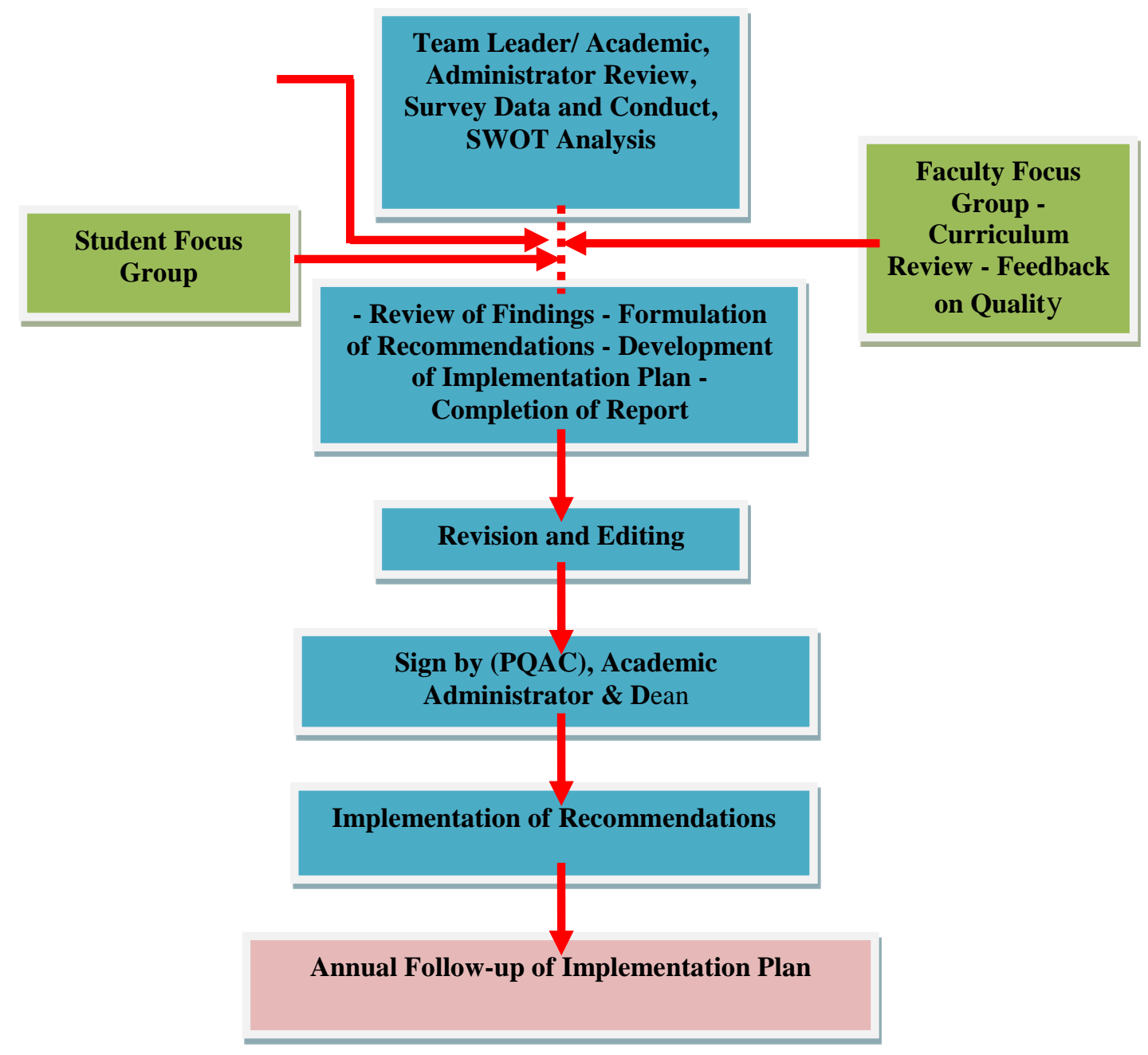

*Note: Normally conducted on a 5 year schedule.

\section{3-THE HIEGHER EDUCATION QUALITY PERSPECTIVES:}

TQM can be of benefit at many levels of the educational process; however, it is certainly unrealistic to see such efforts as the solution to the higher education system. If TQM is about learning and building upon specific experiences, then HEIs need to focus on documenting and evaluating the many different pilot experiences that are now occurring. Consistent with TQM principles, even a failure represents a step in the right direction as long as learn from it. Total Quality Management means to continuously strive to fulfill or exceed the needs and expectations of external and internal customers in all processes in which everyone is committed to their continuous improvement. TQM brings together the best aspects of organizational excellence by driving out fear, offering customer- driven 
services, doing it right the first time by eliminating error, and maintaining inventory control without waste. (Ahmed, 2008).

\subsection{1- Student-Customer TQM Perspectives:}

Since TQM is most often based on the idea of customer-defined quality, this then raises the question of what is meant by quality in higher education. The definition provided by the Quality Assurance Agency for higher education (QAA), the body charged with providing an integrated quality assurance service for higher education across the United Kingdom, is as follows: "Academic quality is a way of describing how well the learning opportunities available to students help them to achieve their award. It is about making sure that appropriate and effective teaching, support, assessment and learning opportunities are provided for them" (QAA, 2004).

The above definition is too general to be readily operationalized. Srikanthan and Dalrymple (2003,) suggested that the definition changes according to the perspective of each customer, or stakeholder group. The differences they identified between the perspectives are summarised in Table (5.1). The lack of consensus among the stakeholders' perspectives illustrates the problems inherent in deciding on appropriate measures by which quality of educational outcomes can be assessed. There are undoubtedly different groups of students who may have both different objectives in studying and different perspectives of their role as customers. These factors may possibly under-recognised by academic and administrative staff at the HEI. For example, there will be differences between students relatively new to university study who are seeking a qualification before entering the world of work, compared to a mature student with substantial work experience who is undertaking study as part of continual professional development.

There is very little doubt that current and prospective students see gaining an advantage in terms of future career as a key indicator of the quality of a higher education. There is considerable doubt about whether they believe that high standards are a sine qua non of either high quality or of career enhancement. The HEIs may have shown what students see a degree as a route into a better career or are indifferent regarding whether or not this involves high academic standards.

Table (5.1) Summarised HEIs'quality perspectives

\begin{tabular}{|l|l|}
\hline Stakeholder group & Quality perspective \\
\hline Funding bodies and society at large & Value for money; return on investment \\
\hline Current and prospective students & $\begin{array}{l}\text { High standards in order to gain an advantage in future } \\
\text { employment }\end{array}$ \\
\hline
\end{tabular}




\begin{tabular}{|l|l|}
\hline Employers & $\begin{array}{l}\text { Competencies of graduates should match the functions } \\
\text { required in employment }\end{array}$ \\
\hline $\begin{array}{l}\text { Academics and administrators } \\
\text { within HEIs }\end{array}$ & $\begin{array}{l}\text { Consistency, recognition of, and respect for, the challenges } \\
\text { of educating a diverse student body }\end{array}$ \\
\hline Source: Based on Srikanthan and Dalrymple, 2003.
\end{tabular}

One prominent interpretation of the "student as customer" (as a member of stakeholders) concept is that it has developed within the wider context of changes to the ways in which higher education institutions are funded and managed and has its origins in the total quality management (TQM) movement. The application of TQM principles to higher education was seen as a way of making the sector more relevant and responsive to the needs of all stakeholders' group including funding agencies. The basic principles of TQM as applied to higher education are as follows: (Eagle \& Brennan, 2007)

(a)Delight the students: Delight means being best at what matters most to students, and this changes over time. Also means of delighting the students as a customer has been directly interpreted as delighting the student-customer and is therefore regarded as somewhat problematic. Being in touch with these changes and delighting the students now and in the future is an integral part of TQM.

(b)People-based management: Knowing what to do, how to do it and getting feedback on performance is one way of encouraging people to take responsibility for the quality of their work. Involvement and commitment to stakeholder's satisfaction are ways to generate this.

(c)Continuous improvement: Continuous improvement or incremental change, not major breakthroughs, is the aim of all who wish to move towards total quality.

(d)Management by fact: Knowing the current performance levels of the products or services in the customers' hands and of all employees is the first stage of being able to improve. Management must have the facts necessary to manage HEIs at all levels.

\subsection{2-TQM Perspectives of HEIs:}

Students, their families, education, stakeholders and government agencies, all are requesting for good quality education for students, good research, and useful community services. The most effective means of Quality and the introduction of total quality management in higher education institutions have been discussed in details through the previous chapters. TQM programmes have been popularized for changing the culture and performance of higher education institutions. Accordingly, the primary aim of this section is to provide an alternative conception of higher education institutions and the higher education systems (HES). In which they operate in an attempt to comprehend the ways in which such institutions and systems adapt and maintain themselves over time. 
Some of the most important applications of TQM principles, processes, and tools in higher education institutions are: (Based on Srikanthan and Dalrymple, 2003)

1- Administrative processes in academic institutions are similar to those of other service organizations; therefore, it is not surprising that early TQM implementation efforts in higher education institutions have started in administrative units, such as admissions, the registrar's office, human resource management, or accounting, where the implementation experience of other service organizations could be applied.

2- To use TQM processes such as Hoshin Planning for strategic planning: One key TQM principle is the need to connect the mission and vision of an institution with short-, medium-, and long-term objectives and implementation plans. This may seem to be an obvious requirement in any planning effort, and not a particular contribution of TQM. However, the congruence of objectives and means is difficult to achieve in practice when the PDCA model (the key model of process improvement) has not been institutionalized. Vision and mission statements tend to be somewhat abstract, and, therefore, difficult to translate into achievable objectives. Within the context provided by the institutional mission and vision, TQM processes (such as Hoshin planning) provide a framework that develops coherence between clearly stated objectives and specific implementation plans to achieve such objectives in a stated amount of time.

3- To use TQM process in academic units: Existing processes such as tenure, or values and principles such as academic freedom, have largely been blamed for these failures elsewhere. However, an overlooked and equally important cause of failure is the disparity of academic units with traditional service organizations. To introduce TQM in academic units with any hope for success, the first step is to examine which values would relate to TQM, and secondly, which objectives would be appropriate for academic functions. Are the standards by which faculty performance is evaluated something that is functional within a "TQM" framework.

4-To use TQM processes for the development of new academic programs: Process such as quality function deployment allow programs' planners, to take into account the interests and needs of diverse constituencies in the development of new products and services. This approach may be particularly well suited to the development of new academic programs in professional institutions, i.e., those programs in which the skills required by employers should play an important role in program design.

5-To foster the development of partnerships among communities, industries, governmental agencies, and higher educational institutions: Higher education institutions play a unique role in society, providing a community of experimentation and innovation. It is important to note that HEIs are fundamentally different from other economic organizations because they generate broader economic benefits. First, their primary mission is teaching and augmenting human capital. This is perhaps the greatest impact of HEIs, although the process of education takes time. Second, HEIs provide longterm impact through research and subsequent knowledge transfer and technology commercialization, thus creating jobs and new businesses that promote local economic growth. Knowledge transfer may be direct through licensing or may be less direct through 
partnerships with local organizations, through consulting or simply as a result of conversations. Students will be educated but, if there is no opportunity for local jobs, nationwide participation incentives and human resource investments may slip away as students migrate to regions of greater opportunity. Similarly, university ideas will be commercialized in distant locations if there is limited local support to start firms, or if there are no nearby receptive organizations.

Thus, in the absence of other local committed actors, HEIs have become active in providing businesses assistance; in this role, they are increasingly involved in developing incubators and science parks and engaging in partnerships with entrepreneurs and large organizations. At the same time, HEIs are a source of a wider base of ideas and actions that contributes to the local economy and, unlike teaching and research. This contribution has not been well studied, even though, increasingly, universities have become major employers in many cities and, consequently, can affect the stability and vitality of a local economy.

6-To introduce TQM curricula into professional programs: TQM modules describing particular TQM processes, such as team based problem solving or statistical process control (SPC), increasingly are part of business and engineering core courses such as organizational behavior or operations management. Engineering curricula had integrated (SPC) long before the quality movement acquired high visibility. A course with TQM content is becoming commonplace as elective undergraduate and graduate, engineering and business seminars. They usually focus on the "soft" skills (such as team building), and/or the "hard" skills (Statistical Process Control) needed for TQM implementation.

\subsection{3- Role of Higher Education in $21^{\text {st }}$. Century:}

In an increasingly comprehension society, to a greater extent people inquire regarding education as the optimism for an improved expectations, the solution to superior jobs and careers and to momentous and satisfying lives. It clears the fact that higher education will thrive in the coming years. So the commitment to provide advance education will become a more strategic issue for the colleges and universities (Ajeenkya, 2014). For enhancing quality the various measures are:

- Persistence of the reforms in higher education will have to be followed in the field of pedagogy, administration, programme offerings, research, curriculum, academic, etc.

- Well structured and complete reforms on a large scale with strong policies and practical programmes to smooth the progress of improving quality and to encourage excellence in higher education.

- A waling incentives through funding for academic reforms like introduction of semester system, grading, choice-based credit system, examination reforms, accreditation, etc. can go a long way towards enhancing quality.

- Focus should be on generation of a new knowledge society from the learners' perspective, satisfying the national and international demands of the society. 
- Development of new models of accreditation and systems for implementation with the dual objectives of national level coverage and compulsory accreditation of all higher education institutions shall be undertaken in a time bound manner.

- In order to internalize quality inputs, all higher education institutions, government and society-aided institutions are to be supported with full-fledged Internal Quality Assurance Management (IQAM) as a nationwide-supported scheme, on regular basis with the required Digital Information Technology (DIT) infrastructure and supportive manpower.

\section{4- TQM CONTRIBUTIONS to ACADEMIC PROCESSES in HIGHER EDUCATION}

Concern about quality of teaching and quality of learning in higher education is widespread. So, the strongest potential contributions of the quality movement to academic applications in higher education are:

1-The literature offers many useful ways to conceive and operationalize the notion of quality.

2- Quality models, such as the PDCA, provide a structure that allows for the integration of specific quality improvement efforts. The overall aim is continuous improvement, achieved through systematic, documented learning from experience.

3- A third major contribution of TQM is focus on improvement in quality is a result of systematically from focusing on improving specific critical processes.

\subsection{1- Quality of Academic Processes:}

Academic quality is a way of describing how well the learning opportunities available to students help them to achieve their award. It is about making sure that appropriate and effective teaching, support, assessment and learning opportunities are provided for them.

HEIs are placing a greater emphasis on the retention of students for continued enrollment and on the evaluation of outcomes from programs that serve students. Academic advising has been acclaimed by many writers as an essential component in the retention of undergraduate students (e.g., Metzner 1989). Furthermore, improvement in academic advising ranks among the most frequently recommended and implemented interventions for increasing retention. According to Metzner (1989) there are several major reasons appear to underlie the widespread appeal of academic advising as a means of promoting student retention. The most important is an academic advising offers the potential of linking students' goals with institutional resources on a personalized basis.

However, high-quality advising can help students clarify their educational goals and relate these goals to the curriculum and to future careers. Also, it can encourage academic success by assisting students with a selection of course work that is compatible with their interests, abilities, outside commitments, and career aspirations; facilitate referral to other services and programs at the institution. And establish a personal bond between a student and personnel of the college. For students, the linkage of their goals with institutional resources may subsequently create a better appreciation of the benefits of a 
college education, greater involvement in the institution, increased learning, a more satisfying college experience, and stronger motivation for continued enrollment.

The quality in the academic processes includes the followings: (Based on Loukkola and Zhang, 2010)

The First Approach: is quality assurance, which refers to the determination of standards, appropriate methods and quality requirements by an expert body. This should accompanied by a process of inspection and evaluation that examines the extent to which practice meets these standards. From this perspective as discussed before, clearly defined standards provide a benchmark and a measure of progress. On the other hands, those quality assurance norms such as ISO 9000 may be increasingly a requirement for higher education institutions.

Furthermore, the academic quality assurance is a demonstration or verification that a desired level of quality of an academic activity has been attained or sustained, or is highly likely to be attained or sustained. Also, Quality assurance can be defined as "part of quality management focused on providing confidence that quality requirements will be fulfilled." The confidence provided by quality assurance is twofold internally to management and externally to customers, government agencies, regulators, certifiers, and third parties.

The Second Approach: is contract conformance, where some quality standard has been specified during the negotiation of forming a contract. In academic practices this definition may translate into meeting specific contractual obligations by both the instructors, and the students. Homework assignments provide a useful example of conformance which is assessed by the instructors in terms of on-time performance (meeting deadlines) by the students and an assessment of the student's ability to meet the requirements of the task. The students in terms of the instructor's assesses conformance on time performance in returning the assignment (marked and commented upon) and on the instructor's reliability in making from student to another. Quality means meeting agreed deadlines in appropriate ways.

The importance of contracting in the classroom is emphasizes the need for the instructor to focus both on the content and process of learning. This model, referred to by some as the case method, is one of the most consistent with principles advocated in the quality literature. The similarities between both approaches stem from the emphasis on managing processes and on shared responsibilities for teaching and learning on the part of both the instructor and the students.

The Third Approach: is stakeholders-driven quality; the notion of quality in which those who are receive graduated persons or services make explicit their expectations for this persons or services and this quality is defined in terms of meeting or exceeding the expectations of stakeholders. Students (as members of stakeholders) are not the only customers who receive the benefits provided by educational services. Among the key stakeholders are also employees (who require graduates with certain skills), parents (who finance the education of their kids) and the government (which subsidizes public education). These divers' customers are entitled to both high-quality educational processes and measurable learning outcomes. 
Further, students' needs, rather than simply expectations, include measurable outcomes such as skills required by employers. Thus, the definition of customer-driven quality can be fully compatible with current concerns about measurable learning outcomes.

The final area of alleged incompatibility between the concept of stakeholder-driven quality and current academic thinking relates to the goals of a broadly based liberal arts education, which may not translate immediately into learning outcomes valued by most employers. This incompatibility may be more apparent than real, since a high-quality liberal arts education translates into higher-level cognitive skills, which are increasingly, valued in knowledge-intensive, state-of-the -art industries. Further, skills such as highlevel writing ability and critical thinking are highly valued even in specialized technical fields.

\subsection{2- "PDCA" in the Classroom:}

There is another important part of potential contributions of TQM to academic processes in higher education is the "PDCA" Cycle, proposed by Deming, which provides a structure for continuous improvement efforts (see Chapter Two). Moreover, Total Quality Management (TQM) literature and Kaizen have demonstrated different efforts to illustrate the application of these approaches in traditional classroom style of higher education institutions. Meanwhile, the quality management of classroom teaching is the basis of teaching quality management in higher education institutions. "PDCA" Model can be broadly translated as a systematic approach to teaching and learning from experience and acting upon what has been learned. This simple notion should be a guideline to all learning, since it is simply common sense in operation.

Higher education institutions should emphasizes the importance of instructor (teacher) preparation as the best means for preventing problems before they arise. Students entering the classroom should be greeted by instructors (teachers) who have prepared themselves, their classrooms, and even the work in anticipation for a productive day's learning. A well-managed classroom is one where students know what to expect and where instructors are proactive, providing clear direction on everything from how to answer a question to when to turn in homework, to how an assignment will be graded.

Teaching quality management is the plan, organize and control process of the effective output expected by the HEIs. It is mainly embodied in setting quality standards, decomposition and implementation, assessment of the implementation status (including examining, evaluation, feedback, and application of the results), and improvement. Its essence is to bring out the continuous improvement of teaching quality. Thus, the HEIs' teaching quality management processes is a continuous circular and spiral loop. And this is exactly the main reason why the "PDCA" Cycle theory is effectively referred to and applied in college teaching quality management. Following is the discussion of the "PDCA" components in some details (Based on Xuegao, 2013; Harvey, 2012).

1-Planning (P): This is means the teaching objectives formulation stage. Also, this is the embodiment of the planning function of management in the teaching management. At this stage, first, is the recognition of the main problem, which could be system problem, the instructors (teachers), the students, the curriculum, or the teaching procedure that affecting

the teaching quality. Second, to improve the initiative and participation of students in the 
classroom learning, while the teaching reformation requiring the instructors to set the teaching activities student-centered, the curriculum arrangements need to be reorganized.

In any classroom, especially the one that involves higher studies, there is a need for proper planning to understand the problems that might be faced by the students from different socio-economic background and to eradicate them in the best possible way so as create an in-class environment conducive for both the instructor (teacher) and the learners. Planning under TQM, and its application to course delivery in higher education settings, includes two critical notions:

(a) Previous teaching and learning and experiences should influence the new plans. Unless a course is offered several times by the same instructor, systematic learning from past experiences is the exception rather than the norm in the development of syllabi for courses. (b)All relevant constituencies should participate directly or indirectly in the planning phase. Course design is commonly decided unilaterally by the instructor, who may or may not follow broad curricular guidelines in designing current courses. Uniformity or standardization of course content is fundamentally a function of content uniformity of textbooks used in higher education.

In general opinion, current course design practice violates a basic TQM principle- shared decision making. It is evident that the instructor needs to unilaterally make some decisions before the semester begins, such as textbook choice; however, other decisions (such as specific course delivery methods and type and due date of projects) may easily be made jointly. Currently there is an unwarranted degree of rigidity in course design. Every process should relate to specific course objectives rather than to the preferences of an individual instructor.

Potential implementation guidelines for the planning in a manner consistent with "PDCA" include:

Review syllabi, written feedback and any other relevant documentation if the course has been offered before.

Review the current learning objectives and prescribed content for the course as stated in the official course catalogue.

$\square$ Define instructor's objectives for the course. Do not confuse the objectives with the operationalization of them.

$\square$ Discuss the course objectives, defined in the catalogue and approved by the curriculum committee, and instructor's objectives with the course participants. Have the participants define "their" objectives.

Implementation (materials and pedagogy used) should be function of the three sets of objectives (official curriculum, instructor, and participants).

2-Doing (D): This means the process of the teaching activities. The doing or implementation of the plan should be a direct function of the objectives set of the course. The next step related to the proper execution of the procedure in the classroom depends on the way the plans are put into action or their performance. A plan, unless, put into action is as good as nothing and that should not be the case as far as class management is concerned. The performance of the process in the proper way helps in the smooth running of the management process. 
The instructor and students may have available a variety of possible approaches or pedagogies to achieve specific learning objectives. Learning style considerations may provide additional criteria for the selection of particular process to achieve the chosen learning objectives. In this part, the instructors should teach the students according to their aptitude, realizing the function of the faculty to impart knowledge. Instructors are supposed to design a lesson, a learning topic or a chapter as a unit to launch the planning, implementation, observation, reflection and modification of the process. Sufficient communication should be made by the instructors to access the suggestions and opinions of the students.

Suggested guidelines for classroom implementation:

Define alternative teaching methods and instructional materials which relate directly to the objectives of the course (lectures, videos, cases, student presentations, group projects, and so on).

Consider learning styles in the final selection of learning processes.

Emphasize teamwork.

3- Checking - C (Learning): This means teaching evaluation results of implementation need to be evaluated, since they represent a critical tool for improvement. Evaluation focuses on unambiguous "vital signs" that measure performance of specific process steps against clearly defined benchmarks. The need of checking or monitoring every step with utmost care is absolutely an ardent requirement for the smooth running of the planned procedure in class management. If the checking part is absent, it becomes a real problem to eradicate and also affects the proper communication process between the teacher and the learners.

The literature offers rich insights into the potential use of assessment as a learning process in its own right (as in the use of portfolios as tool for self-reflection for students). In my opinion, the usefulness of assessment models has been hampered by two factors: First, the apparent contradiction between assessment and evaluation understood as measurement against absolute standards. The use of one approach does not preclude the other. The Second handicap is the lack of willingness to assign sufficient resources to systematic assessment and evaluation. This could change if a structured approach to improvement, such as the PDCA model, were applied at the course, departmental, or institutional level (institutional accountability).

Therefore, on one hand, the effects of student-centered teaching methods need to be evaluated. On the other hand, the implementation of the syllabus should also be evaluated. The effect of teaching methods can be reflected in each lesson. Departing from the original problem to be solved of the project, such as the students' classroom participation or learning initiative, some certain conclusions can be drawn by observing the learning state in the classroom and homework completion after class.

4-Adjusting (A): Last but not least, it is very important to act upon or put the plan into action so as to derive the desired result from it. However, if there is a chance to improve the procedure and upgrade into something even more significant and impacting, it should always be taken and chanced upon to get a better than expected result, which will help to build the process in the best way possible and present a concrete learning procedure in the classroom environment. This means summarizing the outcome. Basing on the test results, 
analyze the specific practices of the instructors in the implementation of the plan and sum up the mature experience, which can be integrated into the standard rules and regulations, aiming at consolidating the achievements. Meanwhile, put the unresolved issues in the current round of "PDCA" Cycle into the next round to solve. The planning stage of the work of the next round is based on the summary and treatment of the previous round. By forming up such a closed loop, it keeps improving the quality of teaching.

The final stage in the "PDCA" model is the one missing frequently in academic processes in higher education: the information collected is not used as a tool for systematic improvement, for several reasons:

The course is only taught once, or is taught again by somebody else, who redesigns it to fit his/her own preferences. In the best of cases, syllabi or comments about pedagogical tools, such as instructional materials, may be shared.

Assessment or evaluation instruments are used either to grade students or because they are mandatory (state laws demanding accountability of HEIs and it uses mostly to evaluate the contracted-based instructors). The information does not include the instructor (except for often ill-designed student evaluations) and is not seen as an important tool to improve teaching and learning.

$\square$ Teaching performance remains of low priority in the tenure process.

Finally, if action is not taken, as results of lessons learned from experience gained systematically, there will be no improvement.

Most of the decision related to the improvement of academic processes in higher education has focused on quality of inputs (better students, better instructors, more pedagogical aids). The missing link has been to learn systematically from each instructor's experience and to translate the lessons into improved processes. The main problem with focusing the discussion of quality in academic processes on quality of inputs is that lack of resources is often a convenient excuse for lack of improvement. This is simply unacceptable. Better teaching and better learning result from focusing on improving specific, critical academic processes, based on the lessons learned from experience.

The product of education is not a product at all; it is a process of never ending education. To be empowered in this way requires that the student gain from education:

Knowledge of how to continue learning and developing for the rest of her/his life,

Skills in continuing to learn and develop,

A state of mind and being that enables lifelong learning, that sees and feels self-guided learning to be natural, doable, and fun, and

A strong drives, a will, to continue learning and developing her/himself.

\section{5-TQM IMPLEMENTATION EFFORTS IN HIGHER EDUCATION INSTITUTIONS}

TQM in higher education is a process that involves the institutions adopting a total quality approach to the entire academic processes and environment (i.e. attempting to improve the quality of administrative and academic processes, the students' meaningful learning in every possible way) so that the needs of the students. TQM in a classroom setting is a philosophy and a set of guiding principles and practices the instructors apply to teaching that represents the foundation for continuous learning and improvement on the part of the students and the instructors. It is the application of procedures related to instruction that improves the quality of education provided to the 
students and the degree to which the needs of the students and their employers (all stakeholders' members) are met, now and in the future.

It's important here to emphasize the importance of quality learning, which should be focused on meaning and not on reproduction. However, underlines that the vital competence in academic disciplines consists in understanding the way in which students apprehend and discern phenomena related to the subject. The students, the primary customers of the institution, need and want more than library books and an impressive set of faculty degrees enumerated at the end of the college catalog. After a long entrenchment in old ways of thinking, namely, the resource view of quality, some higher education institutions had begun to embrace a performance view of excellence in education; motivated by competition, costs, accountability, and a service orientation. This means that the quality of an institution of higher education is determined by its outputs -outcomes efficient use of resources, producing uniquely educated, highly satisfied and employable graduates, and meeting the needs of national sustainable development.

The following examples are intended to be descriptive rather than normative and reflect the experiences of higher education institutions of the most important applications of TQM principles, processes, and tools in higher education institutions are: (Based on Zabadi, 2013; Todorut, 2013; Sudha, 2013)

1- To use process improvement teams and models in administrative units: Administrative processes in higher education institutions are similar to those of other service organizations; therefore, it is not surprising that early TQM implementation efforts in higher education institutions have started in administrative units, such as admissions, the registrar's office, human resource management or accounting, where the implementation experience of other service organizations could be applied.

2- To use TQM processes such as Hoshin (strategic) planning: One key TQM principles is the need to content the mission and vision of an institution with short-, medium-, and long-term objectives and education implementation plans. This may seem to be an obvious requirement in any planning effort, and not a particular contribution of TQM. However, the congruence of objectives and means is difficult to achieve in practice when the "PDCA" model (the key model of process improvement) has not been institutionalized. Vision and mission statements tend to be somewhat abstract, and, therefore, difficult to translate into achievable objectives. Within the context provided by the institutional mission and vision, TQM processes (such as Hoshin Planning) provide a framework that develops coherence between clearly stated objectives and specific implementation plans to achieve such objectives in a stated amount of time.

3- To use TQM processes in academic units: With little exception, attempts to introduce TQM processes into academic units have stalled. Existing processes such as tenure, or values and principles such as academic freedom, have largely been blamed for these failures. However, an overlooked and equally important cause of failure is the disparity of academic units with traditional service organizations. To introduce TQM in academic units with any hope for success, the first step is to examine which values would relate to TQM, and, secondly, which objectives would appropriate for academic functions. Are the 
standards by which faculty performance is evaluated something that is functional within a "TQM" framework?

Tenure is a process based on values such as "academic freedom," rooted in widely held societal beliefs such as the need to encourage independent intellectual inquiry and reflection. Academics are supposed to be to freely voice their opinions without fear of retaliation by the administration. Higher education institutions are held to be areas in which diverse opinions can be freely expressed, rather than "one-man or party" organizations with singular ideological and political agendas.

It is inappropriate to engage in a discussion regarding values such as academic freedom with concepts such as efficiency. Values provide a fundamental framework upon which institutions are built, and cannot be directly measured for "efficiency." Efficiency can only be measured against clearly defined strategic objectives, and values precede strategy. Therefore, if academic freedom is an essential value, it cannot be judged by concerns with efficiency. Thus, a more direct "framing" question is whether tenure is the best process to ensure academic freedom, and, from a pragmatic perspective, it is unlikely that tenure will be abolished in tradition and experience.

Still, the difficulty of implementing TQM in academic units remains. An organizational analysis of academic institutions might provide some answers. Higher education institutions are essentially "loosely coupled systems" in which committees and subsystems (each class or course) have a high degree of autonomy. This is the fundamental operational basis of a "college" or "department" in which each member is seen as a specialist in his/her field.

It is likely that TQM experiences related to the development of teams formed by professionals (as in Quality Function Deployment applications) may be relevant for academic environments. Also, consistency between mutually agreed-upon objectives and specific implementation efforts can be sought. However, any efforts to bring about a major power shift under the guise of efficiency concerns are likely to fail. Centralization of power proposed by the administrators of academic units will be fought against by the members of institutions with a clear collegiate tradition.

4- To use TQM processes for the development of new academic programs: Processes such as Quality Function Deployment (QFD) allow planners, to take into account the interests and needs of diverse constituencies in the development of new products and services.

This approach may be particularly well suited to the development of new academic programs in HEIs, i.e., those programs in which the skills and depth capturing theory required by stakeholders and national sustainable development, and should plan an important role in program design. Quality Function Deployment (QFD) is such a methodological tool with great popularity that is used for the development of new programs and services or the improvement of existing ones. QFD is used for improving quality, reducing the number of new programs that fail to successfully enter the markets. And reduce the costs for the development of programs and services; reduce the time for design the new programs (or services) and the final program (or service) that is released to the market and improving the competitiveness of the HEIs. 
5- To introduce TQM principles and values into mainstream educational thought: Some of the founders of the quality movement, such as Deming, Juran, and Feigenbaum, have written about fundamental changes they consider necessary in educational practices. Deming went as far as advocating the abolition of the grading system, which, in his view, fosters senseless competition and stifles the basic human instinct to learn for the sake of learning.

6- To introduce TQM curricula into professional programs, such as engineering and business: TQM models describing particular TQM processes, such as team-based problem solving or statistical process control (SPC), increasingly are part of business and engineering core courses such as organizational behavior or operational management. Engineering curricula had integrated (SPC) long before the quality movement acquired high visibility.

Courses with TQM content such courses are becoming commonplace as elective undergraduate and graduate, engineering and business seminars. They usually focus on the "soft" skills (such as team-building), and / or the "hard" skills (statistical process control) needed for TQM implementation.

7- Use the Practical, Robust Implementation and Sustainability Model (PRISM): Although numerous studies address the efficacy and effectiveness of health interventions, less research addresses successfully implementing and sustaining interventions. As long as efficacy and effectiveness trials are considered complete without considering implementation in non-research settings, the HEIs of the original investments will not be realized. A barrier to progress is the absence of a practical, robust model (PRISM) to help identify the factors that need to be considered and addressed and how to measure success

A conceptual framework for improving practice is needed to integrate the key features for successful program design, predictors of implementation and diffusion, and appropriate outcome measures.

Developing PRISM: A comprehensive model for translating research into practice was developed using concepts from the areas of quality improvement, chronic care, the diffusion of innovations, and measures of the population-based effectiveness of translation. PRISM - the Practical, Robust Implementation and Sustainability Model — evaluates how the health care program or intervention interacts with the recipients to influence program adoption, implementation, maintenance, reach, and effectiveness (Feldstein, and Glasgow, 2008).

A campus-wide continuous improvement process that uses an interactive special programme outcomes, that:

(a) An ability to apply knowledge of all sciences,

(b) An ability to design and conduct experiments, as well as to analyze and interpret data,

(c) An ability to design a system, component, or process to meet desired needs,

(d) An ability to function on multi-disciplinary teams,

(e) An ability to identify, formulates, and solves learning and researching problems,

(f) An understanding of professional and ethical responsibility,

(g) An ability to communicate between the academics units inside and outside the HEIs effectively, 
(h) A recognition the needs for, and an ability to engage in life-long learning, researching, and servicing,

(j) A knowledge a tackling the contemporary issues,

(k) An ability to use the techniques, skills, and modern learning tools necessary for teaching practice.

\section{CHAPTER SIX: ACCREDITATION AND CRITERIA-BASED}

\section{EVALUATION SYSTEMS IN HEIS}

6.1- Introduction to Criteria-Based Evaluation System

6.1.1-Relationship Criteria to Academics' Programs

6.1.2-Continuous Assessment-Features and Purpose

6.2- The Concept of Education Assessment Criteria

\section{3- PROGRAMS EVALUATION SYSTEM}

6.2.1- Curriculum Evaluation

6.2.2- Course Evaluation

6.2.3- Subject Evaluation

6.3- Learning Outcomes

6.4- Faculties' Evaluation 
6.4.1- Peer-to-Peer Assessment

6.4.1- Students Assessments

6.5- Infrastructure Evaluation

6.5.1- Information Communication Technology

6.5.1- Labs Evaluation

6.5.3- Library Evaluation

\section{CHAPTER SIX: ACCREDITATION AND CRITERIA-BASED} EVALUATION SYSTEMS IN HEIS

The Higher Education Institution's Board (HEIB) may have initiated several measures to bring equity, efficiency and excellence in the Higher Education System of country. The important measures taken to enhance academic standards and quality in higher education include innovation and improvements in curriculum, teaching-learning processes, examination and evaluation systems, besides governance and other matters. So, the purpose of this chapter is an attempt to identify quality evaluation through which the education quality performance concerning TQM implementation in a higher education context could be measured from internal academic and administrative management perspectives. 


\section{1- INTRODUCTION to CRITERIA-BASED EVALUATION SYSTEM:}

The Higher Education Institution's Board (HEIB) has a fully responsibilities to formulate various regulations and guidelines from time to time to improve the higher education system and maintain minimum standards and quality across the higher educational institutions. While the HEIs must have the flexibility and freedom in designing the examination and evaluation methods that best fits the curriculum, syllabi and teachinglearning methods, there is a need to devise a sensible system for awarding the grades based on the performance of students. Presently the performance of the students is reported using the conventional system of marks secured in the examinations. The conversion from marks to letter grades and the letter grades used vary widely across the HEIs all over the world. This creates difficulty for the academia (especially for graduate levels, such like M.Sc. and Ph.D) and the employers to understand and infer the performance of the students graduating from different HEIs based on grades.

Evaluation system in higher education institutions should be focus on the individual learner, a course an academic program and the institution. Evaluation embedded at the course level (sometimes referred to as embedded assessment or authentic assessment) typically involves the use of assignments. Students receive feedback on their performance on tests and assignments and faculty gain knowledge of student learning to use for grading. (Based on FINEEC, 2016)

Assessment criteria are descriptive statements that provide learners and instructors with information about the qualities, characteristics, and aspects of a given learning task. However, the assessment criteria make it clear to learners what they are expected to do, to demonstrate achievement of the learning outcomes and factors instructors will take into account when making judgments about their performance. Sharing assessment criteria with students at the beginning of the course is an effective way to help students build confidence in their learning and improve their performance. Making assessment criteria explicit helps them recognize what is important and valued in the curriculum. Also, focus their efforts on key learning outcomes and evaluate their own performance through self-assessment and reflection. Assessment criteria are a way to provide formative feedback throughout a course to support ongoing learning, as well as to provide end-of-term summative evaluation.

Assessment criteria take the "guess-work" out of grading for instructors and students. Well-defined assessment criteria allow instructors to evaluate learners' work more openly, consistently and objectively. This increases a sense of fairness from the students' perspective and makes it easy for the instructor to explain / justify how marks have been awarded. An example for assessment criteria are: (Bingham, 2002)

- Create a students' assessments plan design brief that incorporates design process and principles

- Analyze assessment distributions using probability and data analysis techniques

- Use tools and models to integrate quantitative and qualitative information in problembased analysis using relevant tools and models

- Adopt a variety of roles on a consulting team task force

- Justify management's actions in selecting specific recommendations among alternative possibilities. 
The importance of evaluation is helping to ensure that objectives are met, identifying successes, problems and weakness so they can be rectified, and providing information to aid further development. According to Wikipedia (en.wikipedia.org) Evaluation is a systematic determination of a subject's merit, worth and significance, using criteria governed by a set of standards. The perspectives of evaluation are:

1. Activities.

2. Characteristics.

3. Outcomes.

4. The making of judgments on a program.

5. Improving its effectiveness,

6. Informed programming decisions.

The main types of evaluation are process, impact, outcome and summative evaluation. Before instructors are able to measure the effectiveness of their project, they need to determine if the project is being run as intended and if it is reaching the intended audience (mypeer.org.au). To evaluate is defined as to judge the value or worth of someone or something. An example of evaluate is when a instructor reviews a paper in order to give it a grade. To draw conclusions from examining; to assess, it could be taken much time to evaluate the material gathered in the survey

(www.yourdictionary.com).An example, findings show principals collect ongoing observational data of instructors' instruction and consider all instructor observations when evaluating instructor performance. Additionally, principals consider instructors' efforts at improving their practice when evaluating instructor performance. Strong instructor evaluation systems, when paired with supports and incentives, are designed to do the following: (www.frontlineeducation.com.)

(1) Provide a more valid measure of instructor (teacher) quality by distinguishing between instructors (teachers) at different performance levels;

(2) Recognize strong instructors (teachers) and keep them in the classroom;

(3) Encourage consistently.

\subsection{1-Relationship Criteria to Academics' Programs:}

Before design the assessment criteria it is important to understand how assessment criteria relate to course design. The following diagram (Figure 6.1) illustrates how assessment criteria both inform and is inform by learning outcomes.

Figure (6.1) Planning an academic unit of study ((Bingham, 2002)

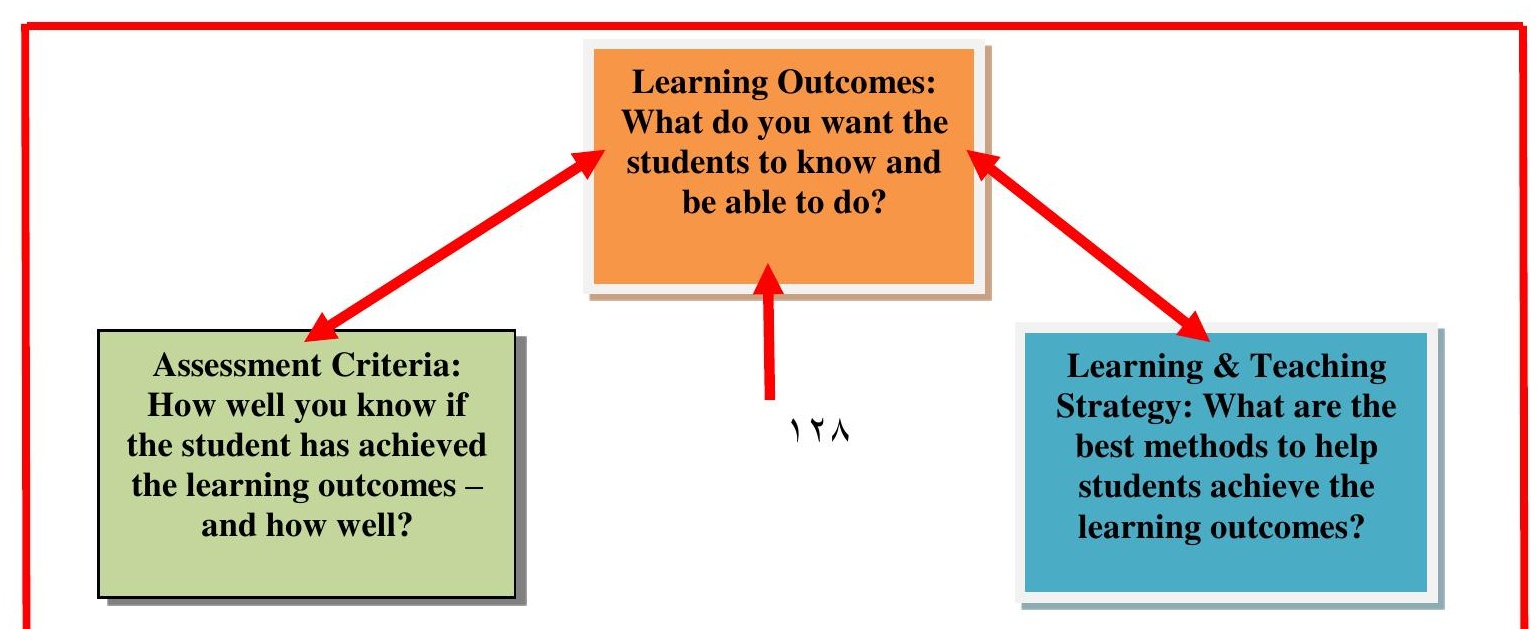




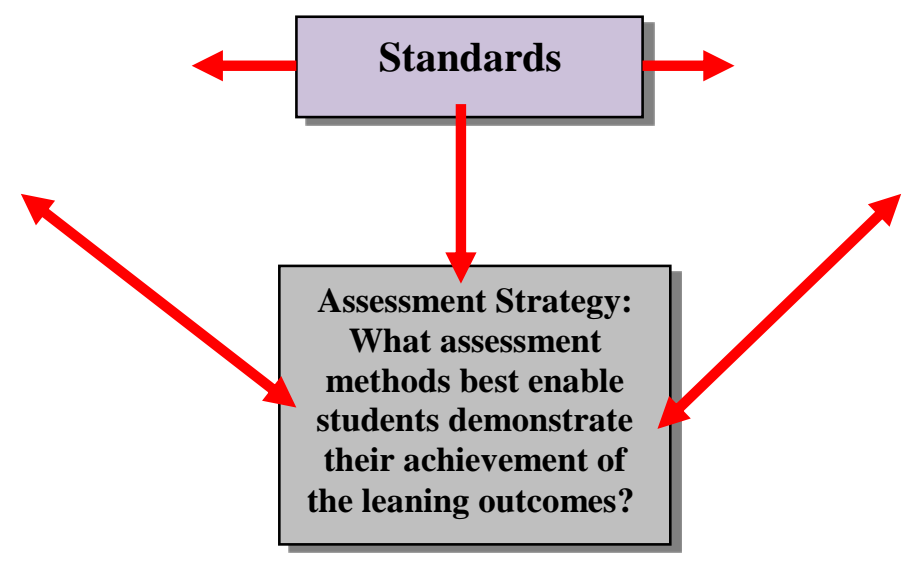

However, the academics units have to define the interrelated focus areas regarding evaluation, with the mutual goals of foresight and impact. These areas are (FINEEC, 2016): 1. Developing learning and competence with evaluation. Evaluations implemented with different enhancement- led methods aim at improving learning results and competence at all educational levels.

2. Functionality and development of the educational system. Evaluation activities that cover all educational levels provide information on the functionality of the entire educational system and policy. The evidence-based evaluation information forms a basis for development work. Evaluations are also targeted at the educational level boundaries and various transition phases.

3. Themes which are central and critical in the society. Evaluations are targeted at societal important and critical themes. Based on an analysis of the changes in the operating environment, significant development targets in education may be raised for evaluation.

4. Supporting education providers in quality management and in strengthening an operating culture based on enhancement-led evaluation. The Higher Education Institution Board (HEIB) should supports academics' units in developing quality management by evaluating their quality systems and producing information on good practices in quality management and development, as well as by spreading the information across different educational levels.

Meanwhile, the academics' unit should checked to ensure that course learning outcomes are carefully constructed to clearly articulate what students will know, be able to do, and value at the end of an educational experience. Also, check to ensure that assessment tasks are designed to provide adequate opportunity for students to demonstrate that they've achieved the intended learning outcomes and are constructively aligned with the learning outcomes, learning opportunities, and assessment method.

The evaluations are based on an enhancement-led evaluation approach. Enhancement-led evaluation emphasises participation as well as trust between the party implementing the evaluation and evaluation participant. Also based between responsibility of education providers (government agencies and stakeholders), and higher education institutions (HEIs) in enhancing the quality of their operations. The evaluations are organised with the purpose to: 
1. Support the local, regional and national development and decision-making with regard to both the evaluation processes and the evaluation results;

2. Improve the quality of education, the learning of the students and the work of the teaching staff; and

3. Promote the attainment of the goals set for the renewal of the educational system and enhance the monitoring of the development of learning results.

However, the alignment of assessment with other features of a course is the basis of course design and central to effective assessment. The model shown in Figure (6.2) summarises the relationships. If the aims are unclear then the system crumbles. Clear and realistic outcomes provide students with a good guide to what has to be learnt and instructors with a guide on how to teach and what learning opportunities to provide. Relevant learning opportunities help students to achieve the learning outcomes. Effective assessment methods and tasks are related to the learning outcomes and the methods of learning. If the criteria are too fuzzy or unduly specific then it is difficult for assessors to ensure consistency of judgement and for students to fulfil the demands of the assessment task. Without close links between feedback, criteria and the assessment tasks, lecturers cannot help students to achieve the learning outcomes of a course or a programme. (Based on Brown, 2001)

However, the model is not as simple as it appears. It leaves open the questions of whether the outcomes that are being assessed should be those of the degree program or those of the module (or short course) and whether every learning outcome should be assessed. Although informal, verbal feedback is an on-going part of any teaching and learning situation, most educators become aware of feedback when they are assessing students' work. Assessment feedback is usually written, rather than verbal and is therefore accessible to a wider audience (including colleagues and inspectors/evaluators). In addition, many institutions have formal mechanisms for monitoring feedback. Knowing that the words that write about a student's work may themselves be assessed by someone else can be quite daunting but it does serve to focus the mind very clearly when composing assessment feedback.

Figure (6.2): The aligning assessment (Brown, 2001)

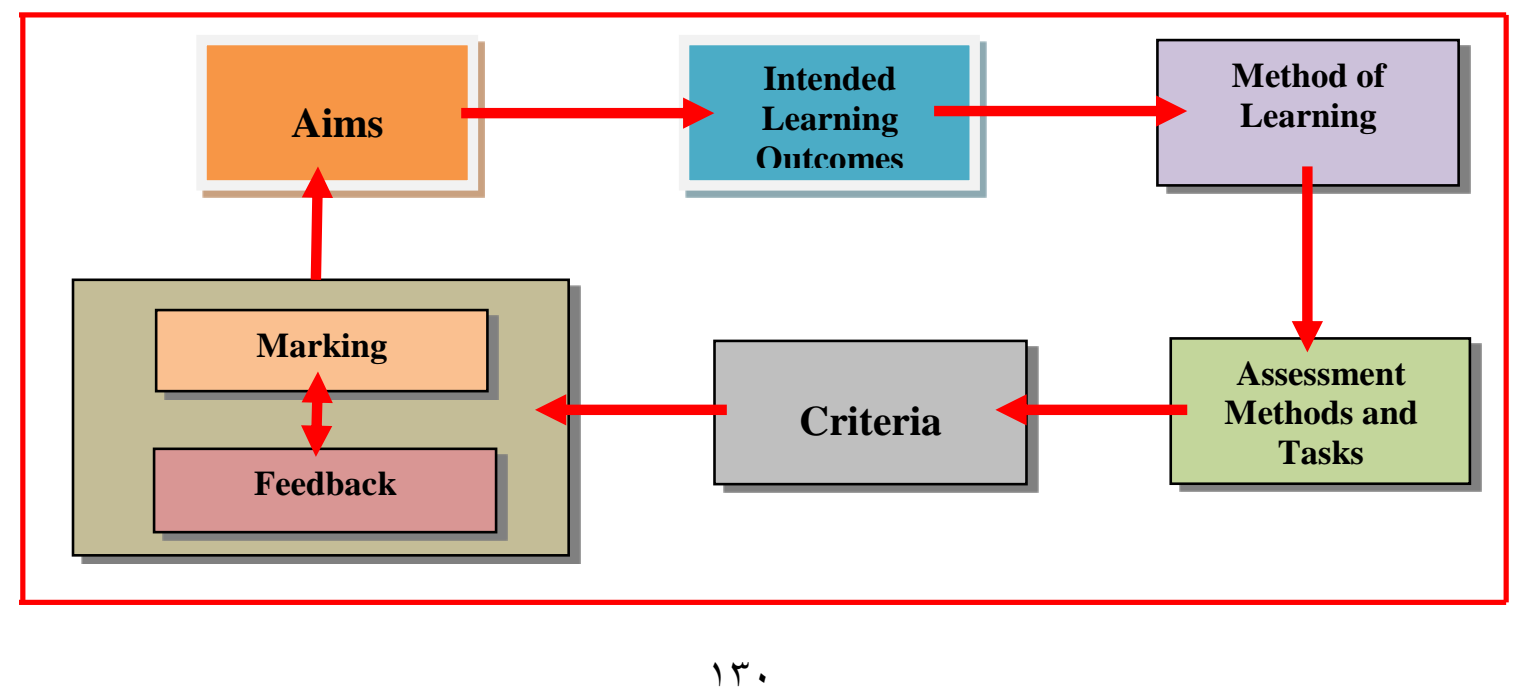


There are two main purposes of assessment:

1. Evaluation of student learning against some pre-set, possibly external standard often at or near the end of a course of study (summative assessment)

2. Discovery of student strengths and weaknesses during the course of study, with a view to guiding and enhancing learning (formative assessment).

Assessment can only serve the latter function if feedback is provided as well as (or instead of) a grade or mark. Most higher education courses contain both elements and single assessment exercises may fulfill both functions.

\subsection{2- Continuous Assessment-Features and Purpose:}

Continuous assessment is as the name suggests continuous and frequent analysis of the learning performance. Moreover, this method is more of a tool, considering the increase in the need for constantly assessing students. Further, it also proves to be a technique of performance assessment that many higher educational institutes adopt. (Based on Shukla, 2019)

Continuous Assessment or Comprehensive Analysis: Testing students on the basis of knowledge that they acquire from classes, books, and videos are not sufficient. Many times, students are excellent when it comes to studying the course out of a well-written book. However, the challenge lies in testing the student on something more. This is often in relation to the program curriculum and the course.

If a student is able to score excellent grades in a written test or a viva, this is great! However, it does not show how the student is able to differentiate themselves with others. In order to be able to test the student on various skills, continuous assessment is crucial. Also students may have proved that they can burn the midnight oil and get their grades. But this does not showcase the knowledge that they have acquired over a period of time from the course. Therefore, continuously and regularly assessing and testing their performance on the various parameter is critical.

Features of Continuous Assessment: There are certain characteristic features of continuous assessment that makes it different from the mainstream tests. They are as follows. (Shukla, 2019)

- They are regular and frequent in nature.

- Also, cntinuous assessment can either be an intensive tool or a relaxed yet efficient technique.

- They focus primarily on the course module and ensure that they are treated as regular feedback.

- Moreover, the form of the continuous assessment can be different than usual, considering the final objectives.

- The continuous assessment technique is an effective instrument to determine and develop competencies. 
- This method is comprehensive, cumulative, diagnostic, formative, guidance-oriented and systematic in nature.

Purpose of Continuous Assessment: There are three main and primary purposes for continuous assessment:

1- Enhancing the student's learning. Continuous and comprehensive assessment of the knowledge that the student acquires during the course of the module is very important. Moreover, this ensures that the student invests considerable time in studying, preparing and building on academic skills. This also ensures that the students are in constant touch with the curriculum and all that it has to offer. A constant, continuous and regular assessment of student performance and learning is the key to building a competent and skilled prospective workforce.

2- Improving the faculty's teaching skills. The pressure of continuous assessment can ensure optimum performance of the instructors as well. Let's say that a particular curriculum only has one final examination for (100) marks at the end of its course. In this case, the students, as well as the instructors, will find the necessity to consistently perform throughout the term and not only towards the end of the course, making it a great performance improviser.

3- Improving the education and institutional assessment system. An education system that understands the importance of comprehensive assessment is great. Not only does this kind of system portray development but also shows how serious they are when it comes to providing opportunities and student performance.

Finally, the benefits of the continuous assessment are as follows:

- Increasing sense of feeling inclusive

- Early indicator of student performance

- They provide a higher and qualitative learning standards for students

\subsection{3- Learning, Teaching, \& Research Model:}

The Learning, Teaching, and Research Model (LTRM), updated in 2019, are a cornerstone of many leading higher education institutions worldwide success. The institutions aim to provide learning; teaching and research. This will help people transform careers and lives by solving problems and creating opportunities in the world. As set out producing citizens of the world who are passionate, determined and confident lifelong learners, integrated into a broad network of like-minded learners, and who can confidently manage and resolve complex, real-life problems.

This updated Learning Teaching and Research Model (LTRM) offers a snapshot of the values, worldviews, attributes and practices that reflect and shape the unique learning environment, culture, practice and service. This LTRM can be distilled to three core categories of values that express what our faculty, academic staff, students-learners, alumni (graduated students), advisory councils and other community members perceive as 
unique and forward-thinking in our work: applied and authentic, caring and communitybased, and transformational. The Figure (6.) illustrates the LTRM Model (RRU, 2019).

Figure (6.3) LTRM Model

\begin{tabular}{|c|c|c|}
\hline $\begin{array}{l}\text { Applied \& Authentic: } \\
\text { *Interdisciplinary \& } \\
\text { Transdisciplinary } \\
\text { * Experiential \& } \\
\text { Participatory } \\
\text { * Flexible \& } \\
\text { Individualized } \\
\text { * Outcomes-based } \\
\text { * Openly Practiced }\end{array}$ & $\begin{array}{l}\text { Caring \& Community- } \\
\text { Based: } \\
\text { * Inclusive \& Diverse } \\
\text { * Community-based } \\
\text { Learning } \\
\text { * Supportive } \\
\text { * Team-Based } \\
\text { * Co-Creative } \\
\text { *Place-and virtual space- } \\
\text { Based }\end{array}$ & $\begin{array}{l}\text { Transformational: } \\
* \text { Social Innovative } \\
\text { * Respectful of Gender, } \\
\text { Minorities } \\
\text { * Impactful } \\
\text { * Reflective } \\
\text { * Others }\end{array}$ \\
\hline
\end{tabular}

\section{2- The CONCEPT of EDUCATION ASSESSMENT CRITERIA}

According to Bingham (2002) the aassessment criteria usually include two components-criterion and performance standards. Criterion is a property or characteristic by which the quality of something may be judged but make no statement or assumptions about actual quality. Standards are about definite levels of quality or achievement, or performance. The definition of assessment criteria is the statements specifying the standards that must be met and the evidence that will be gathered to demonstrate the achievement of learning outcomes. They should describe what the learner is expected to do to show that the learning outcome has been achieved.

Assessment criteria are statements specifying the standards that must be met and the evidence that will be gathered to demonstrate the achievement of learning outcomes. The purpose of assessment criteria is to establish clear and unambiguous standards of achievement for each learning outcome. They should describe what the learner is expected to do to show that the learning outcome has been achieved. They should not, however, be confused with the actual assessment tasks. Rather, the assessment criteria specify how the task will be evaluated. (This material based on Brown, 2001)

There are three broad types of assessment criteria:

1- Threshold standards tell the learner what must be done in order to demonstrate achievement of the learning outcomes of the unit i.e. what is the minimum requirement for passing this unit.

2- Grading criteria provide a general description of the standard required for achievement of each pre-established grade, marking band or degree classification i.e. an example first class honours award requires (80\%) or more, an upper second requires (70\%-79\%), etc.

3- General criteria provide general outcome descriptors that can be achieved more or less well. Students' work will be judged to fall at a point within a performance range and marks 
are allocated accordingly. Typically, criteria of this sort are used to evaluate such things as use of referencing, accuracy of language, use of supporting evidence in drawing conclusions, quality of critical thinking, etc.

Writing assessment criteria: Many of the points to note when writing assessment criteria are the same as those for writing learning outcomes. This means clarity, unambiguity and brevity are all important and the language should be understandable by both teaching staff and students. The criteria must be measurable in a valid and reliable way and should concern themselves solely with those aspects of performance that are essential for achieving a pass or the specified grade.

The assessment criteria creation process: This process should follow:

1. Writing assessment criteria starts with a consideration of the learning outcome being tested.

2. Then this needs to be set alongside the assessment task.

3. Requirements for, or attributes of, successful performance of the task should be listed.

4. If necessary, these requirements can be placed into context of expectations at this level of learning.

5. The final criteria must focus on what is deemed essential amongst the requirements and these should be formed into clearly worded criteria.

6. These criteria need to be checked to ensure that they are reliably measurable and clear in their intention.

7. This process can be refined until a satisfactory set of assessment criteria has been created.

Assessment criteria should reflect the overall, published, aims of the program. If, for example, the course claims to prepare students for entry into a particular profession, then the achievement of the entry requirements for that profession should be specified in the assessment criteria. So, the criteria must be informed by the published learning outcomes of the module. They should not, however, merely repeat what has been stated as learning outcomes but must expand on these to make clear how and to what extent the student is expected to use particular skills or knowledge in order to meet these outcomes.

Moreover, assessment criteria should reflect the level of the module. Higher level modules will generally require more complex analytical skills and greater depth of knowledge than lower level ones. This must be reflected in the language used to write the criteria, with more descriptive verbs such as 'define' or 'describe', giving way to increasingly sophisticated analytical and critical ones such as 'compare', 'evaluate' and 'critique'. Also, the criteria must reflect the distinctive epistemological characteristics of the particular subject or discipline being assessed.

On the other hand, assessment criteria must be comparable to standards set in other institutions offering the same award. Whilst each course will have, and should retain, its distinctive individual features, the meaningfulness of any qualification depends on it 
representing the same value wherever it has been obtained. And assessment criteria need to relate to the specific requirements of the assessment task i.e. they should describe the performance required for the task set. Oral presentation criteria will be quite distinct from the criteria set for an essay or portfolio.

The way of using assessment criteria: Assessment criteria are chiefly of value in so far as they enable students to focus their learning more effectively and make the assessment process more transparent and fair. For this reason, if no other, the expected outcomes and assessment criteria for any module should be discussed with students before they are expected to undertake any assessed work. Such discussions can be facilitated using the following structure:

- Decide on the essential criteria

- Make the criteria or checklist simple to use

- Allow for brief global impressions

- Give the criteria to the students before they do the assignment

- If possible, involve them in the design of the criteria and checklist

- Encourage students to use the criteria.

The essentials of good criteria are that they:

- Match the assessment task and learning outcome

- Enable consistency of marking

- Can pinpoint areas of disagreement between assessors

- Help students to achieve the learning outcomes

- Be used to provide useful feedback to students.

Assessment methods: Critical to the success of any outcomes-based learning program is the alignment between assessment methods, assessment tasks, learning opportunities and intended learning outcomes (learning objectives). This alignment of assessment with other features of a course is the bases of course design. Effective assessment methods and tasks are related to the learning outcomes and the methods of learning. Close links between feedback, criteria and the assessment tasks enable students to achieve the learning outcomes of a course or a programme in a systematic fashion.

Accordingly, the outcomes used as the basis for assessment tasks can be either the programme or the module-level learning outcomes. A module-level learning outcome is a statement of what the student-learners is expected to be able doing on successful completion of the module to demonstrate their knowledge, understanding, skills and/or competences. Assessing every outcome of every level in every module can lead to overassessment of students. Assessing solely for program outcomes, however, risks not assessing essential knowledge and skills in sufficient detail, although it does give a framework for estimating student progression and achievement. A successful strategy is to ensure that within each module, teaching and learning opportunities are provided which 
move the students closer to the program outcomes and that some program outcomes are assessed in some of the modules so that all are covered at least once over the duration of the course.

Methods of assessment: There is a wide variety of assessment methods available to choose from. Each method has its strengths and weaknesses and some are more suited to the evaluation of certain types of learning outcomes than they are to others. A combination of different assessment methods over a course or programme will allow for the testing of a wider variety of outcome types and help sustain students' interest and engagement with the course.

The following list of assessment methods is by no means exhaustive and suggestions are listed in order of likely familiarity.

Essays: A standard method. There are several types of essays that test different styles of writing and types of thinking. They measure understanding, synthesis and evaluation, if the right questions are posed. They are relatively easy to set and grading based on impressionistic marking is fast. However, marking for feedback can be more timeconsuming. Criteria are best kept simple.

Course Projects, Group Projects and Study Report: Good all-round ability testing with potential for sampling wide range of practical, analytical and interpretative skills. Allows a wider application of knowledge, understanding and skills to real/simulated situations and provides a measure of project and time management. Group report projects can provide a measure of teamwork skills and leadership. Marking for grading can be time-consuming. Marking for feedback can be reduced through peer and self-assessment and presentations. Learning gains can be high particularly if reflective learning is part of the criteria. Variations between markers are possible but use of criteria reduces variability.

Classroom Presentations: These test preparation, understanding, and knowledge, capacity to structure, information and oral communication skills. Feedback can come from tutor, self or peers. Marking for grading based on simple criteria is fast and potentially reliable. Measures of ability to respond to questions and manage discussion could be included.

Cases and Open Problems: These have potential for measuring application of knowledge, analysis, problem-solving and evaluative skills. Short cases are relatively easy to design and mark. Design of more complex cases and their marking schemes can be challenging. Marking for grading and feedback are about the same as for essay marking.

Work based Assessment: A variety of methods is possible, including learning logs, portfolios, projects, and structured reports from supervisors or mentors. Supervisors and mentors need training in the use of criteria. Work experiences can be variable so reliability can be low. Validity is dependent upon clear learning outcomes.

Multiple Choice Questions (MCQs): A standard method. This can sample a wide range of knowledge quickly and has potential for measuring understanding, analysis, problem solving skills and evaluative skills. More demanding (MCQs) require more time to set. 
Better ones are based on case studies or research papers. It is easy to mark and analyse results so they are useful for self assessment and screening with potentially high reliability, validity and manageability. Feedback to students is fast. The danger of (MCQs) is that they often end up testing only trivial knowledge. A team of assessors, working to the same learning outcomes, can brainstorm and produce several questions in an afternoon.

Problems: A standard method. Problems have the potential for measuring application, analysis and problem solving strategies but complex problems and their marking schemes can be difficult to design. Marking for grading of easy problems is fast. Marking for feedback can be slow. Variation between markers is fairly low when based on model answers or marking schemes. Allow for creative, valid solutions by bright students.

Short Answer Questions: A standard method with the potential for measuring analysis, application of knowledge, problem-solving and evaluative skills. Easier to design than complex (MCQs) but still relatively slow. Marking to model answers is relatively fast compared with marking problems but not compared with (MCQs). Marking for feedback can be relatively fast.

Learning Logs/ diaries: A wide variety of formats exists ranging from an unstructured account of each day to a structured form based on tasks. Some training in reflection is recommended. They are time-consuming for students and require a high level of trust between assessors and students. Measuring reliability is difficult. They may have high validity if the structure matches learning outcomes.

Portfolios: These can come in a wide variety of types, from a collection of assignments to reflection upon critical incidents. The latter are probably the most useful for developmental purposes. There is rich potential for developing reflective learning if students are trained in these techniques but they require a high level of trust between assessors and students. Measuring reliability is difficult. They may be high on validity if the structure matches objectives of training.

Computer-based assessment: Usually software will be used to format multiple choice questions, mark and analyse results. A wider range of graphics and simulations can be used. Optical Mark readers can be used - but some students may still not mark the items clearly. They are time consuming to set but can be marked very fast. Reliability is high but validity (match with outcomes) needs careful attention. Like (MCQs), it can be difficult to go beyond and evaluation of the trivial with these.

Single Essay Examination: These are relatively easy to set but attention to criteria is needed. They allow for a wider range of ability tested including the capacity to draw on a wide range of knowledge, to synthesize and identify recurrent themes. Students are able to show depth as well as breadth of knowledge and understanding. Marking for feedback is relatively slow. Marking for grading is relatively fast providing the criteria are simple.

Reflective Practice Assignments: Measure capacity to analyse and evaluate experience in the light of theories and research evidence. These are relatively easy to set. Feedback 
can potentially come from peers, self and tutors. Marking for feedback can be slow. Marking for grading is about the same for essays. Use of criteria reduces variability.

Poster Sessions: Test the capacity to present findings and interpretations succinctly and attractively. There is a danger of focusing unduly on presentation methods over content but this can be avoided by the use of simple criteria. Feedback potential exists from tutor, self and peers. Marking for grading is fast. Use of criteria reduces variability.

Modified Essay Questions (MEQs): these are a sequence of questions based on a case study. After students have answered one question, further information and a question are given. The procedure continues, usually for about one hour. These are relatively easy to set and they may be used in teaching or assessment for developmental or judgmental purposes. They can be computer-or paper-based and they can encourage reflection and analysis. MEQs have potentially high reliability, validity and manageability.

Orals: Test communication, understanding, capacity to think quickly under pressure and knowledge of procedures. There is great potential for immediate feedback. Marking for grading can be fast but some standardization of interview procedures is needed to ensure reliability and validity.

Simulated interviews: Useful for assessing oral communication skills and for developing ways of giving and receiving feedback on performance. Video-recorded sessions take more time to prepare but are more useful for feedback and assessment. Peer and self assessment can be used. Sensitive oral feedback on performance is advisable. Assessment by simple rating schedule or checklist is potentially reliable if assessors, including students, are trained. This technique can be used in business, legal practice, management, psychology, science courses, medical, engineering and social sciences. It is particularly useful for assessing quickly practical and communication skills.

\section{3- PROGRAMS EVALUATION SYSTEM}

The outcomes-based approach to teaching and learning is increasingly being used in higher education as the model for best practice in constructing courses and evaluating students' work. Learn more about this approach with this simple, practical guide to building academic outcomes-based programs (OBPs). Program learning outcomes PLOs) are a description of the knowledge, competencies and values a student displays at the end or/and conclusion of the program. Program learning outcomes help students understand why this knowledge and these competencies will be useful to them. On the other hand, a module learning outcome is a statement of what the learner is expected to be able to do on successful completion of the module to demonstrate their knowledge, understanding, skills and/or competences. (Brown, 2001)

The Outcomes Based-Evaluation (OBE) implementation process includes: 1- Establish Mission Statements, Program Educational Objectives (PEO).

2- Map Mission Statements with Program Educational Objectives (PEOs). 
3- Define Program Learning Outcomes (PLO).

4- Map Program Educational Objectives with (PLO).

5- Define Course Objectives (CO).

The following detailed discussions of the components of program evaluation system are discussed respectively.

Program-level assessment: Program assessment is a best practice in higher education. The process involves a framework for placing priority and attention on the process of student learning and most specifically, the program objectives, organization of curriculum, pedagogy and student development. However, a module learning outcome is a statement of what the student-learners are expected to be able to do on successful completion of the module to demonstrate their knowledge, understanding, skills and/or competences (enwikipedia.org/wiki/assessment_in_higher_education).

Ultimately, all instructors (Professors and teachers) who teach a course or offer learning activities want their students to gain specific knowledge, perform certain activities related to the discipline, or develop the sensitivities required to practice the discipline. The same applies to programs of study created and developed by professors (or team of instructors), where the higher education institutions and sequence of courses allow students to acquire knowledge, competencies and values. The program's learning outcomes are essential to the discipline as taught in a specific context. These program learning outcomes are considered necessary for students to pursue their studies at a higher level and contribute to all stakeholders' members and society in general.

Program learning outcomes are a description of the knowledge, competencies and values a student displays at the end or/and conclusion of the program. Program learning outcomes help students understand why this knowledge and these competencies will be useful to them. They highlight the context and potential applications of knowledge and competencies, help students connect their learning to various situations, and guide the selection of evaluation methods. Good learning outcomes focus on knowledge application and integration. Instead of concentrating on the material and content covered, program learning outcomes show how students can make use of the material and content, both inside and outside of the classroom (OQA, 2020).

\subsection{1- Curriculum Evaluation:}

The outcomes-based approach to course design is intended to make the expectations of the designer/instructor more transparent to both the students and any regulatory or accrediting body. Unlike the traditional model of course design in higher education, where the instructor would decide what to include on a syllabus, based on his or her own judgement of what was important for students to know; or on personal research or other interests. The outcomes-based approach starts with a specification of what the student will be expected to achieve by the end of the unit.

These learning outcomes may be of knowledge acquisition, mastery of skills, or development of attitude or ability. All the different outcomes expected will be specified in publicly shared statements and these will be linked in a clear way to explicit assessment criteria by which they will be measured. The program is then written; complete with 
assessments designed to test the criteria, in such a way as to enable students to work towards achieving the stated outcomes.

The outcomes-based approach has been developed in conjunction with programbased modular frameworks in which each unit carries a specified number of units, awarded on its successful completion. In order to achieve the desired qualification, the student must amass a given number of units, usually in stated proportions from different levels (Gosling, and Moon, 2002)

The Principles of Outcomes-based Course Design are:

1- All learning can be expressed as demonstrable outcomes to be achieved.

2- All units are described in terms of their learning outcomes and assessment criteria.

3- The type and number of learning outcomes and assessment criteria form the basis for assigning a number of units and a level to a particular unit.

4- For this reason, no unit can be assigned to more than one level.

5- Learning outcomes need to be clear and unambiguous.

6- Learning outcomes set out the necessary learning, which represents the minimum requirement for a pass grade on the unit.

7- Assessment criteria should specify how a satisfactory performance of the learning outcomes will be demonstrated.

8- Assessment criteria should be designed to ensure that learning takes place at a level appropriate to the assigned unit level.

9- Learning outcomes should contribute to the transparency of the overall qualification gained by enabling students, parents, prospective employers and other educational professionals to understand exactly what has been learned in order to achieve a passing grade.

10- This will facilitate student and graduate mobility, internationally, and in a life-long learning context.

A program can be described by a specification written in terms of program outcomes similar to the learning outcomes specified for the individual units within it. These larger outcomes are more general and they may not be specifically assessed as part of the course of study but they act as guides in establishing the ethos and direction of the program. Where the program aims for validation or accreditation to some larger standard, the program specification should reflect the requirements of that standard and make reference to available benchmarks. The Figure (6.4) shows the road map of the learning outcomes. (Brown, 2001)

The Figure (6.4): The road map of the learning outcomes. (Brown, 2001)

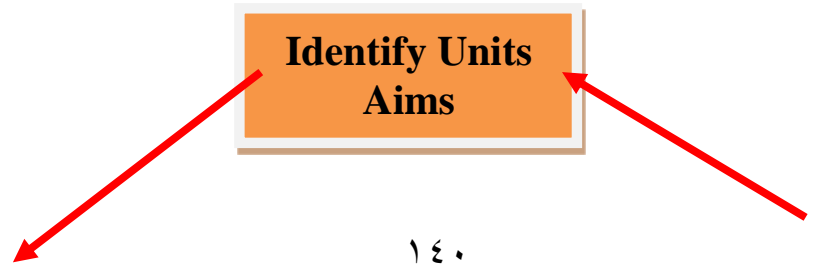




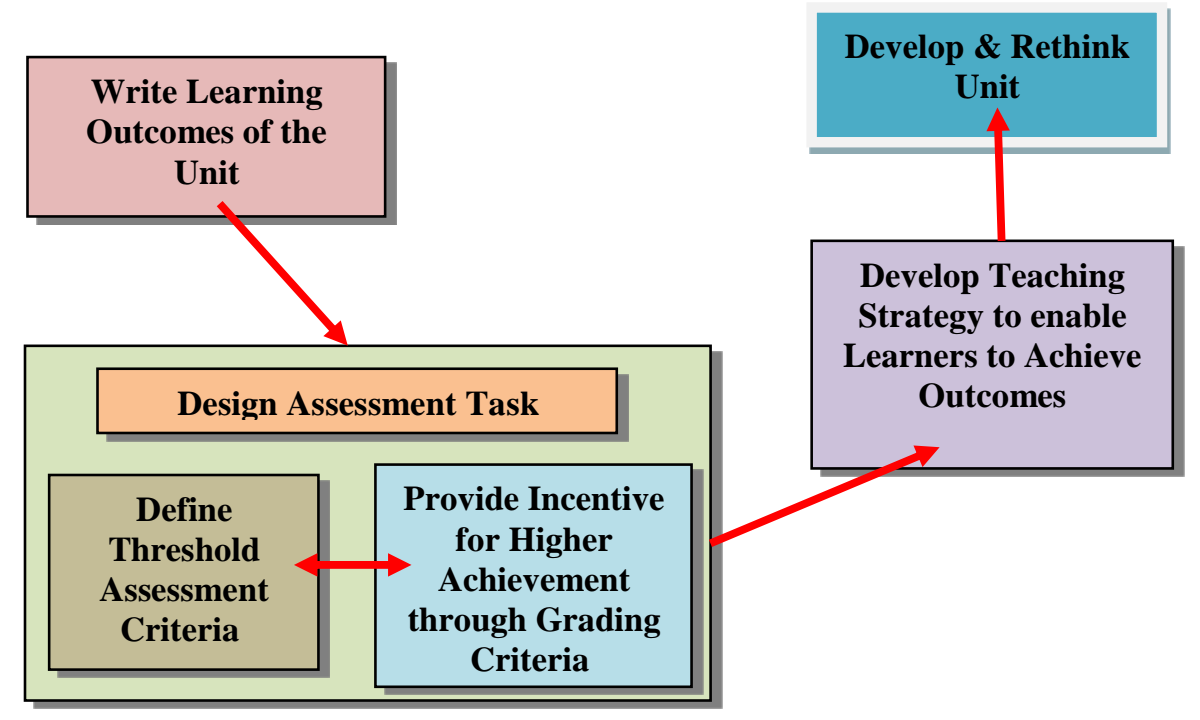

For such a model, as represented in Figure (6.4), any theory of learning can have only an effect on the translation of the program's curriculum into pedagogy. However, the stronger effect on the link between assessment and pedagogy, with assessment being used mainly as a means to diagnose the understanding of the students as individual learners. A first requirement, as have been emphasized above, is that the curriculum needs to be fashioned in terms of a model, grounded in evidence, of the paths through which learning typically proceeds as it aims for the desired targets. That is, the curriculum reflects and provides a strong model of progression in learning. This road map in Figure (6.4) may then inform both pedagogy and the assessments of steps 4 and 5. In that an articulated set of tools can be tailored to stages in progression along the road, so that such tools will help to identify the road where failure gives way to success. The assessment is seen as more valid in that it is an indicator of a student's progression in learning. Thus the first issue to be addressed is to reform the interaction between curriculum and assessment, a reform which should be strongly driven by theories of student learning as in Figure (6.4). But also its strongly influenced by the observation and interpretation of student growth as represented in the analysis of student responses assessments.

The second issue is to develop the use of the road-maps, formulated from the explorations through assessment and the interpretation of students' responses, as guides to the pedagogy. They will serve this purpose well if instructors are closely involved in the final summative judgments of their students. If instructors share responsibility for some of the tasks on which this final judgment is based, they can both match these to their own formative work. And can also influence the formulation of these tasks, and the criteria by which they are assessed, so that the results are valid in reflecting and motivating good learning practices. However, this can only be achieved if teachers are given the training in the formulation of such tasks that many will require.

Johnson, and Papageorgiou, (2010) give an account of work developed for this purpose. Instructors will also be well placed to explain the assessment regime to their 
students and to show that there is continuity between testing events and normal classroom learning. For example, as students work on an open-ended project task, instructors can ensure that it is sufficiently similar to work done previously so that they can be confident that every student understands what is expected. In addition, as students proceed with a task, a instructor can give help to any students who encounter obstacles which might prevent progress and which might thereby mean that these students will not give a full account of their capabilities. At the same time, the instructor will be in a position to allow for that extra help in making the final overall judgments.

The road-maps will underpin all of the steps. As guides they will not only help strategize the planning, whether on a macro-scale of step 1 or the micro-scale of step 2, but they will also help the actual execution in step 3 in that the flexibility required by a formative approach will draw upon the road-maps to optimize the steering along the road.

\subsection{2- Course Evaluation:}

Faculty course evaluations have the potential to affect professional and career advancement, promotion, and tenure. Few areas in higher education cause more anxiety than course evaluations and few areas have been studied more for validity and reliability. A course evaluation is a short survey conducted by an instructor at the end of a class or course of study. The evaluation form aims to collect general information on what each student liked and disliked most about the class with the goal of improving the educational experience for future students (tophat.com). Filling out a course evaluation gives head of academic department an opportunity to reflect on instructors' progress throughout the course. Filling out course evaluations in a timely manner also means the instructor gets to see his final grades as they come in.

Course evaluation forms may be created be standardized across an academic department or an entire higher educational institution. The format of the evaluation almost always conforms to the type of instruction that is being offered. For example, online forms are usually provided for web-based courses while paper copies are generally handed out during the final class for in-person coursework.

Evaluation has become an essential process for higher education institutions that are required to report to the head of academic department on the progress of initiatives and programs. Feedback is a vital part of any learning process, as much for instructors as for students. The feedback is a necessary part of the process for instructors to improve their teaching. So, there are several instruments used for course evaluation, these are (Based on Noguera, et.al, 2018):

1- Student satisfaction survey: The students' course satisfaction evaluation should be determined by an institutional survey committee consisting of dozens items divide into three roles covering four categories: overall course satisfaction, course instructor, teachinglearning resources, and type of assessment. These roles and categories listed below. However, the survey consists in statements for responses on a Likert scale of (1 to5) (labeled from 'strongly disagree' to 'strongly agree'), or (1 to 100\%) or otherwise. This survey usually is given at the end of each course.

2- Complementary survey on agile strategies: The above survey should build on agile strategies The students' perception of the usefulness of the agile method was obtained 
through a complementary survey comprising the group of items covering three categories: agile strategies for team regulation (e.g., meetings, roles), agile strategies for project management (e.g., work cycles, task lists), and acquired knowledge of the agile method.

3- Teacher interviews: The instructor's perspective also will collect through two semistructured interviews consisting of questions regarding his experience in designing and guiding an agile-based course. The first interview will conduct at the end of the first semester of academic year, and the second at the end of the second semester of academic year, respectively. The results of the interviews will be use to respond to all questions.

4- Marks: The marks from the semesters during which the agile survey will implement and the marks from the two previous semesters will contrast in order to explore whether or not there were significant differences in the learning outcomes. The data were used to answer the questions, which is a student's final mark in the course was determined by a weighted average of the marks that instructor will receive for each assessment activity. Grades ranged from A (Excellent) to D (Fail).

5- Data collection process: Students complete the surveys anonymously online. The institutional survey was given at the end of both semesters.

6- Data analysis: The research questions were answered by examining the data from the institutional survey, the complementary survey, the interviews and the students' marks. A deductive approach will implement for data analysis. The research questions were used to group the data and detect the main findings. Data were collected on the basis of the reports that instructors will receive from the academic unit management.

The procedure of running the students' course evaluation contains the following instructions: (Based on Svinicki, 2001; Donovan, et.al. 2010, and Noguera, et.al, 2018)

Role One: Keep in minds before completing course evaluation: This includes:

1- Anonymity: Your course evaluations was completely anonymous, both the numerical results and written comments. Your responses are not linked to ID number (or name). Not that this is why each evaluation must be completed in one sitting.

2- Confidentiality: The complete results are confidential to the instructor and unit head (Chair, Director, or Dean).

3- The instructor cannot see the results until the final grades for the course have been submitted and processed.

$\underline{\text { Role Two: }}$ Considerations when answering course evaluation: Questions are asked on a 5 point scale. This includes:

1 = "Strongly Disagree," 2 = "Disagree," 3 = "Neutral," 4 = "Agree," and 5= "Strongly Agree". Or otherwise.

2 -You should choose 3 = "Neutral" only when you feel that your response is between the two endpoints.

3-Choose "Not applicable" when the question is not relevant to your course or instructor. 4-You can choose which questions to answer; comments are welcomed and encouraged. 
5-While course and teaching quality are highly interdependent; the questions have been designed to explicitly address the course or the instructor. Please direct your feedback appropriately.

6-Questions about the course are only asked once when there are multiple instructors.

7-When you are providing feedback; you will be comparing the instructor to other instructors, either consciously or unconsciously. When you are comparing, remember that the comparison group should be other professors and courses at the University.

Role Three: Considerations when writing comments: Constructive feedback from students is a valuable resource for improving teaching. This includes:

1- The feedback should be specific, focused, and respectful. It should also address aspects of the course and teaching that are positive as well as those which need improvement.

Keep the following in mind when writing your comments on course evaluations:

2-Be respectful; derogatory comments or criticisms based on race, religion, gender, sexual orientation, etc. are not appropriate.

3-Be specific and provide examples when commenting on the course or the instructor. Speak based on your own experiences, not on behalf of your classmates.

4-Focus on observable behaviours of the instructor, or on specific aspects of the course and describe the situation you are commenting on.

5- Avoid personal or emotional comments instead, describe actual incidents.

6- Describe how the instructor's behaviour or elements of the course affect you.

7- Offer alternative solutions or suggestions to address your critiques of the instructor or the course, which help the instructor when planning the course for the following year.

8-To help instructors improve the course and their teaching; please provide both positive and negative comments in a constructive manner. Comments should offer specific reasons for judgment. These are very helpful as they inform the instructor of what you suggest is kept or changed. While comments regarding what needs to change may come more readily, it is just as helpful to remind the instructor about what went well.

9-If your course had Teaching Assistants; you will be given the opportunity to provide feedback to them. Please take the time to provide constructive comments about strengths and areas for improvement. Feedback early in their teaching careers will be instrumental in helping them become great teachers.

10-There are comment boxes associated with many questions; in these cases please try to target your comments to the specific issue addressed in the question. In other cases, there are Comment boxes that are more general in scope. Thinking of the following categories when completing the questionnaires may help you organize your thoughts:

\begin{tabular}{|l|l|l|}
\hline Overall (course or instructor) & Teaching strategies & Outside of classroom communications \\
\hline Clarity \& difficulty & Assignments & Personal traits \\
\hline Organization \& structure & Interest or motivation & Physical environment \\
\hline
\end{tabular}

11-Consider area of responsibility. While the instructor clearly has influence and control over many of the factors that influence the quality of a course and the teaching, in many 
instances that influence is shared with the students and/or the administrators. By thinking about who is in a position to change problem areas - or maintain successful practices-it can help you frame your comments usefully.

12-Comments about the personal traits (for example When possible, make suggestions from the student perspective as to actions that the instructor or administrators could take to help improve the situation. accent or apparent unfriendliness) of the instructor often elicit strong emotions and should be made with sensitivity. Focus your comments on behaviours that can be improved. Also, describe the impact on your learning - this will help the instructor improve the learning experience. For example: "The instructor was often sarcastic which made me not want to ask questions or participate in discussions." This makes it clear to the instructor that there is a real impact on the students' learning experience.

\section{A Template of Students' Course Evaluation:}

Instructors are supposed to be experts in learning. Although there is a lot of research on how teachers may promote student learning, the scarcity of systematic research on understanding and improving the learning processes of teachers themselves is striking. However, teachers are the most important agents in shaping education for students and in bringing about change and innovation in educational practices. Too often educational innovations have failed because they did not recognize the need for teacher learning (Bakkenes, et.al, 2010).

There is a growing awareness of the necessity of assisting instructors in their professional development. Numerous efforts are being made to enhance instructor learning, with varying degrees of success. Moreover, systematic research on teacher learning is scarce. The present study aimed to contribute to such a conceptual framework by exploring secondary school instructors' learning activities and learning outcomes in the context of educational innovation. In recent years some attention has been paid to the learning activities of experienced teachers in the workplace (Kwakman, 2003; Lohman \& Woolf, 2001; Van Eekelen, et.al. 2005).

These learning activities were, however, mostly characterized as concrete, visible activities, such as searching for information on the internet, exchanging ideas with colleagues, helping students during classroom activities, etc. The description of learning activities was not focused on teachers' thinking processes associated with their visible activities. Different teachers who are apparently engaged in the same visible activity may actually use quite different thinking processes leading to different learning outcomes. Exhaust (6.1) illustrates a template of students' course evaluation.

Exhaust (6.1): A template of students' course evaluation.

Template of students' course evaluation: (Course' Title)

Please choose the best answer for each of the following. 
The textbook was relevant and useful

The textbook was used on a regular basis

The course description accurately described the course content

Exams were based on material covered in assignments and lectures

I was academically prepared for this course

The instructor was qualified to teach this course

The class size was appropriate

The course increased my knowledge of the subject matter

The course increased my interest in the subject matter

I would recommend this course to other students

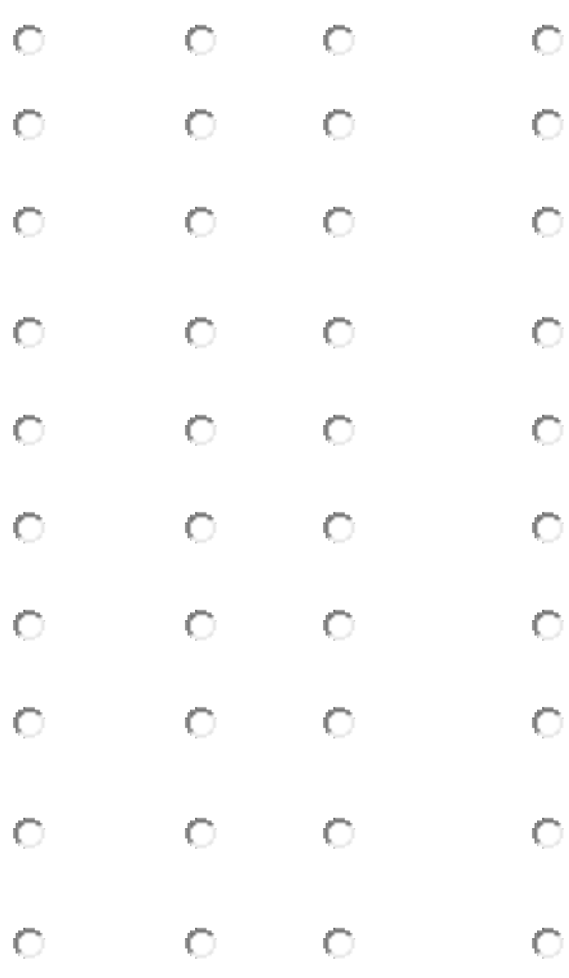

How would you rate the overall intellectual challenge of this course?

$$
\checkmark \text { Very Easy }{ }^{\circ} \text { Easy } C \text { Average } C \text { Difficult }{ }^{\circ} \text { Very Difficult }
$$

What did you most like about this course?

What did you least like about this course?

General Comments:

\section{4- LEARNING OUTCOMES:}

Let us first define the learning outcomes, which are statements referring to the specific knowledge, practical skills, areas of professional development, attitudes, or higherorder thinking skills that instructors expect students to develop, learn, or master by the end of their learning. On other words, learning outcomes are statements that describe the knowledge or skills students should acquire by the end of a particular assignment, class, course, or program, and help students understand why that knowledge and those skills will be useful to them. Figure (6.5) illustrates the general view of learning outcomes (Suskie, 2009).

Figure (6.5): The general view of learning outcomes

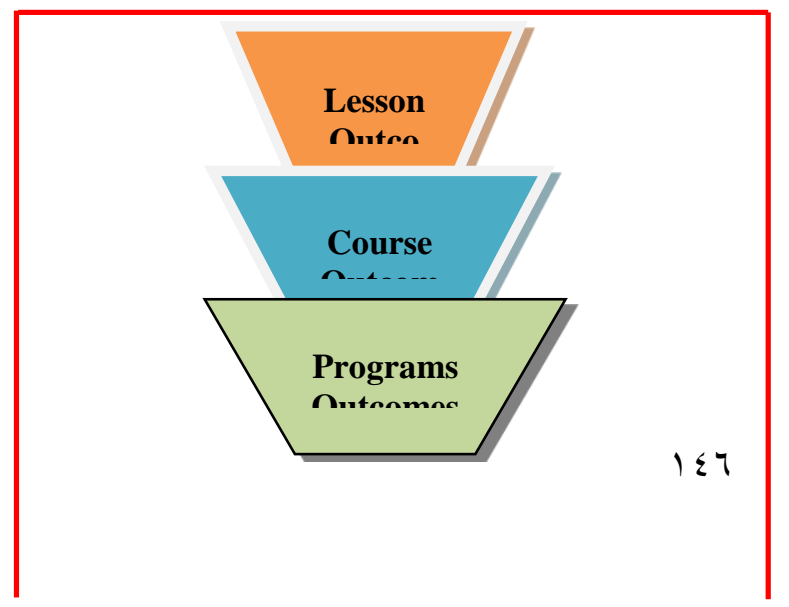




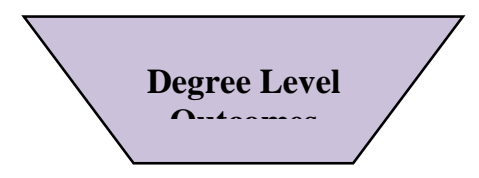

Learning outcomes typically include the following elements:

- A short and consistent stem such as "By the end of this course/program, successful students will be able to..."

- An action verb that identifies the depth of learning expected.

- A statement of the learning to be demonstrated - addressing the what.

- A statement of the context in which this learning will occur - addressing the how? Or why?

The following exhibit (6.2) illustrates the above elements.

The Exhibit (6.2) illustrates the above elements.

\begin{tabular}{|l|l|}
\hline \multicolumn{2}{|c|}{ Learning Outcomes } \\
\hline STEM & By the end of this lesson, students will able to .. \\
\hline ACTION VERB & Describe \\
\hline LEARNING & $\begin{array}{l}\text { The relationship between form and function of the } \\
\text { program curriculum }\end{array}$ \\
\hline CONTEXT & In an oral presentation \\
\hline
\end{tabular}

Important Considerations: In selecting an action verb, consider the most appropriate type of performance, whether it is in the cognitive, behavioral, or affective domain for your students. Also consider the type of performance that students are expected to reach by the end of their learning. For assistance with this, we recommend taxonomies of learning, such as Bloom's, and associated verbs:

Verb for Learning Outcomes: It is also important to consider how learning is demonstrated, using concrete actionable or operational verbs (such as create, apply, interpret, describe, identify) rather than verbs that are difficult to measure (such as know, learn, become aware of, experience).

The Importance of Communicate to Students: Students' learning is enhanced when they know what is expected of them. When learning outcomes are communicated to students, they are more likely to take deep approaches to learning and tend to hold more favourable perceptions of their courses and instructors. However, helping students reach learning outcomes takes more than simply listing those outcomes in your syllabus (Schoepp, 2017).

Learning outcomes are most influential when students can see the connection between intended course outcomes and course requirements (i.e. activities and assessments). Consider taking one of the following approaches for making this connection clear:

- list course outcomes and assignments side-by-side to show how each outcome is to be demonstrated

- include a paragraph in your syllabus that articulates how students will work towards the learning outcomes

- explain the course's learning outcomes to students on the first day of class 
- revisit learning outcomes regularly throughout the course to show students how course concepts connect to one another

According to the above discussions, the elements of the Creativity, Activity, Service (CAS) learning outcomes are:

1-Strength \& growth: Students are able to see themselves as individuals with various skills and abilities, some more developed than others, and understand that they can make choices about how they wish to move forward.

2- Challenge \& skills: A new challenge may be an unfamiliar experience or an extension of an existing one. The newly acquired or developed skills may be shown through experiences that the student has not previously undertaken or through increased expertise in an established area.

3-Initiative \& planning: Students articulate the stages from conceiving an idea to executing a plan for a CAS experience or series of CAS experiences. This may be accomplished in collaboration with other participants. Students may show their knowledge and awareness by building on a previous experience, or by launching a new idea or process. 4-Working collaboratively with others: Collaboration here means the volunteering job by students, can be shown in many different activities, such as team sports, playing music in a band, or helping in a kindergarten. At least one project, involving collaboration and the integration of at least two of creativity, action and service, is required.

5- Showing perseverance and commitment: Students demonstrate regular involvement and active engagement in CAS activities, and accept a share of the responsibility for dealing with problems that arise in the course of activities.

6- Global engagement: Students are able to identify and demonstrate their understanding of global issues, make responsible decisions, and take appropriate action in response to the issue either locally, nationally or internationally (for example, environmental concerns, caring for the elderly).

7- Recognize and consider the ethics of choices and actions: Students show awareness of the consequences of choices and actions in planning and carrying out CAS experiences. Ethical decisions arise in almost any CAS activity (for example, on the sports field, in musical composition, in relationships with others involved in service activities).

The important note: All seven outcomes must be present for a student to complete the CAS requirement. Some outcomes may be demonstrated many times, in a variety of activities, but completion requires only that there is some evidence for every event and each outcome.

\subsection{1- Method Course Design:}

Always there is a need to consider the mechanism of course design. So, curriculum conversations will occur across faculties and departments as part of a larger movement toward aligning program outcomes, assessments, and courses. Using a course design process that helps align course outcomes, assessments, and teaching and learning strategies not only helps you, as the instructor, to clearly map out the key ideas in a course, but it will help you to address the following three questions that are the basis of good course design:(Biggs ,2003).

1. What do I want students to know?

2. How will I know that they have learned it? 
3. What techniques/resources will I use to share information?

Your responses to these questions are also important to students. The academic units spend huge amounts of time crafting what they believe to be a suitable course syllabus to present to students in the first class of the semester. However, the information that students want to know - What will I learn?; How will I be assessed?; and What will we be doing in class? - is also contained in those three questions. Good course design begins with considerations of outcomes (what will students know and be able to do), Assessment (how will I know that they have learned it), and Teaching Strategies (what techniques/resources will I use to share information). This notion of Constructive Alignment was forwarded by Biggs (2003) as shown in Figure (6.6).

What do I want students to know? In designing a cohesive course, begin at the top of the triangle with outcomes $\sim$ what is it that students will know and be able to do as a result of learning in your course? In order to not become mired in the myriad detail of content knowledge, it is helpful to think of meeting a student in the future. What key concepts would you hope that they would recall from your course years later? These ideas become the Enduring Understandings (Wiggins \& McTighe, 2005), "statements summarizing important ideas and core processes that are central to a discipline and have lasting value beyond the classroom".

Enduring understandings:

- Frame the big ideas that give meaning and lasting importance to such discrete curriculum elements as facts and skills.

- Can transfer to other fields as well as life beyond the classroom

- Help "unpack" areas of the curriculum where students may struggle to gain understanding or demonstrate misunderstandings and misconceptions

- Provide a conceptual foundation for studying the content area.

Figure (6.6) Constructive curriculum alignment

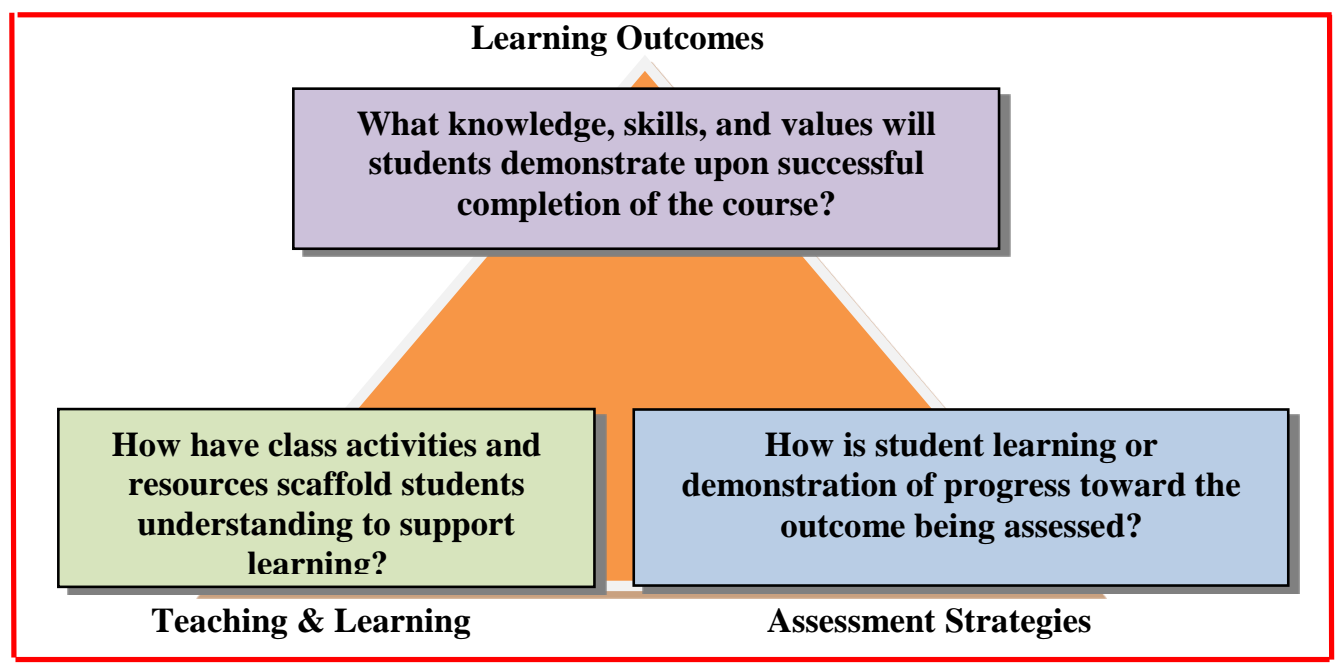

Enduring Understandings are BIG IDEAS and must be broken down into key or "Essential Questions" around which your course can be framed. McTighe and Wiggins 
(2013) explain the relationship between enduring understandings (Big Ideas) and essential questions in this way:

"If the content that you are expected to teach represents "answers", then what questions were asked by the people who came up with those answers? This conceptual move offers a useful strategy both for seeing a link between content, and important questions, and for coming up with ways of engaging students in the very kind of thinking that is required to understand the content... The questions thus serve as doorways or lenses through which learners can better see and explore the key concepts, themes, theories, issues, and problems that reside within the content."

To illustrate the relationship between the two, here are sample of questions from a number of disciplines of Enduring Understandings and Essential Questions illustrate in Exhibit (6.3) that have been adapted from McTighe and Wiggins (2013).

Exhibit (6.3) Sample of questions

\begin{tabular}{|l|l|}
\hline Enduring Understanding (Big Idea) & Essentials Questions \\
\hline $\begin{array}{l}\text { The geography, climate, and natural resources of a region } \\
\text { influence the economy and lifestyle of the people living in the } \\
\text { area. }\end{array}$ & $\begin{array}{l}\text { How does where you live } \\
\text { influence how you live? }\end{array}$ \\
\hline $\begin{array}{l}\text { Statistical analysis and data display often reveal patterns. } \\
\text { Patterns enable prediction. }\end{array}$ & $\begin{array}{l}\text { What will happen next? } \\
\text { How certain are you? }\end{array}$ \\
\hline
\end{tabular}

Essential Questions become course outcomes: When you have determined the several essential questions that are addressed in your course, the next step is to change these questions into outcome statements. Nilson (2010) asserts that an "outcomes-centred course design guarantees a high level of student engagement because the process steers you toward student-active teaching strategies". A learning outcome is a statement of exactly what your students should know, value, or be able to do after completing your course, or at specified times during your course. An outcome consists of three parts: a statement of performance, a statement of conditions for the performance, and the criteria and standards for assessing the performance. It may guide your thinking to consider frameworks that are arranged as taxonomies of cognitive operations from lower order (knowledge) to higher order (synthesis/evaluation). Outcomes that are written using a higher order verb (critique, defend, construct, design, validate) expect students to demonstrate their knowledge using more sophisticated means. In turn, your assessment tools and classroom teaching and learning strategies must support and enable these demonstrations of learning. Exhibit (6.4) illustrates Bloom's Taxonomy staircase indicating the cognitive levels and corresponding activities. Exhibit (6.4) Bloom's Taxonomy staircase (Adapted from Nilson, 2010) 


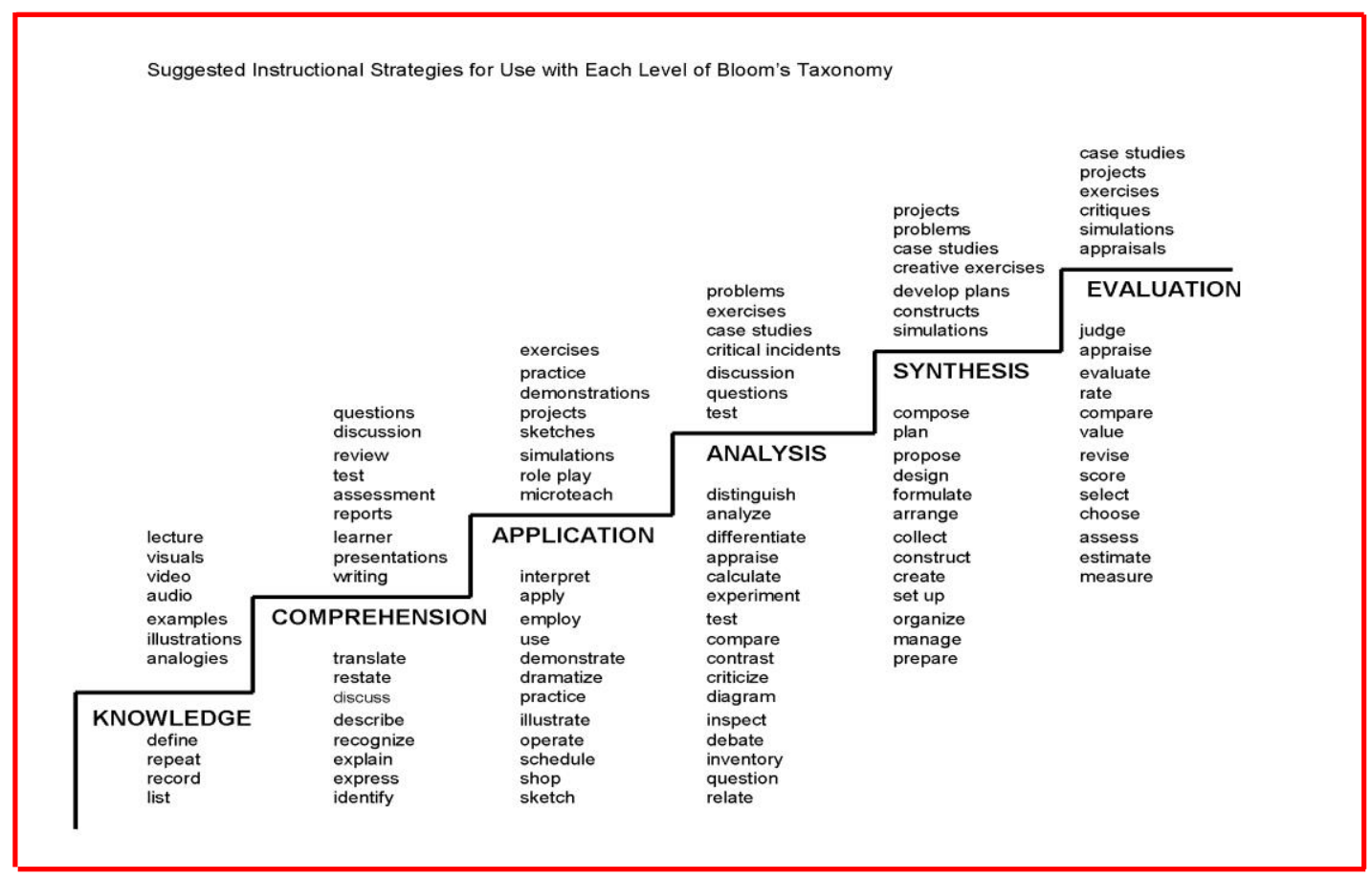

Finally, when creating course outcomes, it's important to remember the followings: 1- Outcomes must be observable and measurable - that is the instructor can observe (see or hear) and evaluate each learner's performance according to a standard (e.g., how well, how many, or to what degree).

2-Most outcomes require high degrees of cognition according to Bloom's taxonomy.

3-Outcomes must be achievable for students given the length of the course, the number of course hours, and the level of scaffolding provided through classroom instruction and activities.

4-Course outcomes are related to the essential questions and are therefore relevant to the course and meaningful to students.

\subsection{2- Course Learning Outcomes:}

Course Learning Outcomes (CLOs) are central to your course's curriculum. They articulate to students, faculty, and other stakeholders what students will achieve in each course and how their learning will be measured. According to previous point (6.4.1), a course learning outcome (CLO) is a measurable, observable, and specific statement that clearly indicates what a student should know and be able to do as a result of learning. Wellwritten course learning outcomes involve the following parts as shown in Figure (6.7):

- Action verb

- Subject content

- Level of achievement

- Condition of performance (if applicable)

Figure (6.7) the steps of well-written course learning outcomes

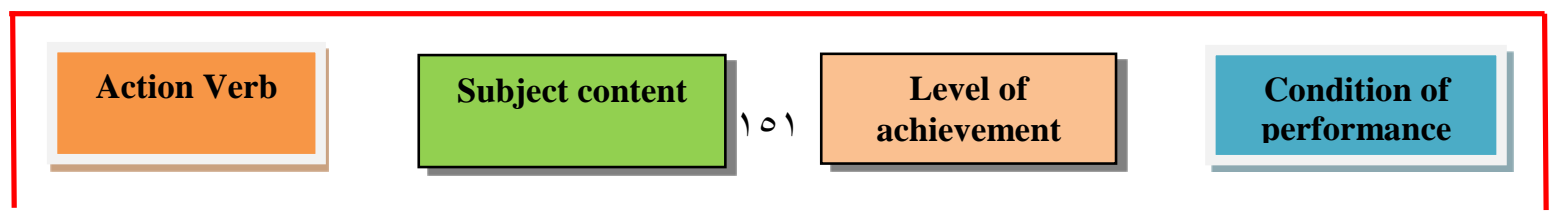


For example:

- (CLO 1) List areas of consensus and disagreement among publications on global warming.

- (CLO 2) Synthesize learning assignments with vocation-specific expectations using reflective enquiry.

\section{Steps to Writing Course Learning Outcomes for the Course:}

Step 1: Select an action verb using Bloom's Taxonomy as illustrates in Figure (6.8).

Figure (6.8) CLO using Bloom's Taxonomy

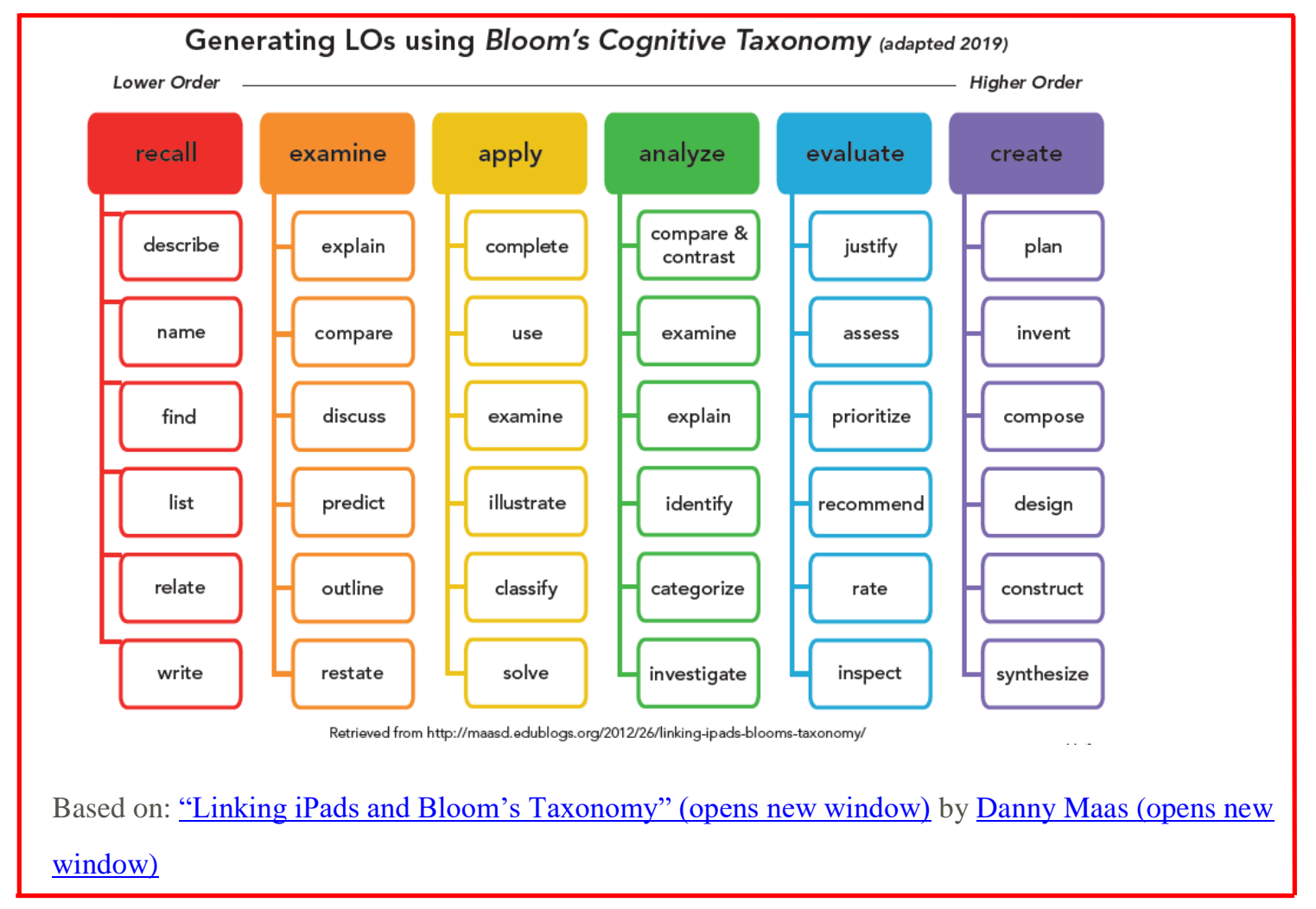

Step 2: Next, select the subject content students are performing that task for. For example, in (CLO 1) above, "areas of consensus and disagreement among publications on global warming" is the subject content: this is what the students are listing. Similarly, in the CLO "Develop a business plan for a small business", the subject content is "a business plan".

Step 3: Next, decide if (CLO) requires either a level of achievement or a condition of performance. 
Levels of Achievement: A level of achievement identifies how proficient students need to be in a task. For example, in a composition course, instructor might say "Write a literature critique with no grammatical errors". This tells students the level of achievement that's expected of them. Importantly, instructor doesn't need a level of achievement for every (CLO). He doesn't need to say "effectively", "accurately", or "correctly" on a (CLO), for example: these are all implied. Always, instructors expect students to achieve all outcomes in all courses correctly and accurately. Levels of achievement are for specific cases.

Conditions of Performance: A condition of performance identifies if students are only performing this outcome in a specific context. For example, in a Strategic Planning course, instructor might say "Demonstrate SWAT analysis techniques with limited supervision". This tells students that they will be performing this task, but that they will be supervised while they do so. Here once again, instructor doesn't need a condition of performance for every (CLO). Only include a condition of performance if that information clarifies the specific outcome students will achieve in the course.

Finally, Course Learning Outcomes (CLOs) should be SMART outcomes. Use the following chart to see if your outcomes follow SMART principles shown in Exhibit (6.5). (Doran, 1981)

Exhibit (6.5) SMART principles

\begin{tabular}{|l|l|}
\hline Specific & $\begin{array}{l}\text { Is there a description of a precise behavior and the situation it will be performed } \\
\text { in? It is concrete, detailed, focused, and defined? }\end{array}$ \\
\hline Measurable & Can the performance of the objective be observed and measured? \\
\hline Achievable & $\begin{array}{l}\text { With a reasonable amount of effort and application can the objective achieved? } \\
\text { Are you attempting too much? }\end{array}$ \\
\hline Relevant & $\begin{array}{l}\text { Is the objective important or worthwhile to the learner or stakeholder? Its } \\
\text { possible to achieve this objective? }\end{array}$ \\
\hline Time-bound & $\begin{array}{l}\text { Is there a time limit, rate number, percentage for frequency clearly state? When } \\
\text { will this objective be accomplished? }\end{array}$ \\
\hline
\end{tabular}

Course Learning Outcomes (CLOs) should have only one verb, and only one area of significant subject content. If your (CLO) includes multiple verbs, select the one that articulates the highest level of learning students will demonstrate in the course. If your (CLO) includes multiple topics, select the one that articulates the key outcome.

\subsection{3-Instructors' Learning Outcomes:}

It is one of the introductions of the current context of higher education that monitoring and assurance systems should be generating veritable bureaucracies within institutions. However, at the same time as policy has discovered, and is celebrating learner autonomy, independence and lifelong learning. The instructor (teacher) is stuck in the 
middle between tight adherence to achieving pre-specified outcomes, on the one hand, and optimizing the opportunities for the development and support of independent, autonomous and lifelong learners, on the other. The resulting fog of rhetoric and justification threatens to stifle originality and responsiveness within classrooms.

What counts as good teaching is evidently subject to change. Shulman and Shulman (2004) developed a model of teaching with the following components:

(a) Vision. An instructor (teacher) must have a certain vision on teaching and student learning.

(b) Motivation. An instructor must have the willingness and motivation to invest energy in a certain way of teaching.

(c) Understanding. An instructor must understand the concepts and principles on which a particular pedagogical model is based.

(d) Practice. An instructor must be able to realize a certain way of teaching into practice.

(e) Reflection. An instructor must be able to reflect on his or her experiences in order to learn from them.

(f) Community. An instructor must be able to function as a member of a education community and to form learning communities with other instructors (teachers) and colleagues.

The relations between the various components are supposed to be particularly important. Small discrepancies, for example, between instructor s' vision and practice, may generate motivation to learn. Large discrepancies, however, may discourage learning and lead to withdrawal, despair, or frustration.

On the other side, some studies introduce four types of instructor' learning activities (Bakkenes, et.al. 2010). These are:

(a) Learning by experimenting, for example, trying out a new teaching method or lesson format, making new materials or tests, etc.;

(b) Learning in interaction, for example, talking with students and colleagues, and sharing materials, participating in project groups;

(c) Using external sources, for example, reading books and magazines, attending a seminar; and

(d) Consciously thinking about one's own teaching practices (reflection).

A problematic feature of these categorizations is that there is no clear distinction between individual and interactive activities. In our view, learning in interaction should not be a separate category because each of the other three types of learning activities can be conducted both individually and interactively. Another problem is that the categories do not distinguish mental processes. The kind of thinking processes instructors engage in, for example, seem to determine whether instructors learn from collaboration and what they learn (Little, 2002). Similarly, in student learning, the fact that a student underlines fragments in a study text as such does not make the primary difference; but whether instructor does so as a function of a deep or surface approach to learning does.

The quality of these learning processes determines the quality of the learning outcomes students achieve. In a review of research on student learning, Vermunt and Vermetten (2004) concluded that four qualitatively different ways of learning were repeatedly found:

(a) Reproductive learning, meaning that students study subject-matter thoroughly and in detail, trying to memorize it to be able to reproduce it. 
(b) Meaning oriented learning, in which students try to relate different parts of the study materials, try to gain an overview, critically process information and focus on understanding what they study.

(c) Application-oriented learning, which focuses on applying the things one learns in practice, visualizing the subject-matter and thinking about how it can be used in real life.

(d) Undirected learning, meaning that students do not really know how to learn, and experience a lot of problems in learning. Recent studies yielded some insights into the learning activities of student teachers.

Tynja“la" (2008) presented a comprehensive review of recent research on workplace learning. Based on recent studies, she summarized how people learn at work as follows: (Bakkenes, et.al, 2010)

(a) By doing the job itself;

(b) Through co-operating and interacting with colleagues;

(c) Through working with stakeholders through the students;

(d) By tackling challenging and new tasks;

(e) By reflecting on and evaluating one's work experiences;

(f) Through formal education; and

(g) Through extra-work contexts.

Furthermore, Eraut (2004) presented a typology of learning outcomes in the context workplace learning. He discerns outcomes in a broad array of domains: (Bakkenes, et.al, 2010)

(a) Task performance;

(b) Awareness and understanding;

(c) Personal development;

(d) Teamwork;

(e) Role performance;

(f) Academic knowledge and skills;

(g) Decision making and problem solving; and

(h) Judgment.

In principle every activity can lead to a change in knowledge, beliefs or practices. Therefore, every activity can be a learning activity, even when a instructor does not has the intention to learn from that activity.

\subsection{4- Learning Outcomes Guide:}

Learning outcomes are clear, plain language descriptors of knowledge and performance tasks as discussions earlier. In other words, learning outcomes state the skills and knowledge that the learner is expected to demonstrate. Often the learning outcome will indicate what specifically will be assessed to determine success. Ideally, a learning outcome should be measurable and achievable. However, not all learning outcomes will be easy to measure; often some of the most important outcomes are challenging to measure. So, it's important here to summarize the Learning outcomes, which provide a powerful framework upon structure curricula. According to Harden et al. (2007b) learning outcomes: 
1- Help to provide clarity, integration and alignment within and between sequences of courses;

2- Promote a learner-centred approach to curriculum planning;

3- Encourage a self-directed and autonomous approach to learning, as students can take responsibility for their studies, and are able to actively gauge their progress;

4- Promote a collegial approach to curriculum planning, as instructors collaborate to identify gaps and redundancies;

5- Ensure that decisions related to the curriculum and learning environment are streamlined;

6- Foster a philosophy of continual monitoring, evaluation and improvement; and,

7- Help to ensure accountability and assure quality of our education programs.

8-Helps instructors select a teaching strategy that is matched to the outcome

Accordingly, the most important issue for HEIs is to develop a Learning Outcomes Guide which should be covered all the evaluations' techniques of academic processes, research activities, selection and coordination of appropriate content. And covering teaching and learning activities and assessment educations' strategies that promote the overall teaching and learning processes. Instructors measure students' learning - and the level of competency achieved - against the intended result (the learning outcome).

The developing Guide is intended to support programs, departments and instructors as they continue to develop and assess learning outcomes such that curricula become increasingly coherent, aligned and evidenced. It will ensure that instructors, departments, programs and the HEIs are actively able to demonstrate and account for student achievement of learning outcomes. An outcomes-based approach to education clearly specifies what students are expected to learn and arranges the curriculum such that these intended outcomes are achieved (Harden, 2007b). Learning outcomes provide the base for an effectively aligned and integrated curriculum, where instructional activities and assessment strategies are explicitly linked to course-specific and degree-level learning outcomes, which are tied to institutional and provincially-defined graduate degree level expectations. Learning outcomes bring transparency, fairness, and flexibility to curriculum design, delivery, and assessment.

The way of using learning outcomes guide at HEIs: Learning outcomes' guide describes knowledge that graduates of HEIs will attain or the performance tasks that they will be able to accomplish upon completion of their course or program of studies. The outcomes represent a high level of integration and application of knowledge, skills, attitudes and values to complex real world situations. In many ways, the HEIs outcomes-based approach 
is a promise to learners, employers, and external quality reviewers, that graduates will have demonstrated competency in all of the areas identified in their programs.

Within the context of the HEIs, the goal of the learning outcomes guide's philosophy of education is to assist learners to acquire, integrate and apply the requisite learning so that it may be transferable to real-life situations. The development of learning outcomes guide may differs from one higher education institution to another depending upon programs. And it is important that to identify which learning outcomes will be evaluated in the course. Some programs will assign the learning outcomes that must be assessed in each course. In other programs, there is some flexibility to select the learning outcomes from the program's list. So the selecting learning outcomes need the followings: (Based on RRU, http://ctet.royalroads.ca/rru-learning-and-teaching-model)

1- Keep the end in mind. What knowledge, skills and attitudes does the instructor want learners to demonstrate in the course and the assignments?

2-There are many critical and related skills in your course, and instructor might be unsure how many outcomes are appropriate. There is no hard and fast rule on the number of learning outcomes, although instructional designers may recommend few outcomes per course.

However, the learning outcomes can address a wide range of levels of learning. The level of learning is important for both the learning outcomes and the assessment. There will be a range of skills and knowledge areas that instructors want learners to demonstrate, at different levels during the course. When creating or applying learning outcomes, it is helpful to frame the outcome and assessment criteria in terms that describe what the learners will be able to know or do, and choose verbs that indicate the hierarchical level at which the learning is to take place.

Writing and using assessment criteria: Learners' performance is judged against a set of criteria which has been predefined and transparent. In educational terminology, this is often called "criterion-referenced assessment". Assessment criteria should be derived from the learning outcome. Generally speaking, assessment criteria should be as precise as possible; they should describe evidence that is observable; and they should describe only that which is essential to demonstrate achievement of the learning outcome. Assessment criteria should describe characteristics of a course wherever possible. Where it is necessary to describe the characteristics of actions/activities, critical aspects of the context in which actions/activities are demonstrated, should be defined. More generally, one should avoid specifying procedures and methods unless these are specified in the learning outcome (Based on RRU, 2020 and Vermunt,et.al. 2004). Exhibit (6.6) illustrates a sample of learning outcomes and assessment criteria (RRU 2020).

Exhibit (6.6) Sample of guide learning outcomes and assessment criteria 


\begin{tabular}{|l|l|}
\hline Communicate in writing & $\begin{array}{l}\text { A structure is used that makes it easy for the audience to } \\
\text { identify the main points and ideas. }\end{array}$ \\
$\begin{array}{l}\text { The text is legible, accurate and conforms to the } \\
\text { grammatical conventions that match the purpose and } \\
\text { expectations of the audience. }\end{array}$ \\
$\begin{array}{l}\text { A varied vocabulary and sentence structure is used to } \\
\text { convey particular effects. }\end{array}$ \\
\hline $\begin{array}{l}\text { Model values and practices that } \\
\text { encourage trust, knowledge sharing, } \\
\text { empowerment and mutual success. }\end{array}$ & $\begin{array}{l}\text { Interacts effectively with all other learners in team, group } \\
\text { and class work. Listens carefully, provides and receives } \\
\text { feedback as part of learning. }\end{array}$ \\
\hline $\begin{array}{l}\text { The learner will be able to evaluate the } \\
\text { effectiveness of his/her own actions } \\
\text { within a leadership context of their } \\
\text { choice. }\end{array}$ & $\begin{array}{l}\text { Encourages alternative views, encourages everyone to } \\
\text { participate fully. }\end{array}$ \\
\hline $\begin{array}{l}\text { The feedback: The learner is able to } \\
\text { respond sensitively to a variety of } \\
\text { feedback sources within the working } \\
\text { context. }\end{array}$ & $\begin{array}{l}\text { Is sensitive to a wide variety of feedback. Responds } \\
\text { promptly when the current approach is not working. } \\
\text { Seeks out advice and responses from knowledgeable } \\
\text { sources. }\end{array}$ \\
\hline $\begin{array}{l}\text { Is aware of major sources of feedback. Responds and } \\
\text { adjusts when correction is needed. Listens to the advice of } \\
\text { others. } \\
\text { Is insensitive to some important sources of feedback. } \\
\text { Responds and adjusts when correction is needed. Listens } \\
\text { to the advice of others. } \\
\text { Ignores major sources of feedback. Responds negatively } \\
\text { to unfavorable information. }\end{array}$ \\
\hline
\end{tabular}

Achieving consistency in grading within a course or program, with one of more instructors, can be challenging. Instructors may find it useful to develop a rubric, for their own use and/or to share with colleagues and learners, which describe the performance (see the feedback column in Exhibit 6.6).

\section{5- EVALUATION EDUCATION EFFECTEFENESS}

Students have evaluated teachers for as long as there have been individuals claiming to be teachers. Programs of formal collection of students' evaluations were introduced in the previous sections. The topic has been one of the most frequently studied and controversial in American educational research during the last century (Marsh, 1987). Evaluations Students' evaluations of teaching effectiveness are commonly collected at most North American universities. Appropriate purposes of these evaluations are to provide:

1) Diagnostic feedback to faculty about the effectiveness of their teaching;

2) A measure of teaching effectiveness to be used in personnel decisions;

3) Information for students to use in instructor/course selection; 
4) An outcome or a process description for research on teaching; It will be argued here that students' evaluations as typically defined are not appropriate for the evaluation of courses as opposed to the instructors who teach the courses.

Information from students' evaluations depends upon the content of the items. Poorly worded or inappropriate items will not provide useful information. If a survey instrument contains a non-clear of different items and student ratings are summarized by an average of these items, then therefore is no basis for knowing what is being measured. So, it's so important to develop and run an evaluation guide for education academic unit such as department or/and college from the students points of view.

\subsection{1- Student Evaluation of Instructor Performance:}

Research on teaching involves at least three major questions (Marsh, 1987): How do teachers behave? Why do they behave as they do?, and What are the effects of their behavior? To conceptualize this research in terms of process variables, global teaching methods and specific teaching behaviors; presage variables, characteristics of teachers and students; context variables, substantive, physical, and institutional environments; and product variables (student academic/professional achievement, attitudes, and evaluations). Student ratings are important both as a process-description measure and as a product measure. This dual role played by student ratings, as a process description and as an evaluation of the process, is also inherent in their use as diagnostic feedback, as input for tenure promotion decisions, and as information for students to use in course selection.

Within-network studies attempt to ascertain whether students' evaluations consist of distinct components and, if so, what these components are. This involves logical approaches such as content analysis and empirical approaches such as factor analysis and multitrait-multimethod (MTMM) analysis. Clarification of within-network issues must logically precede between-network studies in which students' evaluations are related to external variables. Inherent in this construct approach is the adage that one validates not a test, but the interpretation of data arising from specific applications, as responses may be valid for one purpose but not for another. Construct validity is never completely present or absent, and most studies lead to an intermediate conclusion in which the emphasis is on understanding relationships.

The construct validation approach described here and elsewhere (Marsh, 1987) has been incorporated more fully in the design, development, and research of the Students' Evaluations of Educational Quality (SEEQ) than with other student evaluation instruments. Consequently, the focus of this overview will be on my own research with SEEQ. In each section that follows, relevant SEEQ research is described, and methodological, theoretical, and empirical issues are related to other research in the field. The emphasis of this article on my own research with SEEQ can be justified by the nature of the article as an invited lead article, but also because SEEQ has been studied in a wider range of research studies than have other student evaluation instruments.

This research overview emphasizes the construct validation approach described above, and several perspectives about student-evaluation research that underlie this approach follow: (Based on Marsh, 1987; Marsh and Dunkin 1992) 
1. Teaching effectiveness is multifaceted. The design of instruments to measure students' evaluations and the design of research to study the evaluations should reflect this multidimensionality.

2. There is no single criterion of effective teaching. Hence, a construct approach to the validation of student ratings is required in which the ratings are shown to be related to a variety of other indicators of effective teaching. No single study, no single criterion, and no single paradigm can demonstrate, or refute, the validity of students' evaluations.

3. Different dimensions or factors of students' evaluations will correlate more highly with different indicators of effective teaching. The construct validity of interpretations based on the rating factors requires that each factor be significantly correlated with criteria to which it is logically and theoretically related, and less correlated with other variables. In general, student ratings should not be summarized by a response to a single item or an unweighted average response to many items. If ratings are to be averaged for a particular purpose, logical and empirical analyses specific to the purpose should determine the weighting each factor receives, so that the weighting will depend on the purpose.

4. An external influence, in order to constitute a bias to student ratings, must be substantially and causally related to the ratings, and relatively unrelated to other indicators of effective teaching. As with validity research, bias interpretations should be viewed as tentative hypotheses to be challenged in different contexts and with different approaches which are consistent with the multifaceted nature of student ratings. Bias interpretations must be made in the context of an explicit definition of what constitutes a bias.

Information from students' evaluations necessarily depends on the content of the evaluation items. Poorly worded or inappropriate items will not provide useful information. Student ratings, like the teaching they represent, should be unequivocally multidimensional (e.g., an instructor may be quite well organized but lack enthusiasm). This contention is supported by common sense and a considerable body of empirical research.

An important issue in the construction of multidimensional rating scale instruments is the content of the dimensions to be surveyed. A logical analysis of the content of effective teaching and the purposes of students' evaluations, coupled with feedback from students and faculty members, is one typical approach. An alternative approach based on a theory of teaching or learning could be used to posit the evaluation dimensions, though such an approach does not seem to have been used in student evaluation research. However, with each approach, it is important to also use empirical techniques such as factor analysis to further test the dimensionality of the ratings. The most carefully constructed instruments combine both logical/theoretical and empirical analyses in the research and development of student rating instruments.

If a survey contains separate groups of related items derived from a logical analysis of the content of effective teaching and the purposes the ratings are to serve, or a carefully constructed theory of teaching and learning, and if empirical procedures such as factor analysis and multitrait-multimethod analyses demonstrate that the items within the same group do measure separate and distinguishable traits, then it is possible to interpret what is being measured. The demonstration of a well-defined factor structure also provides a safeguard against a halo effect - a generalization from a subjective feeling, an external influence, or an idiosyncratic response mode-which affects responses to all items.

An important issue in the construction of multidimensional rating scale instruments is the content of the dimensions to be surveyed. A logical analysis of the content of 
effective teaching and the purposes of students' evaluations, coupled with feedback from students and faculty members, is one typical approach. An alternative approach based on a theory of teaching or learning could be used to posit the evaluation dimensions, though such an approach does not seem to have been used in student evaluation research. However, with each approach, it is important to also use empirical techniques such as factor analysis to further test the dimensionality of the ratings.

However, the students' evaluation HEI teaching should take under consideration the following group of factors: (Based on Marsh, 1987; Marsh and Dunkin 1992)

Group One: Characteristics of the Course:

1- Class meeting time:

2- Level of Course:

3- Class Size

4- Subject Area

5- Workload of Course

6- Instructor Presence in Classroom

Group Two: Characteristics of the Instructor:

1- Instructor Rank and Experience

2- Reputation of Instructor

3- Research Productivity

4- Personality of Instructor

5- Seductiveness

6- Gender of Instructor

In the context of teacher evaluation, several questions need to be considered. First, the question of who should evaluate teachers - their peers, supervisors, students or some of these combined? While teachers are usually evaluated by their peers and supervisors, the adequacy of involving students in this process is questionable owing to their subjectivity, personal opinion, affect etc., all of which can have an impact on evaluation (Hajdi, and Pažu, 2012). Although teachers have a great impact on the teaching effectiveness and it is impossible to completely separate them from the teaching process, a conceptual difference between instructor and teaching effectiveness has to be made. Apart from certain teacher characteristics, teaching effectiveness depends on a wider range of elements.

\subsection{2- Peer-to-Peer Assessment:}

Peer assessment is defined as "an arrangement in which individuals consider the amount, level, value, worth, quality or success of the programs or/and course or outcomes of learning of peers of similar status". In addition to increasing instructors' efficiency in grading, peer assessment is advocated as an effective pedagogical strategy for enhancing learning For instance, peer assessment has been found to increase students' engagement, promote students' critical thinking, and increase students' motivation to learn. Additionally, peer assessment can function as a formative pedagogical tool or a summative assessment tool (Xiong, et.al. 2014).

However, despite the great potential of peer assessment, researchers and practitioners remain concerned about whether students have the ability to assign reliable and valid ratings to their peers' work (Liu \& Carless, 2006). Specifically, reliability refers to inter-rater consistency across peer raters, whereas validity refers to the consistency 
between peer ratings and instructor ratings, assuming instructor ratings to be the gold standard. Validity is a major concern for instructors who are interested in using peer assessment and is also the primary focus of the present meta-analysis. In this meta-analysis usually use the term "instructor ratings" to be consistent with Falchikov and Goldfinch (2000), whereas an alternative term used in the literature is "expert ratings." A "instructor" could refer to a HEI President, Dean, Department Chair, classroom instructor, a teaching assistant, or a supervisor.

In their meta-analysis, Falchikov and Goldfinch (2000) further investigated the influence of various factors on the agreement between peer and teacher ratings. Among the major factors they explored were subject area, quality of study, number of peer raters, level of course, nature of assessment task, and dimensional versus global judgment, etc. Regarding peer assessment procedures, one factor is the constellation of assessors and the constellation of assesses (i.e., those who are assessed). For instance, assessors and assesses can be individuals, pairs, or groups. Other factors are the number of peer raters per assignment and the number of instructors per assignment (Falchikov \& Goldfinch, 2000). In addition, because the social context of peer assessment may introduce pressure, risk, or competition among peers, it is important to examine whether assessors and assesses are matched at random or not.

Another potential factor is whether peer assessment is compulsory or voluntary. Some studies entailed compulsory participation in peer assessment, whereas in others, participants were self-selected (e.g., Xiong, et.al. 2014). Additionally, friendships among peers may result in scoring bias. Thus, it is necessary to examine whether the peer assessment is anonymous or not. Furthermore, feedback format may be an influential factor (Falchikov, and Goldfinch, 2000). Sometimes, peer raters provided only scores, whereas at other times they provided both scores and qualitative comments.

Finally, establishing high-quality peer assessment requires organizing, training, and monitoring peer raters. Rating quality is said to improve when peer assessments are supported by training, checklists, exemplification, instructor's assistance, and monitoring. As discussed by Falchikov and Goldfinch (2000), peer raters' familiarity with and ownership of assessment criteria tend to improve the accuracy of peer assessment. Therefore, the present meta-analysis also includes three variables to reflect whether peer raters receive training, whether explicit rating criteria are used, and whether peer raters are involved in developing rating criteria.

Meanwhile, The growing focus on teaching quality and improving the student experience has been paralleled by the increased focus on institutional metrics and the professionalization of tertiary teaching. It is within such a climate that it has seen the emergence of peer observation of teaching (POT) and its pivotal role in quality assurance and quality enhancement systems. O'Leary suggests that continuous improvement and quality have become 'the mantra' of further education policy and (POT) sits at the coalface of instructor professional development. What constitutes professional development in further education and how this is undertaken, however, remains a contentious issue (Hammersley-Fletcher, 2017).

The peer observation of teaching should be classified as 'evaluative', 'developmental' or 'collaborative'. These classifications represent distinct principles, practices and processes. Across the spectrum of (POT) there are significant challenges that can undermine the potential of the process to deliver needs-based professional development 
for continuous improvement. These challenges are underscored by the prevailing tension between the converging agendas of quality assurance versus quality enhancement. Some Researchers highlight that an emphasis on the institutional imperative for quality assurance undermines sustained and meaningful engagement in POT (Gosling 2014). When framed as a mechanism for quality measurement, POT can be viewed, experienced and resisted by educators who perceive such a process as a means of ensuring compliance with a purely managerial agenda.

Finally, the developmental (POT) can enhance teaching practice by encouraging critical self-reflection, creating opportunities for teaching staff to become more aware of student experiences, and enabling groups to identify and disseminate good practice. Developmental (POT) schemes recognize the heterogeneous, contested and contradictory production of 'academic cultures' through the process of learning and teaching. However, developmental (POT) schemes require 'consensual leadership and skilled education management to gain the confidence and the support of academic staff (HammersleyFletcher, 2014).

\section{CHAPTER SEVEN: RESEARCH MANAGEMENT IN HIGHER EDUCATION INSTITUTIONS}

\section{1- INTRODUCTION:}

The theory and educational research bridges the old-age theory divide by demonstrating how researchers can use theories to determine appropriate empirical research strategies, and extend the analytical, critical and sometimes emancipator power of data gathering and interpretation. Dressman (2008) further states that theory circumscribes methods of thinking about educational problems and inhibits creativity among researchers, policy makers and teachers. According to Suppes (1974), there are five kinds of arguments for using theory in educational research:

(a) Argument by analogy (although the argument that the success of the natural sciences in the use of theory provides an excellent example for educational research, it does not follow that theory must be comparably useful moving from one subject to the other);

(b) Reorganization of experience (a more important way to think about the role of theory is to attack directly the problem of identifying the need for theory in a subject matter);

(c) Recognition of complexity (one of the thrusts of theory is to show that what appear on the surface to be simple matters of empirical investigation, on a deeper view, prove to be complex);

(d) Dewey (Library Vocabulary System) is a problem solving (inquiry is the transformation of an indeterminate situation that presents a problem into one that is determinate and unified by the solution of the initial problem); and

(e) Triviality of bare empiricism (recording of individual facts and with no apparatus of generalization or theory).

According to Maxwell (2010), no fact, investigation, or conclusion can be theory

free. The issue is whether one is aware of the theory one is using and whether one is using 
it critically or uncritically. In order to understand any educational phenomenon, one needs to also look at the larger social, economic and political contexts within which that phenomenon is embedded, and seek out theories that connect there. Theories can be used not just to understand the individuals, situations and structures studied, but also to change them. One needs to avoid simply citing theory to support one's argument, and to actually incorporate theory into the logic of one's study and use it to deepen one's research process. So, the education research activities classified into two major categories: student learning teaching research, and faculty's member scientific research.

\subsection{1- Students' Learning Education Research:}

Formal learning and instruction strategies are inseparable. Yet learning theories only describe how learning occurs, but do not describe the specific methods and activities to follow in order to accomplish the intended learning outcomes. For example, learning theories may describe the age at which a learner may learn punctuations, but the instructional theories will provide guidelines on how to execute the teaching of punctuations. The learner brings past experiences and cultural factors to a situation.

According to Mogashoa (2014), the philosophy of constructivism proceeds from the premise that:

1- Knowledge does not exist outside the bodies of cognizing beings (that is, outside the mind of a learner);

2-Knowledge is the construction of reality;

3-Knowledge is the construction of reality; Individuals actively construct knowledge by connecting prior and newer learning while working to solve problems.

Learning is an active process of constructing rather than acquiring knowledge, and construction is a process of supporting that construction rather than communicating knowledge. In other words, learning should be an activity in context. Though learning is construction of knowledge, sometimes learners can also learn by imitation and repetition. This can be done by constructing meaning on what is already known. Acquiring knowledge can also be seen as learning because learners shall have known what they did and what they learn. However, most educational activities in our country and elsewhere are like other forms of social and economic activity in society in that only a slight effort is made to study 
the character of the activities and to understand them as intellectual, economic, or social processes.

Learning to conduct research and design activities can increase student knowledge, skills and awareness about science and multidisciplinary practices. Enhancing their worldview on possible future professions as well as understanding the development of science and the links between research and design. The common challenges around teaching research methods for both students (undergraduate and graduate) and instructors. However, many of these stem from the need to alter teaching practice from principally lecture-based to active and authentic learning strategies. Three key studies that focused specifically on teaching research methods proved particularly useful for developing recommendations and form the core of his paper. These recommendations include (Groessler, 2017):

1. Make research visible by connecting learners to research (active learning)

2. Immerse students in actual research (authentic learning)

3. Encourage students and instructors to reflect upon the research process to enable them to position themselves in the bigger picture (reflexive learning)

4. Encourage a 'pedagogic culture' through discourse and debate between academics and sharing of successes and challenges around teaching research methods.

Interest in applied educational research methodology is growing as instructors and researchers (students) strive to seek empirical evidence about what is effective teaching within distinctive contexts. However, for beginner researchers (students) who are interested in conducting case studies within educational settings and are looking for an appropriate starting point. There are a lot of research engines such as "ERIC database" use for search to focus principally on articles from educational research. Also, the search located many journal articles, which were further analyzed using a survey tool to collect further details such as the teaching approaches used (particularly active and studentcentered), course design, evidence of improvement to student engagement and students' involvement in research practices.

In addition to knowledge acquisition, most observers contend that a high quality undergraduate experience should expose students to new ideas and ways of thinking and actively engage them in exploring and discovering new knowledge. Indeed, being involved in a research project as an undergraduate is associated with various desirable effects such as persistence, graduate school study, and future career choice (Hu, et.al. 2007). A subsequent study (Hathaway et al. 2002) suggested that participation in undergraduate research was also positively related to the probability of pursuing graduate education and conducting research in the future. Furthermore, the most important that undergraduate research experiences were positively related to graduate university success.

Given their inquiry-intensive missions, research HEIs are thought to have a comparative advantage in terms of providing high quality research experiences for their undergraduates. Many research HEIs, including U.S.A. HEIs such as Duke, Michigan, Pennsylvania State University, and the Berkeley campus of the University of California, feature opportunities to work side by side with productive scholars on the cutting edge of their fields. As a research HEI, Duke seeks to connect undergraduate education to the broad 
continuum of scholarship reflected in its faculty. Such a rich setting provides students with opportunities to become involved in a community of learning and to engage in the process of discovery and move beyond being the passive recipients of knowledge that is transmitted to being an active participant in the discovery, critical evaluation, and application of knowledge and understanding (Hu, et.al. 2007).

Furthermore, the important to indicate that the main task in creating conditions for the training of future personnel, corresponding to state priorities for the development of science and technology, able to develop in their national attainability development, thereby increasing its economic potential. The relevance of the chosen direction is determined by the following trends (Zenkina, et.al. 2018):

1 - Emergence of various forms of open education;

2-Focus on the student-oriented concept;

3- Increasing academic mobility of students;

4- Enhancement variability, flexibility and differentiation of educational programs;

5- Implementation of individual educational routes;

6- Use of non-standard forms of educational process organization, going beyond a certain educational organization;

7- Review of technologies and methods of teaching, strengthening of cooperation ties and development of social partnership of educational organizations.

\subsection{2- Academic Research Works:}

In higher education, academic research is used to teach concepts and principles. The instructor (teacher) can use the latest data collected from a research study to prove a point or emphasize the importance. Educating on research is also done to show the continual progression of the field of interest. It's obvious that research is important because hear is about it all of the time in all parts of life. What is academic research and why is it important? Research comes in all different forms and places. A research project in higher education institutions is when someone conducts an experiment to find the answers to a question or to solve a problem they have observed. When someone thinks of an experiment, he/she often think about test hypotheses. But that is not the only kind of experiment that can be run. The possibilities for research projects are really endless. It could be following a group of instructors-researchers over some time, it could be testing new technology, or it could be growing a plant with different variables. A research project can propel the study of any field of interest to find the solutions to the problems facing the society and/or the nationwide economy and environment.

The only requirement is that there is a problem to be solved, a theory to be verified, or a question to be answered. If one of those exists, a research project can be developed to find the resolution. There are two main types of research projects; academic and professional. Academic research is focused primarily on making new discoveries for the scientific community. Professional research is geared more towards solving a specific problem for an organization, often a business, or its customers.

\subsubsection{1- Academic Research:}


While any research is good and can, in certain cases, be helpful, there is a major difference between casual research and academic research. Academic research is usually intended for the sole purpose of creating knowledge. It is not designed to benefit a specific company or organization. Academic research is designed to be from a voice of authority and can change how people view whatever is being researched. For this reason, it is held in higher education institutions and research centers to be a high standard. (Based on Ph.D Assistance Blog, 2019)

Academic Research is defined as a "Systematic investigation into a problem or situation, where the intention is to identify facts and/or opinions that will assist in solving the problem or dealing with the situation". This academic or scholarly research focuses on research goals/questions that arise from independent instructors-researchers. It uses formal, scientific and systematic procedures to discover answers. The scholarly research is guided by an already existing theory in order to reject or support the theory. Furthermore, Academic research helps students in their personal growth as well. Research helps in the development of skills, and students learn how to identify a problem and reach a possible solution or develop a point of view on a specific topic. By creating an academic research paper, students learn to organize their ideas. From the above definitions of academic research includes:

1-Making a rigorous and relevant contribution to knowledge;

2-Understanding of a cause and effect relationship of a given phenomenon or uncovering a new phenomenon;

3-Organized inquiry to provide information for the solution to a problem;

4-A careful and systematic investigation in some field of knowledge, or undertaken to establish facts or principles;

5-Scientific or scholarly inquiry or investigation and the proper communication of the research findings

The term 'research' is applied in so many ways in our daily life, from our quest of customer knowledge to writing a research, to exploring a problem at work. Research is a systematic process of collecting, analysing and interpreting information (data) in order to better understand a phenomenon about which we are interested or concerned. It is a lengthy process, focused, specific, intensive, accumulative and educational, and is not mere information gathering, transportation of facts from one location to another and rummaging for information. Accordingly, the main purposes of research are to inform action, gather evidence for theories, and contribute to developing knowledge in a field of study. In addition, the significant of research is important for everyone-not just students and scientists.

Academic or scholarly research is writing worries more about methodology as it needs to be scientifically validated. It generally circulates within the academy, and has an objective stance, clearly states the importance of the topic, and is managed with sufficient detail. So that other academic researchers/scholars may also try to replicate the results. Academic research writing focuses on scientific journal publications and /or dissertation research and dissertation writing. This is the reason why the scientific method follows the 
same pattern from beginning to end in order to find the most logical conclusion for the question at hand. The researcher creates a hypothesis, which is the answer he/she believes will find.

The hypothesis can be a little bit tricky because though it is important (the project is just trying to prove or disprove that thought), the researcher cannot let it sway the project. Any biases or preconceived opinions can really sway the findings and conclusions if there are no safeguards put in place. When the research is not done to academic standards, it can be hard to trust. And what is the point of doing the research if the audience cannot trust the conclusions? The point of research is to find ways to improve our understanding of what is being studied or to verify that our understanding of the subject is correct. So if you as a researcher find a better way or discover something new but the findings cannot be trusted, then no change will be made. When a researcher writes up the findings from their experiment, they have to use an academic writing style in order to be published.

An important aspect of a legitimate journal article from an academic research project is peer review. When a research project or research article has been peer-reviewed it means that the procedures and findings have undergone intense scrutiny by others who are already familiar with the topic and been found to be valid. This process can look different depending on the specific field the research is being done in and where it is being done. But the process always takes place before the research is presented in an academic journal. The paper is submitted to various peers and experts in the same field. They review the case, research, and findings and give recommendations for edits before it is published.

When an article has been peer-reviewed, it shows the reader that the findings being presented are valid. The peers or experts who are reviewing are looking for how valid the findings are and also whether the information can be trusted. They may suggest taking out parts that are not helpful or for changes the make the paper more insightful. And they may point out problems with the methods used and suggest ways to fix them. A peer-reviewed academic article is typically viewed as more trustworthy than an article that was not peerreviewed.

\subsubsection{2- Professional Research:}

Professional research is defined as work performed to advance an individual's profession. It is a form of communication produced in a professional manner in order to facilitate work. Professional research focuses on research goals/questions that emerge from business requirements. It may or may not use the formal, scientific and systematic procedures to discover answers. It is not grounded in theories and may not require a representative sample. Here, Table (7.1) illustrates the difference between academic research and professional research. The common differences between academic research and professional research are listed below. (Based on Ph.D Assistance Blog, 2019)

Table (7.1) the differences between academic research and professional research 


\begin{tabular}{|c|c|}
\hline $\begin{array}{l}\text { Also called as Scholarly Research Seeks to add } \\
\text { to a larger "body of knowledge" }\end{array}$ & $\begin{array}{l}\text { Also called as Applied Research Seeks to find } \\
\text { solutions to instant problems and issues }\end{array}$ \\
\hline Questions tend to be more conceptual & Problems tend to be more practical \\
\hline Theoretically focused & Organizationally focused \\
\hline Findings are generally made public & Findings are generally kept private \\
\hline $\begin{array}{l}\text { Results generally spur ideas and questions for } \\
\text { future research }\end{array}$ & $\begin{array}{l}\text { Results are generally used internally to make } \\
\text { decisions and set up strategy }\end{array}$ \\
\hline $\begin{array}{l}\text { Assessed through peer review by means of } \\
\text { academic discipline standards }\end{array}$ & $\begin{array}{l}\text { Assessed by client-organisation and/or industry } \\
\text { standards }\end{array}$ \\
\hline $\begin{array}{l}\text { Shared primarily through academic writings } \\
\text { (doctoral dissertation, thesis, dissertation } \\
\text { research, scholarly journals, academic } \\
\text { conferences \& presentations, academic articles } \\
\text { and other publications (e.g., books) }\end{array}$ & $\begin{array}{l}\text { Shared mainly through internal reports to reveal } \\
\text { results; may also be shared more widely through } \\
\text { professional conferences and industry/trade } \\
\text { publications (e.g., articles, case studies, etc.) }\end{array}$ \\
\hline
\end{tabular}

Academic research and professional research also share the following common characteristics:

- Questions asked

- Problems established

- Phenomenon observed

- Seeks to validate the field and profession

- Draws upon a much larger research community

- Results bring in new information/knowledge

- Uses widely accepted research methods (i.e. scientific methods)

- Adheres to ethical standards

Professional research writing is more focused on the use of the information received and is less worried about methodology, and even validation seems to be natural. It uses particular language to communicate information that is easily understood by its target audience, and it may be managed to inform, instruct, persuade, debate, stimulate, or encourage action.

Research and design often go hand in hand, yet can still be seen as two separate practices with separate goals and histories. Research is often employed to explain, explore or compare certain situations by collecting and analyzing data. Research and design have in common that they both are concerned with challenging; structured problems or questions, and both are iterative practices. While many models are described in literature (for example see Vossen,2018), the research process generally consists of these phases: orientation on research question; generate hypotheses; plan research; collect data; organize and analyze data; conclude and discuss; communicate and present. The design process too can be captured in different models, however, it generally consists of the following phases: clarify problem; assemble programme of requirements; plan design; construct prototype; test prototype; repeat steps to optimize prototype; analyze product; communicate and present. Instructors (faculty's members) often employ versions of these models when their students conduct research or design projects.

\section{2- ESTABLISHMENT THE SCIENTIFIC RESEARCH CENTER}


Today's research landscape is global, interdisciplinary, focused on excellence, and rooted in collaboration with partners of all types: including industry, non-profits, governments, and other higher education institutions. This priority area focuses on laying the foundation for building the national research potential and support the guide role of the HEIs and scientific research centers to excel in this increasingly competitive and challenging environment. The HEIs research centers will support collaboration, innovation and foster creativity with cutting-edge design that is adaptable, safe and sustainable.

The significant evidence-based knowledge created through academic research in all sciences and related fields has clearly demonstrated to the national economy and society valuable insights for sustainability nationwide development. Research has demonstrated that managing based on legacy approaches, intuition, or social snapshots imposes costs and substantial risks on the economy. As a result, evidence-based knowledge creation, the forte of academic scholars at universities worldwide, continues to be essential. This focus on higher education institutions research has spurred the creation of research centers, with many dedicated to specialty areas of attention (Kumar, 2017).

Questions about the quality and relevance of educational research were not only raised by policy makers and educational practitioners, but they also came from within the educational research community itself. For example, in a lecture on teaching as a researchbased profession, David Hargreaves accused educational research of not having generated the cumulative body of relevant knowledge that would enable teaching to become a research-based profession. It is important to see that Hargreaves's criticism was not only directed at educational research but also implied a message for educational practice (Biesta, 2007).

On the one hand, Hargreaves's criticism suggested that educational research should not be left to educational researchers but should be subject to centralized agendasetting, both with respect to its contents and its methods, so that it can become more practically relevant. At the very same time, however, his criticism suggested that educational practice should not be left to the opinions of educators but that their work should be based upon research evidence. Hargreaves called, in other words, for a transformation of educational research so that educational practice could be transformed into an evidence-based practice. The call for a double transformation of both educational research and educational practice lies at the very heart of the idea of evidence-based education (Biesta, 2007).

Accordingly, it's so essential to establish a research center in each higher education institutions that can serve as a platform to all the relevant stakeholders in accomplishing their goals to serve the nationwide economy. Established with an international, and most importantly, an interdisciplinary scope, the Center aims to advance the knowledge and practice of modern evidence-based management and to foster impactful research. The creation of these centers was the result of a careful study of the evolving business atmosphere and its critical needs. Pioneering such an agenda, the Center lends itself to contributions in research, teaching, and service to both the academic and the society and the nationwide economy. To achieve these expectations, the Center relies upon five important elements that are essential for a successful research center: structure, academic staff, process, dashboard metrics, and financial support (Based on Kumar, 2017). 
1- Structure: In terms of organizational structure, the Research Center as autonomy Deanship reports to the Provost or to the Deputy President of the HEIs and is composed of faculty members and graduated students, support staff, and graduate assistants. Center is led by the Executive Director (Dean), assisted by the Deputy Dean, and significantly benefits from the leadership of the institution. The graduate students and scholars work with faculty members to drive the research output at the Center. The Center also enjoys the support of a distinguished set of faculty members who form the advisory board, as well as the President and Provost of HEI. All of the Research Center Leadership and faculty members of the advisory board are chaired professors in different disciplines.

2- Academic Staff: Whereas the research output at a research center is primarily driven by the faculty members, visiting scholars, and graduate students (doctoral students), the support personnel are also vital. At most research centers, four types of support staff is a key to efficient functioning.

$\underline{\text { First, }}$ a center administrator is critical in running a research center. This person will typically coordinate the daily operations, support all entities involved in the center, and manage interactions of the center with the other constituents of the department/university and external bodies.

Second, a research coordinator is needed to manage and coordinate all research projects at the center. This would ideally include identifying research needs, coordinating project activities, and generating and delivering reports. In addition, this member can also aid in disseminating research findings via journals, trade-related publications, and books, assist in all writing initiatives at the center, and explore new research opportunities that will keep the research pipeline of the center in steady flow.

Third, a project coordinator who can interact with stakeholders will be helpful for the center. Ideally, this member will liaise with the community to bring in potential clients, attend exploratory research meetings, develop research proposals, help kick start a research project, and compile final reports to be delivered to the clients.

Fourth: a technology coordinator can be helpful in keeping the center in good form by overseeing the technology aspects. Ideally, this member can attend to all the technical needs of a center such as hardware/software procurement and maintenance, programming/coding support as necessary, and server maintenance and upkeep.

3-Process: The main goal of a research center is to enable interaction between faculties, scholars, students, and nationwide economy to enhance research opportunities, academic excellence, real-world problem solving, and knowledge creation and dissemination. This interaction is facilitated by the Center Leadership to advance the art, science, and practice of learning and teaching as it pertains to the unique aspects of managing nationwide economy and society. The integration of knowledge from other relevant disciplines warrants the most sophisticated statistical knowledge to produce useful and cutting-edge knowledge. To facilitate research productivity, Research Center ensures that each faculty member engages with multiple doctoral students, and each doctoral student engages with multiple faculty members (see Fig. 7.1). This creates an atmosphere replete with the healthy exchange of ideas which results in a fertile research environment.

The various entities at Research Center come together to function successfully in five key areas, serving as an example for the formation of other research centers in terms 
of custom research, embedded research, thought leadership, certificate programs, and executive education.

4- Custom Research: Research centers must constantly look for new areas to shed light on and bring to the attention of the academic community, with a focus on rigor, relevance, and actionable implications. This means that not only are the empirical studies rigorous in their approach, but also the conceptual and analytical studies. This makes the faculty associated with Research Center known for their rigorous research, and produces future research scholars with rigor-oriented research acumen. Also ensures that all research studies address the most relevant managerial problems and propose the most appropriate and actionable method. This includes (but is not limited to) (a) solving unique and relevant sustainable nationwide development problems that have received little or no research attention, (b) advancing the theoretical and/or conceptual principles that are also accessible to the practitioner community, and (c) questioning the conventional wisdom and creating new research stream(s).

Figure (7.1) Research center work

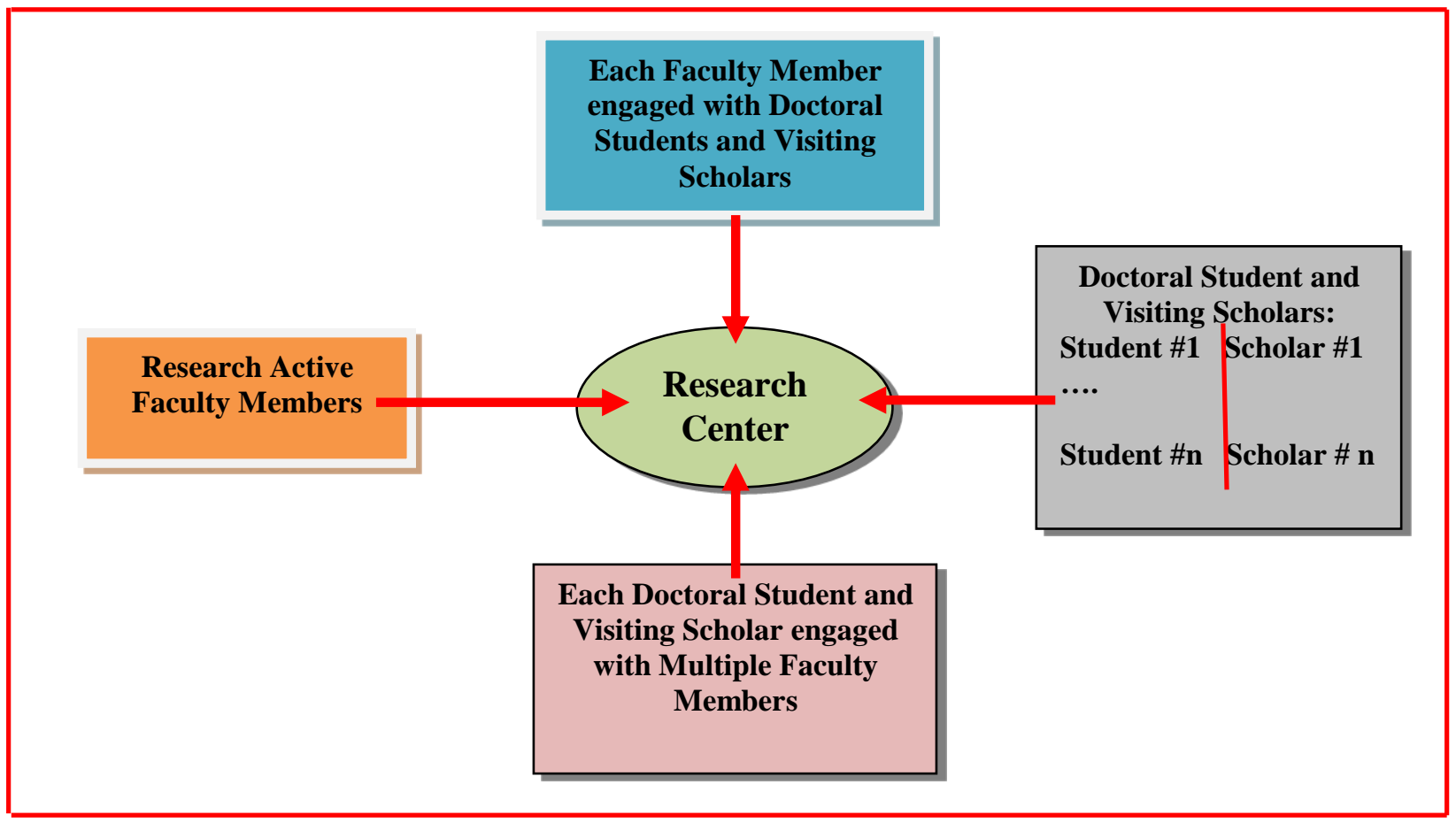

5- Embedded Research: To produce a relevant study, researchers must conclusively answer the "What's in it for me? Questions from the researchers' perspective view. This secures the researcher's attention while solving a relevant research issue. This involves interacting and engaging with the national economy and society to identify their challenges, and exploring novel insights to solve them.

6-Thought Leadership: The culmination of all research initiatives from a research center is dissemination of knowledge through one or more outlets such as (a) publishing in 
premier scholarly journals and trade-related magazines, (b) publishing books, book chapters, and monographs, (c) organizing academic/practitioner conferences, (d) holding seminars for both faculty and doctoral students, and (e) offering workshops for research scholars and managers.

7-Executive education: Research centers can disseminate knowledge by engaging with the nationwide economy and society through teaching initiatives such as executive education programs. Executive education programs such as the Certificate Program in Business Management are designed to be fast-paced and highly-interactive, focusing on the creation and management of profitable relationships with customers by building brand equity. The sessions emphasize the use of information and communication strategies in researching, selecting, entering, and competing in global research areas.

8-Dashboard metrics: Possibly the simplest yardstick of a research center's productivity would be the contributions in terms of research and implementation within the domain, stemming from its ability to generate a continual stream of research ideas, newer methodologies and techniques, strategies and solutions. The example of Research Center's dashboard of metrics offers an approach for other research centers to consider.

Faculty members and doctoral students associated with Research Center have brought worldwide acclaim to the Center for its pioneering work in the area of specified disciplinary. With its research driven by rigor and relevance, Research Center continues to contribute to the growing knowledgebase of the academic community, while also ensuring that the impact of academic research gets duly communicated to the national economy and society.

9-Financial support: The success of a research center relies heavily on its financial wellbeing. Given that the goal of a research center is to conduct research and expand the knowledge base in a safe and secure environment that includes financial stability and security, financial support is critical for its growth and success. Research centers typically receive financial support from one of three sources: endowments, university funding, or self-funding through consulting projects.

\section{3- EVALUATION RESEARCH WORKS at HEIs}

The reasons for ongoing change in higher education are complex and inter-related. Rather than seek to summarize or review the extensive literature on this subject, five key areas will be outlined which are particularly important for their impact on the work of staff within universities. (Based on Coaldrake and Stedman, 1999)

\subsection{1- Reasons for Declining the Higher Education:}

The major reasons for importance of declining educational level in higher education institutions, is the increasing amount of needs and requirements for building the healthy educational and research environment. These reasons are:

1-Growth of Demand on Higher Education: the growth of a mass system of higher education held the potential for serious conflict with established academic traditions. As student numbers increased, higher education institutions were faced with an increasing diversity in student population, both in academic preparation and in terms of culture, 
socioeconomic background and other factors. Students can no longer be assumed to be sufficiently gifted to learn for themselves in the face of indifferent teaching. The mass flow of students has placed in closeness the values of those academics that see higher education as being about critical thinking and disciplinary study. Furthermore, the values of students, many of whom see higher education as being about professional training and the acquisition of a credential which will assist their chances of career advancement.

However, the academic staff and other resources still at the same level with no enough growing rate to meet the mass growing of students. This reason and others leads to declining in quality of even acceptable level of higher education performance.

2-Shortage in Higher Education Financing and Accountability: The expansion of higher education student numbers has not been evenly matched by growth in resources for staffing and other important resources. In particular there has been an increasing separation of resources for research from those dedicated towards general higher education institutions' operations, as already mentioned, and a significant reduction in the level of operating resources per student. Funding for competitive research granting schemes, in particular the government agencies and stakeholders has decreased far faster than standard operating grants.

A further major change has been the shift of responsibility for funding higher education institutions from the Government to the students. Government has gradually repositioned itself from still being a "Godfather" of higher education institutions and allowed the private sector to make the higher education as a highly profitable business and dominate of higher Academic Work, and expects demonstrated accountability and returns for this investment.

3-Level of Knowledge and Creativity: The rapid growth of academic knowledge, not merely within particular disciplines but as new disciplines are created generate new demands for research, and can fragment further the academic profession. This can be achieved through increased competition and the development of separate educational departments, and the advancement of knowledge can go through periods of consolidation, research frequently involves a high degree of specialization and development of knowledge within narrow disciplinary domains.

4-Education and Educational Society: The higher education institutions are bargaining agenda was not pursued at the individual institutional level, but via national pattern bargaining on the part of all the related bodies: government agencies, stakeholders, and society and the higher education institutions. However the environment in which higher education institutions bargaining is occurring, and in particular the absence of salary supplementation, has forced a trade-off between academic staff salary increases and job losses. In such circumstances it has proven extremely difficult to make genuine progress on more fundamental issues to do with changes in academic staff and general staff work.

4-Information Technology and the Digitalization: Information digital technologies have already had a significant impact on higher education, and will continue to reshape the education landscape in coming years. However there are good reasons for believing that the new potential offered by information digital technologies will be markedly different to 
the past. In contrast to the largely static nature of former technological developments, the growing power of networked computing and the convergence of digital information systems and communication technologies hold the promise of enhancing communication and personal interaction, aspects which are central to education.

Increasingly, however, digital technologies applications are underpinning and supporting innovation in teaching and learning. This latter use is perhaps most widely developed in those higher education institutions specializing in distance education, but is not restricted to this group. Initially the use of digital technologies in teaching was driven by motivated individuals, sometimes supported with internal grants. These changes require coordination, planning and resourcing at an institutional level, in an environment where digital technological changes are rapid and demands for tailored applications are growing.

Furthermore, moves towards greater use of technological and resource-based teaching and learning involve reappraisal of the suite of tasks normally undertaken by academic staff. These can comprise (Coaldrake \& Stedman 1998, p. 92):

- Assessing students' credentials and giving credit for entry;

- Designing and coordinating units and courses of study;

- Designing and developing resources used in learning, including textbooks, videos, and computer software packages;

- Assessing resources for education quality;

- Navigating and advising students through choices of study programs' options;

- Delivering instruction - for example, by lecturing or demonstrating practical work in tutorials sessions and laboratories;

- $\quad$ Acting as guide and mentor to students, either individually or in groups;

- Assessing, evaluating and providing feedback on student progress; and

- Certifying completion of award programmes.

\subsection{2-Evaluation Methods of Research Works:}

The objective of evaluation is not a single flawless study, but a succession of studies that critique and improve upon each other as they collectively advance toward norms of formal evaluation methodology. There are advantages and drawbacks of all of the measures and methodologies. Given these pros and cons, many of the methods are complementary. Potential weaknesses of numerical indicators could be remedied by reviewing them by peers, for example (Iorwerth, 2016).

Before getting into detail on what is being evaluated, it may be useful to present a stylized model on how the research process can be represented as a system. The ability of the institution to transform inputs into outputs depends on the structures and processes in the institution but the entire transformative process also depends on the workings of a state's economy. The Figure (7.2) illustrates the simple research system models of research processes. (Iorwerth, 2016)

In Figure (7.2), resources (People, funds, curriculum, and time) are inputs to be used within the higher education institutions in producing the outputs (research works, and community services) through the educational processes. The outcomes from the research works means the benefits that have an impact on society such like development new technology, improve the performance of the nation economy and so on. The ability of the higher education institution to transform inputs into outputs (outcomes) depends on the structures and processes in the institution but the entire transformative process also depends 
on the workings of a national economy. Clearly the feedback of impacts on resources and educational processes is important in educational system.

Figure (7.2) The simple research system models

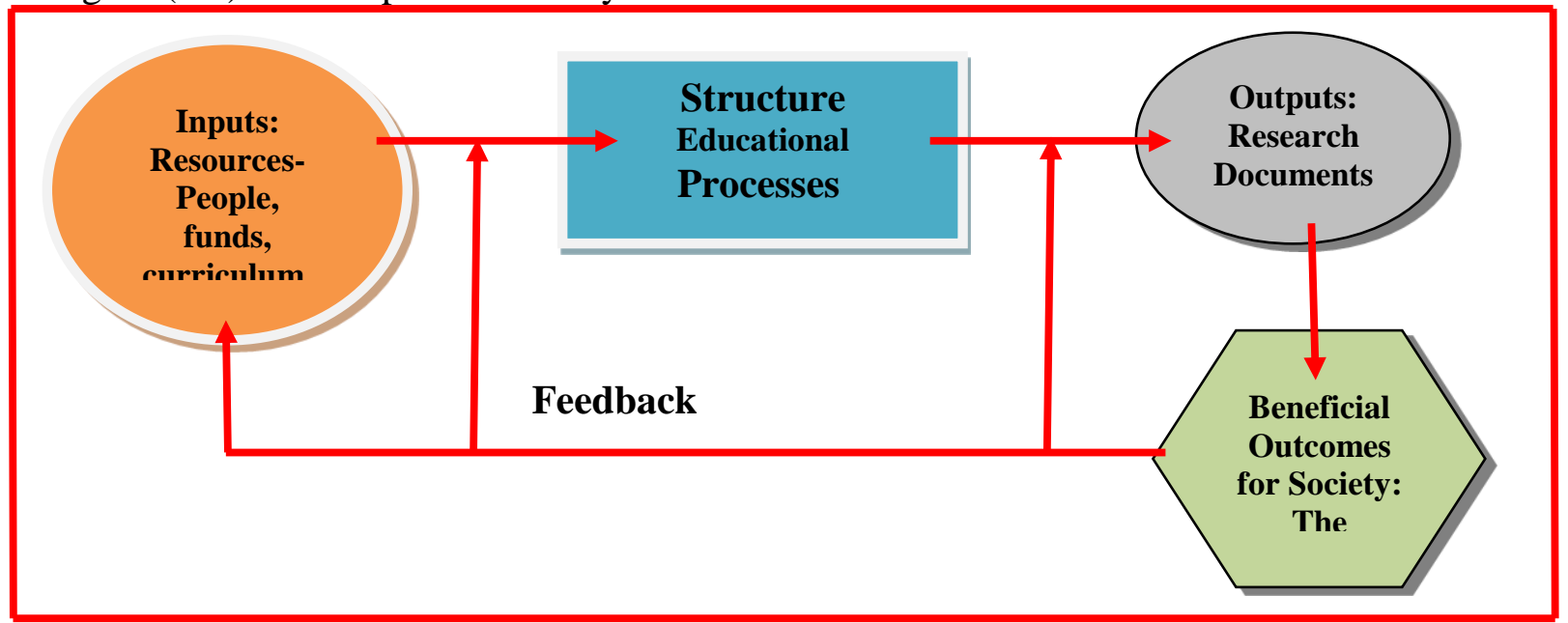

Accordingly, this section addresses three questions: (Based on Iorwerth, 2016)

1. What output is to be evaluated?

2. Who is to be evaluated?

3 . How is evaluation done?

1-The output to be evaluated: The key role of valuation is to assess whether or not goals are being met. In order to fulfill this objective, it obviously follows that the desired goals have to be clearly defined. At this stage, we will merely observe that the government desires beneficial impacts on society. Figure (7.2) can also be used to illustrate some of the concepts used and to demonstrate certain difficulties in understanding the operation of the system. The traditional approach to examining the efficacy of a research system is to quantify the inputs used by institutions, such as the number of researchers or dollars expended. Clearly, these measures do not necessarily illuminate how the research system works or whether there is a beneficial impact.

A further distinction in evaluation is whether it performs a summative or a formative function. Summative evaluation involves assessing the performance of a unit (department, university, etc.) based on accumulated evidence in comparison with that of similar units. The goal of this type of evaluation is to find out what is going on. Formative evaluation on the other hand aims to assist the unit in meeting its goals, in obtaining data that could improve performance. To a certain extent summative evaluation can be an ongoing process to monitor a system whereas formative evaluation can be more exceptional (Iorwerth, 2016). 
For government, consequently, evaluation of higher education institutions research could imply measurement of its:

- Quality

- Efficiency

- Relevance

- Viability

- Effectiveness

2-Who is to be evaluated: A fundamental difficulty with evaluating the research output of a HEI is that: (a) there is fundamental heterogeneity between disciplines (e.g. cost and time to publication); and (b) HEIs will have different specializations. Combining these two factors implies that research output will differ across HEIs not only because of the differences in the quantity and quality of output but also because of composition differences within HEIs.

On the other hand, the how citation rates differ across subjects: there is a much greater rate of citing papers in molecular biology and genetics than in mathematics, for example. Different citation rates could be caused by fewer researchers in a field, greater difficulty in making breakthroughs, different rates of complementarities between research within a field, being more mature subject areas or a host of other explanatory factors. These difficulties are replicated when evaluating the research output of a university as a whole as opposed to an individual department. Consequently producing indicators for HEIs as a whole would seem to be counterproductive. Such an indicator would likely be prejudiced against higher-cost disciplines where there are long lags to publications. Indicators for HEIs as a whole are not informative because they would not give an opportunity for less successful departments to learn. Each discipline should be evaluated separately. But one should emphasize that in evaluating each discipline, it is not necessarily only the academics within each discipline that are being assessed.

The implications of research evaluation are relevant to individual university departments, to higher education institutions, to granting councils and to governments.

3-How research is evaluated depends to a large extent on what one wants to evaluate. Recalling the terminology of Figure (7.2), and Table (7.2) summarized the type of research evaluation that is appropriate.

Table (7.2) Indicators and Evaluation Techniques for Research (Based on Kane, 2001)

\begin{tabular}{|c|c|c|c|}
\hline Level of analysis & Input & Output & Impact \\
\hline $\begin{array}{l}\text { Research } \\
\text { team/Project/Policy } \\
\text { scheme }\end{array}$ & & Peer review & $\begin{array}{l}\text { Case study, } \\
\text { Surveys/Interviews }\end{array}$ \\
\hline $\begin{array}{l}\text { Firms/Institution/ } \\
\text { Discipline/Policy } \\
\text { instrument }\end{array}$ & $\begin{array}{l}\text { Human } \\
\text { indicators }\end{array}$ & $\begin{array}{l}\text { Bibliometrics analysis, } \\
\text { Patents analysis }\end{array}$ & $\begin{array}{l}\text { Cost benefit analysis, } \\
\text { Financial methods }\end{array}$ \\
\hline $\begin{array}{l}\text { Sector/Industry/ Field } \\
\text { of science/ policy } \\
\text { program }\end{array}$ & $\begin{array}{l}\text { Research \& } \\
\text { Development intensity } \\
\text { indicators } \\
\text { (expenditure) }\end{array}$ & $\begin{array}{l}\text { Price and quality } \\
\text { measures (Balance of } \\
\text { payment indicators) }\end{array}$ & $\begin{array}{l}\text { Growth accounting } \\
\text { analysis, Models of } \\
\text { productivity spillovers, } \\
\text { Models of knowledge } \\
\text { flows }\end{array}$ \\
\hline $\begin{array}{l}\text { System-wide: } \\
\text { International, National } \\
\text {, Regional }\end{array}$ & & $\begin{array}{l}\text { Technological } \\
\text { intensity of production }\end{array}$ & $\begin{array}{l}\text { Technology foresight } \\
\text { exercises }\end{array}$ \\
\hline
\end{tabular}




\subsection{3- Establishing the National Education Qualification Center:}

Furthermore, the primary new practices of external academic evaluation and quality assurance and the issues they raise for higher education. (Based on Dill, 2007)

1-Development National Education Qualification Center (NEQC): In response to the changing environment of higher education, it's a time to adopt a National Education Qualification Center of bachelors, masters, and research doctoral degrees. The initial rationale for this center is to provide international recognition for academic degrees as well as to help in placing program graduates in the global market. However, by providing broad descriptors of learning outcomes specific to each level of academic degrees, academic qualification center also provide some potential reference points for external evaluation and quality assurance practices (McInnis, 2005).

A more refined example of degree frameworks is the UK Subject Benchmarks program. The massification of higher education has also produced many new professional or more vocational higher institutions' programs for which clear agreement on academic content and student learning outcomes is often lacking. In response to a growing concern about the comparability of academic standards across academic programs, the UK systematically created Subject Benchmark Committees to publicly define appropriate academic content and threshold standards at the level of each subject field. Over a five year period the UK committees developed subject benchmarks for programs enrolling the vast majority of first level students (Williams, 2005).

The new (NEQC) does play a role in external evaluation and quality assurance, the fact that the higher education component of this center and benchmarks is usually defined by academic staff means that the center's impact on academic standards is limited and usually indirect.

2-Research Evaluation and Quality Assurance: One of the most important functions of the (NEQC) is new practices that should design to assess quality in existing higher education programs and institutions. The new assessment practices included academic research works and audits, programs assessments, and new forms of academic accreditation. Each of these practices which adapt a similar sequence of activities - an institutional self-study, an external peer review, and a public report of findings - but the focus of each practice differed.

According to Dill (2007), subject assessments, as implemented in countries such as the UK, the Netherlands, and Denmark, involved systematic evaluations of the quality of delivered performance of study programs with emphasis on curriculum, teaching, and program relevance to graduates and the economy. In contrast, academic audit as implemented in countries such as Australia, the UK, and Hong Kong, focused on the processes that institutions use to assure themselves that their chosen standards are being achieved, also in Sweden is usefully termed education quality work accreditation. Additionally, as implemented in Europe is similar to US accreditation in its assessment of a program's capacity for quality and its binary judgments about the attainment of threshold academic standards. The Quality and its binary judgments use about the attainment of threshold academic standards. But the European practices differed in their focus on study 
programs rather than institutions, in their comprehensive coverage, and in their attention as well to the effectiveness of program quality assurance activities.

3-Information and System Digitalization: The development of performance indicators to help assure academic standards has become an important external quality assurance practice in many countries. As higher education has become more competitive nationally and internationally indicators of academic quality have increasingly been published by government, academic, nonprofit, and commercial entities. Also, to better inform student choice of an educational program. While government subsidies of higher education in every country are predicated on the belief that the educational value added by higher education programs produce beneficial outcomes for society. These social benefits are difficult to gauge directly, therefore external quality assurance utilizes proxy measures of academic quality. These include: more immediate outcome measures such as graduate placement, salaries, and satisfaction with education program; output measures such as student test scores, completion rates, and marks; and various process measures such as student engagement.

Outcome measures such as graduate placement and salaries are informative and generally valid quality information for potential students and could also be valuable general indicators of effectiveness for academic programs if used by institutions. Readily available output measures such as student marks or graduation rates may be unreliable indicators of academic quality because they can be increased by lowering academic standards. For this reason performance-based funding or contracts, which are usually based upon available input, process, and output measures, has proven to be an inadequate instrument for assuring academic standards (Dill, 2007). However, a need to be supplemented by government mandates on quality information provision and external quality assessments.

While common graduate exams exist in certain professional fields such as medicine, engineering, and teaching have been utilized in association with external assessments by professional accrediting agencies in the UK, Canada, and the US to improve academic standards, common exams do not exist in all subjects. The exams provided influential performance information, but could not effectively assess the actual value-added by an academic programs.

4-Research Grants: The Centre (NEQC) should offer several types of educational research grants for researchers and scholars' different levels. These are:

(a) Reviewing existing grants and awards for educational research at higher education institutions.

(b) The grant for academic publications (papers and books).

(c) Scholarships of graduate studies, teaching, and learning.

(d) Providing research training programs and workshops.

Finally, it's useful to consider here is the relationship between academic work and institutional change. If the higher education institutions are to become more selective at the institutional level, then they must find ways to link the work of individual academics with the overall direction of the institution. This imperative is reinforced by the pressures being felt by academics as their work becomes more complex and specialized and as fewer public resources are available to support a range of activities. This will require not only 
management initiative, but also a renegotiation of the balance between institutional objectives and individual academic freedom, and a reconceptualization of what comprises academic work.

There are several strands which need to be drawn together to achieve this (Dill, 2007).

- Processes and systems which provide the frameworks for linking individual work to organisational strategic goals and comprehensive performance management.

- Staff management systems which recognize and coordinate the contribution to university objectives of the work undertaken by all groups of staff, not only fulltime academics. Thus part-timers and general staff need to be integrally involved in strategic developments and supported by the higher education institutions.

- Greater flexibility in criteria used to assess the performance and prospective work of academic staff. These criteria should applied at the times of appointment and promotion, but should be also a part of a more seamless system of performance management which defines expectations for staff and provides feedback and development opportunities.

- Procedures for determining workload of academics' staff need to be flexible and adapted to local conditions.

- Greater interaction and transfer of academics' staff between higher education institutions and external organizations and between academic and non-academic positions.

- Improved capacity for collaboration among universities and between universities and external organizations.

- Capacity to recognize and reward performance in a more flexible and diverse environment. This might involve, for example, linking remuneration less tightly to academic rank and moderating it by market factors and personal performance.

\section{6- INFRASTRUCTURE EVALUATION}

Education infrastructure includes suitable spaces to learn, well-equipped labs, research facilities, sports' center, information communication technology (ICT), and other service facilities. This is one of the most basic elements necessary to ensure access to education. HEIs' classrooms are the most common place in which structured learning takes place with groups of students.

Infrastructure evaluation at Location of onsite infrastructure (such as fire and life safety; utilities such as boiler house, electrical substation; security; specialized industrial equipment, assets, services and chemicals).Infrastructure serving the site (electric, natural gas, fiber optic cable, water, sewer, storm water, wastewater systems and other utilities or resources).

\subsection{1- Information Communication Technology (ICT):}

The HEIs' environment of the new millennium is responsive, dynamic and competitive, and is in a constant state of stakeholders-centered change. This change has been largely initiated by innovations in information and communication technologies, which have led to the creation of the information-based education. The more technology, human and higher education institution fit with each other, the greater the potential of education information communication system. 
Information communication technologies (ICTs) infrastructure is the components required to operate and manage HEI's IT environments. ICT infrastructure can be deployed within a cloud computing system, or within an HEI's own facilities. These components include hardware, software, networking components, an operating system (OS), and data storage all of which are used to deliver ICT services and solutions.

I- ICT Roles: The framework of ICT incorporates a range of methods including: surveys, interviews, stakeholders groups, administrative and academic processes, education tasks' analysis, research works, log management transforms, education evaluation techniques, evaluation results mapping, and education outcome indicator data analysis. Each of these methods is briefly elaborated below. (Based on Westbrooka, et.al. 2004)

1-HEI Profiling: The HEIs profiling process will capture extant organizational and systems-wide data including budgets, human resource profiles, library profiles and archive profiles, services profile, organizational structure, existing education process indicators and current information technologies.

2-Stakeholders Groups: Thus includes the data analysis from institutional profiling, and stakeholders group, and focus on conducting with administrative and academic staff. The profiling will be structured to determine views and attitudes toward ICT and the impact of these on various aspects of academic and administrative works.

3-Administrative and Academic Processes: The importance of developing a robust and responsive information communication technology (ICT) and information system (IS) infrastructure to support the formal planning and control of administrative and academic processes is increasing in importance. The HEI should take care about the evaluation and management of technology-based resources. In particular, explaining that the management of investment in the capabilities of IT networks, people, data, and software may be one of the most important decisions taken by senior management regarding expenditure. So, the ITC makes it possible to improve administrative and academic processes efficiency and effectiveness, which can provide education cost benefits and competitive advantage.

4-Education Tasks' Analysis: Task analysis is a process in which broad goals are broken down into small objectives or parts and sequenced for instruction. The use and function of tasks' analysis in higher education institutions is becoming the most proposed instructional system for teaching and learning students with learning knowledge problems. Tasks, skills, assignments, or jobs in the classroom become manageable for all children, which allow them to participate fully in the teaching and learning process (Lynch, 2019).

(a) Watching a master: To know how to help students walk the balance beam, watch someone who is doing this task well;

(b) Self-monitoring: To know how to help students make a review the steps that you follow in accomplishing the task;

(c) Brainstorming: To know how to help students plan a research project and ask all the students to give you ideas.

(d) Goal analysis: To know how to help students develop conflict resolution strategies, review the observable and nonobservable aspects of this task, and identify ways to see how it is accomplished. 
5- Education Research Works: Education research is the field of study that examines learning processes that shape educational outcomes. Education researchers may analyze student learning, teaching strategies and training and classroom management. Scholars seek to understand and explain how learning takes place through the course of an individual's life. Education research refers to understanding and articulating how a specific teaching or learning issue may be resolved. This type of research can be quantitativewhich involves statistics - or qualitative - which includes a thematic analysis. The goal of this research is to employ a methodological process to contribute to the existing body of knowledge on the educational landscape.

6- Log Management Transforms: The National Institute for Standards and Technology (NIST) defines log management in Special Publication (SP800-92) as: "the process for generating, transmitting, storing, analyzing, and disposing of computer security log data." Put simply, log management is defining what you need to log, how to log it, and how long to retain the information. This ultimately translates into requirements for hardware, software, and of course, policies.

7- Education Evaluation Techniques: Defined as an instrument to collect evidences of the student's achievement. Achievement test, cumulative record, check list, rating scale, questionnaire, etc are the main tools of evaluation in higher education institutions. The instructor can employ any one of the available tools of education at his/her disposal to know about: (a) The extent to which educational objectives are being achieved; and (b) The effectiveness of the teaching-learning experiences provided in the classroom situation.

8- Education Outcome Indicator Data Analysis: Are statistics that describe key aspects of schooling which permit the evaluation and monitoring of schools, teachers, programs, and students. It is argued that validation of educational indicators should be concerned with the extent to which information provided by each indicator is able to demonstrate effects upon student outcomes.

II-ICT Assessment: The HEIs have become reliant upon Information Technology (IT) and Information Systems (IS) to support their education processes.The ICT infrastructure assessment is a comprehensive review of HEIs' current information communication technology (ICT) systems that is outlined in the service. A complete ITC infrastructure assessment should include a documented review of the following areas:

- Server Environment

- Application Delivery

- Print Environment

- Network and platforms

- End User Devices

- Security

- Backup

- Policies and Procedures

ITC infrastructure assessments can be a valuable tool for the HEIs. However, when considering an assessment for higher education institution, it is important that will have a 
thorough understanding of what you will be getting. Many IT Service providers offer free Assessments that may appear attractive, but often end up being nothing more than a deceptive sales pitch. ICT infrastructure assessments are often the first step in making long lasting, critical changes to the HEIs' IT environment, so it is important that should be comfortable and confident that this assessment will lay the foundation HEI want. Here are a few quick reasons why assessments are an important tool for ICT foundation:

- Identify issues requiring immediate attention: Often, an assessment can reveal significant issues, such as a education issue or students' final scores.

- Demarcation Point: You need to understand the past before you can comprehend the future. Assessments let you know exactly where you stand and can become a comprehensive plan for future ICT infrastructure upgrades.

- Education for top management or/and ICT Executive: Assessments are a particularly valuable tool for the HEIs' leaders to proper leading the institutions. They provided a documented view of the current environment, and can identify issues that the top management may not be aware of.

- Follow up to a significant Outage: If the top HEI's management recently experiences an outage or serious education issue, than an assessment is a great way to kick off the detective process. A proper assessment should identify the reason for the outage, and outline a plan to prevent it from happening again.

III-The Role of ICT in On-Line Learning: Today the focus is not only on online environments but also embraces "a full range of computer based learning platforms and delivery methods, genres, formats and media such as multimedia, educational programming, simulations, games and the use of new media on fixed mobile platforms across all discipline areas" (Nicholson, 2007). Nicholson goes on to state that the key to accommodating e-learning is increased adoption of constructivist paradigm "and the uptake of constructivist pedagogies". This led to increased collaborative online learning environments (Phiri, et.al. 2014). Accordingly, it is important to begin this by differentiating between e-education and e-learning. The e-education involves e-teaching and e-learning along with the various administrative and strategic measures needed to support teaching and learning in an Internet environment. It will incorporate a local, regional, national and international view of education (Phiri, et.al. 2014).

The higher education institutions context, the concept of e-education revolves around the use of (ICT) to accelerate the achievement of national education goals. Eeducation is about connecting learners to other learners, academic staff to other staffs, academic cooperation to other institutions, and to professional support services, and providing platforms for learning. E-Education will connect learners and teachers to better information, ideas and one another via effective combinations of pedagogy and technology. So, the higher education institutions will consider The (ICT) as a: (1) Tool for management and administration; (2) Resource for curriculum integration; (3) Communication tool; (4) Collaborative tool for teachers and learners; and (5) Learning environment that advances creativity, communication, collaboration and engagement.

However, before the outbreak of the pandemic, digital learning was an option at the HEIs. Different education institutions realized its importance and incorporated technology 
as a part of their ecosystem via smart classrooms and other ICT infrastructural developments. But for a world that has been witnessing the impact of COVID-19, digital learning is the new normal and only way to continue imparting knowledge to millions of educational aspirants. Higher education institutions which had a shut campus to curtail the spread of the virus have quickly adopted the digital medium of instruction delivery module. Hence higher education institutions have to invest in building the digital infrastructure to make education accessible for all students.

\subsection{2- Laboratory Evaluation:}

Laboratory assessments allow for precise control of the experimental parameters that elicit participant responses. Assessment of students in a laboratory situation provides a unique source of objective information that cannot be obtained by other means. Evaluation is the collection of, analysis and interpretation of information about any aspect of a programme of education or training as part of a recognized process of judging its effectiveness, its efficiency and any other outcomes it may have (Thorpe, 1988).

There are initially two distinct approaches to evaluation the educational labs in HEIs. These are: (Based on Crompton, 2020)

1-The scientific approach;

2- The social/anthropological or illuminative approach.

The scientific approach is concerned with the measurement of the effects of specific variables against the resultant outcomes. It seeks to examine the achievement of stated goals in relation to a learner's pre-knowledge and skills. The approach is geared towards the measurement of the efficiency of the educational intervention as well as the effectiveness of the learning outcomes.

The illuminative approach on the other hand seeks to examine and explore the process of the educational intervention. The techniques, as such, are therefore more qualitative, some might say, more subjective in nature as they call on personal judgments.

Though these approaches appear to be at either end of a continuum, it is possible to make use of both within the complexity of what is educational research. A selected midpoint will be governed by that which is being evaluated as well as the reason behind the evaluation. It is not uncommon to see a mix of techniques from both approaches combined in an evaluation project. The degree of combination will depend largely on a process of negotiation between the evaluator and the instigator of the evaluation as well as the environment and the time frame in which the evaluation is being performed.

Whichever approach or combination of approaches is used, the evaluation should always be a clear well thought out undertaking. The more effort, that goes into the preplanning of a piece of evaluation the better the evaluation. Before conducting any evaluation it is important to not only have defined that which you are trying to investigate but also how you are going to go about it (Crompton, 2020).

Levels of Evaluation: A differentiates between the scope (Levels of Evaluation) and depth (Levels of Analysis) of an evaluation, are: (Romiszowski, 1988).

Level I - Project Level

Level II - Curriculum Level 
Level III - Unit Level

Level IV - Learning Step Level

It is necessary to predetermine at which level the evaluation is to be conducted. Evaluation is of great importance in all aspects and stages of teaching and learning. All too often it is seen as the last activity and yet states it is an iterative process and should take place at every stage in the design, production, implementation/integration of a new educational intervention (e.g. using learning technology materials) whether it be as a complete course, part of a course, or a particular session or teaching aid. There are two possible stages for evaluation;

a) The evaluation of the IT intervention in isolation, and

b) The evaluation of the IT intervention within the course itself.

The evaluation of a piece of courseware in isolation will tend to focus inwardly on various aspects of the software itself. It will look at aspects like navigation, screen design, text layout, etc. It will examine the scope of the coverage of the material content. The evaluation of the courseware within the course itself will allow us to examine other factors which will lend themselves to the successful integration of the product within the course. These will be: (Crompton, 2020)

- educational setting

- aims and objectives of the course

- teaching approach

- learning strategies

- assessment methods

- implementation strategy

The iterative nature of evaluation should then assist in making the learning experience both more efficient as well as more effective as the feedback is used to continuously improve matters. It is important to recognise at the outset that evaluation is a time consuming exercise and better planning can save time and effort in the actual evaluation process. It is more advisable to do a small evaluation well than to try to do a large evaluation and run out of time. Important to have an adequate amount of time needs to be allocated to both the analysis and writing up stages.

Effectiveness, Efficiency and Relevance: Two main concerns for evaluation in the context of the teaching labs and technology performance (TLTP) initiative have been the need to justify technology-based learning on the grounds of effectiveness and efficiency. A third factor should be added to the list and that is relevance; the applicability and appropriateness to the intended employers and users of the technology, the teachers and students, even the department or institution. The following are factors open to consideration and investigation by an evaluation study (Crompton, 2020). 
(a) Factors in achieving Process (Efficiency):

- Cost

- Structure

- Alternatives

- Resources

- Organisational

(b) Factors in achieving Objectives (Effectiveness):

- Cognitive and/or Physical Skills

- Affective

(c) Factors in achieving Satisfaction (Relevance):

- Affective

- Scope of the Content

- Degree of Effectiveness And Efficiency

The evaluation of these factors will lend themselves to improvements in both the course, in terms of aims, objectives and content, and the procedures for the design and development of the course itself.

Questionnaires: This is probably one of the easiest and simplest instruments to create for data collection. However this apparent simplicity belies the fact that creating and organizing your questions can be quite arduous and time consuming. You should be clear about the areas and concerns that the questionnaire is to cover. Do not attempt to ask everything as this will tend to make the questionnaire too long and by so doing decrease the willingness of the respondent to answer fully and thoughtfully.

\subsection{3- Academic Library:}

According to the growing number of higher education institutions implementing library portals, there are also growing interests among researchers to investigate the effectiveness of library portal. So, driven by effort to better serve users (students, researchers, and learning people), many libraries of higher education institutions have developed and implemented a library portal. In this regard, library portal effectiveness is defined as the composite relationships of inter-related constructs consisting of information quality, systems quality, service quality, user satisfaction and individual impact.

The simple definition a library portal is a personalized, customized and integrated information service to aggregate all kinds of library resources and services through a single access and management point for our users (Masrek, 2010). Enumerates that in a typical academic library portal, the characteristics that should be present include: tools for resources and services discovery; personalization and customization that would help individual users to automatically direct to required resources; cross-searching i.e. The ability to target heterogeneous resources; cross-linking to document delivery and different 
information service; citation management i.e. Moreover, the ability provides the user to effectively manage his searching results; authentication and authorization i.e. a single point of authentication; and statistics about users and usage (Pan et al, 2004).

However, among the benefits of implementing library portals are easier access for users i.e. ease of searching many sources at once; simplified authentication (reducing the barriers of multiple logs-on); unified presentation of quality resources; and personalization (customization according to individual preferences) Pan et al. (2004).

The majority of leading higher education institutions uses the snapshot of the home page of the UiTM digital library portal. Prior to entering into the library portal system, users are required to provide the user name and password. Among the prominent services of the library portal are online public access catalogue; e-resources such as online databases, exam papers, research reports, e-books and e-journals; facilities and services such as SMS service, user guide, serial services, newspaper feeds, virtual research facilitator and virtual tour. Besides the abovementioned services, the UiTM Library Portal also provides numerous information such as Frequently Asked Question; news and events. Within the library portal lays the library information systems known as Integrated Library Management Utility (ILMU). The ILMU system is made of several modules namely acquisition, cataloguing, authority, circulation, info-track, IRS, serials and accounting. In a nutshell, the UiTM Library Portal features fulfill all the basic characteristics of a library portal.

Library Website Evaluation: In the recent decades, usability studies have received significant attention in the field of Library and Information Science. Usability consists of multiple constructs from various perspectives, such as effectiveness, efficiency, subjective pleasure, memorability, and others, focusing largely on interface design. Usability indicates to what extent a Website is easy to use, efficient in performing a specific task, and satisfactory for end users. The usability studies either yields system design principles or intends to improve the design of an existing system. There are different attributes of usability from various disciplines, namely, usefulness, effectiveness, learnability, and attitude. One model, which is one of the most cited in the usability engineering area, posits five attributes: learnability; efficiency; memorability; low error rate (easy error recovery); and subjective satisfaction (Based on Joo, et.al, 2011

Another representative usability model that is proposed by the International Organization for Standardization (ISO) accounts for usability based on three main constructs, such as effectiveness, efficiency, and satisfaction. ISO has established these three constructs as an international standard and named ISO9241-11. Other models of usability share similar perspectives while adding more constructs. For example, Brinck's (2002) definition of usability includes functionally correct, efficient to use, easy to learn and remember, error tolerant, and subjectively pleasing, while Oulanov and Pajarillo (2002) postulated efficiency, helpfulness, and adaptability as usability attributes. In his usability test study, Lee (2004) adopted multiple usability criteria like usefulness, effectiveness, satisfaction, supportiveness, and intuitiveness. More extensively, the MIT Information Services and Technology Department (2011) published a usability guide line that includes ten attributes such as navigation, language and content, architectural and visual clarity, and functionality. There is a small body of research on investigating usability evaluation in library settings, since library evaluation has focused more on usage, service 
quality, and collections. Some examples of usability evaluation are introduced in relation to library websites. Other researchers are investigated users' resource selection while using a library homepage based on user experiments on website prototypes (Joo, et.al., 2011).

In academic libraries, there are a few of evaluation tools customized to academic library settings. Association of Research Libraries (ARL)'s LibQUAL+TM is one of representative evaluation tools developed to assess service quality on the basis of SERVQUAL framework (Cook \& Heath, 2001). LibQUAL+ employed the gap theory of service quality like other SERVEQUAL-based evaluation frameworks. Extending LibQUAL+, recently, DigiQUAL project developed a service quality model reflecting digital environments (Kyrillidou \& Giersch, 2005). These evaluation frameworks specialized for academic libraries has limited to assessment of service quality. Although there are many attempts to assess usability of digital libraries, few usability evaluation models focused on the website of university libraries. In particular, although (ISO 924111) has widely applied to different types of information systems, it is not introduced sufficiently as a way of user survey method for assessing library website usability in HEIs. These efforts in library website usability evaluation have greatly helped to enhance the library website design reflecting users' actual uses of the system. However, in terms of usability test method, usability tests in library website evaluation have been limited mostly to formal usability test, which is usually conducted in labs with a limited number of subjects.

To develop an evaluation tool to evaluate the usability of academic library website on the basis of user survey method. According to (ISO 9241-11, 1998), usability is defined as the extent to which a product can be used by users to achieve specified goals with effectiveness, efficiency and satisfaction in a specified context of use. As the definition shows, three constructs are used to account for usability in this standard, namely effectiveness, efficiency, and satisfaction. The definition for each construct is following:

(1) Effectiveness refers to the completeness at which users achieve specified goals

(2) Efficiency refers to the resources used in completing a task; and

(3) Satisfaction reveals positive attitudes toward using the system (ISO, 1997).

Satisfaction would be a potentially controversy issue in designing usability evaluation research.

Library Measurement items: An initial set of measurement items was extracted from related literature in usability studies. The authors reviewed previous literature in three domains: Firstly, most widely cited usability models were reviewed to identify measurement items, such as in Nielson's usability attributes (Nielson, 1993), (ISO 924111) standards (ISO, 1998), and Shackel's model (Shackel, 1991); Secondly, some practical usability test manuals were utilized to generate initial measurement items (Nielson \& Mack, 1994; Ray, 2002); Lastly, several empirical usability evaluation studies were chosen in various disciplines. All the chosen measurement items were modified to reflect the unique features of academic library websites (Joo, et.al, 2011). 


\section{CHAPTER EIGHT: CONCLUSION AND RECOMONDATIONS}

\section{1-CONCLUSIONE:}

The public higher education institutions (HEIs) are of late under pressure and face many of the challenges that are also faced within the private sector. In response to these pressures for change and in the efforts to become more efficient and effective, public higher education institutions should adopt management techniques that were originally practiced within the higher education institutions. As higher education institutions are leaders in the use and innovation of the technologies' development, can makes perfect sense that they also embark on reengineering their organizations. We believe that business process reengineering (BPR) and total quality management (TQM) are the only thing that stands between higher education institutions and disaster in this fast-changing world. It is time for higher education institutions to reinvent themselves.

It takes into time to implement comprehensive integrated project consists both TQM and BPR, and reach a level where quality becomes the culture. Projectization and project implementation is the first taste of TQM in the higher education institutions. Continuing this trend through continuous evaluation, monitoring and preplanning will lead to the level of change as a culture. With the implementation of TQM in higher education, a radical change can be brought for bringing about satisfaction among the customers for maintaining quality in an effective manner. Moreover, it can be concluded that the TQM is basically concerned with the system approach (input, process, outputs, and outcomes), which can be implemented after identifying the constraints of higher education.

The discussions so far on quality in higher education and its measurement are premised on two important considerations: that the central activity of higher education is that of maximizing the student's educational development; and that it is the continuing improveimprovement to maximize student learning and development that remains the primary goal of HEIs and should be the focus of any concern over quality in higher education and its measurement. Any measurement of quality and performance evaluation in higher education that falls short of the centrality of student's experience is bound to be peripheral and fail. To provide information about how much students are learning and the experience of learning and progressing both intellectually and emotionally throughout their years in HEI.

Learning is an active process of constructing rather than acquiring knowledge, and construction is a process of supporting that construction rather than communicating knowledge. In other words, learning should be an activity in context. Learning to conduct research and design activities can increase student knowledge, skills and awareness about science and engineering practices, enhancing their worldview on possible future professions as well as understanding the development of science and the links between research and design.

An academic program or the institution is an assessment embedded at the course level (sometimes referred to as embedded assessment or Authentic assessment) typically involves the use of assignments. Students receive feedback on their performance on assignments and faculty gain knowledge of student learning to use for grading. 
Assessment criteria are descriptive statements that provide learners and instructors with information about the qualities, characteristics, and aspects of a given learning task. Assessment criteria make it clear to learners what they are expected to do to demonstrate achievement of the learning outcomes. Factors instructors will take into account when making judgments about their performance. Sharing assessment criteria with students at the beginning of the course is an effective way to help students build confidence in their learning and improve their performance.

The present study aimed to contribute to such a conceptual framework by exploring HEI instructors' learning activities and learning outcomes in the context of educational innovation. The most important issue for HEIs is to develop a Learning Outcomes Guide (LOG) which should be covered all the evaluations' techniques of academic processes, research activities, and community services. Furthermore, the selection and coordination of appropriate content, teaching and learning activities, and assessment educations' strategies those promote the overall teaching and learning processes. Instructors measure students' learning - and the level of competency achieved - against the intended result (the learning outcome). Learners' performance is assessed against criteria, rather than against other learners.

Accordingly, the assessment criteria will include two components - criterion and performance standards. Criterion is a property or characteristic by which the quality of something may be judged but make no statement or assumptions about actual quality. Standards are about definite levels of quality (or achievement, or performance). Assessment is a systemic process in higher education that uses empirical data on student learning to refine programs and improve student learning. As a continuous process, assessment establishes measurable and clear student learning outcomes for learning, provisioning a sufficient amount. As a continuous process, assessment establishes measurable and clear student learning outcomes for learning, provisioning a sufficient amount of learning opportunities to achieve these outcomes. And implementing a systematic way of gathering, analyzing and interpreting evidence to determine how well student learning matches expectations.

Program-level Assessment: Program assessment is a best practice in higher education. The process involves a framework for placing priority and attention on the process of student learning and most specifically, the program objectives, organization of curriculum, pedagogy and student development. The outcomes-based approach to teaching and learning is increasingly being used in higher education as the model for best practice in constructing courses and evaluating students' work. Learn more about this approach with this simple, practical guide to building your own outcomes-based programmes (OBPs) and Program learning outcomes (PLOs). These are a description of the knowledge, competencies and values a student displays at the end/conclusion of the program. Program learning outcomes help students understand why this knowledge and these competencies will be useful to them.

HEIs' instructors should be supposed to be experts in learning. Although there is a lot of research on how instructors may promote student learning, the scarcity of systematic research on understanding and improving the learning processes of instructors themselves is striking. However, instructors are the most important agents in shaping education for students and in bringing about change and innovation in educational practices. Too often 
educational innovations have failed because they did not recognize the need for instructor learning.

The most important issue for HEIs is to develop a Learning Outcomes Guide which should be covered all the evaluations' techniques of academic processes, research activities, selection and coordination of appropriate content, teaching and learning activities, and assessment educations' strategies that promote the overall teaching and learning processes. Instructors measure students' learning - and the level of competency achieved - against the intended result (the learning outcome). Learners' performance is assessed against criteria, rather than against other learners.

Within the context of the HEIs, the goal of the learning outcomes philosophy of education is to assist learners to acquire, integrate and apply the requisite learning so that it may be transferable to real-life situations. Developing an engaging course requires a team approach. Each team member brings unique knowledge and perspective to the design and development process, to create an effective course that meets learning outcomes and offers students opportunities to demonstrate their learning.

The outcomes-based approach to course design is intended to make the expectations of the designer/instructor more transparent to both the student and any regulatory or accrediting body. Unlike the traditional model of course design in higher education, where the lecturer would decide what to include on a syllabus, based on his or her own judgement of what was important for students to know; or on personal research or other interests; the outcomes-based approach starts with a specification of what the student will be expected to achieve by the end of the unit.

Student Evaluation of Instructor Performance Program (SEIPP): To conceptualize this research in terms of process variables, global teaching methods and specific teaching behaviors; presage variables, characteristics of teachers and students; context variables, substantive, physical, and institutional environments; and product variables (student academic/professional achievement, attitudes, and evaluations). Student ratings are important both as a process-description measure and as a product measure. This dual role played by student ratings, as a process description and as an evaluation of the process, is also inherent in their use as diagnostic feedback, as input for tenure promotion decisions, and as information for students to use in course selection.

Formal learning and instruction strategies are inseparable. Yet learning theories only describe how learning occurs, but do not describe the specific methods and activities to follow in order to accomplish the intended learning outcomes.

Academic Research Works (ARW): Academic Research is defined as a "Systematic investigation into a problem or situation, where the intention is to identify facts and/or opinions that will assist in solving the problem or dealing with the situation". This academic or scholarly research focuses on research goals/questions that arise from independent instructors-researchers. It uses formal, scientific and systematic procedures to discover answers. The scholarly research is guided by an already existing theory in order to reject or support the theory.

Evaluation Methods of Research Works: The objective of evaluation is not a single flawless study, but a succession of studies that critique and improve upon each other as 
they collectively advance toward norms of formal evaluation methodology. There are advantages and drawbacks of all of the measures and methodologies. Given these pros and cons, many of the methods are complementary.

Development the Research Guide (RG): Rankings have become a widespread phenomenon in an increasingly competitive world of higher education. They differ with regard to their aims, objectives, target groups, and with regard to their relationship to quality and quality assessment. Generally, rankings are an external assessment of the performance of higher education institutions; they enable transparency about systems of higher education. A useful distinction is drawn between internal and external academic quality assurance. Internal quality assurance refers to those policies and practices whereby academic institutions themselves monitor and improve the quality of their education provision, while external quality assurance refers to supra-institutional policies and practices whereby the quality of higher education institutions and programs are assured.

In summary, the measurement of quality teaching and learning within the higher education sector should involve indicators which are significant in informing individual and institutional performance; and where feasible, also significant on a common national or sector wide scale. A useful performance indicator is one that informs the development of strategic decision-making, resulting in measurable improvements to desired educational outcomes following implementation.

Key Performance indicators Program (KPIs) are a means to focus on specific expectations of a program. They facilitate the curriculum delivery strategies, and assessment procedures. There is an important first step that must come before the development of performance indicators, and that is deciding on student outcomes.

Finally, the strongest potential contributions of the quality movement to academic applications in the higher education are:

1- The literature offers many useful ways to conceive and operationalize the notion of quality.

2- Quality models, such as the PDCA, provide a structure that allows for the integration of specific quality improvement efforts. The overall aim is continuous improvement, achieved through systematic, documented learning from experience.

3- A third major contribution of TQM is focus. Improvement in quality is said to result systematically from focusing on improving specific critical process.

\section{2-RECOMMUNDATIOS AND SUGGESTIONS:}

1- This study illustrates efforts to implement Business Process Reengineering through Total Quality Management principles and processes in higher education. These applications are of general interest since colleges and universities are complex organizations with many stakeholders ranging from society at large to local governments, parents, students, faculty, and staff. In other words, a multiorganization institution is responsible for addressing simultaneously a myriad of needs, wants, and claims. 
2- The most important issue for HEIs is to develop a Learning Outcomes Guide (LOG) which should be covered all the evaluations' techniques of academic processes, research activities, selection and coordination of appropriate content, teaching and learning activities, and assessment educations' strategies that promote the overall teaching and learning processes.

3- Assessment criteria should be derived from the learning outcome. Generally speaking, assessment criteria should be as precise as possible; they should describe evidence that is observable; and they should describe only that which is essential to demonstrate achievement of the learning outcome. Assessment criteria should describe characteristics of a product wherever possible.

4- Develop the practical guide to building your own outcomes-based programmes (OBPs) and program learning outcomes (PLOs). These are a description of the knowledge, competencies and values a student displays at the end/conclusion of the program. Program learning outcomes help students understand why this knowledge and these competencies will be useful to them.

5- Develop the students (undergraduate and graduate) research program: Learning to conduct research and design activities can increase student knowledge, skills and awareness about science and engineering practices, enhancing their worldview on possible future professions as well as understanding the development of science and the links between research and design.

6- Develop the Student Evaluation of Instructor Performance Program (SEIPP). Information from students' evaluations depends upon the content of the items. An important issue in the construction of multidimensional rating scale instruments is the content of the dimensions to be surveyed. A logical analysis of the content of effective teaching and the purposes of students' evaluations, coupled with feedback from students and faculty members, is one typical approach.

76-Develop Peer-to-Peer Assessment Scheme: Peer assessment is defined as "an arrangement in which individuals consider the amount, level, value, worth, quality or success of the products or outcomes of learning of peers of similar status". In addition to increasing instructors' efficiency in grading, peer assessment is advocated as an effective pedagogical strategy for enhancing learning.

8- Establishment the Scientific Research Center (SRC): it's so essential to establish a research center in each higher education institutions that can serve as a platform to all the relevant stakeholders in accomplishing their goals to serve the nationwide economy. Established with an international, and most importantly, an interdisciplinary scope, the Center aims to advance the knowledge and practice of modern evidence-based management and to foster impactful research.

9- Development the Research Guide (RG): Rankings have become a widespread phenomenon in an increasingly competitive world of higher education. 
They differ with regard to their aims, objectives, target groups, and with regard to their relationship to quality and quality assessment.

10- Establishing the National Education Qualification Center: In response to the changing environment of higher education, it's a time to adopt a National Education Qualification Center of bachelors, masters, and research doctoral degrees. The initial rationale for this center is to provide international recognition for academic degrees as well as to help in placing program graduates in the global market.

11- Establishing Program Quality Assurance Guide (PQAG): The Program Quality Assurance (PQA) process, which has three elements: Annual Curriculum Review (ACR), Annual Program Mix Review (APMR) and Program Quality Review (PQR). PQA also includes the cyclical review of online elective General Education courses.

7- Establish Developing and Assessing Learning Outcomes (DALO): Which should be covered all the evaluations' techniques of academic processes, research activities, and community services.

13- Establish a Key Performance Indicators (KPIs) Guide: is a measurable value that demonstrates how effectively a company is achieving key business objectives.

\section{وهن الله التمونيمت ..}




\section{References:}

1- Abdus Samad, K. and Thiyagarajan,R., (2015), TQM in Higher Education- A

Conceptual Model to Achieve Excellence in Management Education, International Journal of Management (IJM), Volume 6, Issue 1, January 2015, pp. 618-629.

2- Abdus, M. \& HE, W. (2008), A Framework for Process Re-engineering in Higher Education: A Case Study of Distance Learning Exam Scheduling and Distribution. International Review of Research in Open and Distance Learning, 9(3):pp.1-12.

3- Ajeenkya D. Y. Patil, Dr. Gagandeep Nagra, Dr. R. Gopal, (2014), A Study on Total Quality Management in Higher Education, International Journal of Management (IJM), Volume 5, Issue 5, May (2014), pp.1-6.

4- Ahmed, J.U., (2008), Quality and TQM at Higher Education Institutions in the UK: Lessons from the University of East London and the Aston University, AIUB Bus Econ Working Paper Series, No.2008-12. http://orp.aiub.edu/WorkingPaper/WorkingPaper.aspx?year=2008

5-Ahmed, M., (2021), Complete Guide To NAAC For Higher Education Institutions, 08 January 2021.https://www.iitms.co.in/blog/complete-guide-to-naac-accreditation-for-highereducation-institutions.html.

6- Al-Ali, M. A.S, (2012), Developing the Balanced Scorecard Framework for Higher Education: Conceptual Study, Proceedings of the International Conference on Industrial Engineering and Operations Management, Istanbul, Turkey, July 3 - 6, 2012.

7-Aleamoni, L. M. (1987), Student Rating Myths Versus Research Facts, Journal of Personnel Evaluation in Education, Vo1, pp.111-119.

8- Allen, D.K. and Fifield, N., (1999), Reengineering Change in Higher Education, Information Research, Vol. 4, No. 3, February 1999.

9- Amico. S.D. and J.S. Ardaens, (2012), Space Borne Autonomous Formation Flying Experiment on the PRISMA Mission, AIAA Technical Conference, American Institute of Aeronautics and Astronautics, 2012.

10- Ammons, D. N., (1997), A Brief Guide for Performance Measurement in Local

Government. New Brunswick, NJ: National Center of Public Productivity, Rutgers University, 1997.

11-Anthony.W.,(2020),Teaching in a Digital Edge

https://opentextbc.ca/teachinginadigitalage/chapter/5-2-what-is-a-learning-environment/

12- ASQ, (2021) What are Quality Standards?, ASQ, https://asq.org/qualityresources/learn-about-standards.

13-Assurance Agency for Higher Education (QAA) - UK: http://www.qaa.ac.uk/.

14- Atefi, K., (1997), Formal Models of Business Process Reengineering for Design and

Design Validation, http://www.eil.utoronto.ca/wp-content/uploads/ent-eng/papers/atefithesis97.pdf.

15- Attaran, M., (2004), Exploring the Relationship Between Information Technology and Business Process Reengineering, Information \& Management 41 (2004) 585-596.

16- Azhar, Z., Naz, A., Gul, A., and Nawaz, M., (2013), The Role of TQM and BPR in Executing Quality Improvement: A Comparative Study, European Journal of Business and Management, Vol.5, No.1, 2013.

17-Baker, et.al, (2012), Using Assessment Results: Promising Practices of Institutions

That Do It Well, National Institute for Learning Outcomes Assessment July 2012. 
18- Bank, J., "The Essence of Total Quality Management", $2^{\text {nd }}$.Ed. Pearson Education Limited, 2000.

19- Bakkenes, I., Vermunt., J.D., and Wubbels, T., (2010), Teacher learning in the context of educational innovation: Learning Activities and Learning Outcomes of Experienced Teachers, Learning and Instruction $20 \quad$ (2010) 533-548. www.elsevier.com/locate/learninstruc.

20- Bansat, R., (2014), Process Mapping: Business Process Reengineering, December 2014. https://www.slideshare.net/rishabh112/process-mapping-business-process-reengineering.

21-Banton, C., (2020), Acceptable Quality Level (AQL), Investopedia, December 31, 2020.

22-Bateman. G. and Roberts, H. (1993), TQM for Professors and Students, ERIC, September 1993. https://eric.ed.gov/?id=ED384319.

23-Beck, C., (2009), Systems Model of Educational Processes, IGI Global Publisher of Timing Knowledge.

24- Becta (2004), ICT and e-Learning in Further Education: Embedded Technology, Evolving Practice: A Report to the Learning and Skills Council. Coventry, U.K.

25- Bemowski, K, (1991), "The Benchmarking Bandwagon", Quality Progress, pp. 1924, January 1991.

26- Benchmarking, Best Practices, and Performance Measurements for Public Entity

Risk Management, Public Entity Risk Institute, 1999. www.riskinstitute.org.

27-Bingham, R., (2002), Learning Outcomes and Assessment Criteria, Sheffield

Hallam University, April 2002.

https://www.bolton.ac.uk/quality/pda/moduleandprogrammedesign/documents/learnoutcomes asscriteria.pdf.

28- Brinck, T., Gergle, D., \& Wood, S. (2002), Usability for the Web: Designing Web Sites that Work. San Francisco, CA. Morgan Kaufmann.

29- Brown, G., (2001), Assessment: A Guide for Lecturers, Learning \& Teaching Support Network, January, 2001

https://www.emeraldgrouppublishing.com/archived/teaching/insights/outcomes.htm.

30- Business Process Design As-Is and To-Be Checklists Introduction,(2021), http://www.archives.gov/records-mgmt/appraisal/work-group-all.html.

31- Biesta, G., (2007), Why “What Works"' Won’t Work: Evidence-Based Practice and the democratic Deficit in Educational Research, Journal of Educational Theory, Volume 57,No.1,2007.

32- Biggs, J., (2003), Teaching for Quality Learning at the University: What the Student Does. (2nd Ed) SRHE Buckingham, UK: Open University Press.

33- Camp, R., (1995), Business Process Benchmarking- Finding and Implementing Best Practices, ASQC Quality Press, 1995.

34- Bryant,J.,(2018), The Importance of Synergy in Teams, The Pennsylvania State University,.February 19, 2018. $\quad$ https://sites.psu.edu/global/2018/02/19/the-

importance-of-synergy-in- teams/.

35- Camp, R., (1995), Business Process Benchmarking- Finding and Implementing Best Practices, ASQC Quality Press, 1995.

36- Center for Teaching and Educational Technologies, Royal Roads University (RRU), British Columbia, Canada. http://ctet.royalroads.ca/rru-learning-and-teachingmodel. 
37-Centre for Teaching and Learning, WesternU.ca,

https://teaching.uwo.ca/curriculum/coursedesign/learning-outcomes.html.

38- Chalmers, D., (2008), Outcomes of Higher Education: Quality Relevance and Impact, O.E.C.D, September 8-10, 2008, Paris, France

https://www.oecd.org/site/eduimhe08/41216416.pdf

39- Chand, S., (2020),14 Common Pitfalls of Business Process Reengineering.

https://www.yourarticlelibrary.com/business/14-common-pitfalls-of-business-processreengineering/21199.

40- Cheng, M., (2005), The Perceived Impact of Quality Audit on the Work of Academics, Centre for Learning and Teaching, University of Brighton, U.K.

41- Craig, W., (2019), 7 Leadership Method for Empowerment Employees and Building Strong Team, March 05, 2019.

https://www.forbes.com/sites/williamcraig/?sh=118cf7e1a299.

42- Coaldrake, P. \& Stedman, L., (1998), On the Brink: Australia's Universities

Confronting their Future, University of Queensland Press. 1998.

43- Coaldrake, P., and Stedman, L., (1999), Academic Work in the Twenty-first

Century: Changing Roles and Policies, Higher Education Division Department of

Education, Training and Youth Affairs, Australia, September 1999.

file:///C:/Users/Owner/Desktop/7.0-\%20Research\%20Evaluation/7.1.2-

\%20Academic\%20Research.pdf.

44- Coaldrake, P., and Stedman, L., (), Academic Work in the Twenty-first Century Changing roles and policies.

https://citeseerx.ist.psu.edu/viewdoc/download?doi=10.1.1.124.4559\&rep=rep1\&type=pdf.

45- Co o k, C., \& H e a t h, F. (2001), Users' Perceptions of Library Service Quality: A LibQUAL+ Qualitative Study. Library Trends, 49(4), 548-584.

46- Crompton, Ph., (2020), Evaluation: A Practical Guide to Methods, March 2020. http://www.icbl.hw.ac.uk/ltdi/implementing-it/eval.htm.

47- Cronin, J.J., and S.A., (1992), Measuring Service Quality: a Reexamination and Extension, Journal of Marketing, Vol. 56, Issue 3, 1992, pp.55-68.

48- Dabnoon, M., (2017), Impact of Managerial Leadership Styles on Implementation of Business Process Re-engineer (BPR), Imperial Journal of Interdisciplinary Research (IJIR), Vol-3, Issue-1, 2017.

49- Davenport, T.H. (1996), How a Business Fad Went Wrong, The Globe and Mail, January 31, 1996.

50- Debunking the Seven Myths of Business Process Reengineering by Panorama Consulting Group, Mar 18, 2015.

51- DeFeo, J.A., (2019), The Juran Trilogy: Quality Planning, April 15, 2019. https://www.juran.com/blog/the-juran-trilogy-quality-planning/

52- Deming, W.E., (1986), Out of the Crisis, MIT Press, Cambridge, MA.

53- Dill, D., (2007), Quality Assurance in Higher Education: Practices and Issues, UNC College of Sciences \& Arts, The University of North Carolina, U.S.A, June 2007.

54- Donovan, J; Mader, C.E, and Shinsky, J., (2006), Constructive Student Feedback: Online vs. Traditional Course Evaluations, Journal of Interactive Online Learning www.ncolr.org/jiol Volume 5, Number 3, Winter 2006. 
55-Doran, G. T. (1981), There's an S.M.A.R.T. Way to Write Management's Goals and Objectives, Management Review, Vol. 70, Issue 11, pp. 35-36.

56- Dressman, M, (2008). Using Social Theory in Educational Research: A Practical

Guide, London, Sage Publications.

57- Eagle, L., and Brennan, R., (2007), Are Students Customers? TQM and Marketing Perspectives, Quality Assurance in Education Vol. 15 No. 1, 2007 pp. 4460.

58- Emerie-Kassahun, A. and Molla, A. (2013), "BPR complementary competence: definition, model and measurement", Business Process Management Journal, Vol. 19 No. 3, pp. 575-596.

59-Enginess, L., (2017), What is Business Process Mapping? Posted ,09 November, 2017, https://www.enginess.io/insights/business-process-mapping.

60- European Association for Quality Assurance in Higher Education (2003), Quality Procedures in European Higher Education, the Danish Evaluation Institute, European Network for Quality Assurance in Higher Education, Helsinki.

61- Falchikov, N., \& Goldfinch, J. (2000), Student Peer Assessment in Higher Education: A Metaanalysis Comparing Peer and Teacher Marks, Review of Educational Research, Vol.70, No.3, pp.287-322.

62- Farmer, J.R. (1993), Reengineering the Factory, Production and Inventory Management Journal, Vol.34, No. 1, pp.38-42.

63- Fasna M.F.F. and Gunatilake, S., (2019), Issues in Implementing Business Process Reengineering (BPR) Projects, Proceedings of the International Conference on Industrial Engineering and Operations Management Bangkok, Thailand, March 5-7, 2019, IEOM Society International.

64- Federer, D. (2013), How to Synergy. Businessobserverfl.com. Retrieved February 18, 2018, https://www.businessobserverfl.com/section/detail/how-to-build-team-synergy/.

65- Ferhan, S., (2009), Employee Involvement: Its Magical Benefits, May 21, 2009. https://totalqualitymanagement.wordpress.com/2009/05/21/employee-involvement-itsmagical-benefits/\#more-888

66- Feldstein, A.C, and Glasgow, R.E., (2008), A Practical, Robust Implementation and Sustainability Model (PRISM) for Integrating Research Findings into Practice Research Methods, The Joint Commission Journal on Quality and Patient Safety, April 2008 Vol. 34 No. 4.

67- Findler, F., (2021), Program Quality Assurance, University of Findlay, February 26, 2020.

68-Findler, F. and Schönherr, N., (2019), The Impacts of Higher Education Institutions on Sustainable Development: A review and Conceptualization, International Journal of Sustainability in Higher Education Vol. 20 No. 1, 2019 pp. 2338.

69- Finnish Education Evaluation Centre (FINEEC), (2016), National Plan for education Evaluation 2016-2019.

https://karvi.fi/app/uploads/2016/06/National-Plan-for-Education-Evaluations-2016-2019.pdf 70- Fisher, D., K. Rubenson, K. Rockwell, G. Grosjean, and J. Atkinson-Grosjean (2000), Performance Indicators: A Summary,Tertiary Education and Management, 
Vol. 14, No. 4, December 2008, pp. 269-283.

http://www.fedcan.ca/english/fromold/perf-ind-impacts.cfm.

71- Frazer,M., (1994), Quality in Higher Education: An International Perspective. In

Diana Green (ed.), What is Quality in Higher Education. UK: SRHE and Open

University Press 1994.

$72-$

Gallia, A., (2019), Top 10 Business Processes: Our List of Great Hits, https://www.process.st/top-10-business-processes/.

73- Galluzzi, A, (2014) Measuring the Value of Libraries,

https://www.sciencedirect.com/topics/social-sciences/library-assessment

74- Garvin,D.A., (1987), Competing on the eight dimensions of quality, Harvard

Business Review, Vol. 65, No. 6, 1987, pp.101-109.

75-Gates, B, (2006), Business @ the Speed of Thought: Succeeding in the Digital Economy, A Warner Business Book, New York.

76- Gosling, D., Moon, J., (2002), How to Use Learning Outcomes and Assessment Criteria, David Jenny Moon, SEEC, 2002.

77- Gosling, D. (2014), Collaborative Peer-supported Review of Teaching, In Peer Review of Learning and Teaching in Higher Education, International Perspectives, edited by J. Sachs \& M. Parsell, 13-31. Netherlands: Springer.

78- Grace A. Lewis, G. A., and Smith, D. B., (2007), Four Pillars of Service-Oriented Architecture, The Journal of Defense Software Engineering, September 2007. https://resources.sei.cmu.edu/asset_files/WhitePaper/2007_019_001_29275.pdf.

79- Green, D., (), What is Quality in Higher Education, Society for Research into Higher Education \& Open University Press (ERIC), Latest version, U.S.A.,

80- Groessler, Ms.A., (2017), Teaching Research Methods: An Occasional Paper, Institute of Teaching and Learning Innovation (ITaLI) The University of Queensland (UQ), September 2017. https://itali.uq.edu.au/files/1294/Discussion-paper-TeachingResearch\%20Methods.pdf.

81- Grover, V., Jeong, S. R., Kettinger, W. J. and Teng, J. T., (1995), The Implementation of Business Process Reengineering, Journal of Management Information Systems, vol. 12 no. 1, pp. 109-144, 1995.

82- Hajdi, G., and Pažu, K., (2012), Differentiating Between Student Evaluation of Teacher and Teaching Effectiveness, JIOS, Vol. 36, No. 2, 2012.

83-Hammer, M., \& Champy, J. (1995), Reengineering of the Work Systems in the BPR Organizations, an Open Call for the New Administrative Revolution, Cairo: Shamseddine Othman.

84- Hammer, M. and J. Champy (1993), Reengineering the Cooperation: A Manifesto for Business Revolution, New York, Harper Collins Publishers.

85- Hammersley-Fletcher, LJ.,Wingrove, D, Chester, A and Clarke, A (2017), Leading Developmental Peer Observation of Teaching in Higher Education: Perspectives from Australia and England, British Journal of Educational Studies, 66 (3). pp. 365-381.

86- Harvey, L., Kohler, J., Bucher, U, and Sursock, A., (2012), Understanding Quality, Best of the Bologna Handbook, Understanding Quality in Higher Education (5-34). Berlin. 
87- Harb, H., Abazid, M., (2018), An Overview of the Business Process Reengineering in Higher Education, Asian Journal of Management Sciences \& Education Vol. 7(2) April 2018.

89- Hartini, A., Francis, A. and Zairi, M., (2007), Business Process Reengineering: Critical Success Factors in Higher Education, Business Process Management Journal, June, 2007. https://www.researchgate.net/publication/228344304.

90- Hathaway, R. S., Nagda, B. A., \& Gregerman S. R. (2002), The Relationship of Undergraduate Research Participation to Graduate and Professional Education Pursuit: An Empirical Study. Journal of College Student Development, 43, 614-631.

91- Herbert F. W. Stahlke, H.F.W, and James M. Nyce, J. M., (1996), Reengineering Higher Education: Reinventing Teaching and Learning, Cause/Effect, winter 1996. http://www.cause.org/information-resources/ir-library/html/cem9649.html.

92- Hill, F.M., and Collins, L.K.,(1998), "The positioning of BPR and TQM in Long-term Organisational Change Strategies", The TQM Magazine, Vol. 10 No. 6, pp. 438-446

93- Hindreus, T., (2009), Synergy-Based Approach to Quality Assurance, TUT Press, file:///C:/Users/Owner/Desktop/Part\%20Three\%20References/5d3fa2061e9d4c028fb07199afdb6 ad8.pdf.

94- House, R. J. (2004), Culture, Leadership, and Organizations: The GLOBE Study of Societies. Thousand Oaks: SAGE Publications.

file://C:/Users/Owner/Desktop/6.1-\%20Evaluation\%20HEIs/03.pdf.

https://www.iso.org/files/live/sites/isoorg/files/store/en/PUB100080.pdf.

95- Hu, S., Kuh, G.D., \& Gayles, J.G., (2007), Engaging Undergraduate Students in Research Activities: Are Research Universities Doing a Better Job? Innovation High Education Journal., 2007. DOI 10.1007/s10755-007-9043-y.

96- Huitt, W., (2006), Overview of Classroom Processes, Educational Psychology Interactive, Vadosta State University, GA,

http://www.edpsycinteractive.org/topics/process/class.html .

97- Husameddin, H. \& Mohammad, A. (2018), An Overview of the Business Process ReEngineering, in Higher Education, Asian Journal of Management Sciences \& Education Vol. Vol.7, No.2, pp. 99-106.

98- Hwarng, H.B. and Teo, C. (2001), “Translating Customers' Voices into Operations Requirements: a QFD Application in Higher Education", International Journal of Quality \& Reliability Management, Vol. 18 No. 2, pp. 195-225.

99- Iden, J., (1995), Business Process Reengineering: Examining Some Major Roadblocks to Increased Self-Control for the Employee. Conference Paper - January 1995. : https://www.researchgate.net/publication/220729340.

100- Idrus, N., Ubuh, B. and Sukisno, (1998), Instruments and Procedures to Measure Quality Assurance, QA Report, EEDP, Jakarta.

101-ISO Quality, (2020), Quality Management Principles https://www.iso.org/files/live/sites/isoorg/files/store/en/PUB100080.pdf

102- Iorwerth, A.ab., (2016), Methods of Evaluating University Research Around the World, Working Paper, March, 2005.

https://carma.newcastle.edu.au/resources/jon/Preprints/CEIC06-08/fc-report.PDF.

103- Irani, Z., and Love, P.E.D., (2001), Information systems evaluation: past, present and future, European Journal of Information Systems, Vol.10, pp.183-188, ( Published on line on 2017). 
104- Johnson, P. and Papageorgiou, G. (2010) Rethinking the Introduction of Particle Theory: A Substance-Based Framework Journal of Research in Science Teaching, Vol. 47, No. 2, pp.130-150.

105- Joo, S., Lin, S., and Lu, K., (2011), A Usability Evaluation Model for Academic Library Websites: Efficiency, Effectiveness and Learnability, Journal of Library and Information Studies Vol. 9, No.2, December 2011, pp.11-26.

106- Jukes, M., (2019), How to Develop Successfully Quality Framework, 30 April, 2019. https://www.evaluagent.com/blog/how-to-build-a-quality-assurance-framework.

107- Lemmalodesso, S., (2012), Stakeholder Perceptions of Service Quality Improvement in Ethiopian Public Higher Education Institutions, University of South Africa, December 2012. https://citeseerx.ist.psu.edu/viewdoc/download?doi=10.1.1.727.8989\&rep=rep1\&type=pdf. 108- Li, H., Xiong, Y., Zang, X., Kornhaber, M., Lyu, Y., Chung, K.S, and Suen, H., (2014), Peer Assessment in the Digital Age: A Meta-Analysis Comparing Peer and Teacher Ratings. Paper presented at the 2014 Annual Meeting of the American Educational Research Association (AERA), Philadelphia, PA.

109- Lohman, M., \& Woolf, N. (2001), Self-initiated Learning Activities of Experienced Public School Teachers: Methods, Sources and Relevant Organizational Influences. Teachers and Teaching: Theory and Practice, Vol.7, pp.59-74.

110- Loukkola, T., and Zhang, T., (2010), Examining Quality Culture: Part 1 - Quality Assurance Processes, European University Association 2010. Brussels, Belgium.

111- Luburić, R.,(2012), Synergistic Effect of TQM and Operational Risk Management in Central Banks, International Journal for Quality research, Vol.6, No.4, 2012.

112- Lynch, M., (2019), What are the 4 Components of Task Analysis? July 18, 2019. The Advocate. https://www.theedadvocate.org/what-are-the-4-components-of-task-analysis/. 113-Kamboj, S. and Decker, K.S, (2008), Exploring Robustness in the Context of the Organizational Self-Design, https://www.aaai.org/Papers/Workshops/2008/WS-08-03/WS0803-005. pdf.

114-Kane, A., (2001), "Indicators and Evaluation for Science, Technology and Innovation”, mimeo, http://www.economics.nuigalway.ie/downloads/kane/kaneicsti02.pdf. 115-Karlson, K., (2020), 136 Key Performance Indicators Examples (The Complete List), https://www.scoro.com/blog/key-performance-indicators-examples/

116- Kettinger, W.J., Teng, J., and Guha, S., (2007), Business Process Change: A Study of Methodologies, Techniques, and Tools.MIS Quarterly. DOI: 102307/249742, Corpus ID: 39297660

117- Kelly, M., (2012), Student Evaluations of Teaching Effectiveness: Considerations for Ontario Universities Wilfrid Laurier University, Ontario, Canada.

118- Kumar, V., (2017), The Role of University Research Centers in Promoting Research, Journal of the Acad. Mark. Sci., No.45, 2017, pp.453-458.

119- Kyrillidou, M., \& Giers c h, S. (2005), Developing the DigiQUAL Protocol for Digital Library Evaluation. In M. Marlino, T. S umme r, \& F. S h i pma n (Ed s.), Proceedings of the Fifth ACM/IEEE-CS Joint Conference on Digital Libraries, pp. 172-173. New York: ACM Press. 
120- Kwakman, C. (2003), Factors Affecting Teachers' Participation in Professional Learning Activities, Journal of Teaching and Teacher Education, No.19, pp.149-170.

121- Ma, Q., Pearson, J.M., and Tadisina, M., (2005), An Exploratory Study into Factors of Service Quality for Application Service Providers, Journal of Information and Management, Vol. 42, Issue 8, December 2005, pp. 1067-1080.

122- Magutu, P. O.; Nyamwange, S. O. \& Kaptoge, G. K. (2010), Business Process Reengineering for Competitive Advantage: Key Factors that May Lead to the Success or Failure of the BPR Implementation (The Wrigley Company), African Journal of Business \& Management, Vol. 1, pp. 135-150.

123- Maire, J.L and Büyüközkan, G, (1997), Methods and Tools for First Five Steps of Benchmarking Process, Research Gate.

https://www.researchgate.net/publication/261132260_Methods_and_tools_for_first_five_steps_of benchmarking_process.

124- Masrek, M.N., Jamaludin, A., and Mukhtar, S.A., (2010), Evaluating academic library portal effectiveness A Malaysian case study, Library Review Vol. 59, No. 3, 2010 pp. 198212.

125- Marsh, H.W., (1987), Students' Evaluations of University Teaching: Research Findings, Methodological Issues, and Directions for Future Research, Reports Evaluative/Feasibility (142). https://files.eric.ed.gov/fulltext/ED338629.pdf.

126- Marsh, H. W. \& Dunkin, M. J. (1992) Students' Evaluations of University Teaching: A multidimensional Perspective, in: J. C. SMART (Ed.) Higher Education: Handbook of Theory and Research, Vol. 8, pp. 143-233 (New York, Agathon Press).

127- Maxwell, J.A. (2010), Review of (Theory and Educational Research: Toward Critical Social Explanation). Virginia. George Mason University.

128- McCluney, A, (2020), A Quick Guide to 11 Types of KPIs, July 23, 2020, https://www.brightgauge.com/blog/quick-guide-to-11-types-of-kpis.

129- McRoy, I. \& Gibbs, P0, (2009). Leading change in higher education, London: Sage Publications.

130- McTighe, J., and Wiggins, G., (2013), Essential Questions: Opening Doors to Student Understanding. Alexandria, VA: Association for Supervision and Curriculum Development.

131- Meher, V., and Baral, R., (2019), Total Quality Management (TQM) in Higher Education: A Conceptual Study, International Journal of Innovative Knowledge Concepts, Vol. 7, Issue 7, July, 2019.

132- Meirovich, G., (2006), Quality of design and quality of conformance: contingency and synergistic approaches, Total Quality Management and Business Excellence, Vol. 17, No. (2), 205-219.March 2006.

133- Metzner, B.S., (1989), Perceived Quality of Academic Advising: The Effect on

Freshman Attrition, American Educational Research Journal Fall 1989, Vol 26, No. 3, pp. 422-442.

134- Mishra, S., (2006), Quality Assurance in Higher Education: An Introduction, National Assessment and Accreditation Council (NAAC), India. 
135- Mogashoa, T., (2014), Applicability of Constructivist Theory in Qualitative Educational Research, American International Journal of Contemporary Research Vol. 4, No. 7; July 2014.

136- Mokhtar, S.A., Alias, R.A., and Rahman, A.A., (2006), Rubric Assessing ICT Infrastructure in Malaysia Higher Education. https://core.ac.uk/reader/11779520.

137- Moran, R.T., Abramson, N.R., \& Moran, S.V. (2014).Managing Cultural Differences, $9^{\text {th }}$.ed. Oxford: Rontledge.

138- Morocco, A., (2006), Management of Scientific Assets and Future Directions for the Director of the Twenty-first Century. Egypt: Modern Library

139-Morton, S., (2015), The Role of IT In BPR Information Technology Essay, January 2015, Information Technology.

https://www.ukessays.com/essays/informationtechnology/the-role-of-it-in-bpr-informationtechnology-essay.php.

140- Mushaathoni, A.M., (2015), A Business Process Reengineering Framework to Enhance Strategic Planning within Higher Education: The Case of the Tshwane University of Technology. October, 2015.

https://repository.nwu.ac.za/bitstream/handle/10394/16152/Mushaathoni_AM_2015.pdf?sequenc $\underline{\mathrm{e}=1}$.

141- Nadim, Z.S. and Al-Hinai, A.H., (2016), Critical Success Factors of TQM in Higher Education Institutions Context, International Journal of Applied Sciences and Management Vol. 1, No. 2, 147-156, 2016.

142- Najafabadi, H.N., Sadeghi, S, and Habibzadeh. P., (2008), Total Quality Management in Higher Education Case Study: Quality in Practice at University College of Borås, https://hb.diva-portal.org/smash/get/diva2:1310821/FULLTEXT0. 143- Naz, A., Azhar, Z., Nawaz, M., and Gul, A., (2013), Role of Human Resources Management in the Effectiveness of Business Process Reengineering, Journal of Resources Development and Management - An Open Access International Journal Vol.1 2013.

144- Nel, M.E., (2009), An Approach to Business Process Management at a Higher Education Institution, November 2009.

file:///C:/Users/Owner/Desktop/BPR\%20Applications\%20in\%20HE\%202021/nel me(1).pdf.

145- Neubauer, T, Klemen, M., Biffi, S., (2006), Secure Business Process Management: A Roadmap, Proceedings of the First International Conference on Availability, Reliability and Security (ARES'06) 0-7695-2567-9/06, 2006 IEEE.

file:///C:/Users/Owner/Desktop/BPR\%20Applications\%20in\%20HE\%202021/nel_me(1).pdf

146- Nicholson, P., (2007), A history of e-learning: echoes of the pioneers. In B. Fernández Manjón (Ed.), Computers and education: e-learning, from theory to practice, 1-11, 2007. 147- Niedermeier, F., (2017), Designing Effective Quality Management Systems in Higher Education Institutions. Module, Training on Internal Quality Assurance Series, Link: http://duepublico.uni-duisburg-essen.de/servlets/DocumentServlet?id=43222.

148- Nilson, L., (2010), Teaching at its best: A Research-Based Resource for College Instructors, 3rd Ed, San Francisco: Jossey-Bass.

149- Noguera, I., Guerrero-Roldan A.E., and Mas, R., (2018), Collaborative Agile Learning in Online Environments: Strategies for Improving Team Regulation and Project Management, Computers \& Education, Vol. 116 ,2018, pp.110-129. 
150- Nuttall, D. L. (1994), Choosing Indicators. In: Riley, K. A. and Nuttall, D. L. Measuring Quality: Education Indicators, United Kingdom and International Perspectives, London: The Falmer Press. 17-40; 1994.

151- Office of Quality Assurance (OQA), (2020), Program Learning Outcomes A Guide for University of Ottawa Faculty, The University of Ottawa, Canada.

https://www.uottawa.ca/vice-president-academic/sites/www.uottawa.ca.vice-presidentacademic/files/guide_rap_eng_4.pdf

152- OECD. (2007). Education at a Glance, Retrieved January. http://www.oecd.org/document/30/0,3343,en $264939263238 \quad 39251550111,00 . \mathrm{Html}$

153- Ohmae, K. (1982). Retrieved from www.toolshero.com:

https://www.toolshero.com/strategy/3c-model-ohmae/.

154- Oulanov, A., \& Pajarillo, E. J. Y. (2002), CUNY Web: Usability Study of the Web based GUI Version of the Bibliographic Database of the City University of New York (CUNY). The Electronic Library, 20(6), 481-487.

155-Quality Assurance Framework and Guide, (2019) Ontario's Universities Council on Quality Assurance, Ontario, Canada, November 26, 2019.

156- Quality Assurance Agency for Higher Education (2004), “A Brief Guide to Quality Assurance in UK Higher Education", www.qaa.ac.uk/aboutus/heGuide/guide.asp.

157- Pan, W., Chen, Y., Zheng, Q., Xia, P. and Xu, R. (2004), "Academic digital library portal: a personalized, customized, integrated electronic service in Shanghai Jiaotong University Library', Lecture Notes in Computer Science, Vol. 3334, pp. 563-7.

158- Parasuraman, A., Zeithaml, V.A. and Berry, L.L. (1988), "SERVQUAL: A Multiple Item Scale for Measuring Consumer Perceptions of Services Quality”, Journal of Retailing, Vol. 64 No. 1, pp. 12-40.

159- Particle Measuring Systems (PMS), (2020), How to Achieve Quality by Design $(\mathrm{QbD})$ in a new Pharmaceutical Fill Line: Intro and Regulatory (Series Part 1 of 6) https://www.pmeasuring.com/blog/advisory-services-quality-by-design/.

160- Peel, K.L., (2020), A Beginner Guide to Applied E Educational Research using Thematic Analysis, Practical Assessment, Research, and Evaluation: Vol. 25 , Article 2. : https://scholarworks.umass.edu/pare/vol25/iss1/2.

161- Ph.D Assistance Blog, (2019), https://www.phdassistance.com/blog/what-is-thedifference-between-academic-research-and-professional-research/. January 23, 2019.

162- Phiri, A.C., Foko, T., and Mahwai, N., (2014), Evaluation of a pilot project on information and communication technology for rural education development: A Cofimvaba case study on the educational use of tablets, International Journal of Education and Development using Information and Communication Technology (IJEDICT), 2014, Vol. 10, Issue 4, pp. 60-79.

163- Pitt, L.F., Watson, R.T., and and C.B. Kavan (1995), Service quality: A Measure of Information Systems Effectiveness, MIS Quarterly, 19(2), 1995, pp.173-187.

164- Pushpa L, (2015), Implementation of Total Quality Management in Higher Education Institutions, International Journal of Scientific Engineering and Research (IJSER), ISSN (Online): 2347-3878, https://www.ijser.in/archives/v4i5/IJSER15813.pdf.

165- Rook, L., (2013), Mental Models: a robust definition, www.emeraldinsight.com/09696474.htm.

166- Ramaprasad, A., (1983), On the Definition of Feedback, Journal of Behavioral Science, Volume 28, 1983. 
167- Rashidat.O., and Anthony O., (2019), Business Process Reengineering and Federal Tertiary Institutions' Competitive Advantage: Evidence from Federal Polytechnic, ILARO., 16th is Teams Multidisciplinary Research Nexus Conference, 9th - 11th June, 2019., The Federal Polytechnic, ILARO.

168- Ring, J., (2014), Design Review Checklist for a Business Process Model, November 2014, https://doi.org/10.1002/j.2334-5837.1998.tb00073.x.

169- Romiszowski, A.J. (1988) "The Selection and Use of Instructional Media", Kogan Page, London.

170- Renu,V., (2013), Business Process Re-Engineering: Roadblocks, Myths and Corporate Practices, September 24, 2013, https://ssrn.com/abstract=2330474.

171-Rowe, K., (2004). Analysing \& Reporting Performance Indicator Data: 'Caress' the Data and User Beware! ACER, Background Paper for The Public Sector Performance \& Reporting Conference, under the Auspices of the International Institute for Research (IIR). 172- RRU, (2019), Learning, Teaching, and Research Model (LTRM), Center for Teaching and Education Technologies, Royal Roads University, 2019. https://ctet.royalroads.ca/learning-teaching-research-model.

173- Seel, N.M., (2017), Model-based Learning a Synthesis of Theory and Research, Educational Technology Research and Development, January 2017. https://www.researchgate.net/publication/312317058.

174- Slack, N.; Chambers, S. \& Johnston, R. (2007), Operation Management, $5^{\text {th. }}$ Ed., Prentice Hall. UK

175- Shroff, R.H. and Keyes, C.J., (2017), A Proposed Framework to Understand and the Intrince Motivation Factors on University Students' Behavioral Intention to Use a Mobile Application for Learning, Journal of Information Technology Education Research, Vol. 16, 2017.

176- Shulman, L. S., \& Shulman, J. H. (2004). How and What Teachers Learn: A

Shifting Perspective, Journal of Curriculum Studies, Vol.36, 257-271.

177-Shukla, A., (2019), Continuous Assessment-Features and Purpose,June 12th, 2019. HTTPS://WWW.TOPPR.COM/BYTES/CONTINUOUS-ASSESSMENT-FEATURES-AND PURPOSE/

178- Siddique, A., at.el. (2011) Impact of Academic Leadership on Faculty's Motivation and Organizational Effectiveness in Higher Education System, International Journal of Academic Research, Vol.3, No.3, May, 2011, II Part. 179- Srikanthan, G. and Dalrymple, J. (2003), "Developing Alternative Perspectives for Quality in Higher Education", The International Journal of Educational Management, Vol. 17 No. 3, pp. 126-36.

180- Stahlke, H.F.W., and Nyce, M. J., (1993), Reengineering Higher Education Reinventing Teaching and Learning, CAUSE/EFFECT Vol. 19, No. 4, Winter 1996, pp. 44-51.

181- Stigmar, M., (2016), Peer-to-peer Teaching in Higher Education: A Critical Literature Review, Mentoring \& Tutoring: Partnership in Learning, Vol. 24, No. 2, pp.124-136. 182- Sudha, T., (2013), TQM in Higher Education Institutions, International Journal of Social Science \& Interdisciplinary Research (IJSSIR), Vol. 2 No.6, June (2013). 
183-Sudsawad, P., (2007), Knowledge Transfer: Introduction to Models, Strategies and Measures, Austin, TX: Southwest Educational Development Laboratory, National Center for the Dissemination of Disability Research. http://www.ncddr.org/kt/products/ktintro/.

184-Sudsawad, P., (2007), Knowledge Transfer: Introduction to Models, Strategies and Measures, Austin, TX: Southwest Educational Development Laboratory, National Center for the Dissemination of Disability Research. http://www.ncddr.org/kt/products/ktintro/.

185- Sungau, J., Ndunguru P.C, and Kimeme K., (2013), Business Process Reengineering: The Technique to Improve Delivering Speed of Service Industry in Tanzania, http://www.ijmp.jor.br/index.php/ijmp/article/view/68/335.

186- Suppes, P. (1974). The Place of Theory in Educational Research. Stanford University, Stanford, Vol. 3, Issue 6, June 1974. https://doi.org/10.3102/0013189X003006003.

187- Suskie, L., (2009), Assessing Student Learning: A Common Sense Guide, $2^{\text {nd }} . e d$. , San Francisco: Jossey-Bass, California, U.S.A.

188-Svinicki, M.D. (2001), Encouraging Your Students to Give Feedback, New Directions for Teaching and Learning, No.87, Fall 2001, pp. 17-24. John Wiley \& Sons, Inc John Wiley \& Sons, Inc.

189- Tam, M, (2011), Measuring Quality and Performance in Higher Education, Journal of Quality in Higher Education, Vol. 7, No. 1, 2001.

190-Tella, C.O. Ayeni S. O. Popoola (2007), Work Motivation, Job Satisfaction and Organisational Commitment of Library Personnel in Academic and Research Libraries in Oyo State, Nigeria, Library Philosophy and Practice, 2007. https://www.researchgate.net/publication/28157288.

191- THINK Education, (2020), THINK Assurance Quality Framework, http://www.think.edu.au/about-us/think-quality-assurance-framework. 192-Todorut, A.V., (2013), The need of Total Quality Management in higher education, 2nd World Conference on Educational Technology Researches WCETR2012,Procedia Social and Behavioral Sciences Vol.83, 2013: pp.1105 - 1110.

193- Thorpe, M., (1988), Handbook of Education Technology, Ellington, Percival and Race, 1988.

194- Tsinidou,M.,Gerogiannis, V., and Fitsilis, P., (2010),Evaluation of the factors that determine quality in higher education: an empirical study, Journal Quality Assurance in Education Vol. 18 No. 3, 2010 pp. 227-24.

195- Utaberta, N.; Che-Ani, A.I., Zaharimi, A; and Abdullah, N.A.G., (2012), CriteriaBased Assessment and Grading in Architecture Design Studio, Procedia- Social and Behavioral Sciences, January 2012. https://www.researchgate.net/publication/228442706.

196- Vakola, M. and Rezgui, Y., (2008), Critique of Existing Business Process Reengineering Methodologies, Business Process Management Journal, Vol. 6 No. 3, 2000, pp. 238-250. 
197- Van Eekelen, I. M., Boshuizen, H. P. A., \& Vermunt, J. D., (2005), Self-regulation in Higher Education Teacher Learning, Journal of Higher Education, Vol.50,pp.447471.

198- Vermunt, J. D., \& Vermetten, Y. J. (2004). Patterns in Student Learning: Relationships between Learning Strategies, Conceptions of Learning, and Learning Orientations. Educational Psychology Review, Vol.16, pp.359-384.

199- Vlăsceanu, L., Grünberg, L. \& Pârlea, D.(2004). Quality Assurance and Accreditation: Glossary of Basic Terms and Definitions. Papers on Higher Education, Bucharest:UNESCO-CEPES 2007 First edition 2004.

200- Vossen, T.E., Henze, I, Rippe, R.C.A., , Van Driel, J.H., \& De Vries, M.J., (2018), Attitudes of Secondary School Students Towards Doing Research and Design Activities, International Journal of Science Education, 2018, Vol. 40, No. 13, 1629-1652 https://doi.org/10.1080/09500693.2018.1494395.

201- Xuegao, Z., (2013), The Research and Exploration about Teaching Reform Based on The New Three Centers -PDCA Management Cycle Method for Reference, International Conference on Education Technology and Information System (ICETIS 2013).

202-Wachtel, H.K., (2006), Student Evaluation of College Teaching Effectiveness: a brief review, Assessment \& Evaluation in Higher Education, Vol. 23, No. 2, 1998, (published on-line on August 03, 2006). https://doi.org/10.1080/0260293980230207.

203- Watty, K., (2002), Quality in Higher Education: The Missing Academic Perspective, School of Accounting and Law RMIT University Melbourne AustraliaResearch Gate.

https://www.researchgate.net/publication/254701075_Quality_in_Higher_Education_The_M ssing_Academic_Perspective

204- Westbrooka ,J.I., Braithwaiteb, J., Iedemab, R., and Coieraa, E.W., (2004),

Evaluating the impact of information communication technologies on complex

organizational systems: a multi-disciplinary, multi-method framework, MEDINFO

2004, Amsterdam: IOS Press. file:///C:/Users/Owner/Desktop/6.6-

\%20Quality\%202021/6.6.1-.pdf.

205- Williams, (2005), Williams, G. (2005) Subject benchmarking in the United Kingdom. Research Program for Academic Quality, Public Policy for Academic Quality Research Program, Chapel Hill: University of North Carolina. http://www.unc.edu.

206- World Bank policy paper examining the state of higher education in developing countries, 1994.

207- World Bank - Tertiary Education: http://www.worldbank.org/

208-Zabadi, A.M.A., (2013), Implementing Total Quality Management (TQM) on the Higher Education Institutions - A Conceptual Model, Journal of Finance \& Economics Vol. 1, Issue 1 (2013), pp. 42-60.

209-Zeithaml, V.A., and Bitner, M.J. (2003). Services' Marketing: Integrating Customer Focus Across the Firm. $3^{\text {rd }}$ Ed. NY: McGraw-Hill

210- Zenkina, S., Konopko, E., Pankratova, O., and Ardeev, A., (2018), Model of Organization of Network Project-research Students aAtivities in Collaboration with City-forming Enterprises, Proceedings of REMS 2018 - Russian Federation \& Europe Multidisciplinary Symposium on Computer Science and ICT, Stavropol - Dombay, Russia, 15-20 October 2018. http://ceur-ws.org 
211- Zeithaml, Berry, and Parasuraman, (1993), The Nature and Determinants of Customer Expectations of Service Quality, Journal of the Academy of Marketing, Vol. 21, Issue 1, 1993, pp. 1-12.

212-Zigiaris, S. (2000), "Business process re-engineering (BPR)", available at: www.academia.edu/14273758/Report (accessed 24 February 2021).

وهن الله التمهنيتة....

Short Biography

Professor Abdulsattar Mohammad Al-Ali, Ph.D. Prod. Eng.

$$
\text { الأستاذ الدكتور عبد الستار محمد العلي }
$$

Ph.D Prod. Eng., M.Phil., HDep. In Industrial Engineering, M.Sc. in Industrial Economics, Senior Member IIE, MCSCMP, ASQ, EFQM.

asmalali.alali@gmail.com. 


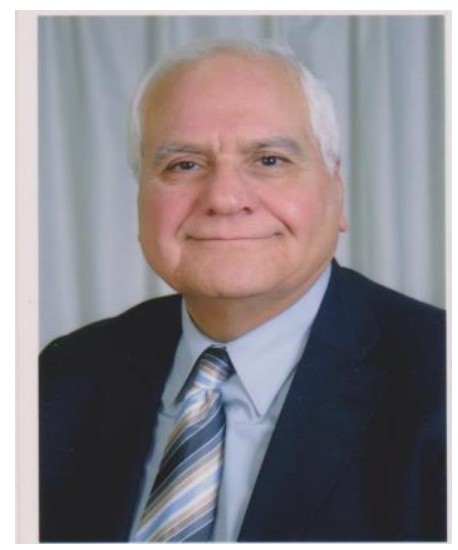

العمل السابق: أستاذ في قسم الانتاج والمعادن ، الجحامعة التكنولوجية ، بغداد - العراق. Advisor, Dr. Kanayalal Rania Inc., for ( العمل الحالي:خبير غير متفرغ منذ 1919 وحتى الآن Consultancies and Education Development, Ontario, L6T 3W2, Canada,

(www.drklsrania.com,

- استاذ ونائب الرئيس للشؤون العلمية والأكاديمية وعميد ورئيس قسم علمي بالجحامعات العراقية

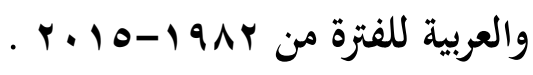

- - حاز على لقب الأستاذ الأول المتميز عن الجامعة التكنولوجية للعام ب999 1، بغداد - العراق. - ـ رئيس قسم وعضو هيئة الخبراء بالمؤسسة العامة لنفط الجنوب ، البصرة - العراق للفترة

$$
.19 \Lambda r-19 V \text {. }
$$


$.19 V \cdot-$

- - المؤلفات والبحوث: (7 1 ) مؤلف بالمندسة الصناعية وادارة الانتاج والعمليات والجودة وادارة المشروعات وغيرها مع أكثر من ( • ¥) بحث منشور في الدوريات العراقية والعربية والعالمية

بالاضافة الى العديد من الدراسات والمثاريع العملية والتطبيقية.

- - الدراسات العليا : اشراف على حوالي ( • ع ) أطروحة دكتوراه (بعضها فاز بجائزة أفضل دراسة دكتوراه على مستوى الوطن العربي من قبل المنظمة العربية للتنمية الادارية وجامعة الشارقة بلدولة الامارات العربية المتحدة بالاضافة الى العشرات من رسائل الماجستير. - عضو عمعيات علمية عالمية والكثير من اللجان العلمية والاكاديمية داخل وخارج العراق . - - المشاركة بالكثير من اللجان العلمية والأكاديمية والمؤتمرات العلمية وورش العمل داخل وخارج 


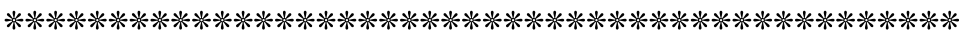

YI. 